Pacific Northwest

National Laboratory

Operated by Battelle for the

U.S. Department of Energy

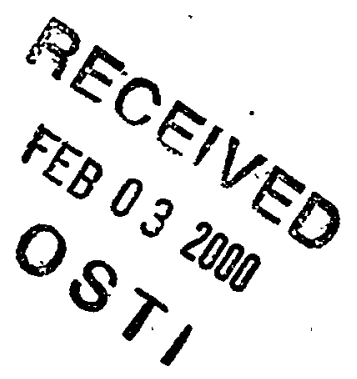

\title{
Dynamics of Crust Dissolution and Gas Release in Tank 241-SY-101
}

SD Rassat

CW Stewart

BE Wells

WL Kuhn

ZI Antoniak

JM Cuta
KP Recknagle

$G$ Terrones

VV Viswanathan

JH Sukamto

DP Mendoza

January 2000

Prepared for the U.S. Department of Energy

under Contract DE-AC06-76RLO 1830 


\section{DISCLAIMER}

This report was prepared as an account of work sponsored by an agency of the United States Government. Neither the United States Government nor any agency thereof, nor Battelle Memorial Institute, nor any of their employees, makes any warranty, express or implied, or assumes any legal liability or responsibility for the accuracy, completeness, or usefulness of any information, apparatus, product, or process disclosed, or represents that its use would not infringe privately owned rights. Reference herein to any specific commercial product, process, or service by trade name, trademark, manufacturer, or otherwise does not necessarily constitute or imply its endorsement, recommendation, or favoring by the United States Government or any agency thereof, or Battelle Memorial Institute. The views and opinions of authors expressed herein do not necessarily state or reflect those of the United States Government or any agency thereof.

\section{PACIFIC NORTHWEST NATIONAL LABORATORY operated by \\ BATTELLE for the \\ UNITED STATES DEPARTMENT OF ENERGY under Contract DE-AC06-76RLO 1830}

Printed in the United States of America

Available to DOE and DOE contractors from the

Office of Scientific and Technical Information, P.O. Box 62, Oak Ridge, TN 37831; prices available from (615) 576-8401.

Available to the public from the National Technical Information Service, U.S. Department of Commerce, 5285 Port Royal Rd.; Springfield, VA 22161 


\section{DISCLAIMER}

Portions of this document may be illegible in electronic image products. Images are produced from the best available original document. 


\title{
Dynamics of Crust Dissolution and Gas Release in Tank 241-SY-101
}

\author{
SD Rassat \\ CW Stewart \\ BE Wells \\ WL Kuhn \\ ZI Antoniak \\ JM Cuta \\ KP Recknagle \\ $\mathrm{G}$ Terrones \\ VV Viswanathan \\ JH Sukamto \\ DP Mendoza
}

January 2000

Prepared for

the U.S. Department of Energy

under Contract DE-AC06-76RLO 1830

Pacific Northwest National Laboratory

Richland, Washington 


\section{Summary}

Due primarily to an increase in floating crust layer thickness, the waste level in Hanford Tank 241-SY-101 (SY-101) has grown appreciably, and the flammable gas volume stored in the crust has become a potential hazard. To remediate gas retention in the crust and the potential for buoyant displacement gas releases from the nonconvective layer at the bottom of the tank, SY-101 will be diluted to dissolve a large fraction of the solids that allow the waste to retain gas. In this work we develop understanding of the state of the tank waste and some of its physical properties, investigate how added water will be distributed in the tank and affect the waste, and use the information to evaluate mechanisms and rates of waste solids dissolution and gas release. This work was completed to address these questions and in support of planning and development of controls for the SY-101 Surface Level Rise Remediation Project. Particular emphasis is given to dissolution of and gas release from the crust, although the effects of back-dilution on all waste layers are addressed. The magnitude and rates of plausible gas release scenarios are investigated, and it is demonstrated that none of the identified mechanisms of continuous (dissolution-driven) or sudden gas release, even with conservative assumptions, lead to domespace hydrogen concentrations exceeding the lower flammability limit.

To "attack" the gas-retaining waste solids the plan is to transfer some SY-101 waste to Tank 241-SY-102 (SY-102) and back-dilute in SY-101 with water in several steps. In the first transfer and back-dilution process, a waste transfer of 88,000 gallons and back-addition of 60,000 (or possibly up to 97,000 ) gallons water is scheduled. A smaller portion of the back-added water $(25,000$ gallons $)$ is to be placed on top of the dry freeboard crust, which contains little retained flammable gas, and the bulk of the water is to be fed through the waste transfer pump inlet at the 96-in. (2.4-m) elevation of the tank. In this report we first postulate the tank and waste conditions expected to exist after the initial transfer and back-dilution operation, and then we focus on potential dissolution and gas release scenarios following subsequent back-dilutions. Many of the analyses presented here are widely applicable to any tank waste dissolution and gas release process.

This report documents the results of studies performed in 1999 to address the issues of the dynamics of crust dissolution and gas release in SY-101. It contains a brief introduction to the issues at hand; a summary of our knowledge of the SY-101 crust and other waste properties, including gas fractions, strength and solubility; a description of the buoyancy and dissolution models that are applied to predict the crust response to waste transfers and back dilution; and a discussion of the effectiveness of mixing for water added below the crust and the limited potential for significant stratification resulting from such additions. The effect of the mixer pump on stratified fluid layers below the crust, should they form, is also addressed. It is hypothesized that the crust may sink after the most gaseous portion near the base of the crust is dissolved and after the liquid layer below the crust is diluted sufficiently. Then we discuss the consequences of crust sinking in terms of gas release, the ability of the in-tank mixer pump to remobilize it, and the potential for recurrence of buoyant displacement gas release events.

Mechanisms and dynamics of waste solids dissolution and gas releases are evaluated theoretically and experimentally in this report. Dissolution and gas release from the mixed slurry 
and nonconvective layers are considered, but greater attention is given to crust dissolution processes and associated gas releases. We present a detailed study of crust and mixed-slurry solids dissolution mechanisms and rates including theoretical calculations, analysis of laboratory results for simulated and actual waste, and a description of laboratory dissolution studies using SY-101 chemical simulant crusts. We also address the kinds of nonuniformity in crust structure that might be expected because of the dynamic dissolution process. A generally applicable model describing transient domespace concentrations of hydrogen is developed and used to analyze the flammability potential of various gas release scenarios. Applying the maximum crust dissolution rates we obtained, on the order of one-centimeter thickness per hour, we then evaluate dissolution-induced gas releases from the floating crust and mixed slurry. Extreme cases, where continuous dissolution of crust occurs at the rate of water addition, are considered, and a variety of sudden or spontaneous gas-release scenarios are also analyzed. Given the tank conditions expected at the time of the second back-dilution, no plausible continuous or sudden gas release scenarios resulting in flammable hydrogen concentrations were identified. Some general and specific conclusions supporting this important result are provided below.

Analysis indicates that the water will be well mixed with the slurry above the addition point, and due to rapid dissolution of fine solid particles in the slurry, the moderate volume of backdilution water added after the first transfer should quickly become saturated. Therefore, negligible dissolution of solids in the base of the crust some 200 inches $(5.0 \mathrm{~m})$ above the addition point is anticipated. As a result, the first back-dilution process is expected to dissolve crust solids only in the top 25 inches $(0.6 \mathrm{~m})$ or so, leaving about 95 inches $(2.4 \mathrm{~m})$ of gasretaining crust. These overall conclusions are supported by the following detailed conclusions:

- Best estimates for solubility properties of SY-101 waste were derived from Hanford waste density and water concentration data and the results of laboratory dilution tests. The properties include the saturated liquid density, density of dissolved and undissolved solids, the water mass fraction in the liquid, and the mass fraction of the solids that are effectively insoluble (Section 2.1).

- Both analyses and experiments with simulant show that the falling top-dilution water will not punch a hole through the crust (Section 5.1). Instead, water will spread through the dry freeboard across the top of the wet crust layer (as is assumed in the crust dissolution model).

- The results of computational modeling with the TEMPEST fluid dynamics code (Section 3.1) show that the bottom-dilution water mixes well with the slurry above the water addition point and will not pool (as dilute liquid) under the crust. Postulating that stratification does occur, in spite of this finding, further modeling shows that four mixer pump runs will be enough to thoroughly mix the part of the slurry that is below the pump intake and significantly decrease any stratification above the intake that may have been caused by dilution. These findings support assumptions regarding bottom-dilution mixing used in the crust dissolution model. 
- The crust dissolution model predicts that the first transfer and back-dilution of $88 \mathrm{kgal}$ transfer, $25 \mathrm{kgal}$ top-dilution, and $35 \mathrm{kgal}$ bottom-dilution, will leave the crust surface at 408 inches and the crust base at 313 inches, well above the chosen operational limit of 295 inches The crust dissolution model indicates that top dilution significantly improves operational flexibility, allowing a greater amount of total back-dilution to be added before sinking the crust (Section 2.4).

Second and later transfer and back-dilution operations will target dissolution of solids in the crust solids-liquid-gas bubble matrix. Given the tank conditions expected at the time of the second back-dilution, no plausible continuous or sudden gas release scenarios resulting in flammable hydrogen concentration were identified. A number of scenarios were considered, including releases from sinking crust, releases from sunken crust mobilized by the mixer pump, buoyant displacement gas releases from the sunken crust, sudden releases from the slurry during water addition, continuous releases from the dissolving crust, bubble-slurry flows, and sudden releases of gas pockets. Combinations of continuous and sudden releases were also considered. The major specific conclusions were as follow:

- The gas release model devised for rising "gobs" of nonconvective layer, when modified to describe sinking gobs of crust, predicts limited gas releases that could not exceed the lower flammability limit (Section 4.1). The same is true for gas releases from rising gobs of sunken crust (Section 4.3). The modeling was based in part on crust strength estimates (Section 2.3).

- A new model derived to describe solids mobilization by the mixer pump shows that gas releases from mobilization of the sunken crust could not cause hydrogen concentrations approaching the LFL (Section 4.2).

- The gas release due to crust dissolution was modeled based in part on crust degradation rates estimated from simulant experiments (Section 5.3). This analysis predicts dome space hydrogen concentrations of less than $9 \%$ of the LFL (Section 6.4) for expected (mass-transport-limited) crust degradation rates on the order of 1-cm thickness per hour. The crust dissolution rates that would be required to reach the LFL are unrealistically high.

- Under very conservative, worst-case conditions (420-inch waste level, 0.1 initial fraction of LFL, and 1-min release duration), release from a gas pocket of nearly $100 \mathrm{~m}^{3}$ volume would be required to reach the LFL. The largest retained bubble, constrained laterally by the location of waste-intrusive activities or risers and vertically by waste strength, is $76 \mathrm{~m}^{3}$ (Section 6.5). 



\section{Contents}

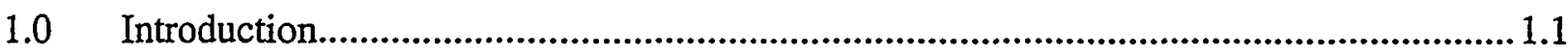

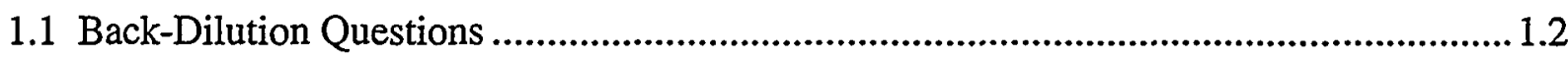

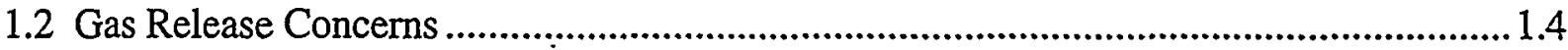

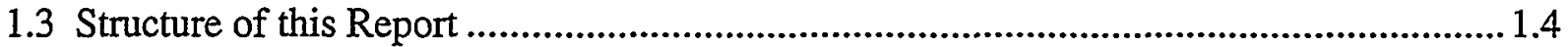

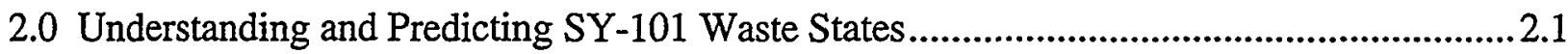

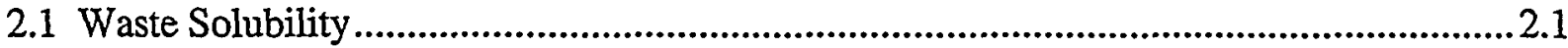

2.1.1 Conceptual Model for Estimating Dilution Effects in Tank SY-101 .........................2.1

2.1.2 Extracting Model Parameters from the Experimental Data........................................ 2.4

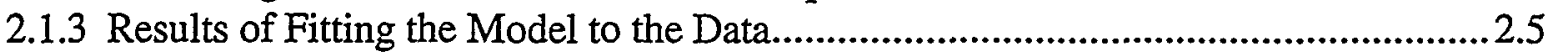

2.1.4 Interpreting the Fitted Parameters ............................................................................... 2.5

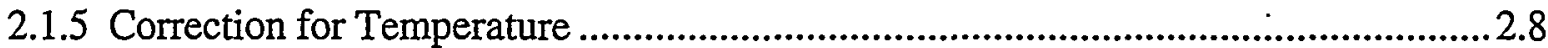

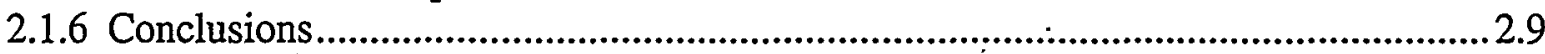

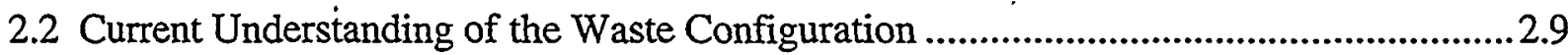

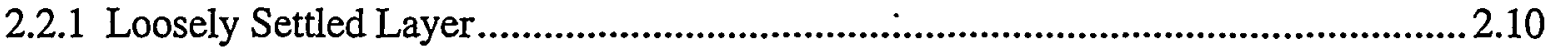

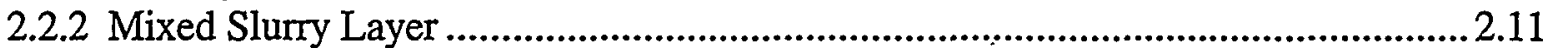

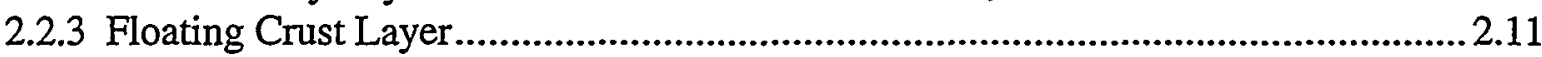

2.3 Crust Layer Yield Stress in Shear ...........................................................................2.13

2.3.1 Description of the Mechanical Mitigation Arm and Water Lance............................2.14

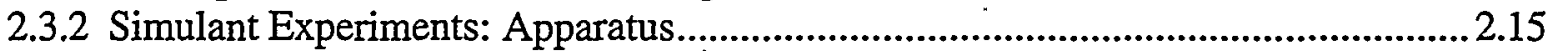

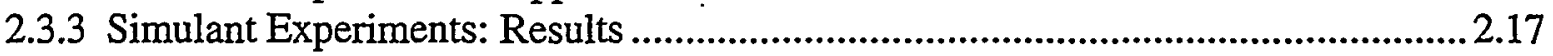

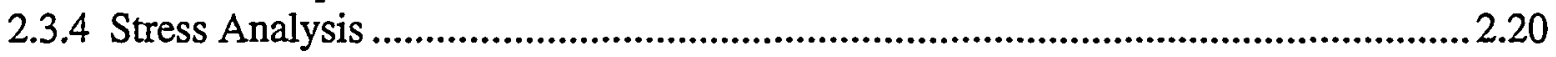

2.3.5 Application of Experimental and Analytical Results ..............................................2.2.

2.4 Crust Behavior Model ..................................................................................................2.2.

2.4.1 Buoyancy Model for Crust Floatation ....................................................................2.2.

2.4.2 Waste Dissolution Model .............................................................................2.2.26

2.4.3 Results for the Initial Transfer and Back-Dilution................................................2.2.

2.4.4 Predicted State of Waste after Initial Transfer and Back-Dilution ..........................2.30

2.4.5 Uncertainty Analysis ...................................................................................................2. 2.31

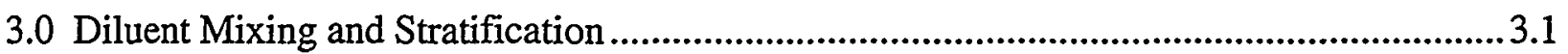

3.1 Diluent Mixing During Addition ..................................................................................... 3.1

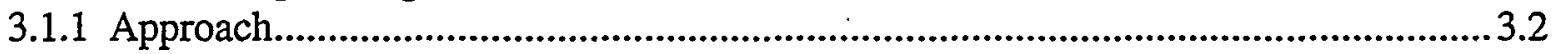

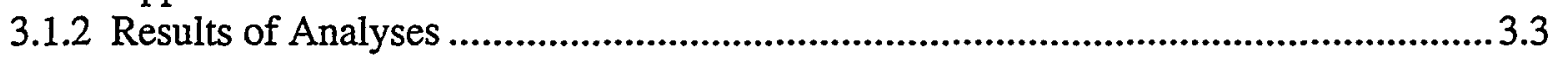

3.2 Mixer Pump Effect on Slurry Layer Stratification ............................................................. 3.6

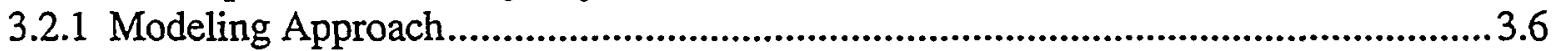

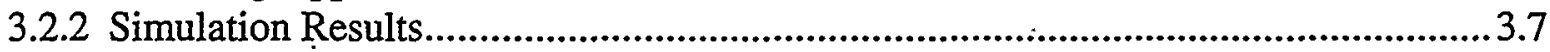

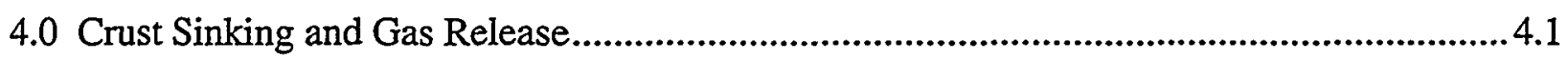

4.1 Evaluation of Potential for Gas Release During Crust Sinking......................................... 4.1

4.1.1 Modification of Model for Sinking Crust................................................................. 4.1

4.1.2 Application of the Model ...........................................................................................4.4

4.2 Mobilization of Sunken Crust Material with the Mixer Pump.......................................... 4.6 


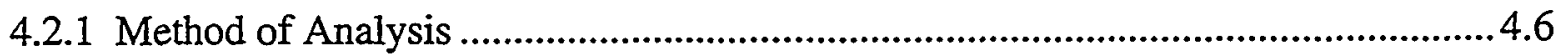

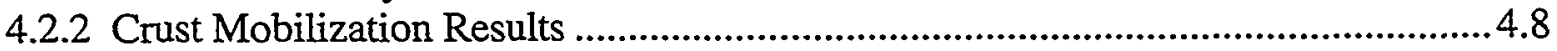

4.3 Buoyant Displacement Gas Release from Sunken Crust ................................................ 4.10

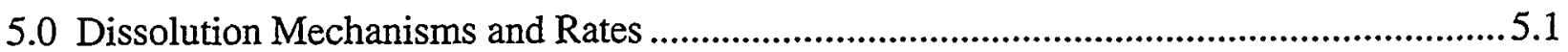

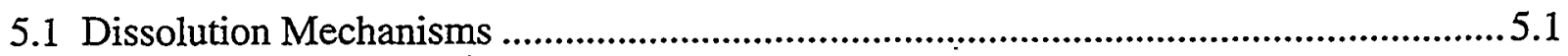

5.1.1 Top-Down Dilution-Spreading............................................................................. 5.1

5.1.1.1 Analysis of Plunging Jet Penetration ..................................................................5.2

5.1.1.2 Experiments-Sugar as Simulated Crust.............................................................5.5

5.1.2 Bottom-Up Dilution-Preferred Channels ................................................................5. 5.8

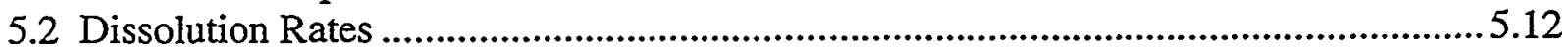

5.2.1 Actual Waste and Other Salt Data...................................................................... 5.12

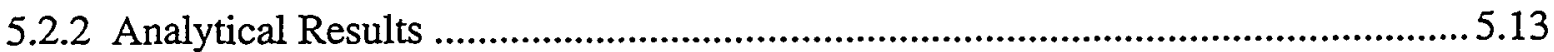

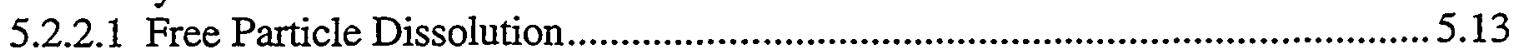

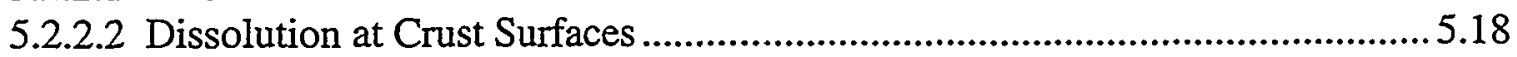

5.3 Chemical Simulant Crust Dissolution Tests .................................................................22

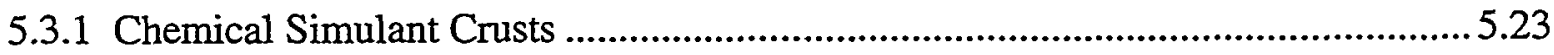

5.3.1.1 Simulant Chemistry and Batch Preparation ................................................... 5.23

5.3.1.2 Formation of Chemical Simulant Crusts........................................................... 5.24

5.3.2 Crust Dissolution Experiment Approach and Apparatus .........................................5.28

5.3.3 Results of Chemical Simulant Dissolution Experiments......................................... 5.29

5.3.3.1 Dissolution and Gas Release Mechanisms....................................................5.30

5.3.3.2 Crust Dissolution and Gas Release Rates ......................................................... 5.35

5.3.3.3 Nonconvective Layer Dissolution Kinetics—Mixed and Unmixed Samples...5.42

6.0 Gas Release Mechanisms, Rates, and Analysis.....

6.1 Domespace Hydrogen Concentration Model .................................................................... 6.1

6.2 Gas Release Mechanisms ................................................................................................6.3

6.2.1 Gas Release from Slurry and Nonconvective Layers................................................6.3

6.2.2 Floating Crust Layer Gas Release Mechanisms .......................................................6.5

6.3 Approach for Modeling Gas Releases from Tank Crust.....................................................6.6.

6.4 Analysis of Continuous Crust Degradation and Gas Release...........................................6.11

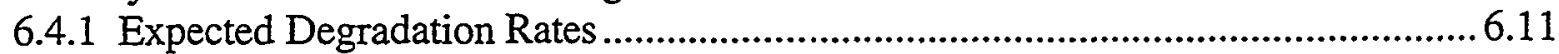

6.4.2 Extreme Cases-Dissolution and Gas Release at the Water Addition Rate ............6.14

6.5 Analysis of Sudden Gas Release Scenarios.....................................................................6.17

6.5.1 Scenarios for Sudden Gas Release Following Continuous Release..........................6.17

6.5.2 Accumulation and Sudden Release of Large Gas Pockets Beneath the Crust.......... 6.21

7.0 References

Appendix: 222-S Experimental Data and Conceptual Model.....................................................1 


\section{Figures}

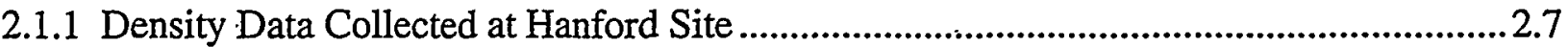

2.1.2 Correlation of Selected Density Data Collected at Hanford Site .....................................2.7

2.1.3 Apparent Densities of Dissolved Solids and Water Inferred from Hanford Data ...............2.8

2.1.4 Correcting $\mathrm{R}_{\mathrm{D}}$ (solubility) for Temperature.......................................................................2.9

2.2.1 Crust Configuration as Indicated by Neutron Profiles....................................................... 2.12

2.2.2 Concept of Crust Configuration and Properties................................................................... 2.13

2.3.1 Schematic of the MMA in Horizontal Position .............................................................2.14

2.3.2 Schematic of Water Lance...........................................................................................2.15

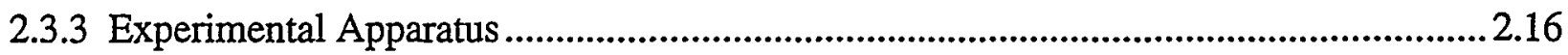

2.3.4 Measured Torque as Function of the Calculated Torque ....................................................2.18

2.3.5 Nondimensional Pressure as Function of Dimensionless Length Scale ..........................2.19

2.3.6 Nondimensional Pressure as Function of Dimensionless Length Scale (bentonite clay) ................................................................................................................2.2.

2.3.7 Schematic of Rectangular Plate at Onset of Plastic Penetration into Medium................. 2.21

2.3.8 Estimated Yield Stress in Shear for Floating Crust Layer in SY-101 ..............................2.2.22

2.4.1 Diagram of Crust Buoyancy Model .............................................................................2.2.

2.4.2 Diluent Added so Crust Is Completely Submerged .........................................................2.2.25

2.4.3 Diluent Mixture Is Dense Enough to Support the Crust ......................................................2.2.25

2.4.4 Schematic of Back-Dilution Locations ...................................................................2.2. 26

2.4.5 Histogram of Dilution Volume for Crust Sinking: 100-kgal Transfer............................... 2.34

2.4.6 Histogram of Dilution Volume for Crust Sinking: 150-kgal Transfer...............................2.35

3.1.1 100-gpm Inflow at 24-in. Elevation of Mixer Pump Sparge Ring

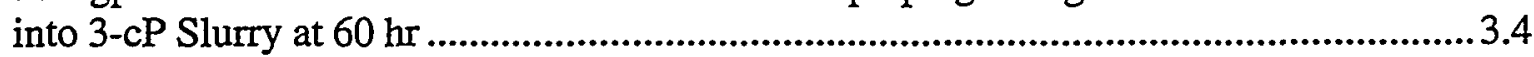

3.1.2 100-gpm Inflow at 96-in. Elevation of Transfer Pump Inlet into

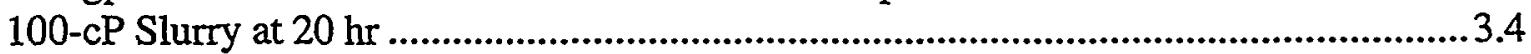

3.1.3 Minimum Mixture Specific Gravity as a Function of Time............................................3.5

3.2.1 Density Distribution and Flow Field in Jet Plane after 25 Min of Mixing ..........................3.8

3.2.2 Density Distribution and Flow Field in Plane 8.5 Degrees from Jet Plane after 25 Min of Pump-Jet Mixing ....................................................................................... 3.10

3.2.3 Density Distribution and Flow Field in Plane 8.5 Degrees from Jet Plane after 125 Min of Pump-Jet Mixing ...............................................................................11

3.2.4 Vertical Density Distribution at 25-min Intervals of the Mixing Process......................... 3.12

4.1.1 Diagram of Sinking Crust...................................................................................................... 4.2

4.1.2 Energy Ratio as a Function of Yield Stress in Shear of the Crust...................................... 4.5

4.2.1 Mixer Pump Hydrodynamic Stress as Function of Distance from Jet Nozzle ................... 4.9

4.2.2 Volume Disturbed by Mixer Pump Operation as Function of Waste Shear Strength ..... 4.10

4.3.1 LFL Fraction in Tank Headspace Due to BD GRE of Sunken Crust Piece..................... 4.12

5.1.1 Schematic of the Plunging Jet Model......................................................................................5.2

5.1.2 Extent of the Penetration Zone for a Plunging Jet ............................................................... 5.4

5.1.3 Plunging Depth as a Function of the "Crust" Thickness.......................................................5.5

5.1.4 Water Spreading and Dissolution of Simulated Crust Layers............................................5.7

5.1.5 Schematic of Stability Analysis for Liquid Displacement in a Tube.................................5.9

5.1.6 Stability Length Scale as Function of Liquid Density at Lower Pore Entrance...............5.10 
5.2.1 Time to Dissolve Solid Spheres to $1 \%$ of Initial Diameter in Solutions of Varying Concentration

5.2.2 Crust Dissolution Rates for Bottom-Up Crust Dissolution ............................................ 5.21

5.2.3 Crust Dissolution Rates for Top-Down Crust Dissolution.........................................5.21

5.3.1 Changes in Crust Properties with Temperature Reduction in Chemical Simulant Sample with Greater Evaporation ...................................................5.26

5.3.2 Changes in Crust Properties with Temperature Reduction in Chemical Simulant Sample with Less Evaporation ......................................................5.27

5.3.3 Temperature Control and Monitoring System for Crust Dissolution Tests ...................5.28

5.3.4 Dissolution and Gas Release from Small Piece of Free-Floating Crust just after Diluent Addition.....................................................................................5.31

5.3.5 Three Thick Crust Samples and the Location of Diluent One Hour After Addition ..... 5.34

5.3.6 Dissolution of Thin Crust with Water Added below Crust Surface ...............................5.36

5.3.7 Dissolution of Thin Crust with Water Sprayed on Top of Crust Surface ........................5.37

5.3.8 Dissolution of Thicker Crust with Water Added below Crust Surface..........................5.39

5.3.9 Apparent Crust Gas Release Volumes for Three Crust Samples in First 10 Hours after Water Addition ..................................................................................5.40

5.3.10 Apparent Crust Gas Release Volumes for Three Crust Samples in the 100 Hours Following Water Addition.

5.3.11 Dissolution Rates of Nonconvective Layers in Mixed and Unmixed Chemical Simulant Samples 5.44

6.3.1 Simple Crust Model Used in Gas Release Analyses..

6.4.1 Transient Response of Hydrogen LFL Fraction Resulting from Degradation of the Model Crust .

6.4.2 Maximum $\mathrm{H}_{2}$ LFL Fraction for Continuous Gas Release from Model Crust for a Range of Realistic Dissolution Rates.....

6.4.3 Transient Response of Hydrogen LFL Fraction During Degradation of Model Crust at Rate Equivalent to Instantaneous Dissolution by Water Added at 240 or $70 \mathrm{gpm}$.... 6.14

6.4.4 Maximum Hydrogen LFL Fraction for Continuous Gas Release from Model Crust Assumed to Dissolve at Rate of Water Addition.

6.5.1 Effect of Sudden Release Duration on Maximum LFL.

6.5.2 Effect of Continuous Paste Layer Degradation Rate on Maximum LFL Fraction ......... 6.20

6.5.3 Gas Releases as Function of Angle of Mixer-Pump Orientation in SY-101 .................6.22

6.5.4 Location of Permanent Gas Release Paths and Intrusive Activities in SY-101 ............6.22

6.5.5 Maximum Gas Bubble Size in SY-101 ................................................................24

6.5.6 Total Gas Release Volume at Atmospheric Pressure Needed to Achieve Hydrogen LFL as a Function of Initial Waste Level . 


\section{Tables}

2.1.1 Simplifying Assumptions for the Conceptual Model ....................................................2.2.2

2.1.2 Results of Least Squares Analysis for Ambient Temperature Dilution Data..................... 2.5

2.1.3 Summary of Recommended Property Values ................................................................2.10

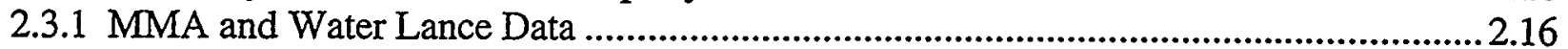

2.3.2 Linear Fits of the Measured Torque as Function of Calculated Torque ..........................2.18

2.3.3 Average Dimensionless Pressure, $\eta$, for the Push Tests ...................................................2.20

2.3.4 Critical Values of $\eta$ for Different Plate Shapes..........................................................2.2.

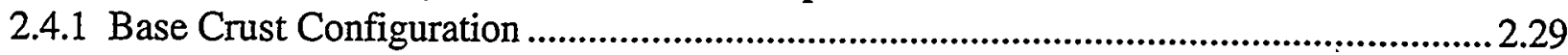

2.4.2 Volume Limits for Back-Dilution below Crust............................................................2.2.30

2.4.3 Waste Conditions before and after Campaign \#1-35-kgal Bottom Dilution ..................2.31

2.4.4 Waste Conditions before and after Campaign \#1-72-kgal Bottom Dilution ..................2.2.31

2.4.5 Crust Dissolution Model Input Distributions and Constraints .......................................2.33

3.1.1 Calculated Mixture Specific Gravity Shortly after Cessation of Water Inflow ...................3.3

3.1.2 Comparison of Calculated Mixture Specific Gravity under Crust at

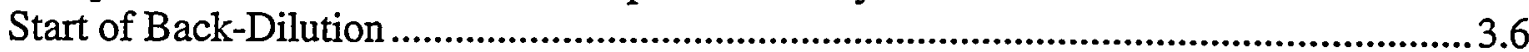

3.2.1 Model Assumptions for Waste Stratification ..................................................................

4.1.1 Gas Release Predictions of Modified Gas Release Model for Sinking Crust ...................... 4.5

5.1.1 Conditions for Sugar Dissolution Experiments .................................................................5.6

5.2.1 Comparison of Dissolution Time and Estimated Settling Time in Slurry ......................5.17

5.2.2 Time to Reduce Dissolving Spheres to $1 \%$ of Initial Diameter..........................................5.18

5.3.1 Composition of SY-101 Waste Chemical Simulants....................................................5.24

5.3.2 Summary of Crust Dissolution Experiments ....................................................................

5.3.3 Waste, Crust, and Water Volumes in Early Stages of Graduated Cylinder

Crust Dissolution Experiments ...................................................................................5.33

6.3.1 Constant Model Parameters Used in Gas Release Analyses ............................................6.9

6.3.2 Possible Waste Levels in Second Waste Transfer and Back-Dilution Operation ............6.10

6.4.1 Comparison of Current and Early Dissolution Gas Release Models .................................6.16

6.4.2 Summary of Dilution Rate Equivalent Crust Dissolution....................................................6.17

6.5.1 Summary of Sudden Gas Release Volumes ......................................................................18 


\subsection{Introduction}

There are 177 underground high-level waste storage tanks at Hanford with a total capacity of 55 million gallons. The tanks contain wastes collected over almost 50 years of plutonium production and include radioactive isotopes, organic solvents, sodium and aluminum salts, and many other organic and inorganic compounds. The waste was initially stored in 149 single-shell tanks (SSTs) built in the 1940s, 1950s and 1960s. Concerns about potential leaks in the SSTs and the need for additional storage volume prompted construction of 28 double-shell tanks (DSTs) in the late 1970s. The SSTs were removed from service in 1980 and the process of pumping their liquid content into the DSTs began.

To conserve tank space, much of the SST liquid was concentrated by evaporation as it was transferred to the DSTs. As the liquid cooled, precipitation resulted in a relatively deep layer of settled solids under a layer of supernatant liquid of approximately equal depth. Because dissipation of the radioactive decay heat drives natural convection in the supernatant liquid layer, it is called the convective layer. Because the settled solids layer develops a yield strength that inhibits convection, it is called the nonconvective layer. Flammable gas mixtures containing hydrogen, ammonia, nitrous oxide, methane, and other gases are generated in the waste. In some of the tanks, gas bubbles that escape from the nonconvective layer carry particles to the waste surface to form a floating "crust" layer on top of the supernatant liquid.

Where the waste has been most concentrated, the resulting combination of high gas generation rate and a deep nonconvective layer causes the gas to accumulate until a portion of the nonconvective layer becomes more buoyant than the liquid above it. The buoyant waste then rises to the surface and releases most of its gas rapidly into the tank headspace. This type of gas release is termed a buoyant displacement gas release event (BD GRE). Six of the DSTs (AN-103, AN-104, AN-105, AW-101, SY-101, and SY-103) exhibit BDs and have thus been placed on the Flammable Gas Watch List (FGWL) (Johnson 1997).

The waste in SY-101 is the most highly concentrated of all the DSTs. Its gas releases averaged about an order of magnitude larger in volume than those of the other five tanks. In fact, the measured flammable gas concentration in the headspace exceeded the lower flammability limit (LFL) at least three times between 1990 and 1993. (The LFL may have been exceeded before this as well, but there are no gas monitoring data to confirm it.) SY-101 is the only Hanford tank in which this is known to have happened.

Starting in the late 1980s, a period of intense study and administrative effort led to creation of the FGWL and spawned a high-priority project to mitigate the gas releases in SY-101. This was accomplished in July 1993 with the installation of a mixer pump that has thus far prevented significant gas retention in the nonconvective layer (Allemann et al. 1994; Stewart et al. 1994; Brewster et al. 1995).

But, in the absence of periodic disruption from large GREs, the action of mixing that releases gas in a controlled fashion has allowed the crust to grow and accumulate gas. This caused the waste level to grow more than 30 inches by the spring of 1999, and the flammable gas volume 
stored in the crust itself became a hazard. To remediate gas retention in the crust and prevent buoyant displacement gas releases from below the crust, SY-101 will be diluted to dissolve a large fraction of the solids that allow the waste to retain gas. The plan is to transfer waste out and back-dilute with water in several steps of about 100,000 gallons each (Raymond 1999) beginning in the fall of 1999.

Because the crust is floating, it can be modeled with simple hydrostatic principles. Most basic is that the weight of the crust must be equal to the weight of fluid displaced. The amount of crust submerged depends on the density of the fluid it displaces. For the crust to float, the specific gravity of the fluid surrounding the crust must be greater than that of the crust. During back-dilution, the specific gravity of the fluid in contact with the crust depends on how well the dilution water mixes with the slurry under the crust and how the crust dissolves. We are also concerned with the potential rates of gas release as the crust dissolves and with the potential consequences of crust sinking. Specific concerns regarding back-dilution and potential gas releases are outlined in Sections 1.1 and 1.2.

\subsection{Back-Dilution Questions}

The first transfer and back-dilution step will involve a transfer of $88 \mathrm{kgal}$ of SY-101 convective waste to SY-102 followed by back-dilution of $25 \mathrm{kgal}$ water on top of the waste and at least $35 \mathrm{kgal}$, but not more than $72 \mathrm{kgal}$, of water added through the transfer pump inlet 96 inches above the tank bottom (Barton 1999). The water added on top of the crust is expected to dissolve most of the current crust freeboard. The water added under the crust is mainly to ensure the crust is raised well above the mixer pump inlet. It is expected to dissolve a portion of the suspended solids in the mixed slurry but should not dissolve much, if any, of the crust (Section 2.4).

This report addresses the effects of the second (and possibly third) transfer and back-dilution campaigns. The dilution planned for the first campaign will not reduce the gas volume stored in the crust nor will it significantly reduce the crust thickness. One major goal of the second campaign is to destroy the crust as a structure and release most of the gas. To plan this process effectively, we must know how the crust will behave as it dissolves and what dissolution and gas release rates can be expected from top and bottom dilution.

The current crust freeboard is known from observation to be quite porous. Water added on top of the crust in the first campaign is expected to flow readily across the tank over the much heavier saturated liquid that defines the bottom of the freeboard layer. Because the surface area for water-solids contact in the freeboard is very large, dissolution is expected to be quite rapid, possibly about as fast as the water is added. There is no concern over gas release with this process, because very little flammable gas is trapped in the freeboard (Mahoney et al. 1999). Once the current freeboard dissolves, the surface area for dissolution is greatly reduced. At the same time, the natural density gradient will keep the most dilute solution on top, away from the solids to be dissolved. Thus, dissolution by top dilution should slow down considerably after the existing freeboard is gone. 
Dissolution from the bottom up, when sufficient water has been added to create unsaturated liquid at the base of the crust, may be faster than from the top down because density gradients tend to keep the most dilute solution in contact with the solids overhead. However, if the solution is so dilute that its density is insufficient to float the crust, the liquid will flow through the crust and act as top dilution. The difference in dissolution rates in these two scenarios needs to be understood.

The plan is to add the dilution water as a point source, whether under or on top of the crust. While we expect the water to distribute itself fairly uniformly across the tank due to gravity and natural spreading, the most dilute solution and therefore the highest dissolution rate will tend to be at the lateral position of the injection point. This will tend to dissolve the crust preferentially from this point outward. The effect is expected to be minor when water is added near the bottom of the tank because the buoyant plume of water mixes quite effectively with the surrounding slurry as it rises. However, top dilution during the first campaign will certainly tend to dissolve the central portion of the crust freeboard first.

Besides this hydraulically induced, tank-scale effect, dissolution is expected to amplify existing unevenness in the crust structure to create local nonuniformity. This effect should be strongest in bottom-up dissolution, where natural convection tends to deepen any existing concavity. The extent of both scales of nonuniformity and their influence on dilutions during the second campaign needs to be assessed.

As the crust dissolves, it will release the trapped gas that makes it buoyant and any insoluble particles layered on top of the crust would continue to add load. At the same time, water addition decreases the density of the liquid the crust floats on. At some point these combined effects are expected to cause the remaining crust to sink. There is a concern that, if the crust is not thinned significantly before it sinks, a potentially excessive gas release might occur or the mixer pump might not be able to mobilize it sufficiently to prevent gas retention. While top dilution minimizes dissolution of the slurry layer, it also leaves degassed insoluble solids on top of the crust as weight. This causes the bulk crust to become increasingly dense as it dissolves, which is potentially a stronger effect than the decrease in slurry density by bottom dilution. The first campaign was designed to ensure the crust would not sink. It is important to understand the effects of top and bottom dissolution on crust buoyancy so the second dilution campaign can be planned effectively.

Finally, the mixer pump will be run periodically between steps in each transfer/back-dilution campaign. The action of the jets will raise settled solids above the water injection point at the transfer pump inlet and inject dilute mixture below it. Bubbles released from the loosely settled layer will also tend to replenish the gas removed from the higher regions by dissolution of attached solids. However, it is doubtful that the fluid between the crust base and the mixer pump inlet would be readily mixed if any significant stratification has occurred. The effect of the mixer pump operation on the density of the fluid on which the crust floats needs to be assessed and included in any predictions of crust behavior. 


\subsection{Gas Release Concerns}

An overriding gas release concern in SY-101 is preventing a return to the large historic BD GREs. Mixer pump operations will thus be required to prevent formation of a deep contiguous nonconvective layer and resulting gas retention until such time as it is determined the hazard no longer exists. Even though buoyant displacements could not resume for many months following a pump failure, it is vital to ensure that the transfer and back-dilution processes do not prematurely degrade the pump's effectiveness below an acceptable level.

The strategy for preserving the pump in the first campaign was to ensure that the base of the crust layer could be raised well above the mixer pump inlet by back-dilution low in the tank. This will be less of an issue in the second campaign because the crust will be dissolving. However, operations should be planned such that the crust is not deliberately lowered around the mixer pump inlet, except temporarily. Conditions that would cause the crust to sink to the tank bottom before it is thinned significantly should be considered carefully because it is not completely clear that the mixer pump jets could remobilize it.

The mechanical disturbance induced by crust sinking could hypothetically cause rapid release of a large fraction of the gas stored in the crust. This potential can be evaluated by comparing the buoyant potential energy released as the crust sinks to that required to yield the crust material. This requires a good estimate of the crust strength. The gas release potential needs to be established to help determine how thin the crust must be before sinking ceases to be a concern.

Gas is also released as the solid particles that hold the bubbles dissolve. We have consistently assumed that the dissolution gas release rate is proportional to the water addition rate. However, this assumption needs to be reassessed in light of our increased understanding of the dissolution process and of the crust structure. The potential for gas holdup and sudden gas release during dissolution needs to be investigated. Finally, the transient headspace hydrogen concentration during back dilution must be estimated as a function of water injection rate for several possible scenarios.

\subsection{Structure of this Report}

This report documents the results of studies performed in the summer and fall of 1999 to answer the questions posed above and to support planning and development of controls for the SY-101 Surface Level Rise Remediation Project. Section 2 summarizes our knowledge of the SY-101 crust and the buoyancy and dissolution models that are applied to predict its response to waste transfers and back-dilution. Section 3 discusses the potential for stratification resulting from water addition and the effect of the mixer pump on stratified fluid layers below the crust. Section 4 discusses the consequences of crust sinking in terms of gas release during sinking, the ability of the mixer pump to remobilize it, and the potential for recurrence of BD GREs. Section 5 presents a detailed study of crust and mixed-slurry solids dissolution mechanisms and rates, including theoretical calculations, analysis of laboratory results for simulated and actual 
waste, and a description of laboratory dissolution studies using SY-101 chemical simulant crusts. This section also addresses the kinds of nonuniformity that might be expected because of the dynamic dissolution process. Section 6 considers the flammability potential from a variety of spontaneous and dissolution-induced gas releases from the floating crust and mixed slurry. Cited references are listed in Section 7. 


\subsection{Understanding and Predicting SY-101 Waste States}

The SY-101 waste column is a dynamic system that involves several key processes. Solid particles attached to small bubbles are released from the loosely settled layer on the bottom and carried up to the crust base due to natural buoyancy and the action of the mixer pump. The waste temperature varies widely through the crust because it acts as a thermal insulator that restricts the flow of radioactive decay heat to the tank headspace. In the cooler region of the crust, solids precipitate from the interstitial liquid, reducing the porosity and increasing its strength. Gas bubbles released from the mixed slurry layer by the pump and generated within the crust itself migrate upward to the tank headspace. Some are trapped within the crust. This retained gas makes the crust more buoyant than the mixed slurry on which it floats.

This section describes the condition of the waste as it has evolved over the last year and summarizes the models that have been used to predict its behavior. It also extends our understanding to predict the state of the waste following initial waste transfer and back-dilution operations because this is the state of concern in this report. Section 2.1 discusses the waste solubility and basic physical properties. Section 2.2 describes the current state of the waste column by layer with dimensions and properties emphasizing the crust. Section 2.3 presents estimates of the crust strength derived from operational data. Section 2.4 summarizes waste behavior models used to predict its response to transfer and dissolution and uses these tools to estimate the configuration of the waste following the initial waste transfer and back-dilution process.

\subsection{Waste Solubility}

The 222-S Laboratory conducted dilution tests on a variety of core and grab samples from SY-101. The laboratory determined volume and mass fractions and densities of liquid and solid fractions before and after dilution to characterize the dissolution of solids by the dilution (Person 1999). These data provide a basis for estimating the tank waste properties (relative quantities and apparent densities of water, dissolved solids, and undissolved solids) as well as the effects of diluting the waste with water.

A simple, uniform approach was adopted for predicting dilution in the tank that also describes all of the pertinent data from these experiments. This section depicts a simplified conceptual model of dilution from which a predictive model was developed and tested by fitting to the experimental data (i.e., regression). The results are reported in terms of fitted model parameters and a comparison of the experimental and predicted results.

\subsubsection{Conceptual Model for Estimating Dilution Effects in Tank SY-101}

We have not considered all of the consequences to dilution of the complex chemical and physical phenomena inherent to the waste and physical configuration in Tank S.Y-101. Instead, we sought a simple conceptual model of the processes that suffices to estimate the consequences of dilution. We adopted the conceptual model described in Table 2.1.1 in terms of our simplifying assumptions. In summary, much of the complexity of the system is subsumed into a 
Table 2.1.1. Simplifying Assumptions for the Conceptual Model

\begin{tabular}{|c|c|}
\hline Actual Situation & Simplified Conceptual View \\
\hline $\begin{array}{l}\text { The solid phase is a mixture of very soluble salts } \\
\text { in equilibrium with the brine (e.g., } \mathrm{NaNO}_{2} \text {, } \\
\mathrm{NaAl}(\mathrm{OH}) 4 \text {, NaNO3), much less soluble salts in } \\
\text { equilibrium with the brine (e.g., } \mathrm{Na}_{2} \mathrm{CO}_{3}, \mathrm{Na}_{2} \mathrm{SO}_{4} \text {, } \\
\left.\mathrm{Na}_{2} \mathrm{PO}_{4} \text { ), and nearly insoluble salts (e.g., } \mathrm{NaC}_{2} \mathrm{O}_{4}\right) \text {. }\end{array}$ & $\begin{array}{l}\text { The solid phase consists of a partially soluble } \\
\text { salt and an insoluble salt. }\end{array}$ \\
\hline $\begin{array}{l}\text { As water is added, the various salts dissolve in } \\
\text { different amounts in accordance with their } \\
\text { solubilities, where the solubilities are affected by } \\
\text { the ionic strength of the solution }\end{array}$ & $\begin{array}{l}\text { The partially soluble salt dissolves with a } \\
\text { constant solubility that is reflected by the } \\
\text { concentration of salts in solution prior to } \\
\text { dilution. }\end{array}$ \\
\hline $\begin{array}{l}\text { The solution phase includes water, partially } \\
\text { soluble salts in equilibrium with their solids } \\
\text { phases, and also soluble species such as } \mathrm{NaOH} \\
\text { and } \mathrm{NaCl} \text {. }\end{array}$ & $\begin{array}{l}\text { The solution includes only water and a single } \\
\text { partially soluble salt in equilibrium with a } \\
\text { solid phase; soluble species such as } \mathrm{NaOH} \\
\text { and } \mathrm{NaCl} \text { are ignored. }\end{array}$ \\
\hline $\begin{array}{l}\text { The mass of solids remaining as water is added is } \\
\text { a complex function resulting from the successive } \\
\text { depletion of the different solids phases. }\end{array}$ & $\begin{array}{l}\text { The mass of solids remaining is simply the } \\
\text { sum of a single partially soluble solid and a } \\
\text { constant quantity of insoluble solid. The } \\
\text { mass of remaining solids ceases to change } \\
\text { once the partially soluble solid has completely } \\
\text { dissolved. }\end{array}$ \\
\hline $\begin{array}{l}\text { The specific volume of the liquid is a complex } \\
\text { function of the composition of the solution, where } \\
\text { the partial molar volumes of the various dissolved } \\
\text { species, including water, are complex functions of } \\
\text { composition. }\end{array}$ & $\begin{array}{l}\text { The volume of the liquid is the sum of the } \\
\text { volumes of water and the dissolved solid, } \\
\text { where their specific volumes are constant. }\end{array}$ \\
\hline $\begin{array}{l}\text { Dilution lowers the } \mathrm{pH} \text { and can cause precipitation } \\
\text { of } \mathrm{Al}(\mathrm{OH})_{3} \text { subsequent to dissolving sodium } \\
\text { aluminate. }\end{array}$ & $\begin{array}{l}\text { No distinction is made among dissolved } \\
\text { species or solid phases. Precipitation of } \\
\text { Al }(\mathrm{OH})_{3} \text { could only be described as a greater } \\
\text { than otherwise expected fraction of solids } \\
\text { remaining, which might offset electing not to } \\
\text { describe the slight dissolution of } \mathrm{Na}_{2} \mathrm{CO}_{3} \text {. }\end{array}$ \\
\hline $\begin{array}{l}\text { The density of the solid phase is a function of the } \\
\text { fraction of solids dissolved because the phase is a } \\
\text { composite of solids with different densities that } \\
\text { dissolve in different amounts. }\end{array}$ & The density of the solid phase is constant. \\
\hline
\end{tabular}

composite physical system consisting of two solids and a two-component liquid. While this is categorically incorrect, it nevertheless serves our limited purpose of describing the dissolution behavior while retaining a physically based conceptual model that allows us to assign physical meaning to fitted model parameters. We then need to confirm that fitted parameters have physically reasonable values to assess the acceptability of our simplifications in the limited context of extrapolating the laboratory data to hypothetical dilution steps in SY-101. 
Based on this conceptual model, we defined the following parameters to estimate the consequences of dilution:

- $\rho_{S}=$ density in solid state of solids in the slurry.

- $\rho_{D}=$ density in dissolved state of solids dissolved in liquid phase of the slurry.

- $\rho_{\mathrm{H}}=$ density in dissolved state of water $\left(\mathrm{H}\right.$ as in $\left.\mathrm{H}_{2} \mathrm{O}\right)$ dissolved in liquid phase of slurry.

- $\mathrm{R}_{\mathrm{D}}=$ ratio at chemical saturation of dissolved solids to water in liquid phase of slurry (roughly proportional to the total molality of solutes).

Given these, the mass fraction of water and dissolved solids in the liquid phase is described as

$$
\mathrm{w}_{\mathrm{H}}^{\mathrm{L}}=\frac{1}{1+\mathrm{R}_{\mathrm{D}}}, \mathrm{w}_{\mathrm{D}}^{\mathrm{L}}=\frac{\mathrm{R}_{\mathrm{D}}}{1+\mathrm{R}_{\mathrm{D}}}
$$

Given the assumption about the liquid being a binary mixture, the density of the liquid phase of the slurry is found from the mass and volume using

$$
\mathrm{V} \equiv\left(\frac{\partial \mathrm{V}}{\partial \mathrm{m}_{\mathrm{D}}}\right)_{\mathrm{m}_{\mathrm{H}}} \mathrm{m}_{\mathrm{D}}+\left(\frac{\partial \mathrm{V}}{\partial \mathrm{m}_{\mathrm{H}}}\right)_{\mathrm{m}_{\mathrm{D}}} \mathrm{m}_{\mathrm{H}}=\frac{\mathrm{m}_{\mathrm{D}}}{\rho_{\mathrm{D}}}+\frac{\mathrm{m}_{\mathrm{H}}}{\rho_{\mathrm{H}}}
$$

where $m_{D}$ and $m_{H}$ are the masses of the dissolved solids and water, respectively, from which

$$
\rho_{\mathrm{L}}=\frac{1}{\frac{w_{\mathrm{H}}^{L}}{\rho_{\mathrm{H}}}+\frac{w_{\mathrm{D}}^{\mathrm{L}}}{\rho_{\mathrm{D}}}}
$$

where the densities are the inverses of the specific volumes appearing in the equation immediately preceding. The mass of solids that dissolve when a mass of water is added to a mixture of solids and saturated liquid is

$$
\Delta \mathrm{m}_{\mathrm{D}}=\mathrm{R}_{\mathrm{D}}^{\text {sat }} \Delta \mathrm{m}_{\mathrm{H}}
$$

so long as some soluble solids remain. Then the masses of solids in the solid and dissolved states are

$$
\begin{aligned}
& \mathrm{m}_{\mathrm{S}}=\mathrm{m}_{\mathrm{S}}^{\text {initial }}-\Delta \mathrm{m}_{\mathrm{D}} \\
& \mathrm{m}_{\mathrm{D}}=\mathrm{m}_{\mathrm{D}}^{\text {initial }}+\Delta \mathrm{m}_{\mathrm{D}}
\end{aligned}
$$

Once the soluble portion of the solids is completely dissolved, the masses of solids in the solid and dissolved states do not change given our simple model. Further addition of water increases only the mass of water, which, in turn, changes the mass fractions of dissolved solids and water in the liquid phase and hence the density of the liquid phase. The situation is described as 


$$
\mathrm{y}=\frac{\Delta \mathrm{m}_{\mathrm{D}}}{\mathrm{m}_{\mathrm{S}}^{\text {initial }}}\left\{\begin{array}{l}
=\mathrm{R}_{\mathrm{D}} \frac{\Delta \mathrm{m}_{\mathrm{H}}}{\mathrm{m}_{\mathrm{S}}^{\text {initial }}}, \mathrm{y}<\mathrm{y}_{\max } \\
=\mathrm{y}_{\max }, \text { otherwise }
\end{array}\right\} .
$$

The volumes of the solid and liquid phases are

$$
\begin{aligned}
& \mathrm{V}_{\mathrm{L}}=\frac{\mathrm{m}_{\mathrm{L}}}{\rho_{\mathrm{L}}}=\frac{\mathrm{m}_{\mathrm{H}}+\mathrm{m}_{\mathrm{D}}}{\rho_{\mathrm{L}}} \\
& \mathrm{V}_{\mathrm{S}}=\frac{\mathrm{m}_{\mathrm{S}}}{\rho_{\mathrm{S}}}
\end{aligned}
$$

The density of the bulk slurry is

$$
\rho_{B}=\frac{m_{L}+m_{S}}{V_{L}+V_{S}}=\frac{m_{H}+m_{D}+m_{S}}{\frac{m_{H}}{\rho_{L}}+\frac{m_{D}}{\rho_{D}}+\frac{m_{S}}{\rho_{S}}}
$$

\subsubsection{Extracting Model Parameters from the Experimental Data}

The same conceptual model applied for estimating the effect of dilution in a tank must apply to describing the effects of dilution on SY-101 waste determined in the 222-S laboratory experiments. In fact, we can describe the measurements made during the dilution tests in terms of the initial mass of a slurry sample, the mass of water added, the parameters described above, and additional parameters specific to the laboratory experiments.

Fewer data were acquired from tests done at tank temperature than at ambient temperature; in particular, very few data were obtained on the mass fraction of water in the liquid, and the result seems counter-intuitive in that the dissolved solids fraction decreased significantly with temperature, yet the liquid density increased. There is also substantially more scatter in the liquid density after dilution. Therefore we elected not to include those data, and our results pertain directly only to waste at ambient temperature $\left(28.5^{\circ} \mathrm{C}\right)$. Therefore, the fitted estimate of the weight fraction of dissolved solids is too low for waste at the expected tank temperature $\left(50^{\circ} \mathrm{C}\right)$. Instead, correction for temperature was accomplished based on the behavior of $\mathrm{NaNO}_{2}$ and $\mathrm{NaNO}_{3}$, as described in Section 2.1.5. However, the other parameters and the structure of the model are probably valid in that they should change little with temperature.

The parameters were determined by nonlinear regression. Specifically, they were fit using a nonlinear least squares approach to best fit the predicted values of the measurements to the actual measured values. The same simple conceptual model used to predict dilution behavior in a tank was used to derive the predictions of the laboratory measurements for the regression analysis. The measurements considered in this analysis and the predictive expressions derived from the simple conceptual model are presented in the appendix to this report. 


\subsubsection{Results of Fitting the Model to the Data}

In performing the least squares analysis, the errors were normalized in two ways. First, they were normalized relative to the mean of the measured values, thus scaling the errors. Second, in subsequently summing the errors before minimizing them, different weights were assigned to the errors of the measured variables. The normalization by the means is entirely objective, but the second normalization requires a subjective assessment of confidence in the measurements. We also attempted to compensate for the number of measurements of the variables, which in some cases differs among the measurements. The subjective weights and the resulting nonlinear leastsquares estimates of the parameters are shown in Table 2.1.2. The weight of $\mathrm{w}_{H}^{\mathcal{L}}$ was augmented because we were particularly concerned about accurately modeling this measurement, which is very important to predicting BD GREs. The mass fraction of water in the undiluted slurry is $\mathrm{w}_{\mathrm{H}, 0} \equiv 1-\mathrm{w}_{\mathrm{S}, 0}-\mathrm{w}_{\mathrm{D}, 0}$, or 0.368 . These parameters correspond to $\mathrm{R}_{\mathrm{D}}=1.066$; a mass fraction of water in the liquid phase is $\mathrm{w}_{\mathrm{H}}^{\mathrm{L}}=0.484$.

Table 2.1.2. Results of the Least Squares Analysis for Ambient Temperature Dilution Data

\begin{tabular}{||c|c|l|c||}
\hline \multicolumn{1}{|c|}{ Measurement } & Weight & \multicolumn{1}{|c|}{ Parameter } & Fitted value \\
\hline \hline $\begin{array}{l}\text { Undiluted Bulk Slurry } \\
\text { Volume }\left(\mathrm{V}_{\mathrm{B}, 0}\right)\end{array}$ & 1 & $\begin{array}{l}\text { Undiluted Mass Fraction } \\
\text { of Free Solids }\left(\mathrm{w}_{\mathrm{S}, 0}\right)\end{array}$ & 0.240 \\
\hline $\begin{array}{c}\text { Diluted Bulk Slurry } \\
\text { Volume }\left(\mathrm{V}_{\mathrm{B}}\right)\end{array}$ & 1 & $\begin{array}{l}\text { Undiluted Mass Fraction } \\
\text { of Dissolved Solids }\left(\mathrm{w}_{\mathrm{D}, 0}\right)\end{array}$ & 0.392 \\
\hline $\mathrm{w}_{\mathrm{H}}^{\mathrm{L}}$ & 30 & $\rho_{\mathrm{H}}$ & $1.034 \mathrm{~g} / \mathrm{mL}$ \\
\hline$\rho_{\mathrm{L}}$ & 0.3 & $\rho_{\mathrm{D}}$ & $2.235 \mathrm{~g} / \mathrm{mL}$ \\
\hline $\begin{array}{l}\text { Mass Fraction of } \\
\text { Centrifuged Solids }\left(\mathrm{w}_{\mathrm{SC}}\right)\end{array}$ & 0.1 & $\rho_{\mathrm{S}}$ & $2.622 \mathrm{~g} / \mathrm{mL}$ \\
\hline $\begin{array}{c}\text { Volume Fraction of } \\
\text { Centrifuged Solids }\left(\phi_{\mathrm{SC}}\right)\end{array}$ & 0.1 & $\begin{array}{l}\text { Maximum Fraction of Solids } \\
\text { Dissolved by Dilution }\left(\mathrm{y}_{\max }\right)\end{array}$ & 0.601 \\
\hline $\begin{array}{c}\text { Mass Fraction of Interstitial } \\
\text { Liquid in the Centrifuged } \\
\left.\text { Solids ( } \mathrm{w}_{\mathrm{ISL}}\right)\end{array}$ & 0.01 & $\begin{array}{l}\text { Volume Fraction of Free } \\
\text { Solids in Centrifuged } \\
\text { Solids }\left(\phi_{\mathrm{S}}\right)\end{array}$ & 0.286 \\
\hline
\end{tabular}

The predicted and measured results for the laboratory tests are included in the appendix to this report. Except for the mass fraction of interstitial liquid in the centrifuged solids, $\mathrm{w}_{\mathrm{ISL}}$, which was given the smallest weight (the values of $\mathrm{w}_{\mathrm{ISL}}$ are difficult to measure and depend on assumptions that are difficult to test), it is apparent the predictions are more reasonable than the scatter in the data would indicate.

\subsubsection{Interpreting the Fitted Parameters}

Although the purpose of our analysis is to provide a model describing the data and not explaining the data per se, it is important nevertheless to show that the fitted values of the parameters are physically reasonable. Otherwise, the conceptual model is probably unacceptable for 
extrapolating laboratory tests to behavior in SY-101. By this criterion, it appears that most of the simplifications are in fact acceptable relative to our limited purposes. Specific gravity data culled from the Tank Waste Information Network System (TWINS) for a host of concentrated solutions measured at the Hanford Site are shown in Figure 2.1.1.(a)

The prominent collection of data at about 50\% water at specific gravity above 1.35 and the "flattening" of the data about the value of $50 \%$ mass fraction of water are probably due in part to the existence of solids in saturated solutions, which occur at about $50 \%$ water by mass. Therefore, to extract from these data information about apparent densities of dissolved solids and water in solid-free liquids, we consider only data for which the fraction of water is $>55 \%$ and the specific gravity $<1.4$. We also eliminate the prominent outliers. The resulting subset is shown in Figure 2.1.2. The data are fitted about their scatter by the equation shown in the figure.

Information about the apparent densities of the dissolved solids (treating them as a single species) and water can be extracted from this correlation using Equation (2.1.3) in the form

$$
\frac{1}{\rho_{L}}=\frac{w_{H}^{L}}{\rho_{H}}+\frac{w_{D}^{L}}{\rho_{D}}
$$

and the definition of the mass fraction and density

where

$$
\frac{d \rho}{d w_{D}^{L}}=\frac{d\left(\frac{m}{V}\right)}{d\left(\frac{m_{D}}{m}\right)}=\left(\frac{m}{V}\right)^{2} \frac{V d m-m d V}{m d m_{D}-m_{D} d m}=\frac{\frac{1}{\rho}-V_{D}}{1-w_{D}^{L}}
$$

$$
V_{D}=\left(\frac{\partial V}{\partial m_{D}}\right)_{m_{H}} \equiv \frac{1}{\rho_{D}}
$$

From the above expression, we have

$$
1-\frac{\rho}{\rho_{D}}=\frac{d \ln \rho}{d \ln w_{H}^{L}}
$$

Thus we can extract $\rho_{D}$ and $\rho_{H}$ from $\rho$ versus $w_{H}^{L}$ data. The result of applying this to.the correlation shown in Figure 2.1.2 is shown in Figure 2.1.3.

The values of the densities of the dissolved solids and water at $48.4 \%$ water by mass are 2.226 and $1.045 \mathrm{~g} / \mathrm{mL}$; which agree well with the values fitted from the 222-S Laboratory data shown in Table 2.1.2 (Person 1999). We adopted these values instead of those fitted from Person's data based on the greater size of the supporting set of data, although we did not attempt an uncertainty analysis for either estimate.

(a) Personal communication with DA Reynolds (LMHC) on October 6, 1999. 


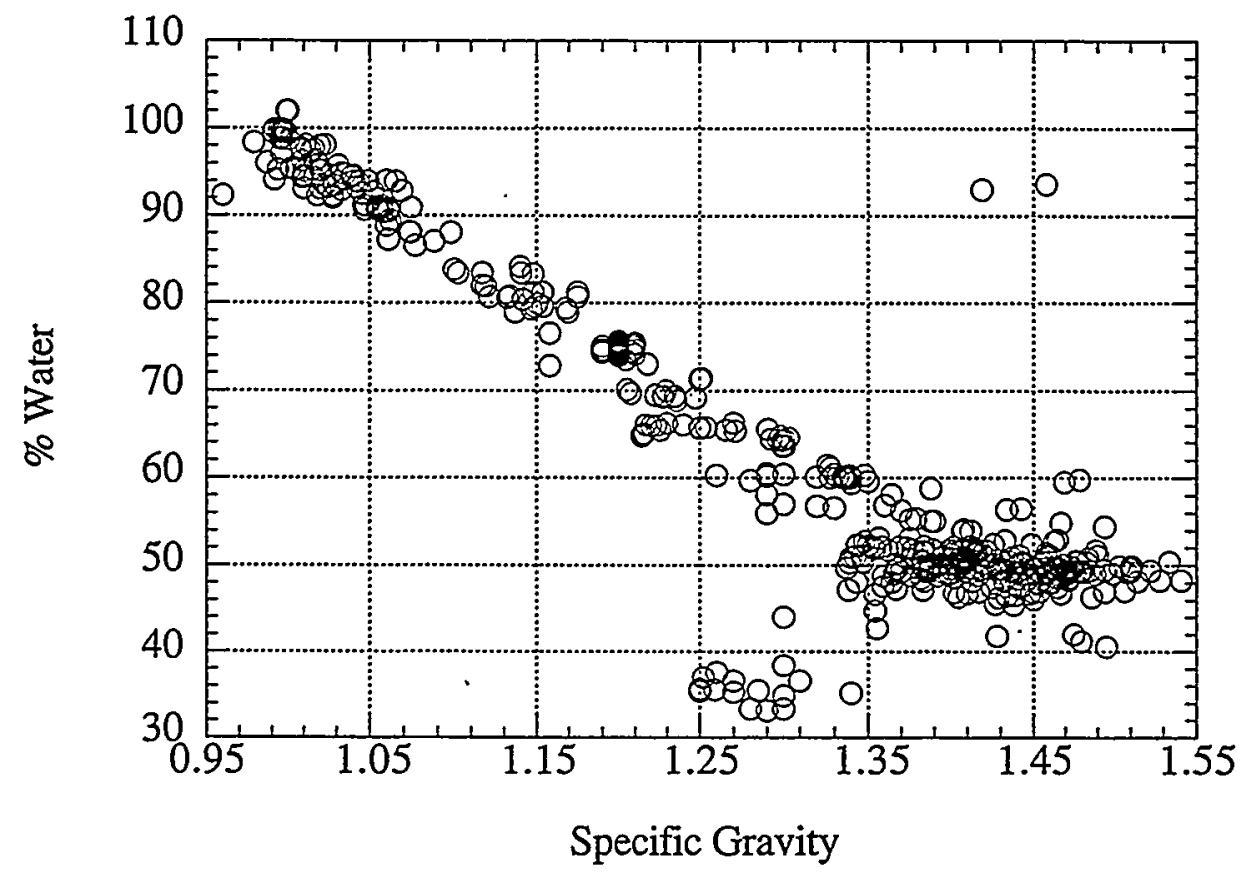

Figure 2.1.1. Density Data Collected at Hanford Site

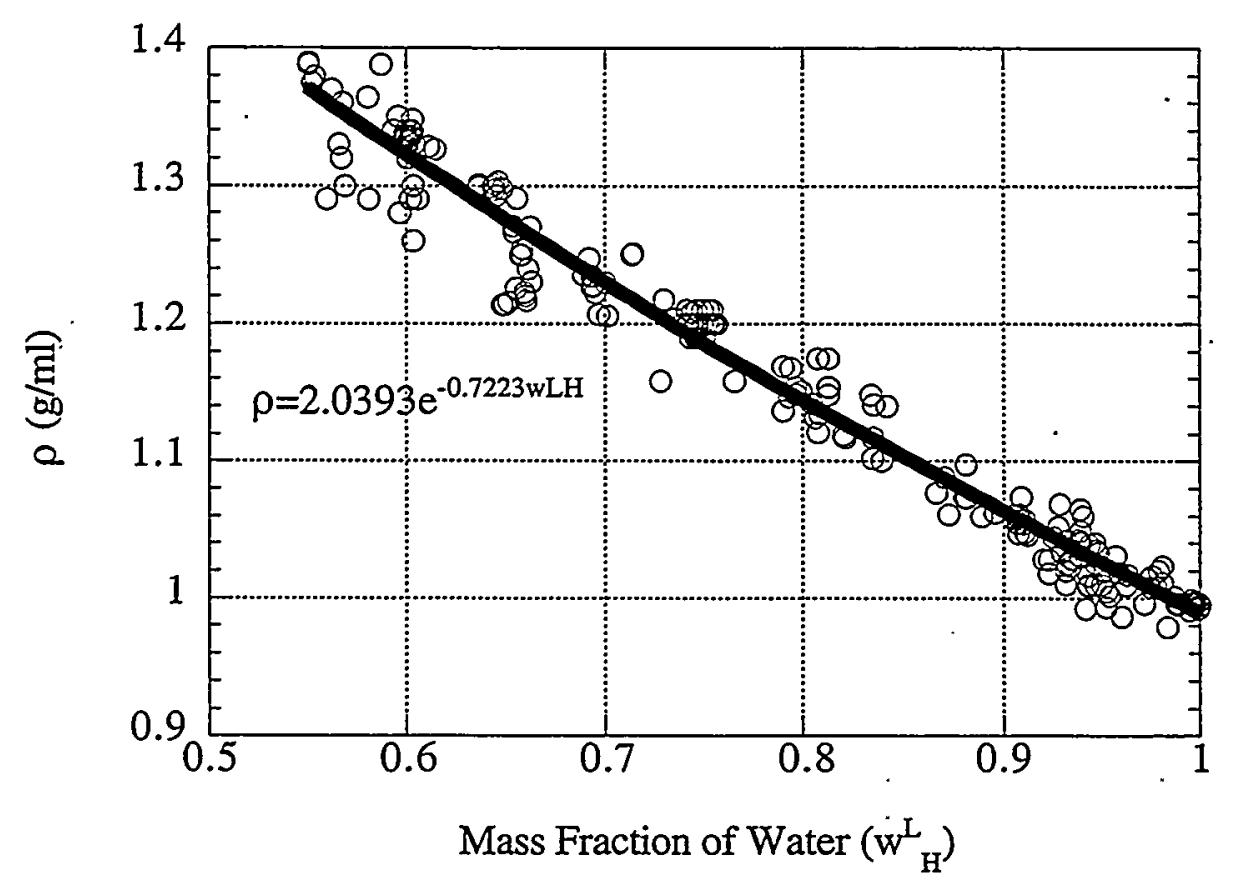

Figure 2.1.2. Correlation of Selected Density Data Collected at the Hanford Site 


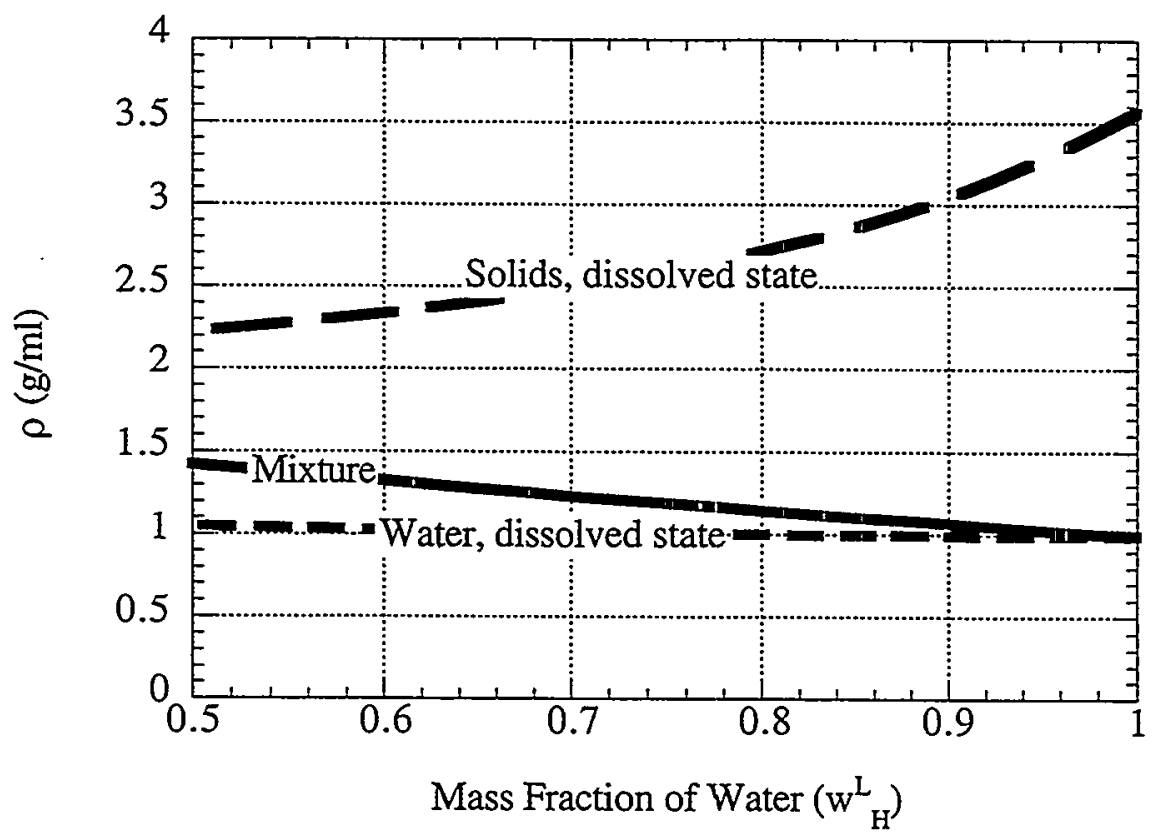

Figure 2.1.3. Apparent Densities of Dissolved Solids and Water Inferred from Hanford Data

Unfortunately, we are less certain about the reasonableness of the density of the undissolved solids, $2.6 \mathrm{~g} / \mathrm{mL}$ (Table 2.1.2). The densities of $\mathrm{NaNO}_{3}, \mathrm{NaNO}_{2}$, and $\mathrm{Na}_{2} \mathrm{CO}_{3}$ are all roughly $2.2 \mathrm{~g} / \mathrm{mL}$ or less, and the mass fraction of dense solids is too small to explain a composite density as large as $2.6 \mathrm{~g} / \mathrm{mL}$. On the other hand, the insoluble fraction probably contains dense metal oxides. Given the simplicity of our conceptual model, we believe it would be prudent to assign a "handbook" density typical of sodium nitrate and sodium nitrite; roughly $2.2 \mathrm{~g} / \mathrm{mL}$.

Kubic and Belooussov (1999) predict that roughly $60 \%$ of the mass (e.g., $\mathrm{NaNO}_{3}, \mathrm{NaNO}_{2}$, and $\mathrm{NaAlO}_{2}$ ) is dissolved easily but that further dissolution (e.g., of $\mathrm{Na}_{2} \mathrm{CO}_{3}$ ) proceeds very slowly. This matches the result for the maximum fraction of solids dissolved from the least squares analysis at ambient temperature (see Table 2.1.2). Therefore it would appear reasonable to use a value of approximately 0.6 at tank conditions. Given our limited purposes, no attempt was made to determine the statistical error of the estimated parameters.

\subsubsection{Correction for Temperature}

The solubility (mass ratio) $R_{D}$ that was inferred from the recent 222-S Laboratory data needed to be corrected from ambient temperature, $28.5^{\circ} \mathrm{C}$, to the expected tank temperature, $50^{\circ} \mathrm{C}$. This was done by assuming that the solubility of "solids" varied with temperature proportionately with the average solubility of $\mathrm{NaNO}_{3}$ and $\mathrm{NaNO}_{2}$. Figure 2.1.4 shows the data used to make this extrapolation, which was determined to be

$$
\ln R_{D}(T)=\ln R_{D}\left(T_{0}\right)-\frac{B}{T}
$$

where $B=782 \mathrm{~K}$, the average of values for $\mathrm{NaNO}_{3}$ and $\mathrm{NaNO}_{2}$. The result is $\mathrm{R}_{\mathrm{D}}=1.267$ at $50^{\circ} \mathrm{C}$. 


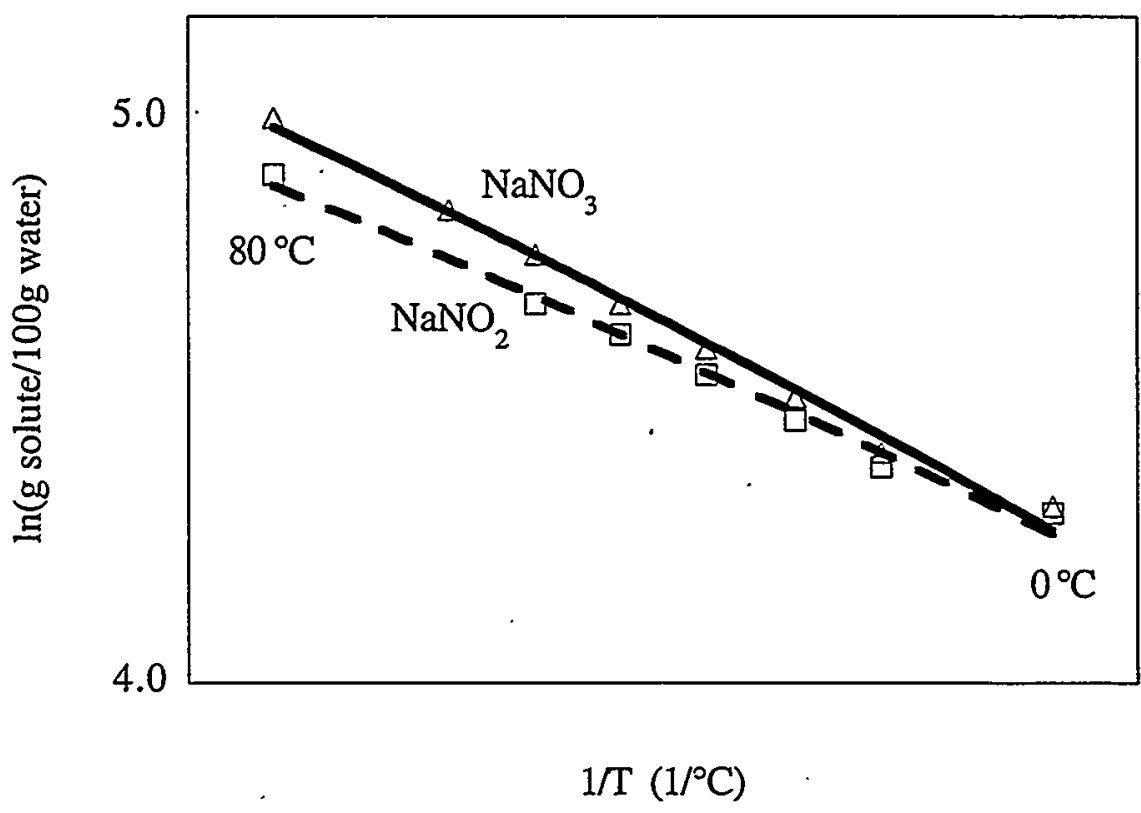

Figure 2.1.4. Correcting $R_{D}$ (solubility) for Temperature

\subsubsection{Conclusions}

Although the model is a blatant simplification of a complex system, the fitted parameters have physically reasonable values except for the density of the solid phase. The model is able to fit diverse attributes of the diluted waste as measured in the laboratory experiments. Together, these confirm that the model is a reasonable basis for describing dilution processes in SY-101.

Because the fitted values of the density of dissolved solids and water agree with those inferred from the compilation of Hanford data, we recommend adopting those values. However, we cannot explain the surprisingly high fitted value of solids density. Until this can be explained, we recommend using an estimate consistent with handbook values for the major salts such as $\mathrm{NaNO}_{3}, \mathrm{NaNO}_{2}$, and $\mathrm{Na}_{2} \mathrm{CO}_{3}$. The mass fraction of water in solution (0.484) calculated from the solubility at ambient temperature agrees well with the clustering of data in the Hanford data compilation at about $50 \%$ mass fraction of water, where we believe the clustering reveals the mass fraction at saturation. Thus we recommend using the solubility inferred from the recent 222-S Laboratory data corrected for temperature. In summary, we recommend that the values in Table 2.1.3 (rounded to three significant figures) be used to describe dilution of the waste. No uncertainty analysis has been conducted on these results.

\subsection{Current Understanding of the Waste Configuration}

Since December 1993, the waste column in SY-101 has been arranged in three main layers: a floating crust; a mixed slurry consisting of a three-phase fluid suspension of liquid, solid particles, and small bubbles; and a relatively thin layer on the bottom composed of loosely settled 
Table 2.1.3. Summary of Recommended Property Values

\begin{tabular}{|l|l|}
\hline Density of solids in the solid state & $2200 \mathrm{~kg} / \mathrm{m}^{3}$ \\
\hline Density of solids in the dissolved state & $2230 \mathrm{~kg} / \mathrm{m}^{3}$ \\
\hline Density of water in the dissolved state & $1050 \mathrm{~kg} / \mathrm{m}^{3}$ \\
\hline Density of saturated liquid at $50^{\circ} \mathrm{C}$ & $1490 \mathrm{~kg} / \mathrm{m}^{3}$ \\
\hline Saturation mass ratio of solids to water at $50^{\circ} \mathrm{C}$ & 1.267 \\
\hline
\end{tabular}

solids, interstitial liquid, and retained gas (Stewart et al. 1998). In late October 1999, the elevation of the top of the crust was about 432 inches above the tank bottom as measured by the Enraf $^{\oplus}$ gauge in riser 1A. Neutron and gamma probe data show that the base crust is at about 312 inches. The free liquid level in the tank is estimated at roughly 412 inches based on the level measured in riser $1 \mathrm{C}$, which has been flushed periodically. These data indicate the crust is 120 inches thick and floats on the liquid with almost two feet exposed above the liquid level. The mixed slurry layer extends from the base of the crust at 312 inches down to the top of the loosely settled layer, which varies from 30 to 50 inches, depending on the location of the last mixer pump run (Conner and Koreski 1999). Additional details of each of the three major crust layers are given from bottom to top in Sections 2.2 .1 through 2.2.3, respectively.

\subsubsection{Loosely Settled Layer}

The loosely settled layer is so named because the mixer pump jet can easily mobilize the solids therein. The thermocouples located 4 inches above the tank bottom in riser 17B (directly north of tank center and 27 feet from the mixer pump) and at 16 inches in riser $17 \mathrm{C}$ (eastsoutheast of tank center and 29 feet from the mixer pump) are regularly uncovered when the mixer pump jet is aimed at them. But the solids appear to settle back into the disturbed area to reestablish a nonconvective layer 30 to 50 inches deep within a few days, as indicated by the typical parabolic temperature profile (Conner and Koreski 1999). This relatively rapid settling rate indicates that the particle size in this region is much larger than in the mixed slurry above.

Though nonconvective, the material in this layer is very weak. The ball rheometer measured its yield stress at less than $30 \mathrm{~Pa}$ in 1995 (Stewart et al. 1995). Its density is expected to be slightly higher than that of the mixed slurry layer, but no accurate measurements are available. The composition of the solids in the loosely settled layer is not significantly different than it is elsewhere in the tank (Steen 1999). Void fraction measurements in the summer of 1998 showed that both the loosely settled layer and the mixed slurry above it contain void fractions of less than 0.02 (Stewart et al. 1998). RGS measurements in December 1998 and January 1999 also showed no difference in void fraction in the two layers (Mahoney et al. 1999). Though the loosely settled layer probably contains a somewhat higher solids fraction and consists of larger particles than the mixed slurry, it is relatively thin and variable and does not retain gas as long as the mixer pump operates regularly. Therefore, we ignore the difference and assume mixed slurry properties apply all the way to the tank bottom. 


\subsubsection{Mixed Slurry Layer}

As its name implies, the mixed slurry layer is a creation of the mixer pump. The action of the mixer pump jets suspends micron and submicron particles and releases small bubbles and small bubble-particle agglomerates from the loosely settled layer. Particles and negatively buoyant bubble-particle agglomerates are also believed to rain down from the base of the crust at times. These processes create a three-phase soup that is continually in motion-the positively buoyant objects slowly rising, and the negatively buoyant ones slowly settling. The sizes of all these entities are apparently quite small and/or they are close to neutrally buoyant because they remain in suspension with very little stratification over periods of a few days to over a week between mixer pump runs.

The density of the slurry has been decreased slightly over the years by an apparent increase in the ambient gas fraction. In 1995 the VFI measured a uniform void fraction of less than 0.005 throughout the slurry layer while the ball rheometer showed a specific gravity of 1.6 (Stewart et al. 1995). In the summer and fall of 1998, the VFI and retained gas sampler indicated the void fraction had increased to between 0.016 and 0.03 (Stewart et al. 1998; Mahoney et al. 1999). Core samples showed that the degassed slurry specific gravity was still at 1.6. ${ }^{(a)}$ If the solids density is $2200 \mathrm{~kg} / \mathrm{m}^{3}$ and the liquid density is $1490 \mathrm{~kg} / \mathrm{m}^{3}$, as given in Section 2.1 , the solids volume fraction must be 0.15 to produce this value. The pump power and discharge pressure trends have been used to extrapolate the slurry void fraction from the value measured by the RGS in January 1999 The slurry void fraction is currently averaging 0.027. During March and April 1999, it approached 0.04. ${ }^{(\mathrm{b})}$

The mixed slurry layer is clearly a fluid as evidenced by its uniform temperature profile, the operation of the mixer pump, and the fact that particles and bubbles can move within it. The ball rheometer data in 1995 showed no yield stress and a shear-thinning viscosity that varied from $500 \mathrm{cP}$ at a shear rate approaching $1000 \mathrm{sec}^{-1}$ to $1000 \mathrm{cP}$ at a shear rate of $1 \mathrm{sec}^{-1}$. The viscosity estimated from the difference in mixer pump discharge pressure when operating in the waste and in water shows an effective viscosity of 500 to $1600 \mathrm{cP}$. .

\subsubsection{Floating Crust Layer}

The current crust configuration is the result of a spontaneous redistribution event from midMarch through early May 1999, during which the base of the crust dropped about 40 inches concurrent with an abrupt and sustained increase in pump-induced gas releases and a gradual reversal of the level rise trend. Over the next month, the crust base recovered about 10 inches and began a gradual rising trend. Prior to the redistribution event, VFI (Stewart et al. 1998) and RGS (Mahoney et al. 1999) void measurements along with the first neutron/gamma profiles

(a) Numatec Hanford Corporation Internal Memo 82100-99-015, Process Engineering to NW Kirch, April 22, 1999. Subject: Dilution Studies of Tank 24I-SY-101 Waste. Preliminary Results.

(b) Void fraction estimates are computed and reported to the SY-101 Surface Level Rise Remediation . Project regularly by Lenna Mahoney, PNNL.

(c) Mahoney LA and FF Erian. 1998. Evaluation of Performance Data from the Tank 241-SY-101 Mixer Pump. PNNL Letter Report TWS99.10, November 18, 1998. 
showed a high-void layer over a foot thick may have existed at the base of the crust. Upward migration and dispersal of the gas in this layer may explain the redistribution. Analysis indicates the average void fraction decreased as crust thickness increased, so the total stored gas volume in the crust remained roughly constant. Accordingly, the redistribution event also resulted in the incorporation of additional solid and liquid mass in the crust. Neutron probe data after July 1999 show that a high void layer, about 10 inches thick, reformed at the new crust base level and grew steadily until early November 1999 when it became constant or decreased slightly.

Recent neutron/gamma count and temperature profiles, operation of the mechanical mitigation arm (MMA) in late May, and crust penetration with the 40-inch spray lance in August show that the crust now consists of four distinct layers. The neutron profiles are in Figure 2.2.1, and a conceptual understanding of the crust configuration is shown in Figure 2.2.2. The bottom layer (312-320 inches) consists of a high-void material termed bubble slurry. Because the neutron count is lower than that recorded when the RGS registered a void fraction over 0.5 , we estimate its void fraction may be approaching 0.6 . It has a relatively low yield stress, $<100 \mathrm{~Pa}$.

The middle two-thirds (320-400 inches) is called the "paste" layer because of its expected consistency. It has a moderate void fraction, about 0.2 , that decreases with height. It is relatively strong, like stiff peanut butter or clay. Estimates of the yield stress in this region (see Section 2.3) are on the order of 1000-3000 Pa. The "wet clay" layer (400-412 inches) just below the liquid level has a very low void fraction, estimated at 0.08 , and is probably very strong. Though we have no direct measurements, its yield stress is assumed to be greater than $3000 \mathrm{~Pa}$. This layer may also contain old wastebergs that existed before mixing though it is not clear whether they could be distinguished from the surrounding material.

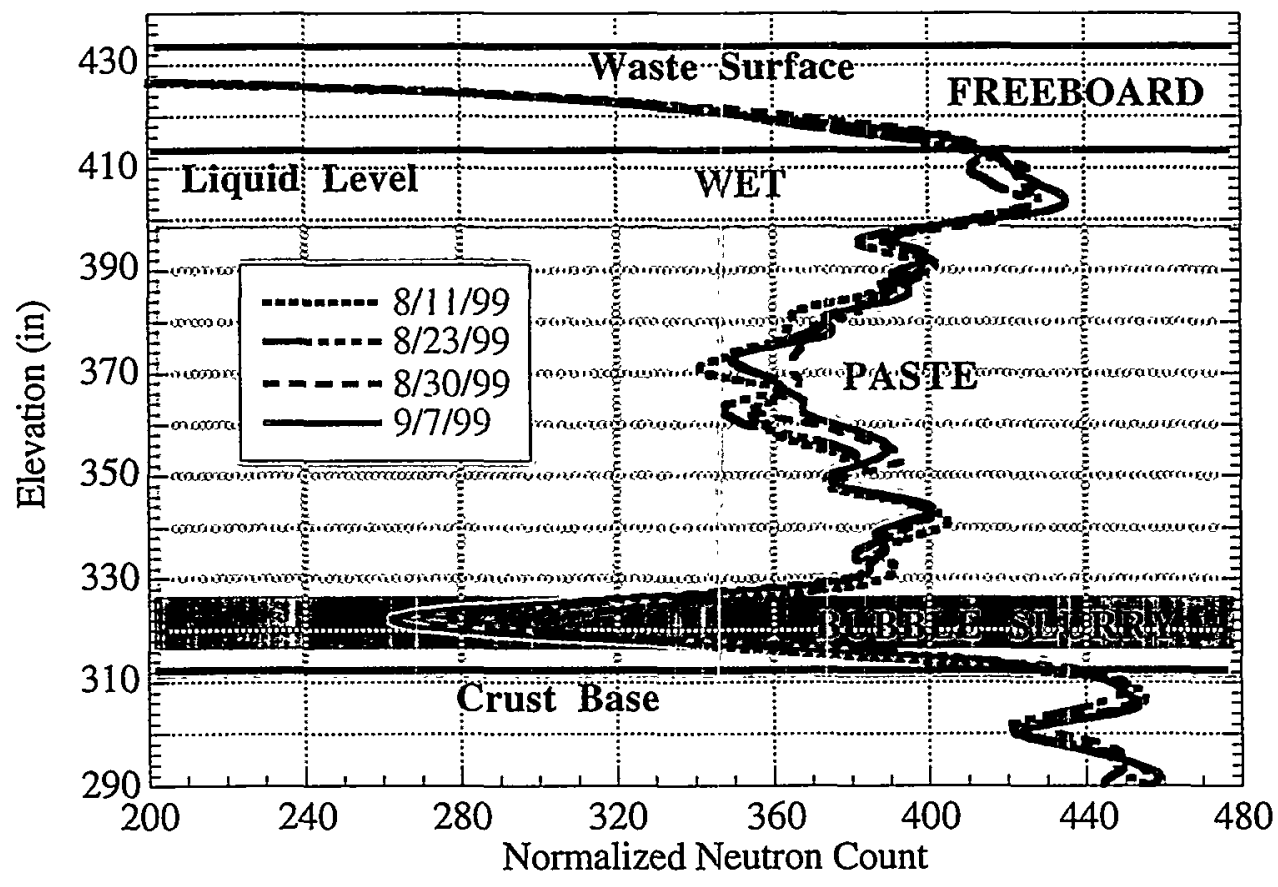

Figure 2.2.1. Crust Configuration as Indicated by Neutron Profiles 


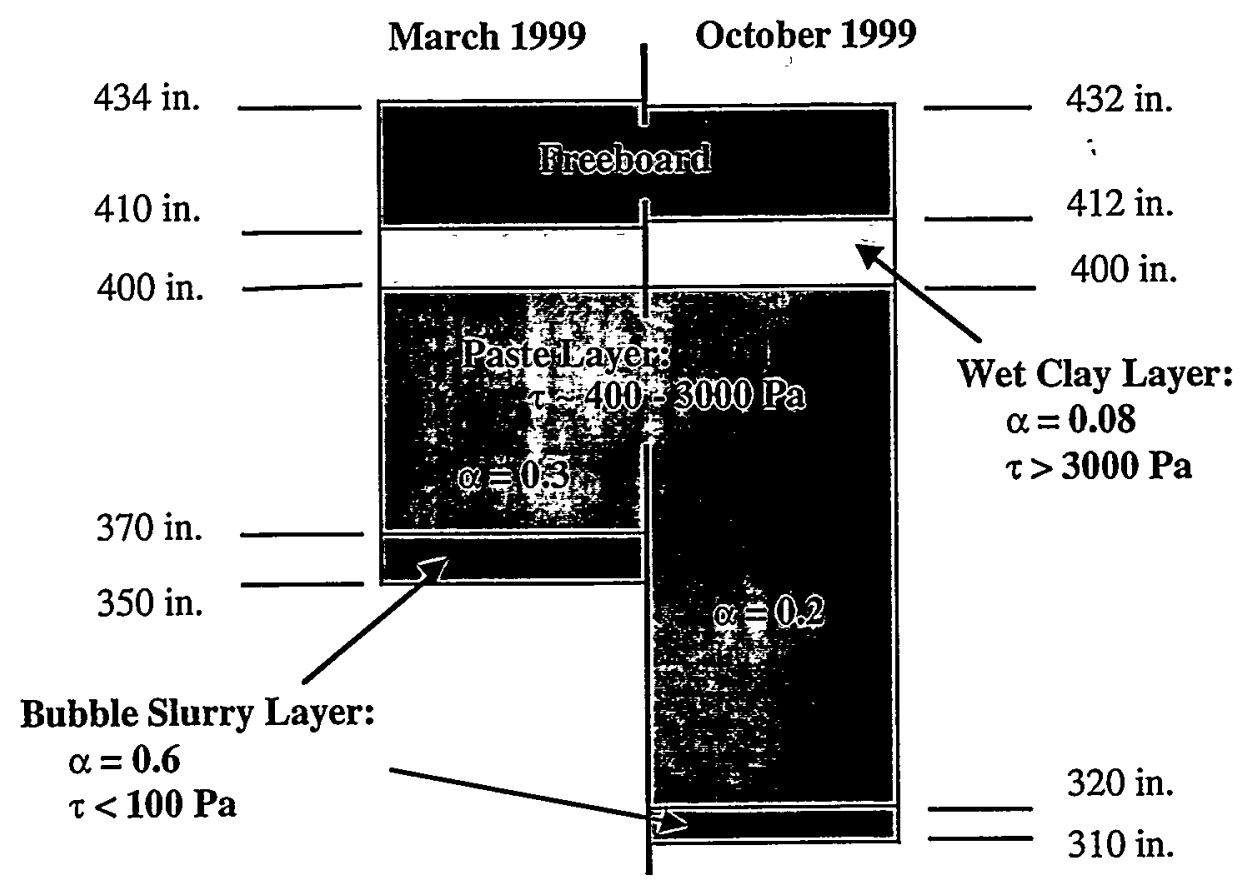

Figure 2.2.2. Concept of Crust Configuration and Properties

The top one-sixth (412-432 inches) represents the current freeboard, the porous broken material above the liquid level. Water added on the waste surface readily flows into this layer. Though individual fragments are quite strong and friable, this layer has no strength as a unit. The height of vertical ledges visible after dissolution by flush water and estimated resistance to the cruciform lance penetration in August 1999 indicates a local yield stress greater than $10,000 \mathrm{~Pa}$.

\subsection{Crust Layer Yield Stress in Shear}

No direct data are available on the strength of the material within the crust layer. However, the deployments of the Mechanical Mitigation Arm (MMA) in late May and the large water lance in early August 1999 provided new insights into the physical structure of the crust and data from which the strength may be estimated. The crust strength, as measured by the yield stress in shear, is necessary in analyses of gas release mechanisms, the ability of the crust to resist mechanical or hydraulic break-up, or possible limitations on the size of physical features.

In this section, the yield stress in shear is estimated for specific regions of the crust. These estimates are based on force and torque data obtained in simulant experiments, structural analysis of the penetration of objects into solids, and qualitative information about the forces and torques exerted during the MMA and water lance operations. The results are applied in Section 4.1 to determine the possibility of gas release due to failure of the crust as it sinks, in Section 4.2, where the ability of the mixer pump to mobilize the sunken crust is analyzed, and for considerations of the maximum single bubble size the crust could hypothetically retain in Section 6.5 . 


\subsubsection{Description of the Mechanical Mitigation Arm and Water Lance}

The MMA consists of a 6-foot horizontal arm with a diameter of 3.5 inches hinged on a vertical mast that allows a crane to insert the arm through a riser into the tank in a vertical position (Figure 2.3.1). Once the hinge is below the base of the crust, the arm is drawn up to its horizontal position with the cable. The crust can be disturbed by lifting the arm up through the crust with the crane or by rotating the arm manually. During the deployments of the MMA, each type of operation was conducted. The device was lifted with the crane that supported the MMA in the tank, and the arm was rotated manually through the waste by means of four levers attached to the mast. The levers were 3 feet long, and each had an operator. ${ }^{(a)}$

The water lance is a cross-shaped device with 1-inch diameter arms, 38-inch long, supported horizontally at the bottom of a mast with an axial separation of 5 inches (Figure 2.3.2). In-tank observations indicate that both arms were in contact with the crust surface at the time of penetration. Support rods connect the ends of the arms back to the mast and prevent them from flexing. Water is sprayed into the waste through nozzles on the horizontal arms. The device is supported in the tank with a crane and is deployed through a 42-inch riser.

The change in the crane load when attempting to lift the MMA through the crust, the torque required to rotate the MMA, and the crane load recorded as the water lance initially penetrated the crust, in conjunction with the geometry of the devices, provide data which may be used to estimate the strength the crust layer. The second deployment of the MMA was conducted in the

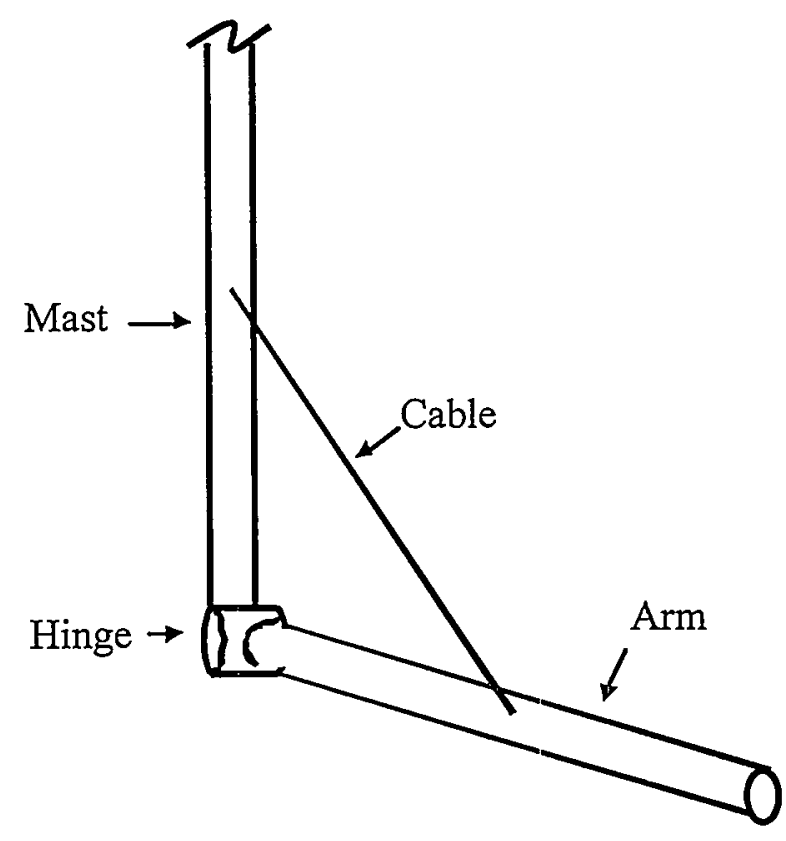

Figure 2.3.1. Schematic of the MMA in Horizontal Position

(a) Stewart CW. April 1999. Initial Operation Plan for Mechanical Crust Mitigation in Tank 241-SY101. Letter Report TWS99.32, Pacific Northwest National Laboratory, Richland, Washington. 


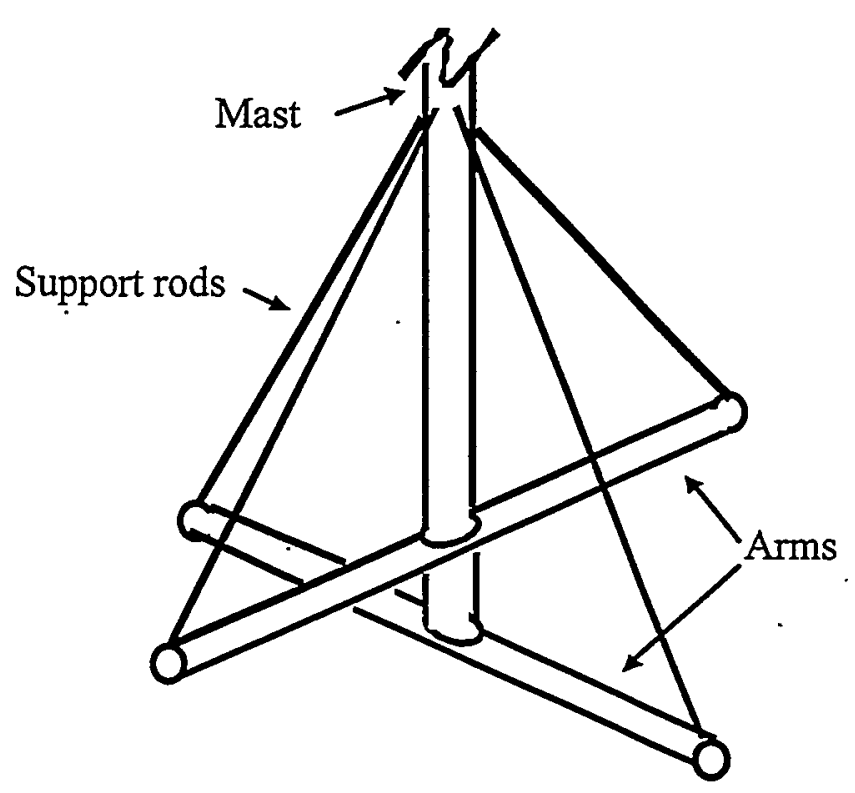

Figure 2.3.2. Schematic of Water Lance

same riser as the first deployment. Therefore, the crust layer in this region had already been disturbed, and strength estimates from this deployment may not represent the undisturbed portion. However, the data from the second deployment may indicate the effect that the activities of the initial operation had on the crust layer. The applicable data from the MMA and water lance deployments is provided in Table 2.3.1.

The estimated torque required for rotating the MMA is based upon qualitative information regarding the operator effort, estimates of maximum applied force by operators, and assumptions that the MMA was rotating smoothly about its longitudinal axis. These estimates may inherently contain large uncertainty.

\subsubsection{Simulant Experiments: Apparatus}

Yielding the crust during the MMA and water lance operations depends on the mechanical properties of the crust and the stress field caused by this action. The relationships among the load applied, the geometry of the loading device, and the shear yield stresses of two simulants were investigated experimentally. An apparatus was developed to mimic the lifting and penetrating actions of the MMA and water lance, allowing varying loads to push a test arm into a simulant with a known yield stress in shear. The same apparatus (with minor alterations) was used to replicate the rotating action of the MMA. Figure 2.3.3 is a schematic of the device.

Four different test arms were used. The first was " $T$ " shaped with a $20-\mathrm{mm}$ horizontal shaft of 6-mm diameter fixed to a vertical shaft. The second and third test arms were flat, 1/8-inchthick plates with dimensions of 6 by $20 \mathrm{~mm}$ (the same projected cross-sectional area as the first test arm), and 20 by $20 \mathrm{~mm}$, again horizontally fixed to a vertical shaft. The fourth test arm was " $L$ " shaped with a 50-mm shaft and a diameter of $6 \mathrm{~mm}$ fixed to a vertical shaft. 
Table 2.3.1. MMA and Water Lance Data

\begin{tabular}{|c|c|c|c|}
\hline $\begin{array}{c}\text { Action } \\
\text { (description) }\end{array}$ & Device & $\begin{array}{l}\text { Height from tank } \\
\text { bottom (in.) }\end{array}$ & $\begin{array}{c}\text { Force or } \\
\text { Torque (source) }\end{array}$ \\
\hline $\begin{array}{c}\text { Lifting } \\
\text { (crane limit reached) }\end{array}$ & MMA \#1 & 390 & $\begin{array}{c}900 \mathrm{lb} \\
\text { (crane load) }\end{array}$ \\
\hline $\begin{array}{c}\text { Penetration } \\
\text { (crane limit reached) }\end{array}$ & $\begin{array}{l}\text { Water } \\
\text { Lance }\end{array}$ & 428 & $\begin{array}{c}1,166 \mathrm{lb} \\
\text { (crane load) }\end{array}$ \\
\hline Rotation & MMA \#1 & 357 & $\begin{array}{c}18,000 \text { in-lb } \\
\text { (estimate) }\end{array}$ \\
\hline Rotation & MMA \#1 & 360 & $\begin{array}{l}22,500 \text { in-lb } \\
\text { (estimate) }\end{array}$ \\
\hline $\begin{array}{c}\text { Rotation } \\
\text { (not possible) }\end{array}$ & MMA \#1 & 361 & $\begin{array}{l}25,500 \mathrm{in}-\mathrm{lb} \\
\text { (estimate) }\end{array}$ \\
\hline $\begin{array}{c}\text { Rotation } \\
\text { (not possible) }\end{array}$ & MMA \#1 & 363 & $\begin{array}{l}25,500 \mathrm{in}-\mathrm{lb} \\
\text { (estimate) }\end{array}$ \\
\hline $\begin{array}{c}\text { Rotation } \\
\text { (oscillated and rotated) }\end{array}$ & MMA \#1 & 365 & $\begin{array}{l}31,500 \mathrm{in}-\mathrm{lb} \\
\text { (estimate) }\end{array}$ \\
\hline $\begin{array}{c}\text { Rotation } \\
\text { (oscillated: not possible) }\end{array}$ & MMA \#1 & 367 & $\begin{array}{l}31,500 \mathrm{in}-\mathrm{lb} \\
\text { (estimate) }\end{array}$ \\
\hline $\begin{array}{c}\text { Rotation } \\
\text { (oscillated: not possible) }\end{array}$ & MMA \#1 & 385 & $\begin{array}{l}31,500 \mathrm{in}-\mathrm{lb} \\
\text { (estimate) }\end{array}$ \\
\hline Rotation & MMA \#2 & 378 & $\begin{array}{l}19,500 \text { in-lb } \\
\text { (estimate) }\end{array}$ \\
\hline Rotation & MMA \#2 & 382 & $\begin{array}{c}25,500 \mathrm{in}-\mathrm{lb} \\
\text { (estimate) }\end{array}$ \\
\hline \multirow[t]{4}{*}{ Scale } & & $\begin{array}{l}\text { Height } \\
\text { Adjustment }\end{array}$ & \\
\hline & & $\begin{array}{l}\text { Mass } \\
\text { Platform }\end{array}$ & \\
\hline & & - Test Arm & \\
\hline & & $\leftarrow$ Simulant & \\
\hline
\end{tabular}

Figure 2.3.3. Experimental Apparatus 
The mass platform was connected to the test arm with an aluminum shaft, which was constrained to vertical motion by the nylon bushings. The zero point of the scale was necessarily the mass of the platform, shaft, and test arm. To conduct a push test, each of the first three test arms was used. The height of the test arm was adjusted so that it was in contact with the simulant surface while the scale was at the zero point. Mass was then added to the mass platform until the test arm was pushed into the surface of the simulant, at which point the scale reading was recorded as well as the added mass.

To conduct the rotation test, the mass platform was replaced with a lever arm to which a scale was attached. The length of the lever arm could be adjusted, and the apparatus was fixed at a single location vertically. Rotation was initiated by pulling the scale horizontally to the shaft and at $90^{\circ}$ from the lever arm. The scale reading was recorded at the onset of motion.

Two different simulants, Cab-o-sil/mineral oil and bentonite clay/water, were used because they exhibit plastic behavior and have physical properties that may be similar to tank waste. The strength of the simulants was controlled through the Cab-o-sil/mineral oil or bentonite clay/water weight ratio. After mixing, the gas void in the simulant was removed by placing it under a vacuum. The shear yield stress of a simulant was then measured using a shear vane attached to a Haake Rotovisco model M5 viscometer immediately before or immediately after the push and rotation tests. For the experiments, the simulants were placed in a glass beaker, and their depth and width were approximately ten times the horizontal length of the push test devices.

\subsubsection{Simulant Experiments: Results}

Initial torque estimates for the MMA were based on the assumption that the drag force on an area element is equal to its projected area times the yield stress of the material in shear. ${ }^{(a)}$ The torque was estimated as

$$
\mathrm{T}=\frac{1}{2} \mathrm{DL}^{2} \tau_{0}
$$

where $T$ is the torque, $D$ is the diameter of the rotating arm, $L$ is its length, and $\tau_{0}$ is the measured yield stress in shear of the material.

This model underpredicts the actual torque because the shear stress distribution in the material is actually three dimensional. The comparison of the measured torque required to initiate rotational motion in the Cab-o-sil/mineral oil to the estimated torque of Equation 2.3.1 is shown in Figure 2.3.4. The results were very similar for the bentonite clay.

To determine the yield stress in shear of a material being subjected to a torque, the relation between the measured and estimated torque must be known. A linear fit to the experimental torque data of the form

(a) G Terrones. April 1999. Torque Required to Rotate the Mechanical Mitigation Arm in the Crust in SY-101. Letter Report TWS99.33, Pacific Northwest National Laboratory, Richland, Washington. 


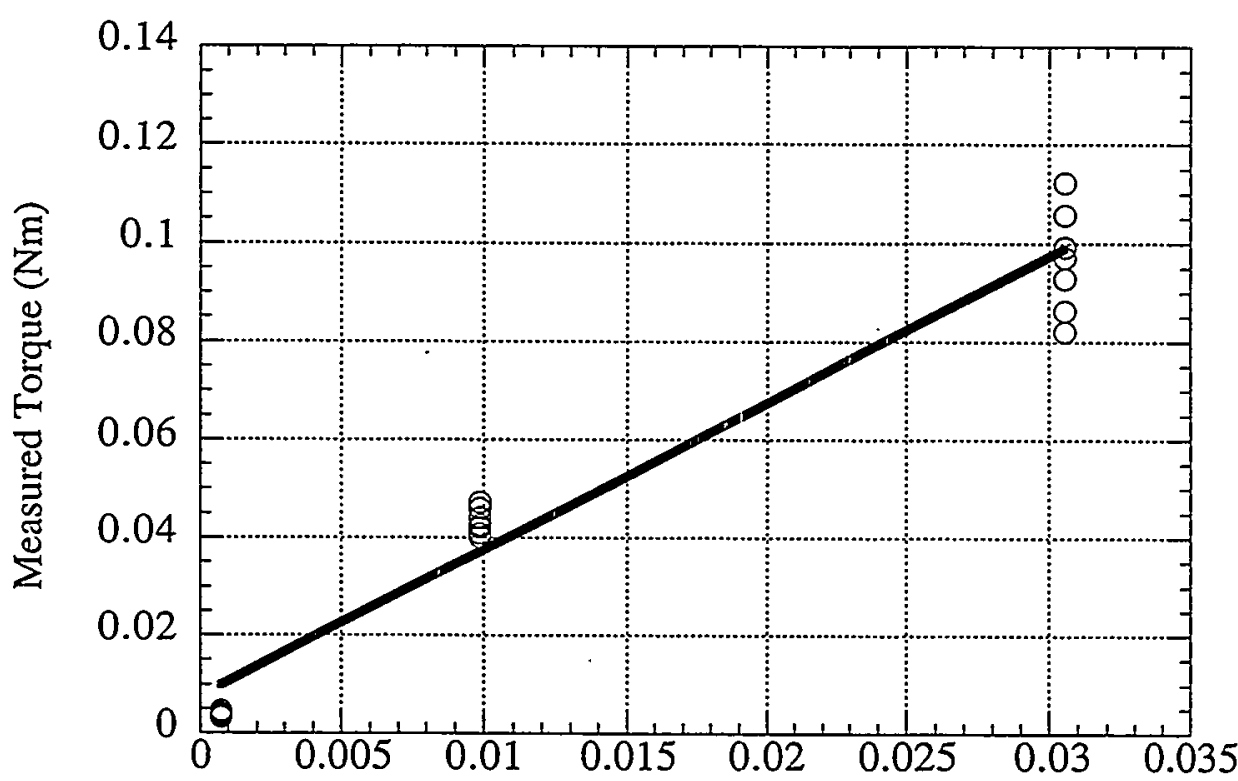

Estimated Torque (Nm)

Figure 2.3.4. Measured Torque as a Function of the Calculated Torque (Cab-o-sil/mineral oil)

$$
\mathrm{T}=\mathrm{a} \frac{1}{2} \mathrm{DL}^{2} \tau_{0}+\mathrm{b}
$$

yields the results given in Table 2.3.2.

Table 2.3.2. Linear Fits of the Measured Torque as a Function of the Calculated Torque

\begin{tabular}{|c|c|c|c|}
\hline Simulant & Test Arm & a & b \\
\hline Cab-o-sil/mineral oil & torque arm & 2.987 & .008 \\
\hline Bentonite clay & torque arm & 5.239 & .004 \\
\hline
\end{tabular}

The intercepts are very small ( $b<<1)$, as expected; a material with a low yield stress in shear does not inhibit rotation. The relation between the yield stress in shear solved from Equation 2.3.1 from the measured torque to the actual yield stress in shear for the material is then taken to be the slope of the linear fits. The factor a indicates the overprediction of a yield stress in shear derived from torque measurements using Equation 2.3.1.

A similar type of analysis is conducted to determine the relationship between the applied force from the push tests to the yield stress in shear of the material. The normal stress (pressure) required to push a test arm into the simulant is simply

$$
\sigma=\frac{\left[\mathrm{m}-\left(\mathrm{S}_{2}-\mathrm{S}_{1}\right)\right] \mathrm{g}}{\mathrm{A}}
$$


where $\mathrm{m}$ is the added mass (see discussion of the push tests in Section 2.3.2); $S_{1}$ and $S_{2}$ are the initial and final scale readings, respectively; $g$ is the acceleration due to gravity; and $A$ is the cross-sectional area of the test arm. The pressure can be nondimensionalized by dividing by the simulant's measured yield stress in shear:

$$
\eta=\frac{\left[\mathrm{m}-\left(\mathrm{S}_{2}-\mathrm{S}_{1}\right)\right] \mathrm{g}}{\mathrm{A} \tau_{0}}
$$

This factor represents the relation between the yield stress in shear of the material and the force required to penetrate the material. The depth to which the test arm was pushed into the waste is necessarily

$$
\mathrm{d}=\left(\mathrm{S}_{2}-\mathrm{S}_{1}\right) \mathrm{Q}
$$

where $Q$ is the change in length per change in mass of the spring scale. A non-dimensional length scale, 1 , can be defined by

$$
I=\frac{d}{\sqrt{A}}
$$

The nondimensional results of the Cab-o-sil/mineral oil and bentonite clay experiments are shown in Figures 2.3.5 and 2.3.6, respectively. Note that there is considerable scatter in some of the tests. The average $\eta$ values are listed in Table 2.3.3. As will be discussed in Section 2.3.5, it is important to keep in mind that the experiments identified the force for small penetration distances beyond the onset of penetration.

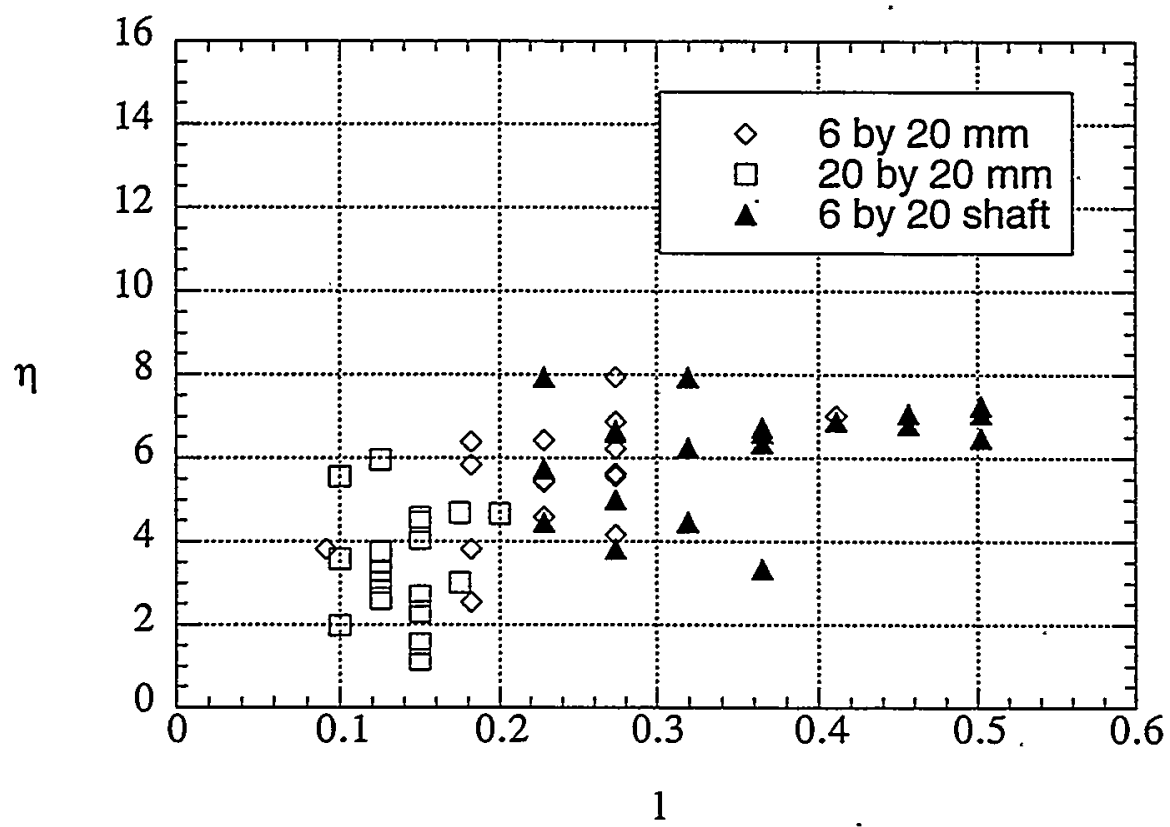

Figure 2.3.5. Nondimensional Pressure $\eta$ as a Function of the Dimensionless Length Scale 1 (Cab-o-sil/mineral oil) 


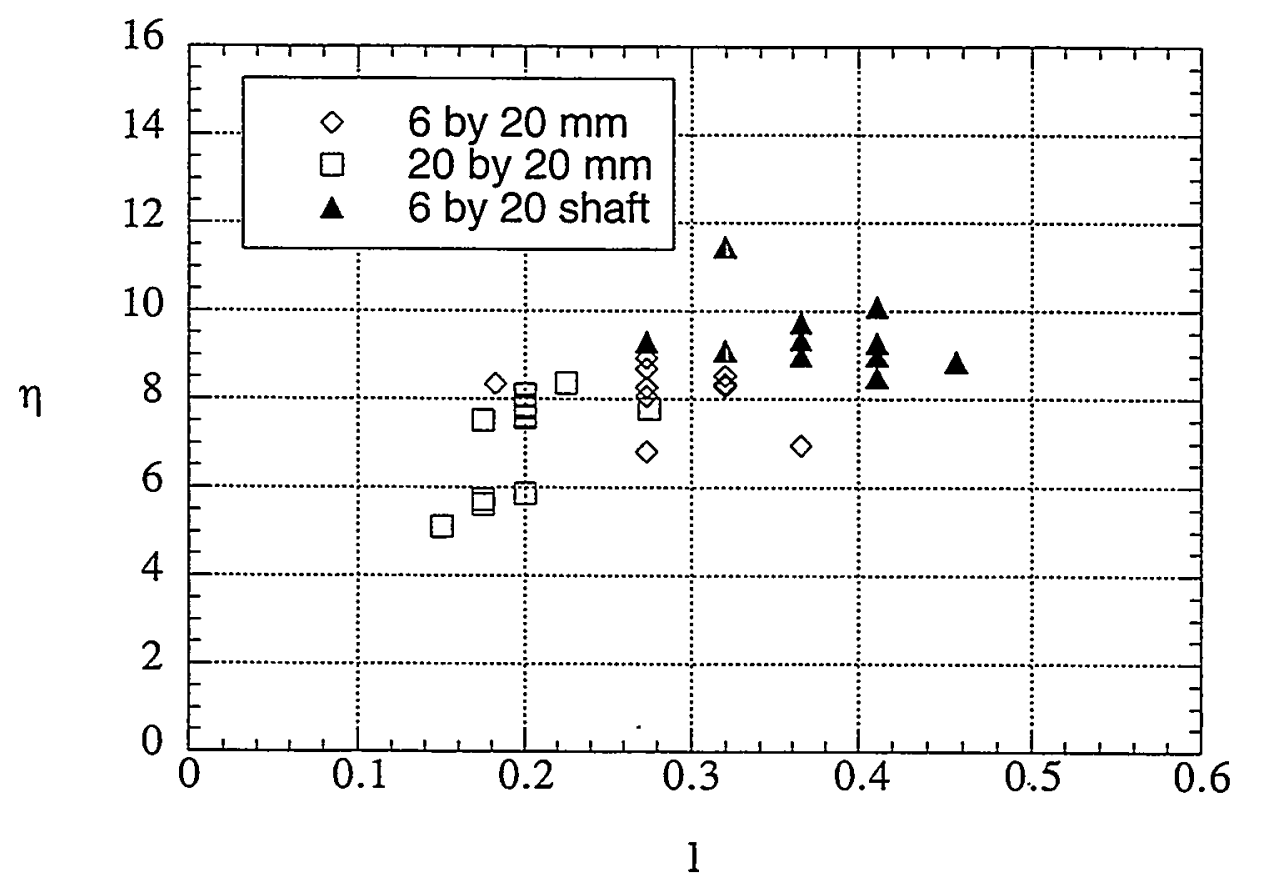

Figure 2.3.6. Nondimensional Pressure $\eta$ as a Function of the Dimensionless Length Scale 1 (bentonite clay)

Table 2.3.3. Average Dimensionless Pressure, $\eta$, for the Push Tests

\begin{tabular}{|c|c|c|}
\hline Simulant & Test Arm & $\eta_{\text {avg }}$ \\
\hline Cab-o-sil/mineral oil & 6 by 20 shaft & 6.16 \\
\hline & 6 by $20 \mathrm{~mm}$ & 5.49 \\
\hline & 20 by $20 \mathrm{~mm}$ & 3.35 \\
\hline & 6 by 20 shaft & 9.39 \\
\hline Bentonite clay & 6 by $20 \mathrm{~mm}$ & 8.18 \\
\hline & 20 by $20 \mathrm{~mm}$ & 7.08 \\
\hline
\end{tabular}

\subsubsection{Stress Analysis}

The effects that the varied shape and cross sectional areas of the push test arms have on $\eta$ is investigated analytically. The minimum force $F_{c}$ per unit area required to set in motion a rectangular plate (of sides a and b) through an elastoplastic medium can be calculated. Consider a semi-infinite medium in three dimensions in which a rectangular plate subjected to a uniform load is located at the interface, as shown in Figure 2.3.7.

The medium is assumed to be incompressible with a yield stress in shear of $\tau_{0}$. The state of stress in a semi-infinite medium below a finite surface of uniform load is calculated by using the stress field that corresponds to a vertical point load and the principle of superposition (integration 


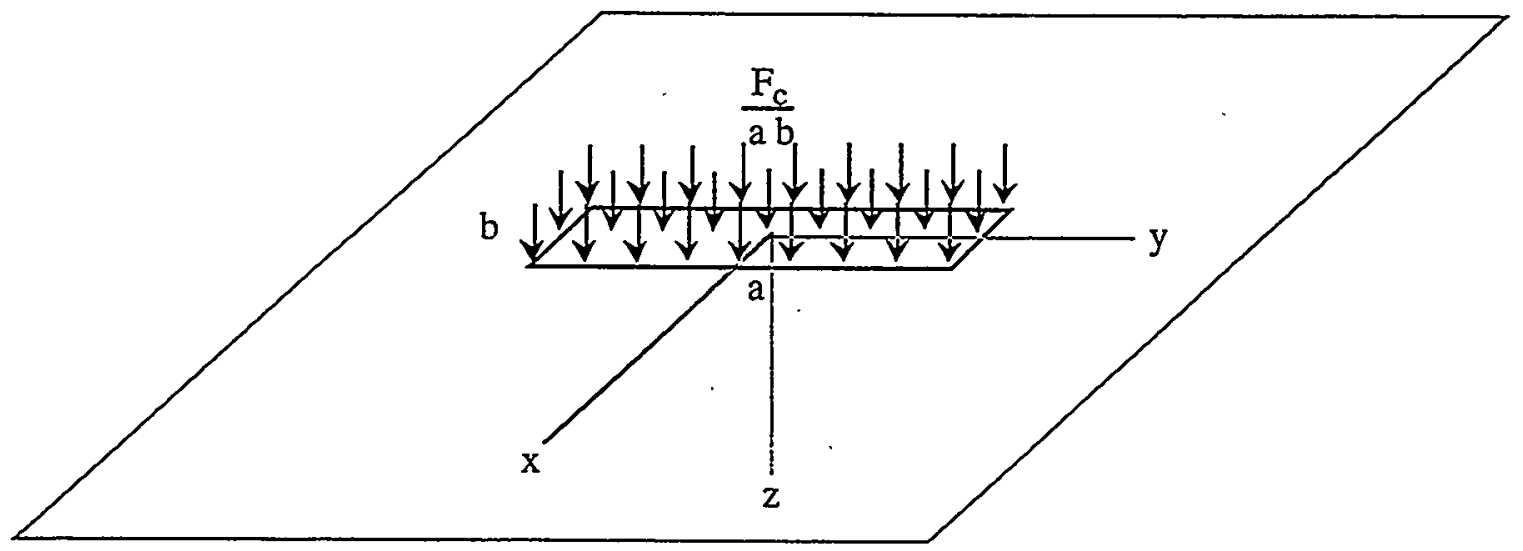

Figure 2.3.7. Schematic of Rectangular Plate at the Onset of Plastic Penetration into Medium

over the plate area). The details of these stress calculations are omitted in this report because of the lengthy expressions involved [the basics of the procedure are outlined by Das (1983)].

The critical force at which the material will yield can be obtained by applying a suitable yield criterion to the state of stress within the medium at any point. A general yield criterion is a function of the yield stresses in tension, compression and shear, and the invariants of the state of stress tensor. A simple yield criterion is that of von Mises, which is a function of the yield stress in shear and the second invariant of the deviatoric stress tensor (Malvern 1969). The dimensionless pressure $\eta$ of Equation 2.3.4 can be expressed as

$$
\eta=\frac{F}{A \tau_{0}}
$$

where $\mathrm{F}$ is the applied force to the plate. Using the von Mises criterion, the critical $\eta$ 's necessary to start plastic displacement in an elastoplastic medium for different shapes are given in Table 2.3.4. For purely plastic media, the critical $\eta$ is larger than 5 (Lubliner 1990).

Table 2.3.4. Critical Values of $\eta$ for Different Plate Shapes

\begin{tabular}{|c|c|}
\hline Plate Shape & $\eta_{c}$ \\
\hline Circular & 3 \\
\hline Square & 3.02 \\
\hline Rectangular $(\mathrm{b} / \mathrm{a}=3.33)$ & 3.13 \\
\hline
\end{tabular}

\subsubsection{Application of Experimental and Analytical Results}

The theoretical analysis considered the force required to set the plate in motion, while the experiments determined the force required to push a test arm into the simulant as a function of a small penetration depth. It is reasonable then that the experimentally determined $\eta$ values are higher than the analytical results. For both the MMA and water lance, the load considered for 
the lifting and penetrating actions occurred at the load limit of the crane, and necessarily, a differential time step prior to the load limit being reached, the device was in motion. It is therefore suggested that the experimental and analytical results are reasonably consistent and applicable to the in-tank data. A $\eta$ value of approximately 7.0 is applicable for the lifting and penetrating actions. The average value for the yield stress in shear of the two simulants is approximately one-fourth (average factor a is 4.1, Table 2.3.2) that determined from the torque tests via Equation 2.3.1. The limitations of applying these results to the actual waste must be considered when viewing the results. The yield stress in shear for the specified elevations of the crust is shown in Figure 2.3.8.

The yield stress in shear determined from the activities of the MMA and the water lance in floating crust layer of 241-SY range from approximately $400 \mathrm{~Pa}$ in the lower region of the paste layer to over $15,000 \mathrm{~Pa}$ at the upper surface of the crust (see Section 2.2 for discussion of crust layer configuration). These results, while conforming to previous estimates, must be considered only in the context of the large uncertainties of the analysis.

Comparison of the estimated yield stress in shear from one layer or activity to another provides useful insights into the nature of the crust layer. It is apparent that the newer bottom layer is weak compared with the upper layers, and the upper dry layer is substantially stronger than the paste layer. In addition, it is evident that the water addition of the first MMA deployment weakened the upper paste layer so that it had a yield stress in shear closer to that of the lower paste region.

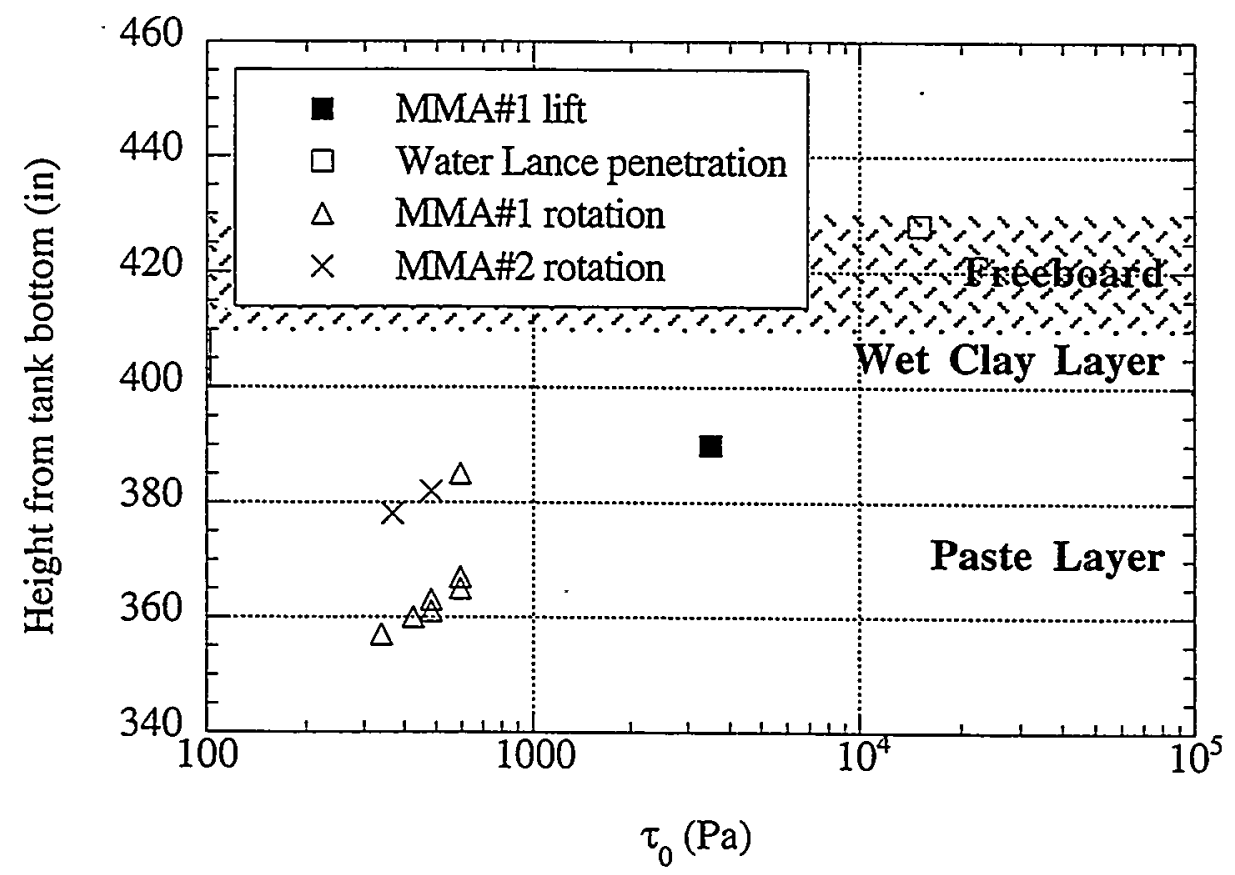

Figure 2.3.8. Estimated Yield Stress in Shear for the Floating Crust Layer in SY-101 


\subsection{Crust Behavior Model}

Two coupled models have been derived to describe the response of the crust to transfer and back-dilution. A basic buoyancy model uses crust and slurry material densities, volumes, and gas content to calculate how the crust floats relative to the surrounding liquid. The dissolution model predicts the amount of slurry solids and crust dissolved as dilution water is added above and beneath the crust. (The mechanisms and rates of dissolution are addressed further in Section 5.) The combined models predict the buoyant equilibrium configuration of the diluted slurry and the reduced crust resulting from specified combinations of waste transfer and back-dilution above and below the crust. The details of the derivation of both models are given in Stewart et al. (1999). Sections 2.4.1 and 2.4.2 summarize the buoyancy and dissolution models, respectively. Section 2.4.3 describes the parameter values used and results obtained for the first transfer and back-dilution step; Section 2.4.4 predicts waste conditions after the initial transfer and back-dilution have taken place; and 2.4.5 contains the uncertainty analysis.

\subsubsection{Buoyancy Model for Crust Floatation}

The crust buoyancy model applies the simple physical principle discovered by Archimedes more than 2300 years ago: the weight of an object floating in a liquid is equal to the weight of the liquid volume it displaces. The crust is made up of solids, retained gas, and liquid held within the porous structure of the crust. The solid material in the crust is by itself too dense to float on the slurry; the crust floats only by virtue of trapped gas within it. We assume that gas is retained in the crust as isolated particle-displacing bubbles that constitute some specific void fraction relative to the total volume of the crust. We also assume that the pores between particles in the submerged portion of the crust are completely saturated with liquid.

The overall density of the submerged portion of the crust depends on its void fraction, the solids volume fraction, and the liquid and solid phase densities. Similarly, the density of the slurry on which the crust floats depends on the solids volume fraction (due to particles suspended in the liquid), the void fraction (due to small gas bubbles that may be attached to the suspended particles), and the phase densities. The density of the unsubmerged portion of the crust (freeboard) also depends on its void fraction, solids volume fraction, and liquid and solid phase densities. These quantities are not the same as in the submerged portion of the crust. The exposed crust contains open pores and void spaces, surrounded by solid crust material, that are assumed open to the headspace and therefore contain gas at the headspace composition. It is assumed that the pore spaces, but not the voids, are partially filled or saturated with liquid due to capillary action. This model is illustrated schematically in Figure 2.4.1.

Balancing the upward buoyancy forces and downward gravitational forces on the crust yields relationships to determine the depth the crust is submerged (S), the height of the liquid level $\left(\mathrm{H}_{\mathrm{L}}\right)$, the height of the crust surface $\left(\mathrm{H}_{S}\right)$, and the height of the crust base $\left(\mathrm{H}_{\mathrm{B}}\right)$. The equations are too complicated to be easily summarized here. Refer to Stewart et al. (1999) for the full derivation.

The amount of mixing that occurs between existing waste and water during back-dilution determines the density of the liquid the crust floats on. Mixing is expected to range from very good to essentially nonexistent. To express this range of possibilities for modeling purposes, 


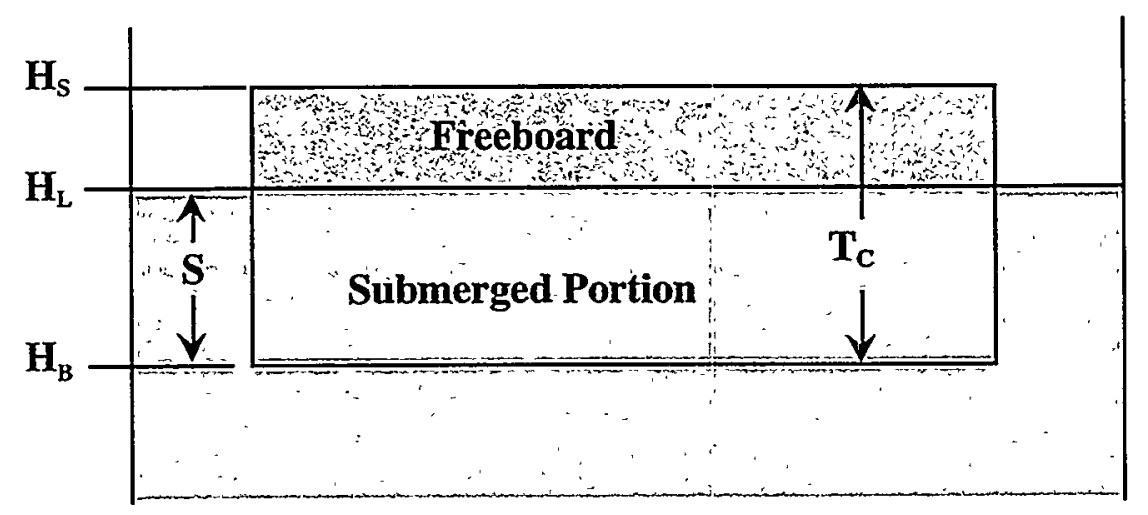

Figure 2.4.1. Diagram of Crust Buoyancy Model

back-dilution is assumed to form two distinct stratified layers in the liquid. The upper layer, above the water injection point, is a homogeneous mixture of dilution water and a given fraction of the original mixed slurry (less than 1.0 to parameterize the effect of imperfect mixing). The lower layer, below the injection point, consists of the original undiluted slurry. The crust itself is assumed to have passages through which fluid can flow relatively easily, such that all hydrodynamic effects can be ignored. That is, the crust behaves purely as a hydrostatic system before, during, and after adding the dilution water.

Because the density of water is much lower than that of the slurry, any water added on top of the crust will initially penetrate only to the existing liquid level. Similarly, even when water is added below the crust, the diluent mixture of water and slurry will of course be lighter than the original slurry, and the diluent mixture will percolate up, through, and around the crust to stratify on top of the unmixed slurry. The crust will rise or sink until it displaces a sufficient volume of fluid to support its weight in the surrounding liquid. Depending on the amount of mixing, the volume of water added, and at what elevation it is added, the diluent mixture density may result in the crust being either partially or wholly submerged in the liquid. The submerged portion of the crust may be supported entirely in the diluent mixture layer or partially in the diluent mixture layer and partially in the underlying original slurry layer.

If the mixed diluent is less dense than the bulk crust material, the diluent mixture will remain above the slurry level and the crust may be entirely submerged, as shown in Figure 2.4.2. The lower part of the crust is submerged in the original (undiluted) slurry, and the upper part is submerged in the new diluent mixture. The sum of the crust submergence depths is equal to the total crust thickness. The diluent mixture will also penetrate the porosity and void space throughout the newly submerged freeboard, which was originally above the liquid surface level before the water addition.

If the diluent mixture remains denser than the bulk crust material, the crust can float entirely supported by the diluent mixture. This is illustrated schematically in Figure 2.4.3. This is similar to the original condition of crust buoyancy described above except that the crust will be submerged to a greater depth, because the density of the diluent mixture must of necessity be somewhat less than that of the original slurry. 


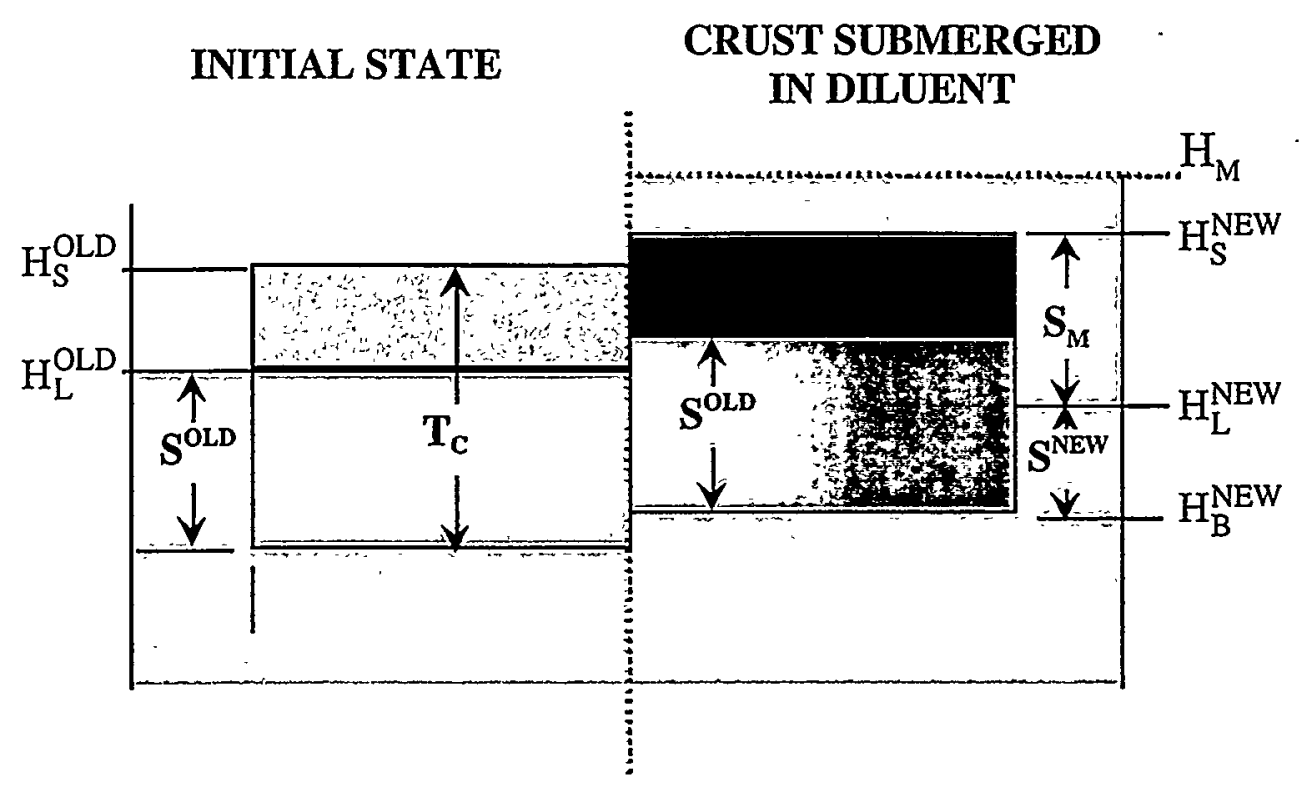

Figure 2.4.2. Diluent Added so Crust Is Completely Submerged

The crust submergence in both the diluent and original slurry after dilution, $\mathrm{S}_{\mathrm{M}}$ and $\mathrm{S}^{\mathrm{NEW}}$, are computed as a function of the original crust thickness and submergence, $T_{C}$ and $S^{O L D}$, and the fluid densities. The elevations of the diluent surface, the interface between the original slurry and diluent, the crust base, and the crust top are then computed by applying mass conservation. These effects have been demonstrated by simple experiments (Stewart et al. 1999).

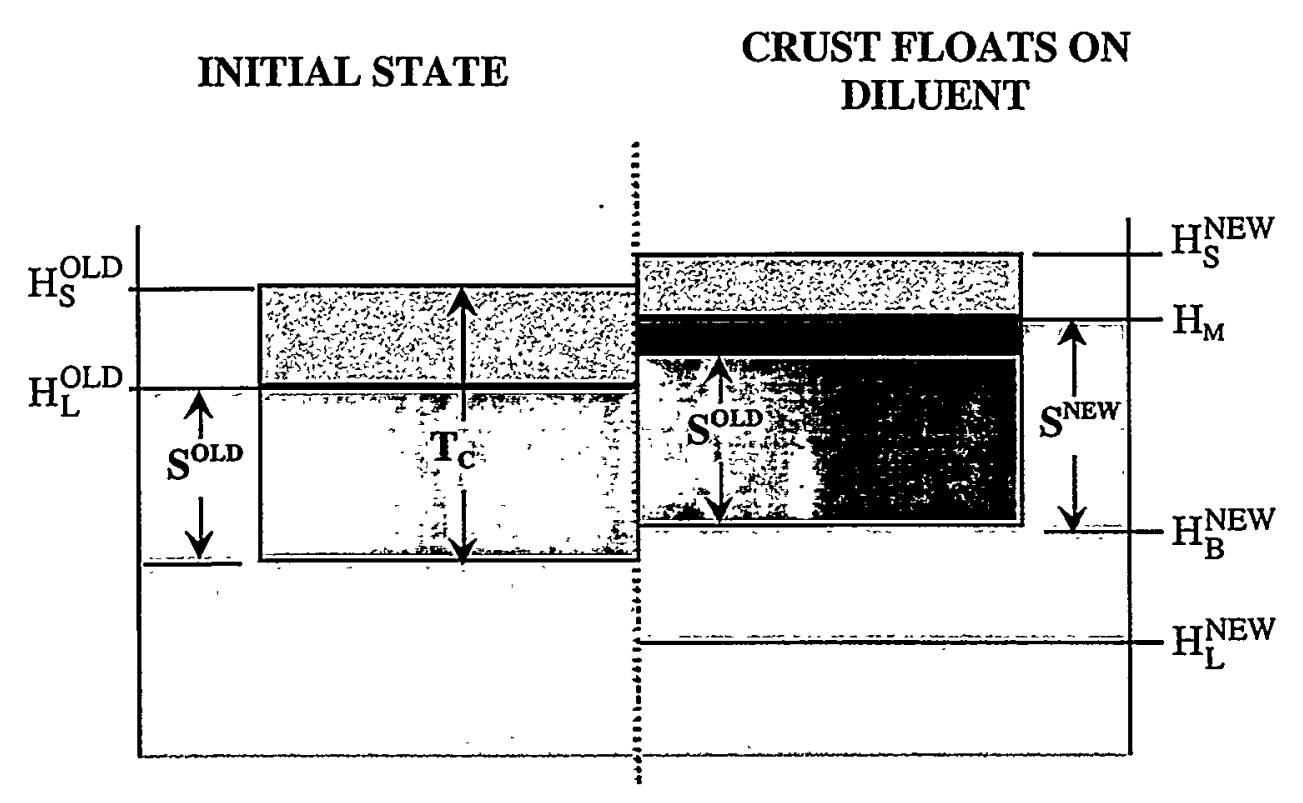

Figure 2.4.3. Diluent Mixture Is Dense Enough to Support the Crust 


\subsubsection{Waste Dissolution Model}

Dilution affects crust buoyancy not only by mixing in the slurry layer but also by changing the mass of the crust through dissolution. The basic buoyancy model described above still applies; dissolution merely changes the dimensions and densities involved. This section again summarizes the dissolution model described in detail in Stewart et al. (1999).

After waste from the mixed slurry layer is transferred out of SY-101 into SY-102, water will be added both on top of and below the crust layer. The back-dilution scheme is sketched in Figure 2.4.4. Water will be placed on top of the crust through a flush line in the transfer pump pit. The water will fall $15-20 \mathrm{ft}$ to the waste surface. Because the water is much less dense than the liquid surrounding the crust, it will flow out across the surface, eventually filling the open space in the current freeboard. Since the water will flow through the freeboard in intimate contact with the solids, dissolution of the freeboard layer is expected to be relatively rapid (on the order of a day). Dissolution depth will probably be slightly greater in the vicinity of the water addition but is expected to be relatively uniform over the entire surface of the crust, because of the barrier of the heavier salt-saturated liquid below (see experimental results for a simulated top dilution in Section 5).

Water will be added below the crust through the in-line dilution system at the inlet of the transfer pump, 96 inches above the tank bottom. Because water is much lighter than the slurry, it will rise as a plume, mixing with the slurry as it goes. Mixing above the injection point is predicted to be very effective with little stratification (Antoniak and Meyer 1999, Section 3.1). The

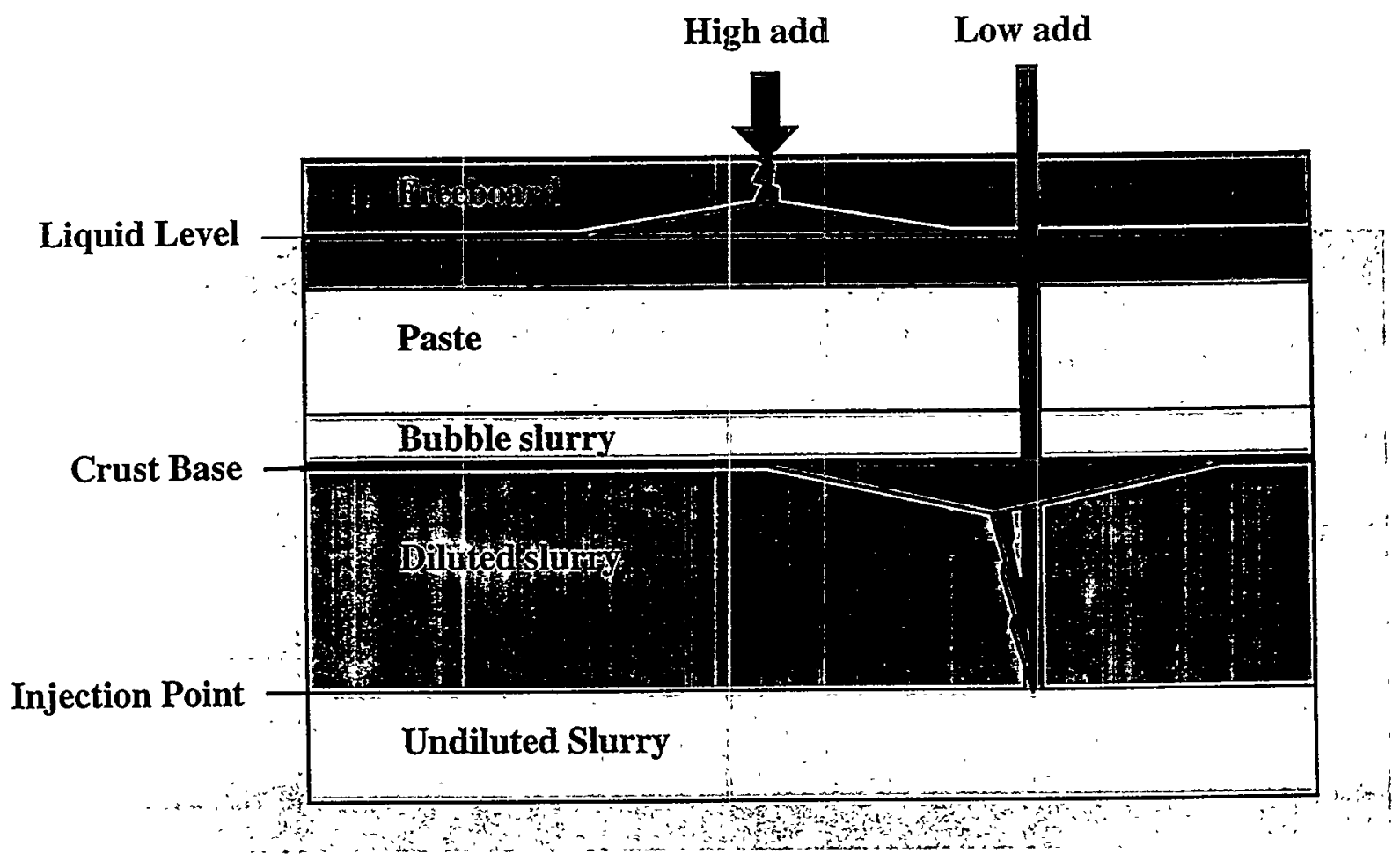

Figure 2.4.4. Schematic of Back-Dilution Locations 
solids suspended in the slurry are quite small and are expected to dissolve rapidly in contact with the water. Assuming pure diffusion, a one-micron particle is $99 \%$ dissolved in less than one second in contact with pure water. Diffusion alone will similarly dissolve $99 \%$ of a 10-micron particle or $90 \%$ of a 100-micron particle in about one minute (Cussler 1984, Section 5.2). As the water accumulates dissolved solids, the dissolution rates will, of course, decrease as discussed in Section 5.2.

Essentially no mixing or dissolution of suspended solids can be expected in the layer of slurry below the water injection point unless the mixer pump is run. Even then, if a large density gradient has formed, slurry mixing will be limited between the pump inlet and the crust base and slow between the pump inlet and the bottom of the tank (Section 3.2). However, there is also provision for adding water through the "burrowing ring" at the base of the mixer pump. The nozzles in the burrowing ring exit through holes in the bottom velocity plate, 9 inches from the tank bottom. ${ }^{\text {(a) }}$ Adding water at this elevation ensures that essentially all of the soluble suspended solids in the entire slurry layer will be dissolved if enough water is added. (In this analysis, dissolution of the additional solids that may be present in the loosely settled layer $50-60$ inches from the tank bottom is ignored)

Solids dissolution is calculated under the basic assumption that soluble solids will dissolve until the liquid mixture of dissolved solids and water is in equilibrium. The mass of dilution water required to dissolve a given mass of solids is therefore equal to the product of the solids mass to be dissolved, the fraction of the solids that are soluble, and the water/solids mass solubility ratio. Based on the statistical interpretation of SY-101 waste dilution data described in Section 2.1, the saturated liquid contains about 0.79 grams of water for every gram of dissolved solids at tank temperature. The solids mass is calculated based on a density of $2200 \mathrm{~kg} / \mathrm{m}^{3}$. This is used for undissolved and dissolved solids as well as for the insoluble solids that compose about $40 \%$ of the total solids mass. Water density is assumed to be $1000 \mathrm{~kg} / \mathrm{m}^{3}$. The resulting density of the saturated liquid at tank temperature is $1490 \mathrm{~kg} / \mathrm{m}^{3}$.

When water is added below the crust, suspended solids are expected to dissolve only in the fluid above the water injection point. Water is assumed to dissolve soluble solids above the injection point until the liquid in that layer reaches saturation or until all available solids are dissolved. Insoluble particles are assumed to remain in suspension. If the slurry layer is unsaturated, it is assumed that the crust begins to dissolve. It is further assumed that gas is released in proportion to the fraction of soluble solids dissolved. (Gas releases associated with tank-scale crust dissolution are discussed in detail in Section 6.) Insoluble solids left as the crust dissolves from the bottom up are assumed to join the slurry.

When water is placed on top of the crust, dissolution is assumed to proceed sequentially from the top down. The water dissolves all the soluble solids available in the top layer first. Only then is any remaining unsaturated diluent mixture available to begin dissolving the next layer down. The top dilution model considers dissolution only of the freeboard, wet clay, and paste layers. It is assumed that the bubble slurry layer dissolves by bottom dilution.

(a) LMHC Interoffice Memo 79000-99-053 from RE Raymond to the SY-101 Project Group. August 18, 1999. Subject: 241-SY-101 Mixer Pump Inlet Level, and SY-101 Mixer Pump Drawing H2-89953. 
The thickness of the remaining crust layers after dissolution and the mass of formerly interstitial liquid and insoluble solids freed by the dissolution are assumed proportional to the fraction of the total soluble solids mass dissolved. The void fraction, solids volume fractions, and other properties of the remaining undissolved material are assumed to remain unchanged at their original values. The liquid mixture after dissolution consists of the dissolved solids and interstitial liquid freed from pores in the crust as a result of dissolution as well as the added water. This mixture is assumed to flow down through the crust and mix completely with the slurry supporting the crust. The insoluble solids freed by dissolution are conservatively assumed to remain as added weight on top of the crust.

We can determine whether the crust will continue to float after dilution by applying the buoyancy model described in Section 2.4 .1 to the diminished crust. If the new average crust density is still lower than that of the surrounding liquid, it will float. The densities resulting from the dissolution model assume perfect mixing in the slurry layer between the base of the crust and the water injection point. Of course, mixing will not be perfect, and some degree of stratification will occur. To characterize the degree of mixing that can be expected, the low back-dilution process was simulated using the TEMPEST code (Antoniak and Meyer 1999, Section 3.1). The simulations predicted very good mixing, with only a slight density gradient between the injection point and the crust base. Stratification is conservatively included by multiplying the well-mixed slurry density by a stratification factor. This factor is calculated as the ratio of the minimum slurry density to the maximum slurry density predicted in the simulations. The stratification factor is $1.52 / 1.56=0.97$.

\subsubsection{Results for the Initial Transfer and Back-Dilution}

The current condition and properties of the crust are needed to apply the buoyancy and dissolution models to the various transfer and back-dilution scenarios. This information was developed by calibrating the buoyancy model results with a series of waste levels (Stewart et al. 1999) measured when the crust and slurry conditions were known from VFI and RGS measurements. When the best-estimate values are applied with the current crust thickness, levels, and estimated void fractions, the basic crust buoyancy model provides a description of the current crust configuration. The results are summarized in Table 2.4.1. The measured waste levels for October 1999 match the predictions well. The crust was just over $10 \mathrm{ft}$ thick and about $84 \%$ submerged. It had an average void fraction of about 0.23 , which was divided into the four layers described in Section 2.2. The bulk slurry void fraction was estimated as 0.027 from the mixer pump volute pressure trend (see Section 2.2).

As water is added below the crust, the density of the slurry above the injection point decreases by dilution from the added water. This is partially compensated for by the release of gas from the slurry, which is assumed to be in proportion to the fraction of solids in the slurry that are dissolved. If there is no top dilution, the analysis assumes that the crust is unaffected until the slurry density, corrected for stratification, falls below the saturated liquid density (1490 $\mathrm{kg} / \mathrm{m}^{3}$ ). At that point, the excess water begins to dissolve the bubble slurry layer. Because the bubble slurry contains a disproportionately high volume of gas, dissolution and gas release from this layer will greatly increase the average crust density. The crust will sink if its density exceeds that of the slurry layer. The impacts of crust sinking are discussed further in Section 4. 
Table 2.4.1. Base Crust Configuration (fall 1999)

\begin{tabular}{|l|c|l|c|}
\hline Input Values & & . & \\
\hline Bulk slurry void fraction & 0.027 & Degassed level (in) & 392.3 \\
\hline Freeboard Thickness (in.) & 20 & Freeboard Void Fraction & 0.34 \\
\hline Wet Clay Thickness (in.) & 12 & Wet Clay Void Fraction & 0.08 \\
\hline Paste Thickness (in.) & 80 & Paste Void Fraction & 0.21 \\
\hline Bubble Slurry Thickness (in) & 10 & Bubble Slurry Void Fraction & 0.60 \\
\hline Total Crust Thickness (in.) & 122 & Avg. Submerged Void Fraction & 0.23 \\
\hline & & Measured Waste Levels (in.) & \\
\hline & & Surface (Enraf 1A) & 431 \\
\hline Computed Values & & Liquid (Enraf 1C) & 412 \\
\hline Submergence (in.) & 102 & Crust Base (in) (neutron probe) & 310 \\
\hline Submerged S.G. (including gas) & 1.34 & Predicted Waste Levels (in.) & \\
\hline Freeboard S.G. & 1.98 & Surface & 431 \\
\hline Average crust S.G. & 1.41 & Liquid & 412 \\
\hline Bulk slurry S.G. (including gas) & 1.55 & Crust Base & 310 \\
\hline S.G. = specific gravity. & & & \\
\hline
\end{tabular}

Because the back-dilution volume is expected to be the same as the transfer volume in most cases, larger transfer volumes will result in an increasingly dilute slurry. At some point, the mixed slurry density will be too low to float the crust, and the back-dilution volume will need to be reduced to prevent the crust from sinking. With the back-dilution volume lower than the transfer volume the crust base will be lower, because the volume of the mixed liquid slurry decreases as transfer volume increases. Thus transfer volume is limited to the amount that allows maximum back-dilution to keep the crust base floating far enough above the mixer pump inlet to ensure effective operation. Because the mixer pump has operated effectively with the crust base as low as 295 inches, this level has been chosen as the lower operational limit.

The back-dilution limitations for the important scenarios with water injected at the 96 -inch transfer pump inlet and the 9-inch mixer pump burrowing ring are listed in Table 2.4.2. The next-to-last entry in Table 2.4 .2 shows that top dilution is very beneficial in providing operational flexibility to the transfer and back-dilution process. The crust base remains well above the 295-inch minimum and does not limit transfer volume. In addition, there are no serious consequences related to gas release if moderate volumes of water are added on top of the crust layer. Because the crust was only about 60 inches thick in the fall of 1998, when the RGS and VFI first detected the bubble slurry layer, it can be confidently thinned to a similar thickness without releasing bubble slurry. This amount of dissolution requires approximately $50 \mathrm{kgal}$ of top dilution. 
Table 2.4.2. Volume Limits for Back-Dilution below Crust.

\begin{tabular}{|c|c|c|}
\hline Transfer type & $\begin{array}{l}\text { Water injected at } 96 \text { in. } \\
\text { transfer pump }\end{array}$ & $\begin{array}{l}\text { Water injected at 9-in. } \\
\text { mixer pump burrowing ring }\end{array}$ \\
\hline $\begin{array}{l}\text { Maximum transfer with equal } \\
\text { back-dilution allowable to avoid } \\
\text { sinking crust }\end{array}$ & $\begin{array}{c}90 \mathrm{kgal} \text { transfer with equal } \\
\text { back-dilution }\end{array}$ & $\begin{array}{l}120 \mathrm{kgal} \text { transfer with equal } \\
\text { back-dilution }\end{array}$ \\
\hline $\begin{array}{l}\text { Maximum transfer and back- } \\
\text { dilution allowable to keep crust } \\
\text { above } 295 \text { in. without sinking }\end{array}$ & $\begin{array}{c}143 \mathrm{kgal} \text { transfer } \\
\text { with } 80 \mathrm{kgal} \text { back-dilution }\end{array}$ & $\begin{array}{c}175 \mathrm{kgal} \text { transfer } \\
\text { with } 112 \mathrm{kgal} \text { back-dilution }\end{array}$ \\
\hline $\begin{array}{l}\text { Maximum transfer and back- } \\
\text { dilution allowable to keep crust } \\
\text { above } 295 \text { in. and } 10 \text { kgal less } \\
\text { than would cause sinking }\end{array}$ & $\begin{array}{l}100 \mathrm{kgal} \text { transfer } \\
\text { with } 72.5 \mathrm{kgal} \text { back-dilution }\end{array}$ & $\begin{array}{l}125 \mathrm{kgal} \text { transfer } \\
\text { with } 103 \mathrm{kgal} \text { back-dilution }\end{array}$ \\
\hline $\begin{array}{l}\text { Maximum transfer with equal } \\
\text { back-dilution allowable to avoid } \\
\text { crust sinking with } 20 \text { kgal of } \\
\text { total added on top }\end{array}$ & $\begin{array}{c}128 \mathrm{kgal} \text { transfer with equal } \\
\text { back-dilution } \\
\begin{array}{c}(20 \mathrm{kgal} \text { on top, } 108 \mathrm{kgal} \\
\text { below) }\end{array} \\
\end{array}$ & $\begin{array}{c}160 \mathrm{kgal} \text { transfer with equal } \\
\text { back-dilution } \\
(20 \mathrm{kgal} \text { on top, } 140 \mathrm{kgal} \\
\text { below) }\end{array}$ \\
\hline $\begin{array}{l}\text { Planned transfer and } \\
\text { dilution for Campaign \#1 }\end{array}$ & $\begin{array}{l}88 \mathrm{kgal} \text { transfer, } 25 \mathrm{kgal} \text { on } \\
\text { top, } 35 \mathrm{kgal} \mathrm{at} 96 \mathrm{in} .\end{array}$ & \\
\hline
\end{tabular}

\subsubsection{Predicted State of Waste after Initial Transfer and Back-Dilution}

The most important result of the initial transfer and back-dilution is to remove negatively buoyant mass from the top of the crust. This is intended specifically to keep the crust floating as long as possible during the second back-dilution campaign. The relatively small amount of water added under the crust will not affect the mixed slurry layer significantly nor will it affect the base of the crust. The crust will contain essentially all of the gas it held initially, though it will be about $75 \%$ of its original thickness.

The baseline plan for Campaign \#1 calls for an 88-kgal transfer with a 60 -kgal back dilution ( $25 \mathrm{kgal}$ on top, $35 \mathrm{kgal}$ at 96 inches). However it is possible that a total of $97 \mathrm{kgal}$ could be added ( $25 \mathrm{kgal}$ on top, $72 \mathrm{kgal}$ at 96 inches) if required to restore mixer pump operation (Barton 1999). Therefore, both the nominal and maximum back-dilution cases need to be included.

The buoyancy and dissolution models are applied to predict the condition of the crust and mixed slurry after each case. The results of the nominal and maximum dilution cases are shown in Tables 2.4 .3 and 2.4 .4 , respectively. It is assumed that the mixer pump will be run regularly between the first and second campaigns and that density stratification is insufficient to inhibit mixing above the mixer pump inlet. Thus the mixed slurry is assumed to be homogenized from tank bottom to crust base before the second campaign.

The expected result of Campaign \#1 is to dissolve all of the freeboard and over half of the wet clay layer, as shown in Table 2.4.3. This should reduce the crust thickness to 95 inches and decrease its density by about $6 \%$. The average crust void fraction increases slightly. At the 
same time, the $35 \mathrm{kgal}$ injected through the transfer pump inlet dissolves about $40 \%$ of the solids volume in the mixed slurry and releases the same fraction of its gas. The net effect is to reduce the slurry density by less than $2 \%$. Since less water is added than waste removed by the initial transfer, the waste level will decrease to 408 inches, 23 inches less than the starting level. The combination of reduced crust thickness and waste level will make the crust base only three inches higher, ending at about 313 inches.

If the entire $72 \mathrm{kgal}$ of water is added below the crust, more solids will dissolve and more gas will be released from the mixed slurry, but the crust layer will not be reduced any more than was already accomplished by the $25 \mathrm{kgal}$ top dilution. As shown in Table 2.4 .4 , the mixed slurry solids fraction and void fraction will decrease by two-thirds and the resulting bulk density by more than $2 \%$. The resulting waste level and crust base are much higher than in the nominal case. The waste level decreases only 12 inches to 419 inches, and the crust base rises 14 inches to 324 inches.

Table 2.4.3. Waste Conditions before and after Campaign \#1-35-kgal Bottom Dilution

\begin{tabular}{|l|c|c|l|c|c|}
\hline Parameter & Before & After & Crust Layers & Before & After \\
\hline Mixed Slurry & & & Freeboard (in) & 20 & Dissolved \\
\hline Solids fraction & 0.15 & 0.092 & Wet Clay (in) & 12 & 5 \\
\hline Void fraction & 0.027 & 0.018 & Paste (in) & 80 & 80 \\
\hline Bulk density $\left(\mathrm{kg} / \mathrm{m}^{3}\right)$ & 1553 & 1527 & Bubble Slurry (in) & 10 & 10 \\
\hline Crust & & & Total (in) & 122 & 95 \\
\hline Bulk density $\left(\mathrm{kg} / \mathrm{m}^{3}\right)$ & 1405 & 1319 & Waste Surface Level (in) & 431 & 408 \\
\hline Avg. void fraction & 0.23 & 0.24 & Crust Base Level (in) & 310 & 313 \\
\hline
\end{tabular}

Table 2.4.4. Waste Conditions before and after Campaign \#1-72-kgal Bottom Dilution

\begin{tabular}{|l|c|c|l|c|c|}
\hline Parameter & Before & After & Crust Layers & Before & After \\
\hline Mixed Slurry & & & Freeboard (in.) & 20 & Dissolved \\
\hline Solids fraction & 0.15 & 0.050 & Wet Clay (in.) & 12 & 5 \\
\hline Void fraction & 0.027 & 0.009 & Paste (in) & 80 & 80 \\
\hline Bulk density (kg/m $\left.{ }^{3}\right)$ & 1553 & 1518 & Bubble Slurry (in.) & 10 & 10 \\
\hline Crust & & & Total (in.) & 122 & 95 \\
\hline Bulk density (kg/m $\left.{ }^{3}\right)$ & 1405 & 1319 & Waste Surface Level (in.) & 431 & 419 \\
\hline Avg. void fraction & 0.23 & 0.24 & Crust Base Level (in.) & 310 & 324 \\
\hline
\end{tabular}

\subsubsection{Uncertainty Analysis}

The crust dissolution model provides single point estimates for the crust thickness, mixed. slurry specific gravity, and crust surface elevation given transfer and back dilution volumes along with crust material properties and initial conditions and dimensions. It is not possible to quantify the effect of all the assumptions employed in developing the model. However, estimates of the overall uncertainty of the model can be derived from the uncertainty of the input 
values. Uncertainty estimates were developed by compiling a large number of outputs while randomly varying the inputs over their uncertainty ranges. The distribution of all the outputs from these simulations represents the uncertainty distribution of the model based on the input uncertainties.

The uncertainty was evaluated specifically for the volume of low back dilution at the 96 inch elevation that would cause the crust to sink assuming no top dilution and transfer volumes of 100 $\mathrm{kgal}$ and $150 \mathrm{kgal}$. This back dilution volume for crust sinking is obtained for each input set by finding the value that makes the crust specific gravity after dissolution equal to the mixed slurry specific gravity after dilution.

The analysis is complicated by the constraints placed on the inputs that are necessary to make the simulation match actual conditions. Values of four of the inputs (Crust Freeboard Porosity, Crust Freeboard Saturation, Crust Freeboard Void Fraction, and Crust Area Fraction) were originally determined from an error minimization based on three input sets for specific days when the waste levels, crust thickness and void fractions were "known" (Stewart et al. 1999). If the four inputs chosen for a specific run did not produce crust levels that matched the three sets of known values to within a root-mean-square difference of 50 inches, the input set was discarded. The 50-inch criterion was determined by manually varying the four inputs and comparing the change in predicted level to the estimated uncertainty in the level measurements.

Four other inputs (Crust Thickness, Crust Submerged Void Fraction, Bulk Slurry Void Fraction, and Degassed Waste Level) were constrained by the known initial conditions prior to transfer and back dilution (see Section 2.4.3 and Table 2.4.1). If the Surface Level, Liquid Level or Crust Base Level predicted with four inputs selected for a specific run were outside their individual uncertainty bounds, the input set was also discarded as above. The range for each of the levels representing the initial conditions was determined as follows:

$\begin{array}{ll}\text { Surface Level } & 430-434 \text { in. } \\ \text { Liquid Level } & 408-415 \text { in. } \\ \text { Crust Base Level } & 305-315 \text { in. }\end{array}$

Further sub-constraints were necessary to keep derived variables within known bounds. In the model, the Crust Submerged Degassed Specific Gravity and the Bulk Slurry Degassed Specific Gravity are calculated from the respective solids volume fractions and the solid and liquid densities. However, they are also known to within quite narrow bounds from analysis of recent core samples. To maintain their values within the established range, the uncertainty was accumulated in the Crust Submerged Solids Volume Fraction and the Bulk Slurry Solids Volume Fraction by back-calculating them from the other inputs.

Likewise, the total crust thickness was required to equal the sum of individual layer thickness and the crust average void fraction was required to be the same as the average computed from the layer void fractions and thickness. In this case, the uncertainty was accumulated in the Paste Layer Thickness and Paste Layer Void Fraction by back-calculating them from the overall averages and the inputs from the other layers. 
Uncertainty distributions and ranges were set for each of the input variables based on engineering judgement, waste characterization data, and previous analyses. Because these choices were made ad hoc, it is not surprising that the initial trial simulations produced very few outputs for which the input sets satisfied the constraints. This required some judicious adjustments of the input ranges to create a reasonable number of "good" outputs. The final set of distributions and constraints is given in Table 2.4.5.

Table 2.4.5 Crust Dissolution Model Input Distributions and Constraints

\begin{tabular}{|c|c|c|c|c|c|}
\hline No. & Input Variable & Distribution & $\begin{array}{c}\text { Con- } \\
\text { straint }\end{array}$ & Min. & Max. \\
\hline 1 & Crust Thickness (cm) & Normal & $\mathrm{B}$ & 300 & 360 \\
\hline 2 & Crust Freeboard Porosity & Uniform & $\mathrm{A}$ & 0.3 & 0.6 \\
\hline 3 & Crust Freeboard Saturation & Uniform & A & 0.4 & 0.8 \\
\hline 4 & Crust Freeboard Void Fraction & Uniform & $\mathrm{A}$ & 0.3 & 0.6 \\
\hline 5 & Solids Sp.G. (undissolved) & Lognormal & & 2.1 & 2.6 \\
\hline 6 & Solids Sp.G. (dissolved) & Uniform & & 2.1 & 2.3 \\
\hline 7 & Liquids Sp.G. at Saturation & Uniform & & 1.48 & 1.5 \\
\hline 8 & Crust Subm. Solids Vol. Fraction & Calc. from $5,7,14$ & Solve & - & - \\
\hline 9 & Crust Submerged Void Fraction . & Normal & $\mathrm{B}$ & 0.21 & 0.25 \\
\hline 10 & Bulk Slurry Void Fraction & Normal & $\mathrm{B}$ & 0.02 & 0.035 \\
\hline 11 & Bulk Slurry Solids Vol. Fraction & Calc. from $5,7,15$ & Solve & - & - \\
\hline 12 & Crust Area Fraction & Uniform & $\mathrm{A}$ & 0.8 & 0.95 \\
\hline 13 & Degassed Waste Level $(\mathrm{cm})$ & Normal & B & 995 & 998 \\
\hline 14 & Crust Submerged Degassed Sp.G. & Normal & & 1.7 & 1.8 \\
\hline 15 & Bulk Slurry Degassed Sp.G. & Normal & & 1.57 & 1.62 \\
\hline 16 & Water/Solids Mass at Equilibrium & Beta, bias low & & 0.6 & 1.0 \\
\hline 17 & Fraction of Solids Insoluble & Beta, bias high & & 0.15 & 0.50 \\
\hline 18 & Freeboard Thickness (in) & Uniform & & 18 & 22 \\
\hline 19 & Wet Layer Thickness (in) & Fixed & & \multicolumn{2}{|c|}{12} \\
\hline 20 & Wet Layer Void Fraction & Fixed & & \multicolumn{2}{|c|}{0.08} \\
\hline 21 & Paste Layer Thickness (in) & Calc. from $1,18,19,23$ & Solve & - & - \\
\hline 22 & Paste Layer Void Fraction & $\begin{array}{l}\text { Calc. from } 1,9,18,19, \\
20,21,23,24\end{array}$ & Solve & - & - \\
\hline 23 & Bubble Slurry Thickness (in) & Normal & & 10 & 15 \\
\hline 24 & Bubble Slurry Void Fraction & Lognormal. & & 0.55 & 0.70 \\
\hline \multicolumn{6}{|c|}{ A. Constrained by data from three "known" waste states } \\
\hline
\end{tabular}

The final series of 10,000 input sets, for the 100 -kgal transfer volume yielded 4757 outputs that satisfied the constraints. The final distributions of the predictions of low back-dilution volume required to sink the crust are shown in Figure 2.4 .5 in histogram form with their percentiles, mean, and standard deviation. The $95 \%$ confidence range (between the $2.5^{\text {th }}$ and $97.5^{\text {th }}$ percentile) for the $100-\mathrm{kgal}$ transfer is 42 to $93 \mathrm{kgal}$ with a mean of $63.4 \mathrm{kgal}$ and a standard deviation of $13 \mathrm{kgal}$. 


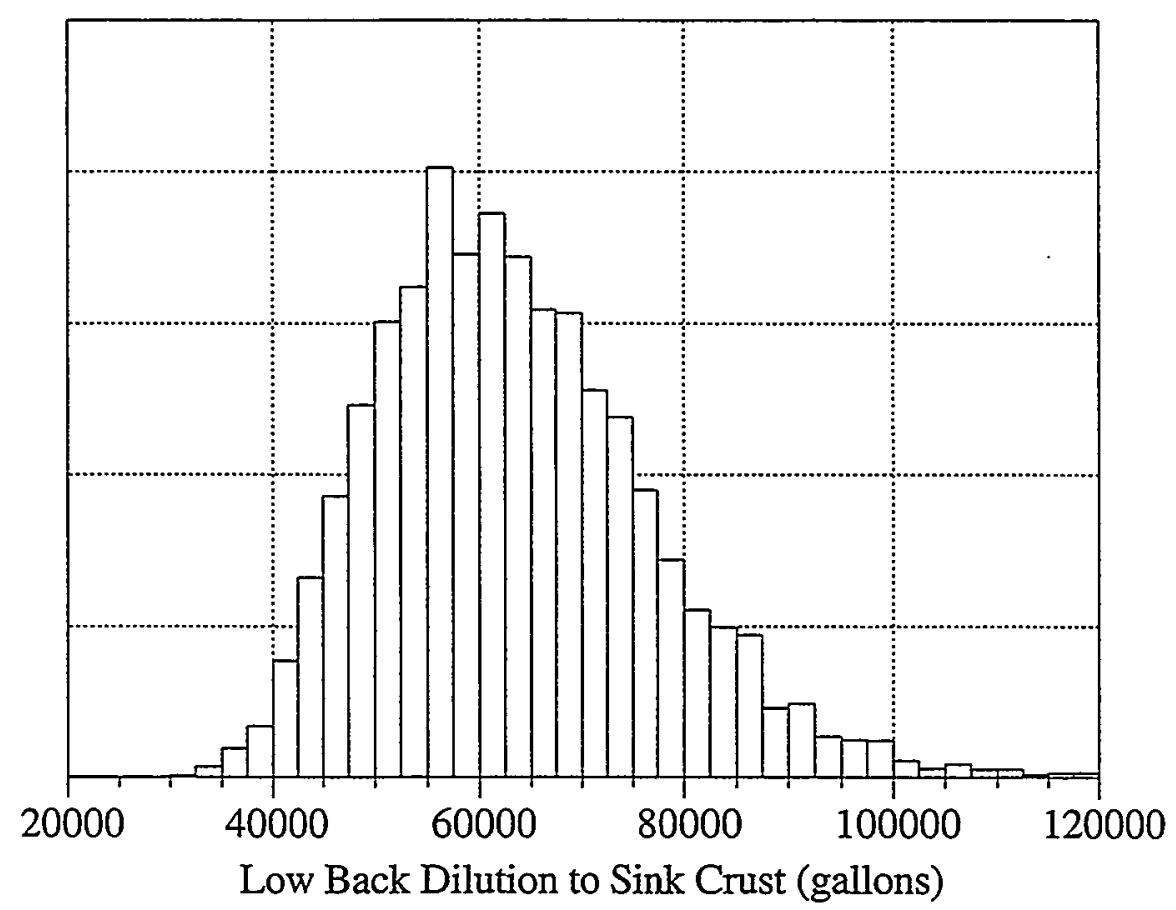

Figure 2.4.5. Histogram of Dilution Volume for Crust Sinking: $100 \mathrm{kgal}$ Transfer

$\begin{array}{llr}\text { maximum } 100.0 \% & 122706 \\ & 99.5 \% & 106508 \\ & 97.5 \% & 92877 \\ & 90.0 \% & 81033 \\ \text { quartile } & 75.0 \% & 71615 \\ \text { median } & 50.0 \% & 61879 \\ \text { quartile } & 25.0 \% & 53961 \\ & 10.0 \% & 47733 \\ & 2.5 \% & 41974 \\ & 0.5 \% & 37070 \\ \text { minimum } & 0.0 \% & 31441 \\ & & \\ \text { Mean } & & 63437 \\ \text { Std Dev } & & 13153\end{array}$

A similar set of 10,000 simulations for a 150-kgal transfer yielded 4761 outputs that satisfied the constraints. The distribution of low back-dilution volumes to sink the crust for this larger transfer is given in Figure 2.4.6. The results are similar to the 100-kgal transfer case though the smaller waste volume remaining after transfer requires less dilution to sink the crust. The $95 \%$ confidence range for the 150-kgal transfer was 38 and $85 \mathrm{kgal}$ with a standard deviation of 12 kgal. 


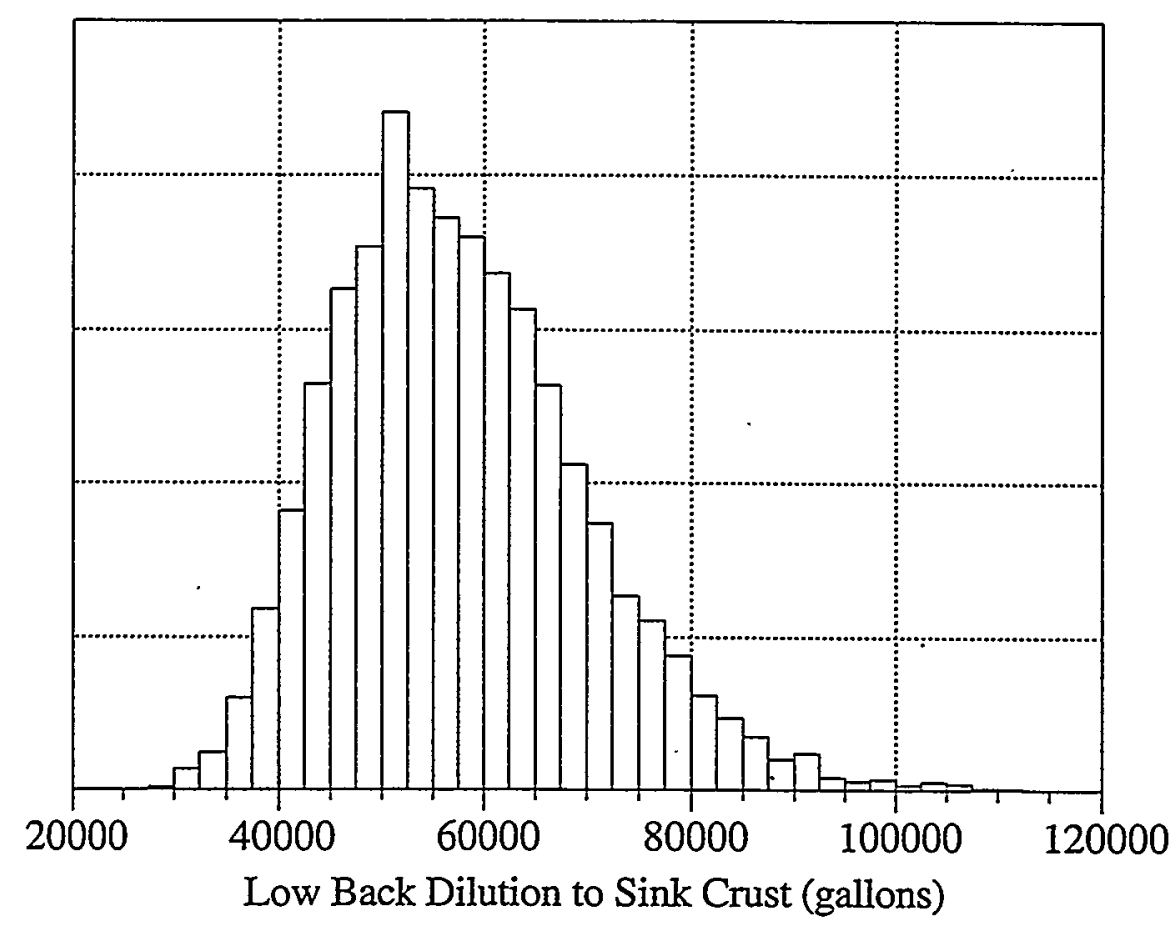

Figure 2.4.6. Histogram of Dilution Volume for Crust Sinking: $150 \mathrm{kgal}$ Transfer

$\begin{array}{llr}\text { maximum } 100.0 \% & 112485 \\ & 99.5 \% & 97229 \\ & 97.5 \% & 84806 \\ & 90.0 \% & 74030 \\ \text { quartile } & 75.0 \% & 65058 \\ \text { median } & 50.0 \% & 56292 \\ \text { quartile } & 25.0 \% & 48891 \\ & 10.0 \% & 43193 \\ & 2.5 \% & 37923 \\ . & 0.5 \% & 33631 \\ \text { minimum } & 0.0 \% & 28454 \\ & & \\ \text { Mean } & & 57679 \\ \text { Std Dev } & & 12124\end{array}$

Though it is probable that the uncertainty distribution might be somewhat different for other scenarios (i.e., top back-dilution, combinations of top and low back-dilution), getting comparable standard deviations for both a nominal and large transfer indicates that similar uncertainties would apply. The 12-kgal margin on transfer volume prescribed for the first transfer is equivalent to one standard deviation. 


\subsection{Diluent Mixing and Stratification}

The capacity of a diluent to dissolve and/or erode crust solids depends in part on the state of saturation of the diluent transported to the crust surface. In turn, the saturation condition of the diluent depends on several factors including the location of water addition, how well the water is mixed with other (supersaturated) waste, how fast solids are dissolved, the properties of the waste mixed with the diluent, and the solubility of solids in the diluent (Section 2.1). Water added directly on top of the crust will be completely unsaturated, whereas water added in or near the nonconvective layer could mix thoroughly with solids in the nonconvective and slurry layers, reaching saturation before buoying to a crust surface. In either case, the possibility exists of a density-stratified layer of partially saturated water/waste mixture forming on top of the slurry layer, in contact with the crust, due to buoyancy effects.

Antoniak and Meyer (1999) have shown that dilution water and waste are mixed rapidly, and the degree of stratification in the slurry layer is low when the water is added through an existing sparge ring on the base of the mixer pump or through the dilution line at the inlet of the transfer pump. Their results are summarized in Section 3.1. In Section 3.2, the ability of the mixer pump to affect a hypothetical density-stratified slurry layer, should one form, is evaluated. These analyses, as they pertain to the saturation level of the diluent in the mixed-slurry layer and in contact with the floating crust layer, are applied in subsequent evaluation of mixed-slurry and crust solids dissolution rates (Section 5.2). Additionally, slurry density and stratification play important roles in the overall buoyancy of the crust (Section 2.4). The impacts of crust sinking are addressed in Section 4.

\subsection{Diluent Mixing During Addition}

This section is adapted from Antoniak and Meyer (1999). The water addition following the waste transfer out of SY-101 is planned in part to ensure that the base of the floating crust layer will be lifted away from the mixer pump inlet with minimal effect on the crust itself. The concern is that the natural tendency for the much lighter dilution water to rise and pool beneath the crust would make the resulting fluid mixture too light to float the crust. If this happens, adding water will not lift the crust away from the mixer pump. However, as long as the volume of added water is not too large and the plume of dilution water mixes sufficiently, significant stratification should not occur in the waste. A fully mixed or partially saturated diluent will necessarily have less effect on the crust layer both in terms of crust flotation and the potential for the slurry liquid to dissolve crust solids.

It is anticipated that water heated to the bulk tank temperature will be added at $\sim 70 \mathrm{gpm}$ either through an existing sparge ring ("burrowing ring") on the base of the mixer pump near the tank bottom or through the dilution line at the inlet of the transfer pump (96-in. elevation). The purposes of this study were 1) to confirm that back-dilution through the mixer pump sparging ring or transfer pump dilution line provides sufficient mixing and 2) to determine whether mixing depends on dilution flow rate. Section 3.1.1 describes the approach used to analyze mixing, including both the TEMPEST hydrothermal code (Trent and Eyler 1993) and an empirical model for plume mixing. Section 3.1.2.presents the results of the analyses. 


\subsubsection{Approach}

The approach used to assess the potential for stratification was a computational fluid dynamic computer simulation of back-dilution in the tank from the two locations. A twodimensional (2-D) TEMPEST model was created specifically for back-dilution from the mixer pump sparging ring. A 2-D model is appropriate for this case because the mixer pump is near the tank center and the resulting flows are nearly axisymmetric. The model consists of 47 radial and 28 vertical divisions with variable spacing for a total of 1316 computational cells.

A second, three-dimensional (3-D) model was also created to address back-dilution at the transfer pump inlet. Because the transfer pump is located in riser 007 (5B) at a 20 - $\mathrm{ft}$ radius, a 2-D model would not represent the back-dilution flow and mixing behavior accurately. This 3-D model contained 40 radial, 28 vertical, and 21 azimuthal divisions for a total of 23,520 computational cells. Small cells are used in the water inflow region where velocity and density gradients are large.

The models represent the assumed waste configuration after removal of 100,000 gallons of slurry. The waste was represented as a single layer of convective slurry with variable density and viscosity. The 50-60-in. loosely settled layer was considered part of the slurry, and the combined layer specific gravity was initially set to 1.6. The viscosity sub-model was used to compute the slurry viscosity as a function of the local water volume fraction. The model simulated slurry convection only, both forced and that due to buoyancy. However, because the model assumed isothermal conditions at $49^{\circ} \mathrm{C}\left(120^{\circ} \mathrm{F}\right)$, thermal natural convection mixing was conservatively neglected. Effects of dissolution of slurry solids were not modeled. This is conservative because dissolution of solids during water/waste mixing would tend to reduce local density gradients and result in less potential for stratification. For added conservatism, the simulations were performed with molecular and turbulent diffusion models turned off.

TEMPEST cannot simulate a moving boundary so the base of the crust was assumed constant at a 312-in. level. Therefore, to satisfy continuity, the model required an artificial outflow cell to balance the water inflow. This cell was at the tank bottom, at the outer wall/radius to minimize its effect on the plume. Because a 100,000-gal back-dilution is less than $10 \%$ of the total waste volume, the effects of assuming a stationary crust are considered negligible.

Back-dilution water was assumed to flow into the tank at 30,100,200, or 500 gpm either at 24-in. elevation (representing the mixer pump sparge ring) or at the transfer pump inlet (at about 96-in. elevation). Note the elevation of the mixer pump burrowing ring was subsequently determined to be 9 in.; mixing effectiveness would increase if the lower elevation were used in the analysis. At the various flow rates, the time needed for 100,000 gal of water replacement varies from 3 to 56 hours. One additional case simulated a total back-dilution volume of 200,000 gal at a flow rate of $100-\mathrm{gpm}$. 


\subsubsection{Results of Analyses}

The purpose of the simulations was to study the degree of buoyant mixing of dilution water with the mixed slurry for a 100,000-gal water addition after a 100,000-gal waste removal. These are generalized volumes, somewhat larger than those planned for the first-phase transfer and back-dilution operations (Section 2.4.4). The trends observed in the analysis presented below suggest that smaller back-dilution volumes would result in comparable, if not improved, mixing effectiveness. By parametrically varying slurry viscosity and water flow rates, the range of conditions that could occur during the transfer and back-dilution operation were simulated for the two proposed locations for water addition. All simulations were run as transients, most of them to a "real" time of 100 hours. Typically about two days of CPU run time on the PNNL SGI computer were required to complete a 2-D run. The 3-D model required approximately a week to complete a run.

The results of all the simulations are summarized in Table 3.1.1. Details are shown in Figures 3.1.1 and 3.1.2, which plot typical density contours shortly after water inflow stopped. Essentially no further mixing occurred after cessation of inflow. Mixing was quite good, even with a 200,000-gallon transfer/back-dilution or a 500-gpm back-dilution flow at the transfer pump. This is clearly evident in Figure 3.1.3, where the minimum specific gravity seen by the crust was 1.46 for the case of very large 200,000-gal back-dilution at 24-in. elevation. While the specific gravity of this material is sufficient to float the current crust (1.41 specific gravity), the unsaturated slurry would likely dissolve and release gas from the bubble slurry layer, increasing the crust density, and lead to crust sinking (Section 2.4).

Table 3.1.1. Calculated Mixture Specific Gravity Shortly after Cessation of Water Inflow

\begin{tabular}{|c|c|c|c|c|c|c|}
\hline $\begin{array}{l}\text { Slurry }^{(a)} \\
\text { viscosity } \\
\text { (cP) }\end{array}$ & $\begin{array}{l}\text { Flow } \\
(\mathrm{gpm})\end{array}$ & $\begin{array}{c}\text { Inflow } \\
\text { elevation } \\
\text { (in.) }\end{array}$ & $\begin{array}{c}\text { Duration for } \\
100,000 \text { gal } \\
\text { (h) }\end{array}$ & $\begin{array}{c}\text { Max. mixture } \\
\text { specific } \\
\text { gravity }\end{array}$ & $\begin{array}{c}\text { Min. mixture } \\
\text { specific } \\
\text { gravity }\end{array}$ & $\begin{array}{c}\text { Time specific } \\
\text { gravity } \\
\text { calculated (h) }\end{array}$ \\
\hline 3 & 100 & 24 & 16.67 & 1.54 & 1.53 & 20 \\
\hline 3 & 100 & 24 & 16.67 & 1.53 & 1.52 & $\begin{array}{c}20 \\
\text { (Figure 3.1.1) }\end{array}$ \\
\hline 3 & 30 & 24 & 55.56 & 1.53 & 1.53 & 60 \\
\hline 30 & 100 & 24 & 16.67 & 1.53 & 1.52 & 20 \\
\hline 30 & 30 & 24 & 55.56 & 1.53 & 1.53 & 60 \\
\hline 100 & 100 & 24 & 16.67 & 1.53 & 1.52 & 20 \\
\hline 1000 & 100 & 24 & 16.67 & 1.53 & 1.52 & 20 \\
\hline 1000 & 30 & 24 & 55.56 & 1.53 & 1.53 & 60 \\
\hline 100 & 200 & 24 & 8.33 & 1.54 & 1.52 & 10 \\
\hline 100 & 500 & 24 & 3.33 & 1.54 & 1.52 & 4 \\
\hline 100 & 100 & 24 & $\begin{array}{c}33.3 \\
(200,000 \mathrm{gal})\end{array}$ & 1.47 & 1.46 & $\begin{array}{c}35 \\
\text { (Figure 3.1.3) }\end{array}$ \\
\hline \multicolumn{7}{|c|}{ The results below represent water inflow at the 20 -ft radius simulated with a 3-D model. } \\
\hline 100 & 500 & 96 & 3.33 & 1.58 & $\begin{array}{r}1.50 \\
\end{array}$ & 4 \\
\hline 100 & 100 & 96 & 16.67 & 1.56 & 1.52 & $\begin{array}{c}20 \\
\text { (Figures 3.1.2 } \\
\text { and 3.1.3) } \\
\end{array}$ \\
\hline 100 & 30 & 96 & 55.56 & 1.55 & 1.52 & 60 \\
\hline
\end{tabular}




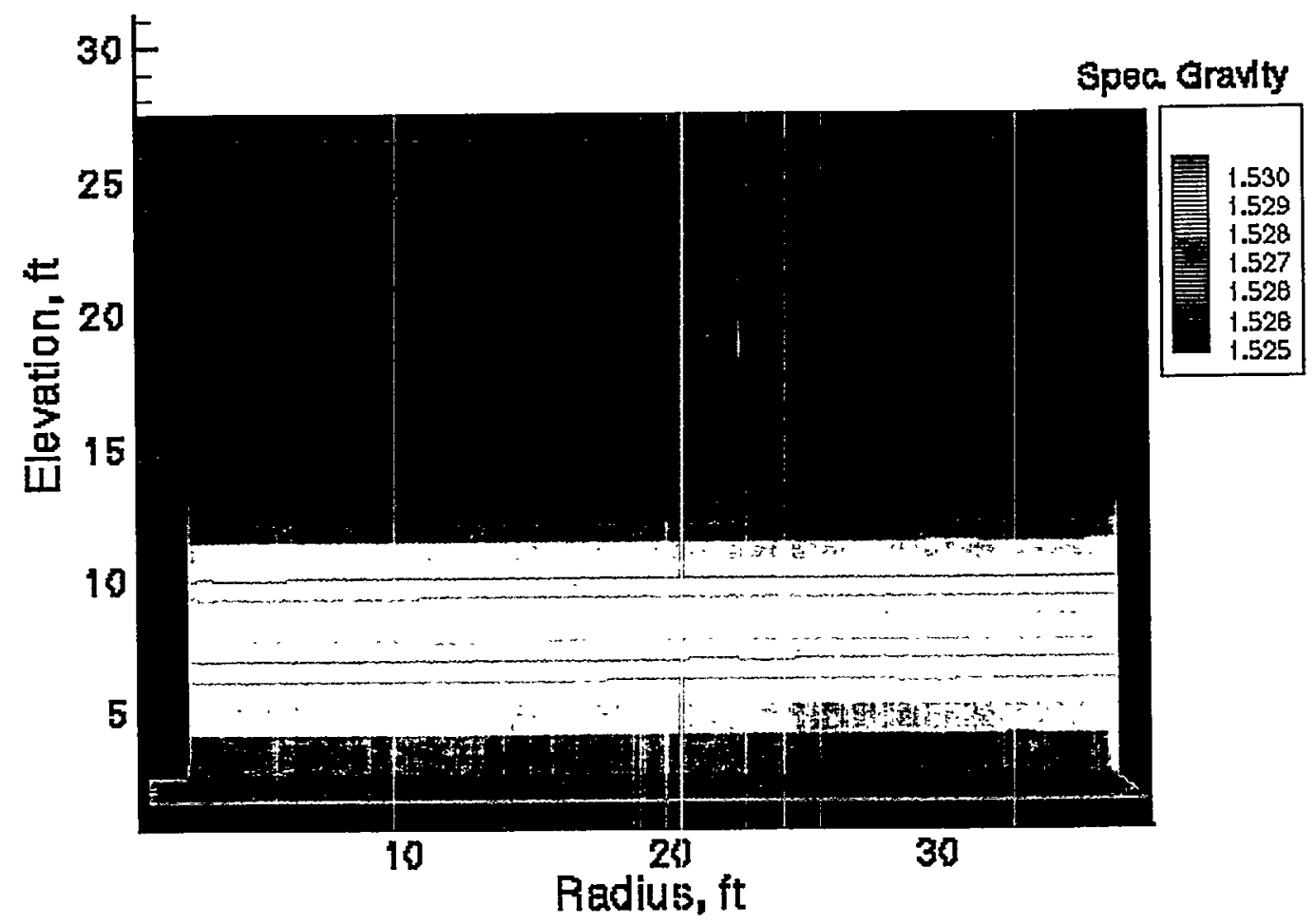

Figure 3.1.1. 100-gpm Inflow at 24-in. Elevation of Mixer Pump Sparge Ring into 3-cP ${ }^{\circ}$ Slurry (density-dependent viscosity) at $20 \mathrm{~h}$

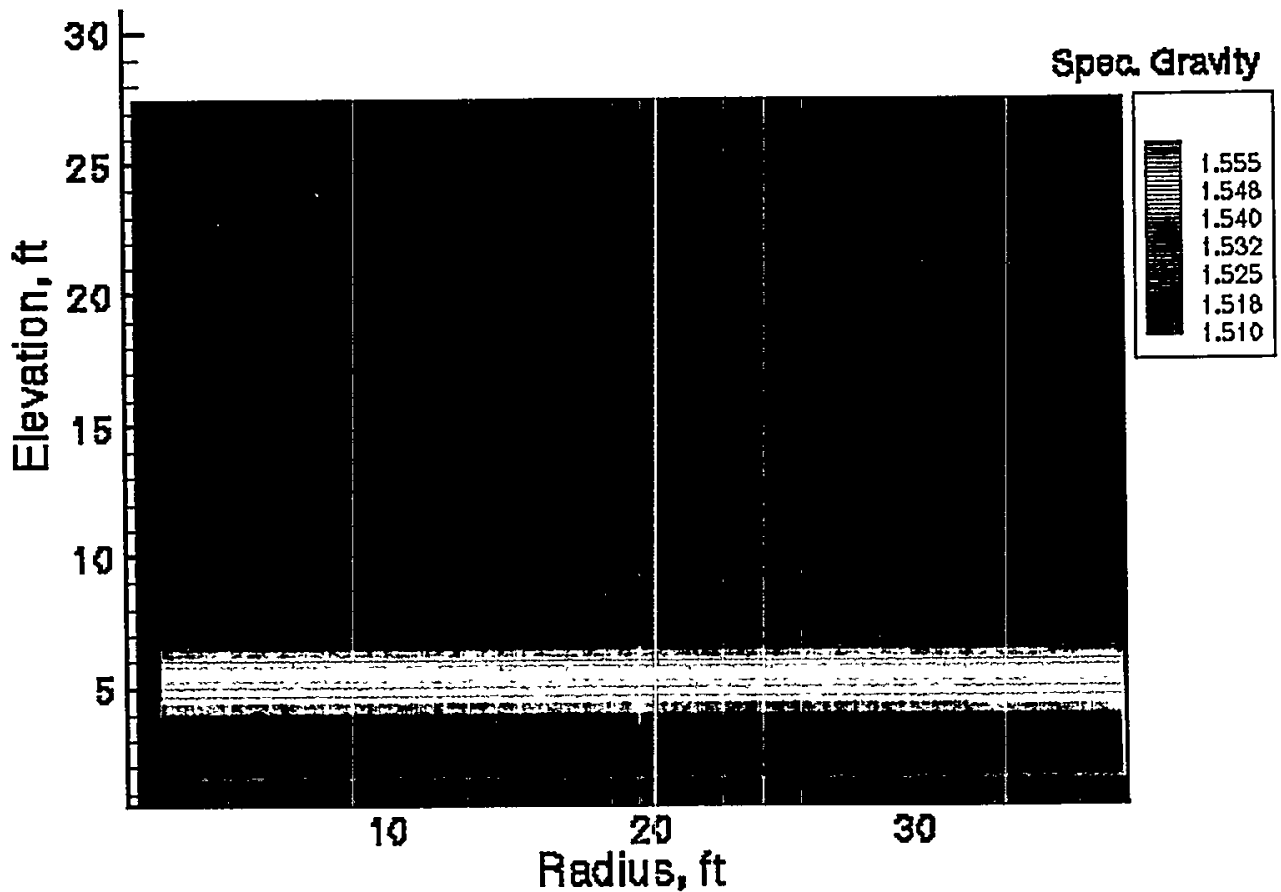

Figure 3.1.2. 100 -gpm Inflow at 96-in. Elevation of Transfer Pump Inlet into $100-\mathrm{cP}^{\circ}$ Slurry (density-dependent viscosity) at $20 \mathrm{~h}$ 


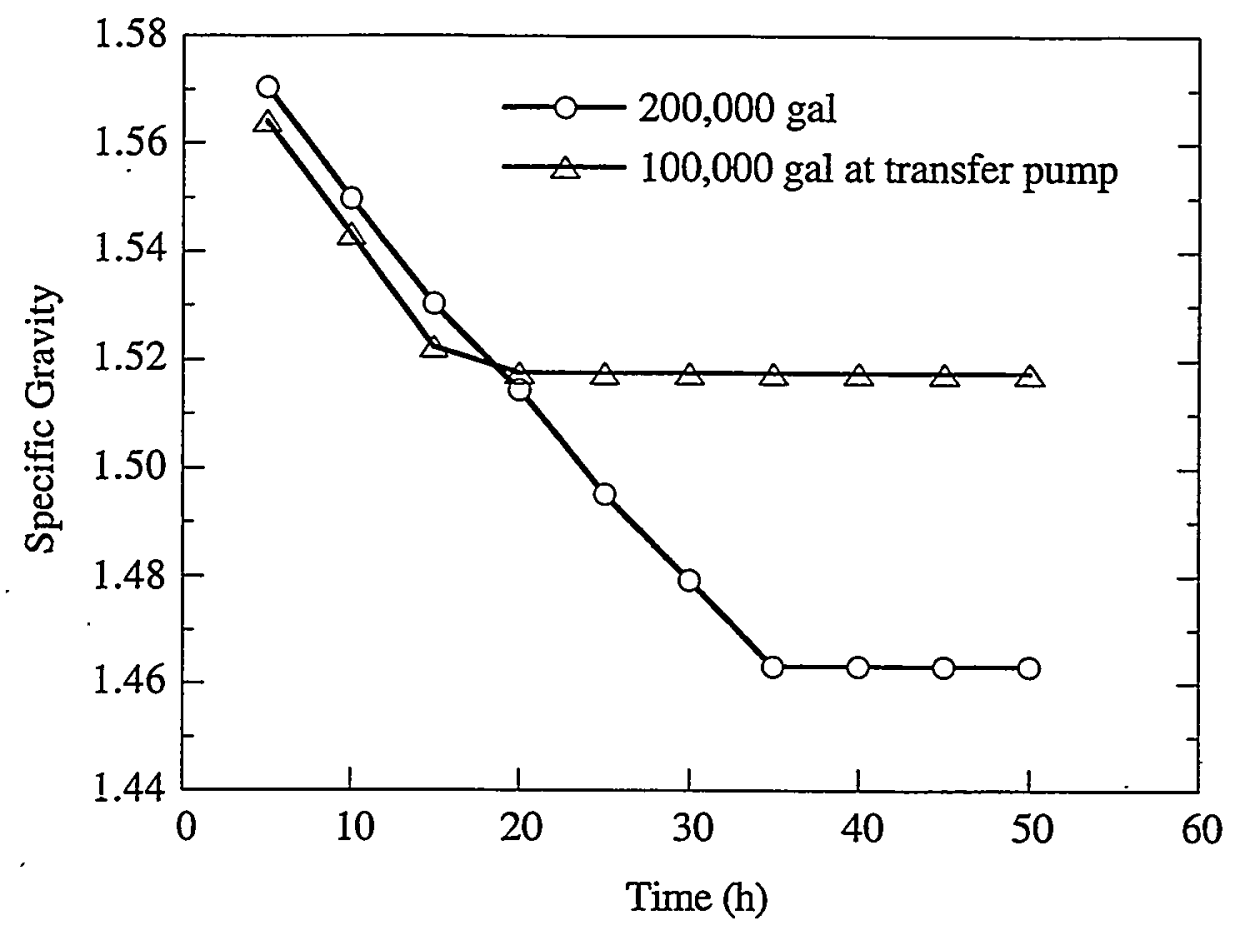

Figure 3.1.3. Minimum Mixture Specific Gravity as a Function of Time (100 gpm flow rate)

The most likely feed point for bottom additions is the transfer pump inlet at 96-inch elevation. Figure 3.1.2 and Table 3.1.1 show minimum and maximum mixed slurry specific gravity values. of 1.52 and 1.56 for this case, which most closely represents the expected conditions of the first transfer (see results for 100-gpm, 96-inch elevation). As noted in Section 2.4, the ratio of the two values is defined as a stratification factor. In this case it has a value of 0.97 . The stratification factor was $>0.98$ for all the 24-inch elevation addition scenarios. In Figure 3.1.3, the trend of linearly decreasing minimum mixed slurry density during the addition period (16.7 hours for 100,000 gal and 33.3 hours for 200,000 gal) suggests consistent mixing effectiveness. Therefore, the stratification factors for smaller transfer and back-dilution volumes for a given set of conditions should be equally as good. The stratification factor could be no worse than the ratio of the minimum density (e.g., Figure 3.1.3) and the initial slurry density.

The simulation results presented above show that mixing of the water and waste is rapid, and the water does not pool under the crust. Mixing is somewhat less complete with water injection at the transfer pump, which is about six feet higher than the assumed base of the mixer pump. The rates of water inflow had only a minor influence on mixing if one accounts for the different inflow duration. That is, 100 hours after the beginning of back-dilution there is little to distinguish among all the cases with the same water injection location. The initial waste viscosity also plays a very minor role in the mixing process, and its influence can be ignored.

An alternative method using hand calculations with equations described by Epstein and Burelbach (1998) was used to estimate mixing of the back-dilution water "plume." These equations only approximate the mixing process by assuming a circular plume released into a radially infinite medium and do not include real geometry, fluid viscosity, or water accumulation effects. Nevertheless, as a bounding check, these calculations also indicate that mixing is rapid, and the 
specific gravity of the mixture beneath the crust approaches the 1.60 specific gravity of the undiluted slurry (see Table 3.1.2). These specific gravity values compare favorably with TEMPEST results, calculated approximately 60 seconds after the initiation of back-dilution when the flow field had established itself, but the total back-dilution volume was still low. This is also evident from backward extrapolation of results in Figure 3.1.3.

Table 3.1.2. Comparison of Calculated Mixture Specific Gravity under the Crust at Start of Back-Dilution

\begin{tabular}{|c|c|c|c|c|}
\hline \multirow{2}{*}{$\begin{array}{c}\text { Slurry } \\
\text { viscosity } \\
(\mathrm{cP})\end{array}$} & \multirow{2}{*}{$\begin{array}{c}\text { Flow } \\
(\mathrm{gpm})\end{array}$} & $\begin{array}{c}\text { Inflow } \\
\text { elevation (in) }\end{array}$ & $\begin{array}{c}\text { Method of Epstein and } \\
\text { Burelbach (1998) }\end{array}$ & $\begin{array}{c}\text { TEMPEST } \leq 60 \text { seconds } \\
\text { after starting back- } \\
\text { dilution flow }\end{array}$ \\
\hline 100 & 30 & 24 & 1.598 & 1.596 \\
\hline 100 & 500 & 24 & 1.593 & 1.596 \\
\hline 100 & 30 & 96 & 1.597 & 1.596 \\
\hline
\end{tabular}

\subsection{Mixer Pump Effect on Slurry Layer Stratification}

While the results of Section 3.1 indicate that a significant stratification of the slurry layer is unlikely when water is added at the 96 -in. elevation, a gradient in slurry density developed. If water were added higher in the tank, say in the vicinity of the mixer pump inlet (235- to 270-in. elevation), a much more significant stratification would be established with a relatively dilute, low-density slurry on top and in contact with the crust. A stratified liquid density configuration is a stable condition that must be overcome if further mixing of the waste is desired. The resistance to mixing is a function of the degree of stratification. The purpose of this study is to predict the degree of mixing to be expected from 25 -min mixer pump runs after back-dilution with 100,000 gal of water in a "most challenging" stratification scenario. The modeling approach is described in Section 3.2.1, and the results are presented in Section 3.2.2.

\subsubsection{Modeling Approach}

To evaluate the effectiveness of pump-jet mixing of the stratified waste, the mixing process was simulated using the TEMPEST code (Trent and Eyler 1993). The 3-D model domain included the volume from tank centerline to the tank wall and from tank bottom to the lower surface of the floating crust. The pump-jet angle was fixed for the duration of the 25-minute model pump runs. This enabled 90 -degree (1/4 tank) symmetry to be used for the model geometry. Because of the 1/4 tank assumption, only one of the opposing jets of the mixer pump is included in the model. The grid contained 21 radial, 28 vertical, and 13 azimuthal cells. In the computations, the continuity and momentum equations were solved but the energy equation was not because the problem was assumed to be isothermal at a temperature of $50^{\circ} \mathrm{C}\left(120^{\circ} \mathrm{F}\right)$. This analysis also assumes no dissolution of crust solids by the adjacent slurry. These simplifications isolate the scope of the computations to that of density stratification in opposition to jet mixing. 
For this analysis, it was assumed that the waste depth to the crust base was 297 in. (near the 295-in. target minimum for transfer/back-dilution processes) and configured in three distinct strata. The initial conditions of these strata for the transient TEMPEST simulation are summarized in Table 3.2.1. The strata included a 53-in. loosely settled solids layer with a density of $1700 \mathrm{~kg} / \mathrm{m}^{3}$ at tank bottom. This layer was assumed to have no yield strength, so some mixing would be expected due to fluid motion induced by the pump jets. A region of undiluted slurry 69 -in. deep with a density of $1560 \mathrm{~kg} / \mathrm{m}^{3}$ was assumed to reside immediately above the settled solids layer. The third stratum, from 122 to 297 in., was assumed to have a density of $1430 \mathrm{~kg} / \mathrm{m}^{3}$. This density was selected because it was near the lower limit necessary to float the crust (Section 2.4), an extreme case. The strata levels were established assuming a transfer and back-dilution in which the water mixed perfectly with the slurry above $122 \mathrm{in}$. and the strata below were unchanged by the water addition. This established a worst-case stratification for bottom addition. (In the real process it is more likely that the density variation would start near an injection point at 96 -in. elevation.) In the TEMPEST model, the $1430 \mathrm{~kg} / \mathrm{m}^{3}$ fluid of the uppermost stratum was established as the base fluid. A solid of $2300 \mathrm{~kg} / \mathrm{m}^{3}$ density was then added to modify the densities and viscosities of the other strata. This solid species was given zero settling velocity and acted essentially as a passive scalar in the computations. The model fluid density increased linearly with solids concentration, and the functional dependence on solid concentration for the viscosity was exponential. A baseline viscosity of $1000 \mathrm{cP}$ was chosen for the mid-level slurry.

In the model, the pump nozzle was located $28 \mathrm{in.} \mathrm{from} \mathrm{tank} \mathrm{bottom.} \mathrm{Intake} \mathrm{for} \mathrm{the} \mathrm{pump} \mathrm{was}$ at the 235-in. level in the uppermost stratum. It wás assumed that operation of the mixer pump at $920-\mathrm{rpm}$ results in jet velocity of $18.3 \mathrm{~m} / \mathrm{s}(60 \mathrm{ft} / \mathrm{s})$ (Allemann et al. 1994). ${ }^{(\mathrm{a})}$ During the simulation, less dense liquid from the intake above was injected to the tank at $60 \mathrm{ft} / \mathrm{s}$ through the 2.6-in.-diameter nozzle to provide momentum for mixing.

Table 3.2.1. Model Assumptions for Waste Stratification

\begin{tabular}{|c|c|c|c|}
\hline Strata & Level (in.) & Density $\left(\mathrm{kg} / \mathrm{m}^{3}\right)$ & Viscosity (cP) \\
\hline Slurry/Water Mix & $122-297$ & 1430 & 180 \\
\hline Slurry & $53-122$ & 1560 & 1000 \\
\hline Settled Solids & $0-53$ & 1700 & 6340 \\
\hline
\end{tabular}

\subsubsection{Simulation Results}

Figure 3.2.1 shows the density distribution in a vertical plane containing the pump jet after 25 -min of jet-pump mixing. The color legend gives the density range from 1430 to $1580 \mathrm{~kg} / \mathrm{m}^{3}$. Included in the $1580 \mathrm{~kg} / \mathrm{m}^{3}$ contour level is the material with density up to $1697 \mathrm{~kg} / \mathrm{m}^{3}$ near the tank bottom-reduced only slightly from the initial value of $1700 \mathrm{~kg} / \mathrm{m}^{3}$. In the figure, the pump intake is at the upper left and the pump jet is at the lower left. The buoyant jet entrains and

(a) The mixer pump in SY-101 is typically operated at $1000 \mathrm{rpm}$, corresponding to a jet velocity of $19.8 \mathrm{~m} / \mathrm{s}$. The lower value specified in this analysis $(18.3 \mathrm{~m} / \mathrm{s})$ reduces somewhat the effectiveness of the mixing, but the overall trends and conclusions are not changed. 

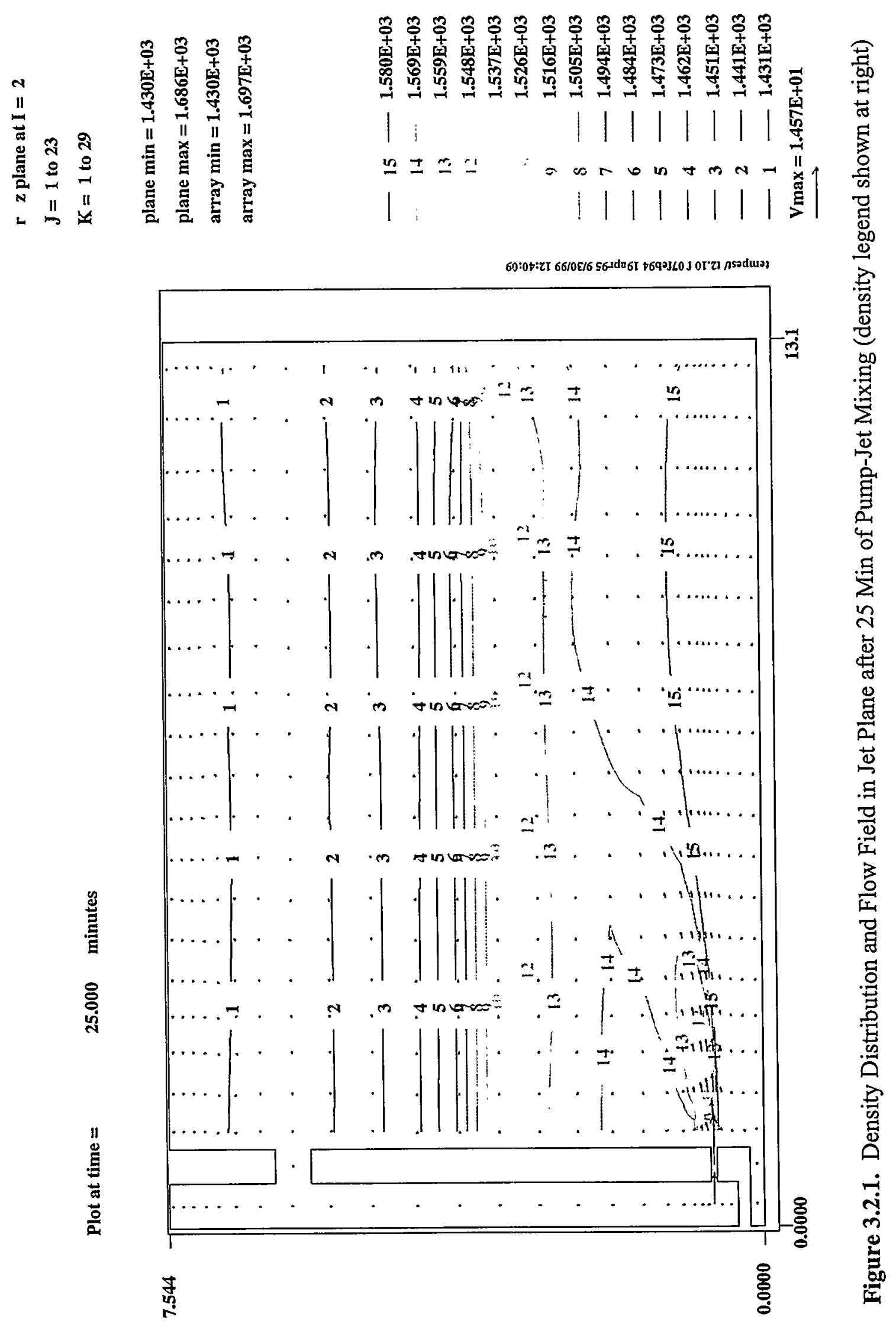
mixes with the surrounding liquid while it expands and loses momentum. At roughly 5-m (15-ft) radius, the momentum has dissipated and the density of the fluid in the jet has increased to that of the surrounding liquid $\left(1560 \mathrm{~kg} / \mathrm{m}^{3}\right)$. Mixing has virtually ceased, and the less dense liquid above is merely being displaced upward to the pump intake. These results for jet diffusion are consistent with the work of Abraham (1963). A single 25-min, 920-rpm pump run results in 6\% of the total waste volume being displaced through the mixer pump. This suggests that numerous pump runs may be necessary to mix the waste through simple volume displacement.

Figure 3.2.2 again shows the density distribution and flow field after 25-min of pump mixing, but this figure represents a vertical plane rotated 8.5 degrees from that in Figure 3.2.1. A non-stratified case would show considerable upward fluid motion at the tank wall. In this case, the flow is concentrated in the lower regions and shows very little vertical fluid motion. The scale of this circulating flow from the simulation results is about $0.2 \mathrm{~m} / \mathrm{s}$. The lack of vertical motion indicates a resistance to mixing due to stratification.

After five 25-min pump runs, a substantial amount of mixing had occurred. The endpoint parameters of a previous pump run were set as the initial parameters in the subsequent pump run. Thus changes that typically occur between actual tank pump runs (e.g., particle settling) were neglected. In this way, the model results of multiple pump runs are equivalent to the results of a continuous pump run of the cumulative duration. Figure 3.2.3 shows the density distribution and flow field after $125 \mathrm{~min}$ of pump mixing. Like Figure 3.2.2, this is in a vertical plane rotated 8.5 degrees from that in Figure 3.2.1. There is now considerable upward fluid motion at the tank wall because the stratification has been removed for the volume of waste between the jet and pump intake levels. The upper stratified region has been reduced and is limited to the region above the pump intake. This result is also shown in Figure 3.2.4, which plots the density versus height from the tank bottom for each 25-min pump run. Densities given in Figure 3.2.4 are taken at a vertical row of cells at mid-radius and are representative of those averaged over the tank area. The solid red line shows the initial condition. At $25 \mathrm{~min}$ (dashed blue line) some mixing has occurred at mid-waste level, but the densities at the tank bottom and adjacent to the crust are virtually unchanged. The density becomes more uniform, particularly below the pump inlet. By the end of the fifth run $(125 \mathrm{~min})$ the density ranges from 1520 to $1526 \mathrm{~kg} / \mathrm{m}^{3}$ between the pump jet and intake levels with a minimum density of $1431 \mathrm{~kg} / \mathrm{m}^{3}$ near the crust and maximum of $1539^{\circ} \mathrm{kg} / \mathrm{m}^{3}$ at the tank bottom. In the fully mixed condition for this case, the bulk waste density would be $1508 \mathrm{~kg} / \mathrm{m}^{3}$ (dashed gray line). After mixer pump runs totaling $125 \mathrm{~min}, 31 \%$ of the liquid waste volume has been displaced from the upper regions and through the pump jets. The displacement of this waste volume coupled with the momentum provided the waste by the pump has mixed a large portion of the waste below the pump intake. The last two pump runs of Figure 3.2 .4 (100 and $125 \mathrm{~min}$ ) indicate a diminishing pump effectiveness for mixing the liquid above the pump inlet.

With exception of this uppermost slurry region, the slurry density is within $2 \%$ of the fully mixed value. While the density gradient in the upper region is reduced with each successive pump run (Figure 3.2.4), the stratification there is clearly much more stable than in the lower regions. A stability analysis of the stratification can be determined using the Richardson number (Schlichting 1979). 
r $z$ plane at $I=4$

$J=1$ to 23

$K=1$ to 29

plane $\min =1.430 \mathrm{E}+03$ plane $\max =1.689 \mathrm{E}+03$ array $\min =1.430 \mathrm{E}+03$ array $\max =1.697 \mathrm{E}+03$

$\begin{array}{rrr}-15 & 1.580 \mathrm{E}+03 \\ 14 & 1.569 \mathrm{E}+03 \\ 1.3 & 1.559 \mathrm{E}+03 \\ 12 & 1.548 \mathrm{E}+03 \\ & 1.537 \mathrm{E}+03 \\ \vdots & 1.526 \mathrm{E}+03 \\ -9 & -1.516 \mathrm{E}+03 \\ -8 & -1.505 \mathrm{E}+03 \\ -7 & -1.494 \mathrm{E}+03 \\ -6 & -1.484 \mathrm{E}+03 \\ -5 & -1.473 \mathrm{E}+03 \\ -4 & -1.462 \mathrm{E}+03 \\ -3 & -1.451 \mathrm{E}+03 \\ -2 & -1.441 \mathrm{E}+03 \\ -1 & 1.431 \mathrm{E}+03 \\ V \max =2.426 \mathrm{E} & 01\end{array}$
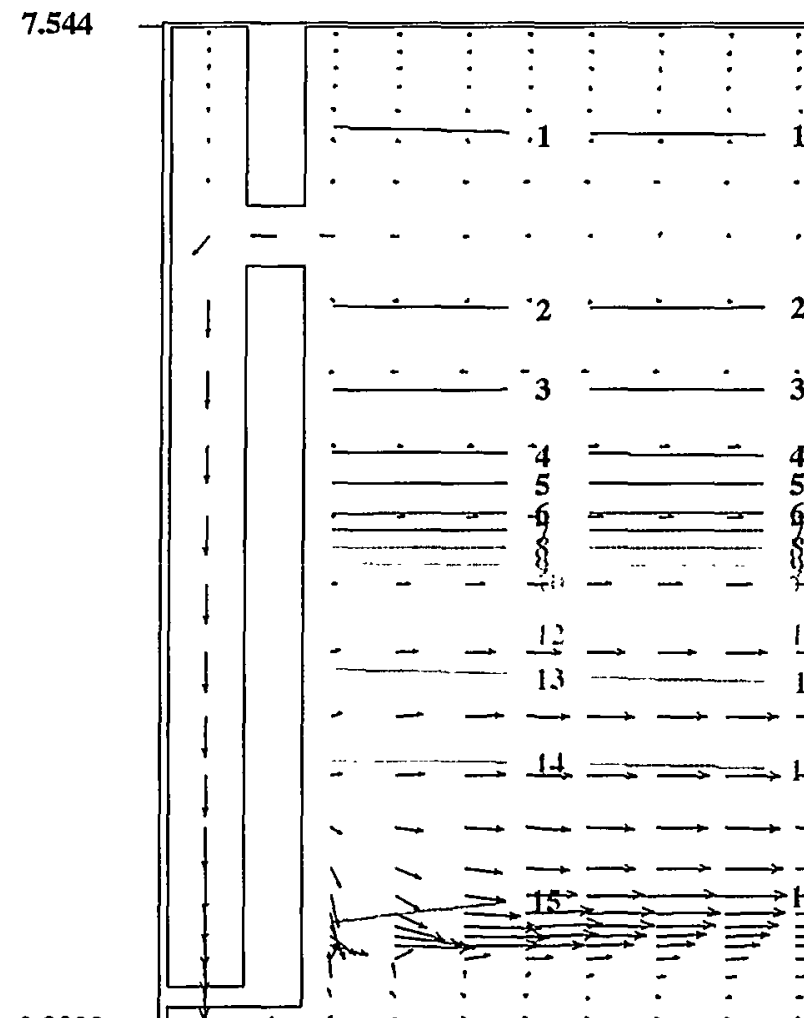

1.
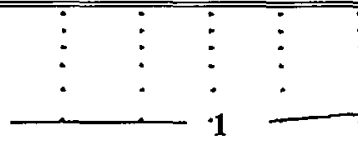

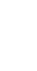

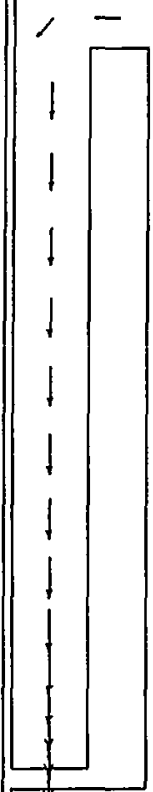

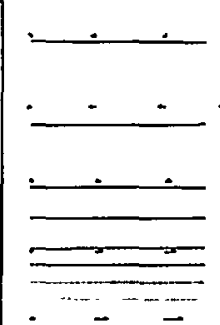

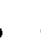

2

$\dot{3}$

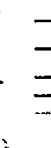

$\bar{\square}$

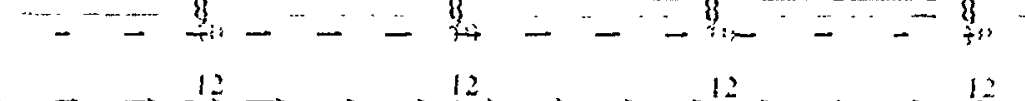

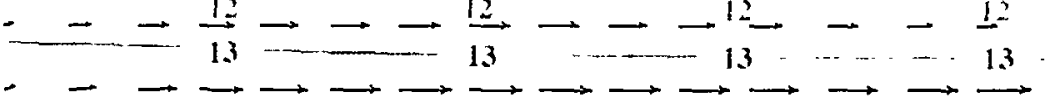

$\because-\Rightarrow 14$

$i$

0.0000

Figure 3.2.2. Density Distribution and Flow Field in Plane 8.5 Degrees from Jet Plane after 25 Min of Pump-Jet Mixing (density legend shown at right) 


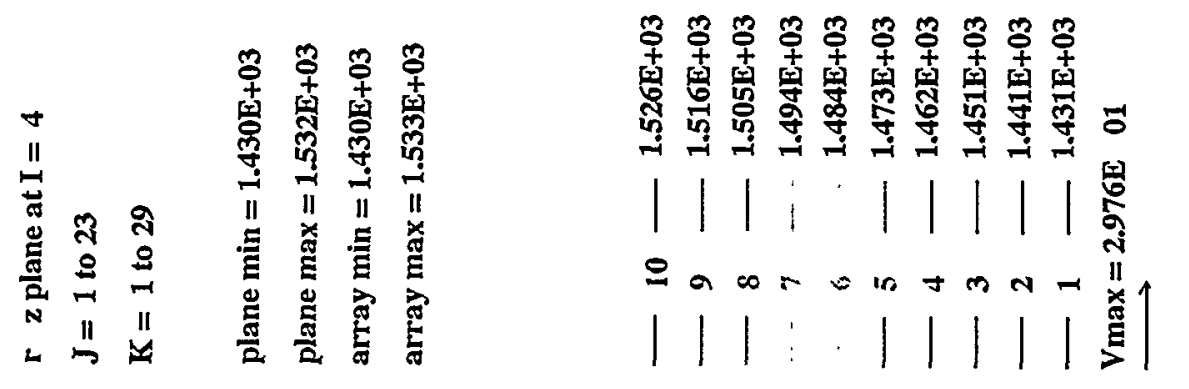

是

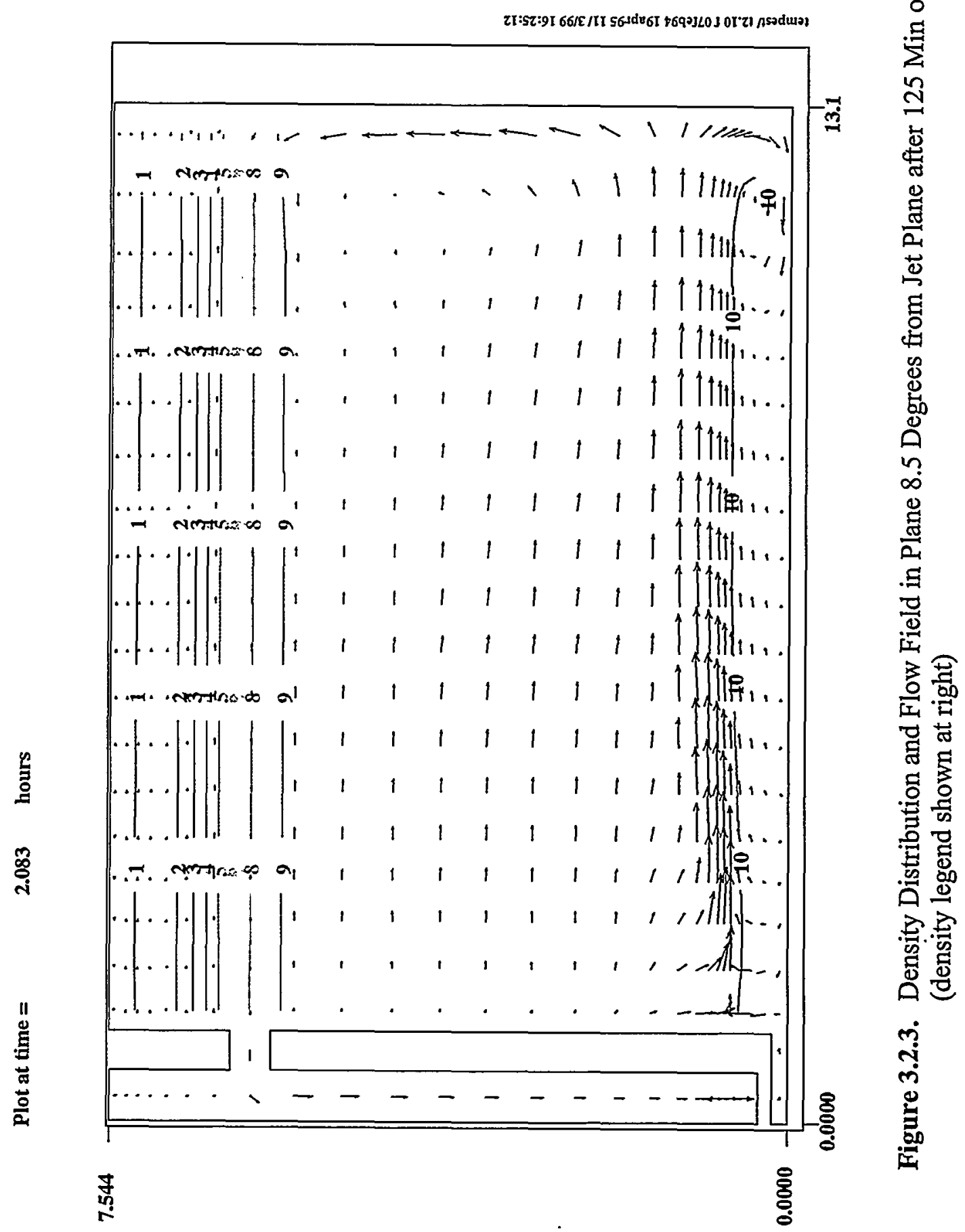




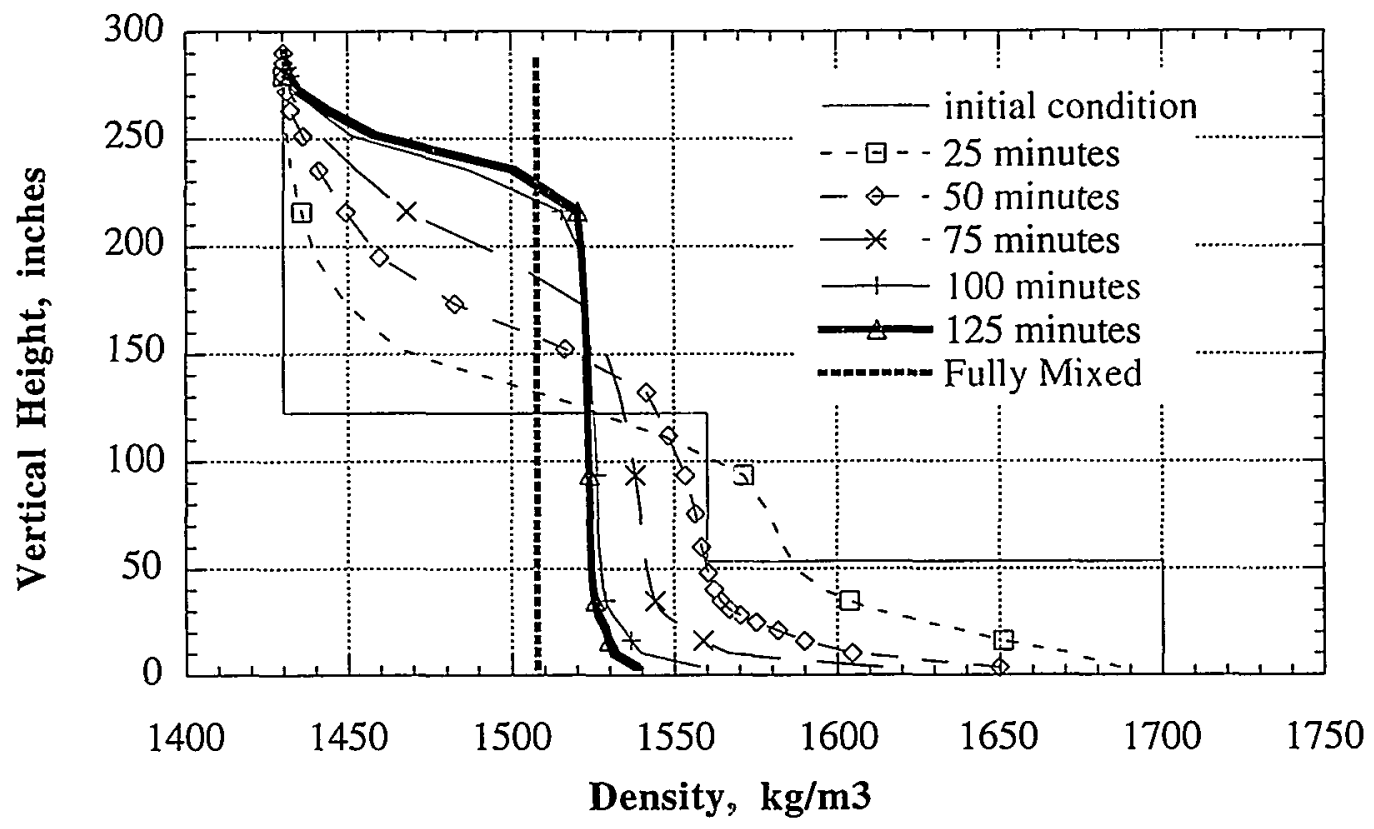

Figure 3.2.4. Vertical Density Distribution at 25-minute Intervals of the Mixing Process

$$
R i=\frac{-g}{\rho} \frac{d \rho}{d y} /\left[\left.\frac{d u}{d y}\right|_{w}\right]^{2}
$$

Here $g$ is the acceleration due to gravity, $\rho$ is the density, $y$ is the height of the stratum, and du/dy is the velocity gradient at the wall. The positive direction of $y$ is measured vertically upwards. Large $\mathrm{Ri}$ indicates a very stable and laminar condition. The lower limit of stability is for $\mathrm{Ri}>$ 0.042. $\mathrm{Ri}=0$ corresponds to a homogeneous fluid, and when $\mathrm{Ri}<0$ the stratification is unstable (Schlichting 1979). In this case, $y$ is the height of the uppermost stratum, and $d \rho$ is the density difference of the upper and middle regions. As noted in discussion of Figures 3.2.1 to 3.2.2, 0.2 $\mathrm{m} / \mathrm{s}$ is a representative velocity of the flow field. For these conditions $\mathrm{Ri}^{-} 1.2$ and the upper region is stable with respect to the middle and lower regions. Stratification in this case is such that the waste is stable in the presence of a mixer pump induced flow field and, similar to the earlier discussion, indicates that further pump-jet mixing may have only limited impact on the liquid stratum above the pump inlet.

The TEMPEST and Richardson number analyses did not consider thermal or dissolution effects on the stratified layer. The thermal effect may be considered negligible because of a relatively small temperature gradient in the convective region and correspondingly small density changes with temperature compared with the magnitude of the density gradient in the stratified upper region. The thermal effect would tend to reduce the stratification as lower density (higher temperature) waste lower in the tank rises into colder fluid near the crust. More importantly, dissolution of the lower crust solids in contact with lower-density, unsaturated diluent above the pump intake would saturate the liquid further and mix the stratified layer due to buoyant effects. 
In summary, the results of Section 3.1 show that water introduced into the tank through the dilution line at the inlet of the transfer pump will be relatively well mixed with the lower waste layers and will not pool as pure water into a stratified layer below the crust. The mixing during water addition results in a slurry layer with a slight density stratification, varying by less than $2 \%$ from bottom to top. Because of the effectiveness of this mixing, more water can be added without risk of sinking the crust (provided slurry solids are quickly dissolved; Section 5.2.2), and greater volumes of water must be added (low in the tank) to create sub-saturated slurry capable of dissolving crust solids, when so desired.

If a low density stratified layer forms between the crust and the mixer pump intake, either due to poorer than expected mixing during back-dilution or created intentionally by addition high in the slurry layer, the layer will resist mixing by the jet pump. As noted above, any crust dissolution adjacent to the stratified slurry layer would tend to ameliorate the effect. The mixer pump alone may be only minimally effective over time at homogenizing a stratification above the pump inlet, but it is clearly capable of mixing the waste below the inlet level through displacement of waste from the intake to the bottom of the tank. 


\subsection{Crust Sinking and Gas Release}

The consequences of crust sinking in terms of gas release and ability of the mixer pump to remobilize it are discussed in this section. Section 4.1 presents the results of modeling and analysis of the possibility of gas release due to failure of the crust if it were to sink intact or as large chunks, without dissolving. In Section 4.2, analyses are presented of the relationship between crust strength and the ability of the mixer pump to affect sunken crust. Section 4.3 contains an analysis of the potential for buoyant displacement gas release from sunken crust should it be unaffected by the mixer pump and continue to accumulate gas.

\subsection{Evaluation of Potential for Gas Release During Crust Sinking}

The gas release model developed previously (Meyer et al. 1997) considers the work done on a "gob" of the nonconvective layer when buoyant potential energy is released as it rises to the surface and compares that energy to the energy needed to yield the material. The two tie together because the change in elevation means that there is a change in pressure in the gas trapped within the gob that may be sufficient to force the gas out of the material. Data from laboratory-scale experiments and observations of the six tanks demonstrating buoyant displacement gas releases indicate that the ratio of these two energies must be greater than about 6 for an energetic gas release to occur and greater than $\sim 4$ for limited gas release.

Turning the logic of this model to crust sinking, we can see that the situation is similar in that the change in elevation means that the pressure "seen" by the gas in the crust changes. The main difference between the two situations is that, rather than a decrease in external pressure expanding the gas-bearing material, the pressure increase compresses the crust as it sinks. This possibility has been ignored as a possible source of gas release. In fact, crust sinking has been identified as the point at which gas release stops (Meyer et al. 1997). However, because the crust layer in SY-101 contains a large volume of gas, it is prudent to investigate this matter.

This section documents the application of the energy ratio gas release model to the sinking crust. Section 4.1.1 presents the modifications to the model formulation that are needed to describe the physical configuration of the sinking crust as opposed to a rising gob of nonconvective material. An analysis of possible crust failure during sinking using the model for a range of estimated values of the crust yield stress is presented in Section 4.1.2.

\subsubsection{Energy Model for Sinking Crust}

The gas release model, which defines criteria for buoyant displacement gas release based on the ratio of the energy of position to the energy required to yield the material, should be applicable to the sinking crust with appropriate modifications in the derivation of the energy terms. Figure 4.1.1 is a schematic depicting the situation just before and just after the crust sinks, assuming it sinks as a single entity. The initial condition (part $a$ of the figure) assumes the crust is barely floating, almost entirely submerged, with the crust surface level with the liquid surface. This means that any gas in the pores of the crust freeboard has been displaced by liquid, and the only gas in the crust is that trapped in bubbles in the material below the freeboard. The 


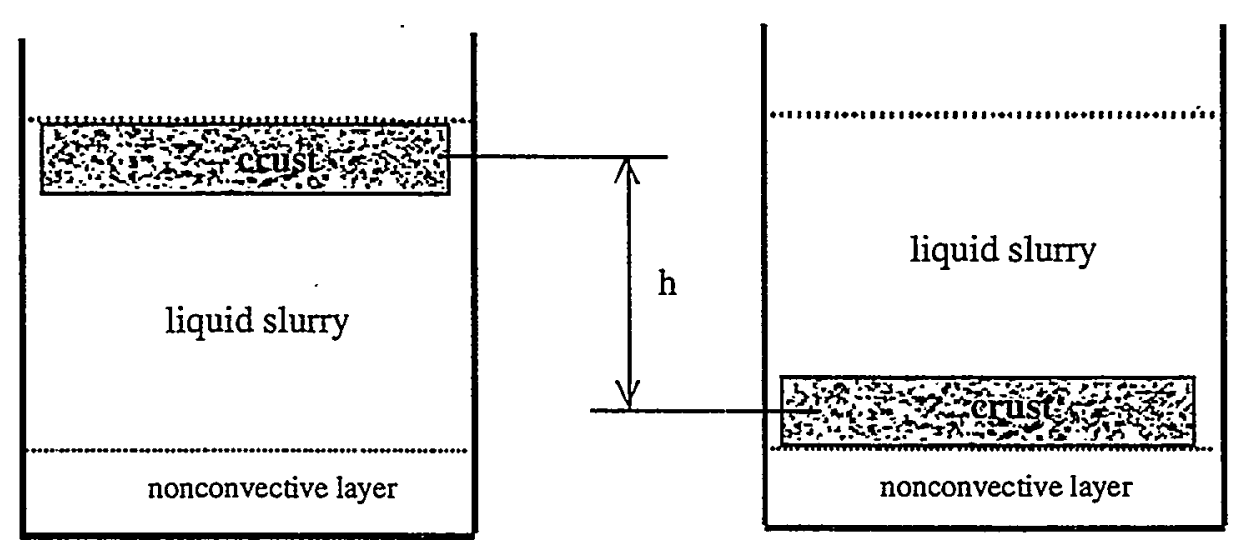

(a) initial state

(b) final state

Figure 4.1.1. Diagram of Sinking Crust

final condition (part $b$ of the figure) has the crust resting on the nonconvective layer, estimated to be about $6.9 \mathrm{~m}$ below its initial position. The sinking process is assumed to be sufficiently rapid that the crust temperature remains constant. No thermally induced dissolution occurs to reduce the material yield stress. This mechanism for weakening the sunken crust is a mitigating factor, however, in mobilization by the mixer pump discussed in Section 4.2.

While Figure 4.1.1 depicts the crust sinking without breakup, this is not a requirement of the energy ratio analysis. The analysis is also valid for gobs of sinking crust that either originated as individual free-floating wastebergs or were created in the sinking process. Such breakups of crust material as it sinks could occur by mechanisms other than those exceeding the yield criterion under consideration here. For example, other mechanical instabilities, such as local variations in buoyant load on the crust due to inhomogeneity in crust structure or interaction with tank hardware, could result in some breakup. Other assumptions implicit in the figure are that the slurry density throughout the liquid layer is not sufficient to float the crust and that there is no dissolution of crust material as it sinks. Some dissolution and commensurate reduction in crust volume is certain if enough back-dilution water is added to sink the crust. To simplify the derivation, the volume of sunken crust at the bottom of the tank is equal to the initial volume (except for changes in gas volume). The model provides a conservative assessment of the possibility of a consequent gas release due to failure of the crust as the gas is compressed.

The potential energy change is essentially the work done in sinking the crust and can be calculated by integrating the force balance on the crust over the distance it sinks:

$$
E_{b}=\int_{h}^{0} F(z) d z
$$


The force balance on the crust is simply the balance between the weight of the fluid displaced by the crust and the weight of the crust. Neglecting the weight of the gas in the crust, this can be expressed as a function of position:

$$
F(z)=\rho_{L} V_{c}(z) g-\rho_{s} V_{N G} g
$$

where

$$
\begin{aligned}
\rho_{\mathrm{L}} & =\text { liquid density, } \mathrm{kg} / \mathrm{m}^{3} \text { (assumed constant) } \\
\rho_{\mathrm{s}} & =\text { density of non-gas crust material, } \mathrm{kg} / \mathrm{m}^{3} \\
V_{\mathrm{c}}(\mathrm{z}) & =\text { volume of liquid displaced by the crust, } \mathrm{m}^{3} \\
\mathrm{~V}_{\mathrm{NG}} & =\text { volume of non-gas crust material, } \mathrm{m}^{3} \\
\mathrm{~g} & =\text { acceleration due to gravity }\left(9.81 \mathrm{~m} / \mathrm{s}^{2}\right) .
\end{aligned}
$$

The only term in Equation 4.1.2 that varies with position is the volume of liquid displaced by the crust. This varies as

$$
\mathrm{V}_{\mathrm{c}}(\mathrm{z})=\mathrm{V}_{\mathrm{NG}}+\mathrm{V}_{\mathrm{gas}}(\mathrm{z})
$$

The only. part of the total crust volume $V_{c}(z)$ that varies with depth is the volume of the trapped gas. Using the equation of state, this can be related to the pressure change with depth, and the integral gives (after some algebraic manipulation)

$$
E_{b}=\int_{h}^{0} F(z) d z=P_{a m b} \alpha_{0} V_{c 0} \ln \left(\frac{1}{(1+\gamma)}\right)+\left(\rho_{s}-\rho_{L}\right) V_{N G} h g
$$

where

$$
\begin{aligned}
& \mathrm{P}_{\text {amb }}=\text { ambient pressure in tank headspace, } \mathrm{Pa} \\
& \alpha_{0}=\text { submerged crust void fraction } \\
& \mathrm{V}_{\mathrm{c} 0}=\text { volume of crust when just submerged, } \mathrm{m}^{3} \\
& \mathrm{H}=\text { distance the crust sinks, } \mathrm{m} \\
& \gamma \quad=\rho_{\mathrm{Lgh}} / \mathrm{P}_{\mathrm{amb}} .
\end{aligned}
$$

We now have $E_{b}$ in terms of known quantities because the volume of the non-gas material in the crust can be expressed in terms of the initial crust volume using the crust submerged void fraction $\alpha_{0}$ :

$$
\mathrm{V}_{\mathrm{NG}}=\left(1-\alpha_{0}\right) \mathrm{V}_{\mathrm{co}}
$$

To apply the gas release model, we also need to determine the energy, $E_{y}$, required to liberate the gas from the crust. As given by Meyer et al. (1997), the energy required to yield the material can be expressed as

$$
E_{y}=V_{N G} \int_{0}^{\varepsilon_{y}} \tau_{y} d \varepsilon
$$

where 
$\tau_{\mathrm{y}}=$ yield stress in shear

$\varepsilon_{y}=$ strain at failure. This can be integrated to give

$$
E_{y}=V_{N G} \varepsilon_{y} \tau_{y}=V_{c 0}\left(1-\alpha_{0}\right) \varepsilon_{y} \tau_{y}
$$

The energy ratio can therefore be expressed as

$$
\frac{E_{b}}{E_{y}}=\frac{P_{a m b}\left[\alpha_{0} \ln \left(\frac{1}{(1+\gamma)}\right)+\gamma\left(1-\alpha_{0}\right)\left(\frac{\rho_{S}}{\rho_{L}}-1\right)\right]}{\left(1-\alpha_{0}\right) \varepsilon_{y} \tau_{y}}
$$

where $\varepsilon_{y} \approx 1$ is the strain at thixotropic transition. The following section presents an application of this model.

\subsubsection{Application of the Model}

Estimates of crust yield stress in shear based on simulant studies and results of tank operations, including water lancing and application of the MMA, are available (Section 2.3). From this information, we have deduced that the crust shear strength varies from about 400 to $3000 \mathrm{~Pa}$ in the "paste" layer starting just above the weak bubble slurry at the base of the crust. The "wet clay "layer above the paste is assumed to have a shear strength of $>3000 \mathrm{~Pa}$. In the crust freeboard, the strength may be as high as $15,000 \mathrm{~Pa}$. However, this layer does not contain trapped flammable gases (Section 2.4) and so will not be considered further in this analysis.

Figure 4.1.2 shows the energy ratio as a function of the crust yield stress in shear. Table 4.1.1 lists the energy ratios (from Figure 4.1.2) for the minimum and maximum paste layer yield stress, as well as the yield stress in shear required to achieve limited and energetic gas releases based on the criteria of Section 4.1 (energy ratio greater than about 6 for an energetic gas release to occur and greater than $\sim 4$ for limited gas release). The following values were used for the model parameters:

$$
\begin{aligned}
\mathrm{P}_{\mathrm{amb}} & =101325 \mathrm{~Pa} \\
\alpha_{0} & =0.23 \\
\rho_{\mathrm{s}} & =1740 \mathrm{~kg} / \mathrm{m}^{3} \\
\rho_{\mathrm{L}} & =1410 \mathrm{~kg} / \mathrm{m}^{3} \\
\mathrm{~h} & =6.9 \mathrm{~m} .
\end{aligned}
$$

These values were obtained from buoyancy and back-dilution models used to evaluate various back-dilution scenarios (Stewart et al. 1999, Sect. 2.4). The liquid (slurry/diluent mixture) density, $\rho_{\mathrm{L}}$, is just slightly less than the (current) bulk average for the crust and is assumed to cause the crust to sink. It can be seen that the energy ratio (Eq. 4.1.8) is a strong function of the liquid density. As shown in Figure 4.1.2, less than a $1 \%$ change in the liquid density.results in a $25 \%$ change in the energy ratio. These results illustrate that the potential for gas release from the crust layer due to compression as it sinks is extremely dependent upon the waste configuration at the time of sinking. 


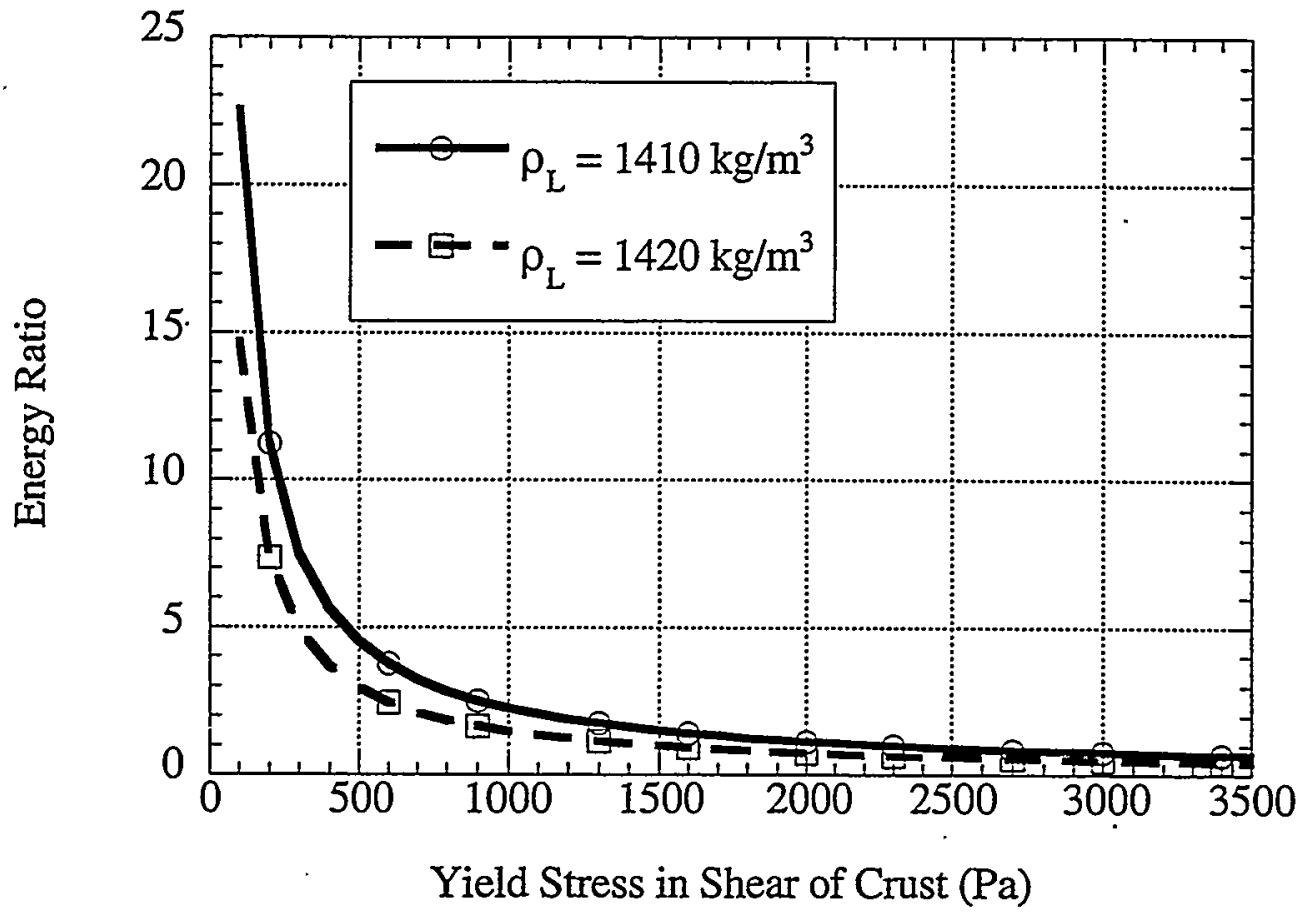

Figure 4.1.2. Energy Ratio as a Function of the Yield Stress in Shear of the Crust

It should be emphasized that a bulk liquid density as low as $1410 \mathrm{~kg} / \mathrm{m}^{3}$ requires very large waste transfer and back-dilution volumes, and it is extremely unlikely this low density will be achieved without significant reduction in the crust volume due to dissolution. As presented in Section 2.4.3, it is more likely the crust would sink at a higher slurry density following the dissolution of the high void-fraction bubble slurry layer. Because the energy ratio falls off rapidly with increasing liquid density (Figure 4.1.2), crust sinking at liquid densities $>1410 \mathrm{~kg} / \mathrm{m}^{3}$ does not appear to pose a gas release threat.

The results summarized in the table show that the crust is in general strong enough that it will not fail, and therefore will not release gas due to increased hydrostatic pressure if it sinks. However, some potential for gas release from the failure in shear of the weaker paste layer is possible if it sinks. The energy ratio for 400-Pa paste (5.6) exceeds the lower bound of 4, which

Table 4.1.1. Gas Release Predictions of Modified Gas Release Model for Sinking Crust $\left(\rho_{\mathrm{L}}=1410 \mathrm{~kg} / \mathrm{m}^{3}\right)$

\begin{tabular}{|c|l|c|c|}
\hline $\begin{array}{c}\text { Yield Stress in } \\
\text { Shear }(\mathbf{P a})\end{array}$ & \multicolumn{1}{|c|}{ Description } & $\mathbf{E}_{\mathbf{b}} / \mathbf{E}_{\mathbf{v}}$ & Gas Released? \\
\hline 375 & shear strength at energy ratio of 6 & 6 & yes, energetic \\
\hline 400 & shear strength (min.) in paste layer & 5.6 & possible, limited \\
\hline 563 & shear strength at energy ratio of 4 & 4 & possible, limited \\
\hline 3,000 & $\begin{array}{l}\text { shear strength (max.) in the paste } \\
\text { layer; shear strength (min.) in the } \\
\text { wet clay layer }\end{array}$ & 0.5 & no \\
\hline
\end{tabular}


indicates the possibility of limited gas release but does not exceed the upper bound of 6 in which larger gas releases are expected (Meyer et al. 1997). The paste layer material with shear strength in the 400- to 563-Pa range is expected to fail in the limited release mode. If it is assumed that the yield stress in shear in the paste layer varies linearly from 400 to $3,000 \mathrm{~Pa}$, the fraction of weaker paste material in this strength range $(400$ to $563 \mathrm{~Pa})$ is roughly $52 \mathrm{~m}^{3}$ or $\sim 6 \%$ of the overall paste layer thickness ( $~ 80$ in.). At $21 \%$ gas fraction (Section 2.4 ), this corresponds to a total gas volume of $11 \mathrm{~m}^{3}$ in the weak material. Even if all this gas were to release suddenly, which is clearly not expected for the moderate energy ratio, the domespace hydrogen concentration would not exceed the lower flammability limit. It is demonstrated in Section 6.5.2 that a sudden release more than an order of magnitude larger in volume is necessary to approach the LFL for conditions expected during the second back-dilution operation.

\subsection{Mobilization of Sunken Crust Material with the Mixer Pump}

After initial transfer and back-dilution operations, it will be necessary to continue to operate the mixer pump to prevent a return to BD GREs from the loosely settled nonconvective layer. (Pump operation is expected to continue until after sufficient water has been added to dissolve a majority of waste solids, thereby eliminating the potential for BD GREs.) One reason backdilution operations are planned is to ensure that the base of the floating crust layer will be lifted away from the mixer pump inlet, allowing continued pump operation. If the crust should sink to the bottom of the tank as a result of large or poorly mixed water addition, the jet mixer pump will be a key tool to attack it and release trapped gas.

There are two aspects to the problem of determining how effective the mixer pump will be in mobilizing solid material from the sunken crust. First, there is simply the question of how effectively the mixer pump can resuspend settled solids, assuming that the crust breaks up into solid particles similar to what is in the settled layer already. Second, if the crust sinks as a relatively intact mass, the question then becomes one of whether operation of the mixer pump will be able to break up the crust into pieces that could be suspended and then dissolved in unsaturated fluid. The effectiveness of the mixer pump action at mobilizing sunken crust material is investigated in this section. Section 4.2.1 describes the method used to analyze breakup of the sunken crust, and the results of this analysis considering the range of strength in crust material are presented in Section 4.2.2.

\subsubsection{Method of Analysis}

The ability of the mixer pump to mobilize waste has been investigated in some detail in various experimental and analytical studies at PNNL (Shekarriz et al. 1997). ${ }^{\text {(a) }}$ It was assumed that mobilization of settled solids in the waste was driven primarily by shear failure along the surface of the settled layer due to the force of the liquid jet from the mixer pump. Experiments were conducted with waste simulants of various compositions, with a range of shear strength and viscosity values. The information obtained in these studies was used to develop correlations for

(a) Additional information is found in two PNNL letter reports: (1) Powell MR, CL Fow, GA Whyatt, PA Scott, and CM Ruecker. 1990. Proposed Test Strategy for the Evaluation of Double-Shell Tank Sludge Mobilization; and (2) Shekarriz A, JN Chung, CT Crowe, and D Sprecher. 1998. Physics of Jet Mixing in Rheologically Complex Mixtures. 
an "effective cleaning radius" (ECR) of the jet. These defined a radius within which it could be assumed that solids would be mobilized and were expressed as a function of the shear strength, density, and viscosity of the waste.

The ECR correlations developed from the simulant experiments give reasonable results over the limited range of data available, predicting ECR values that tend to be inversely proportional to waste simulant shear strength. The correlations are not in general consistent with each other, however, and are supported by only a small amount of data. It is inadvisable to extrapolate outside the range of their respective data values, and the results obtained can be treated only as indicative of general performance and not as reliable predictions of waste mobilization in the tank. Use of these correlations was not deemed appropriate for sunken crust because of the high strength of some crust layers.

Given the weaknesses in the correlations derived from limited experimental data, it was necessary to look at the physics governing the behavior of a free jet, and derive a model from first principles. Within the tank, the jet from the mixer pump is not entirely free, since it is confined by the walls and the settled solids layer at the bottom of the tank. The behavior of a free jet provides an estimate of the lower performance bound of that of a confined jet, however. The forces generated by a confined jet will in general be somewhat greater than those of a comparable free jet, since a confined jet does not decay as rapidly with distance as a free jet with the same throat diameter and exit velocity.

The force exerted by a jet can be calculated, since the jet velocity downstream of the nozzle can be readily determined as a function of the jet centerline velocity. The jet centerline velocity can be expressed as an inverse linear function of distance from the jet origin (Tennekes and Lumley 1990):

$$
\mathrm{U}_{\mathrm{C}}(\mathrm{z})=\frac{6.4 \mathrm{U}_{0} \mathrm{D}_{0}}{\mathrm{z}}
$$

where

$$
\begin{aligned}
& U_{0}=\text { jet discharge velocity } \\
& D_{0}=\text { jet discharge diameter. }
\end{aligned}
$$

The relationship for centerline velocity is valid to 80 jet diameters (or more, based on Chassaing et al. 1994). The jet diameter is 2.6 in $(0.066 \mathrm{~m})$ (Allemann et al. 1994), so the relationship is valid to at least $5.3 \mathrm{~m}$. Here it is applied to the full tank radius $(11.4 \mathrm{~m})$. Once the local jet velocity is known, the pressure normal to the jet can be calculated from the kinetic energy of the jet:

$$
P_{j}=\frac{1}{2} \rho_{L}\left[U_{C}(z)\right]^{2}
$$

where $\rho_{L}=$ density of the pumped slurry. This pressure can then be compared with the shear strength of the waste to predict whether the force of the jet is enough to mobilize the waste. Local breakup of the sunken crust is assumed to occur when the hydrodynamic pressure generated in the waste, as it absorbs the kinetic energy of the mixer pump jet, exceeds the yield strength of the crust. 
This approach does not take into account the transient nature of crust disruption in response to the impact of the mixer pump jet. The model considers only a single waste parameter, shear strength, in determining crust behavior, and implicitly assumes that if it is exceeded, the crust will quickly and easily break up. In reality, of course, the excavation of the waste in the submerged crust and the settled solids layer will be a complex process and may require some time to be fully accomplished.

Experience with mixer pump operation in SY-101, especially during its first year of operation, demonstrates this point well. It required seven runs with the jet pointed at thermocouple tree in riser $17 \mathrm{~B}$ to finally mobilize deeper portions (i.e., down to 4-inch elevation) of the settled solids layer. This material had lain undisturbed for months or years (Brewster et al. 1995; Allemann et al. 1994; Stewart et al. 1994). For riser 17C, which is about $2.5 \mathrm{ft}$ farther from the pump nozzles than $17 \mathrm{~B}$, the waste was excavated only to a depth of about 16 inches after six pump runs. Numerous pump runs were necessary to mobilize the deepest layers. The yield strength of the material was only one of the parameters governing the behavior; mechanisms such as energy deposition, erosion, and resettling were also influential in the waste response.

The sunken crust may initially resist the force of the jet more than the "original" nonconvective settled solids, but it is unlikely that the long-term behavior will be significantly different. In general, it can be expected that mechanisms of erosion and energy deposition will tend to hasten the dissolution of the crust. If the jet is strong enough to break up the crust and suspend particulate solids, these solids will tend to dissolve fairly rapidly in unsaturated liquid (Section 5.2). Therefore, the greatest utility of this relatively simple crust mobilization model is to determine whether pump operation is sufficient to physically disrupt sunken crust.

\subsubsection{Crust Mobilization Results}

The analytical approach described above was evaluated for pump effectiveness at mobilizing sunken crust with shear strength values ranging from 100 to $>15,000 \mathrm{~Pa}$ covering the range of estimated crust shear strength (Section 2.3). The mixer pump jet exit velocity was specified as $19.8 \mathrm{~m} / \mathrm{s}(65 \mathrm{ft} / \mathrm{sec}$ ), corresponding to a typical impeller speed of $1000 \mathrm{rpm}$ (Allemann et al. 1994). Fluid densities were varied from $1600 \mathrm{~kg} / \mathrm{m}^{3}$ (current conditions) down to $1200 \mathrm{~kg} / \mathrm{m}^{3}$ (possible stratified conditions after a total $500-\mathrm{kgal}$ transfer and equal back-dilution). The hydrodynamic pressure due to the jet velocity along the centerline for these operating conditions is shown in Figure 4.2.1.

The plot in Figure 4.2.1 shows that if the waste has very low shear strength (e.g., on the order of $300 \mathrm{~Pa}$ ), the jet pressure will be significantly higher than the yield strength of the crust nearly to the tank wall $>11 \mathrm{~m}$ away. In that case, the crust along the jet axis would probably be broken up or mobilized by the operation of the pump, possibly in a single 25-min mixer pump run aimed in one direction. On the other hand, for waste as strong as that estimated for dry crust freeboard (over $10,000 \mathrm{~Pa}$ ), the jet pressure is higher than the yield strength of the crust only for less than $2 \mathrm{~m}(\sim 6 \mathrm{ft})$ along the jet axis. Very little material would be mobilized by pump operation, if the crust were that strong. The bulk of the current crust consists of the paste layer, estimated to range in shear strength from about 400 to $3000 \mathrm{~Pa}$ with an average value of $\sim 1700 \mathrm{~Pa}$. Figure 4.2.1 shows the average paste layer is likely to be disturbed to $\sim 6 \mathrm{~m}$ from the nozzle. 


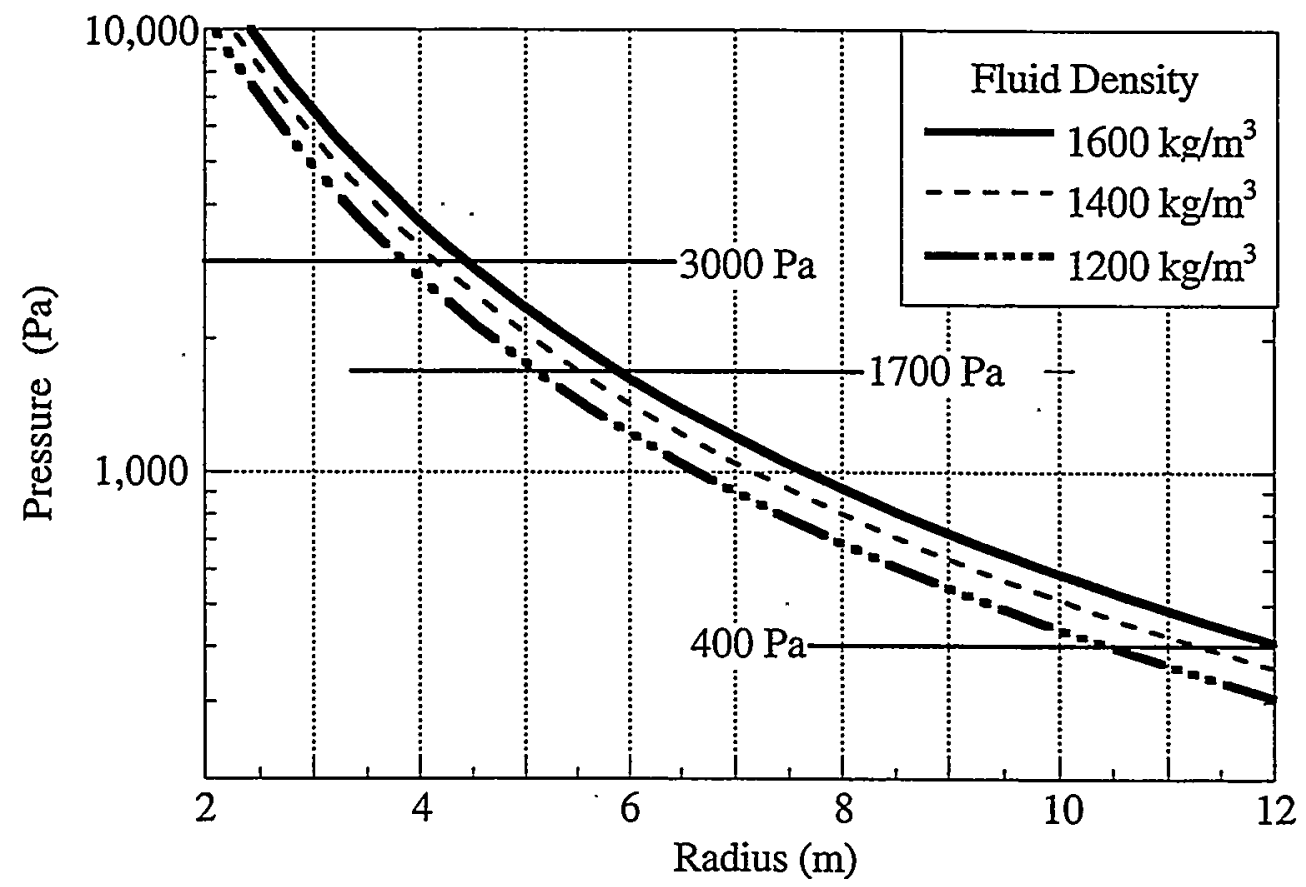

Figure 4.2.1. Mixer Pump Hydrodynamic Pressure as a Function of Distance from the Jet Nozzle $\left(U_{0}=19.8 \mathrm{~m} / \mathrm{s}\right)$

In consideration of gas releases associated with the mobilization of sunken crust, it is the volume of disturbed crust, not just the radius of pump effectiveness, that is important. The volume of crust that can be mobilized by the jet will depend greatly on what part of the crust the jet strikes, but an estimate of the disturbed volume can be obtained by plotting the jet volume as a function of shear strength of the material it must penetrate. This is shown in Figure 4.2.2. The total jet volume during a pump run is calculated as two right cylindrical flat-topped cones 180 degrees apart. The height of each frustum is equal to the distance to the point where the jet pressure has dropped to a value that only just exceeds the strength of the material. A nozzle diameter of 2.6 in $(0.066 \mathrm{~m})$ was specified. Beyond $\sim 13.5 \mathrm{ft}(4.1 \mathrm{~m})$ from the jet nozzle, a tapered sector is removed from the frustum volume to account for the jet segment that impinges on the tank bottom. The calculated volume is an estimate of the volume of material below a given strength that can be disrupted during a jet pump run. The actual amount of submerged crust material that might lie in the path of the jet will depend on the back-dilution scenario under consideration, the actual crust sinking process, and the rate of crust dissolution. The total volume of the undisturbed crust is approximately 6.8 times greater than the largest disrupted volume that can be produced by the jet pump. The maximum jet diameter is only about $6.5 \mathrm{ft}$ ( 2 $\mathrm{m}$ ), while the undisturbed crust is about $10 \mathrm{ft}(3 \mathrm{~m}$ ) thick (Section 2.4). It is therefore reasonable, for the purposes of this analysis, to assume that the entire jet volume could contain crust material.

For material with relatively low shear strength, such as that in the weakest part of the paste layer $(400 \mathrm{~Pa})$, the opposed mixer pump jets are capable of affecting a relatively large volume of sunken waste $\left(-200 \mathrm{~m}^{3}\right)$ in a single run. For stronger material, such as that in the upper paste layer $(3000 \mathrm{~Pa})$, the volume the jets can disturb is probably only about $11 \mathrm{~m}^{3}$. In calculating the 


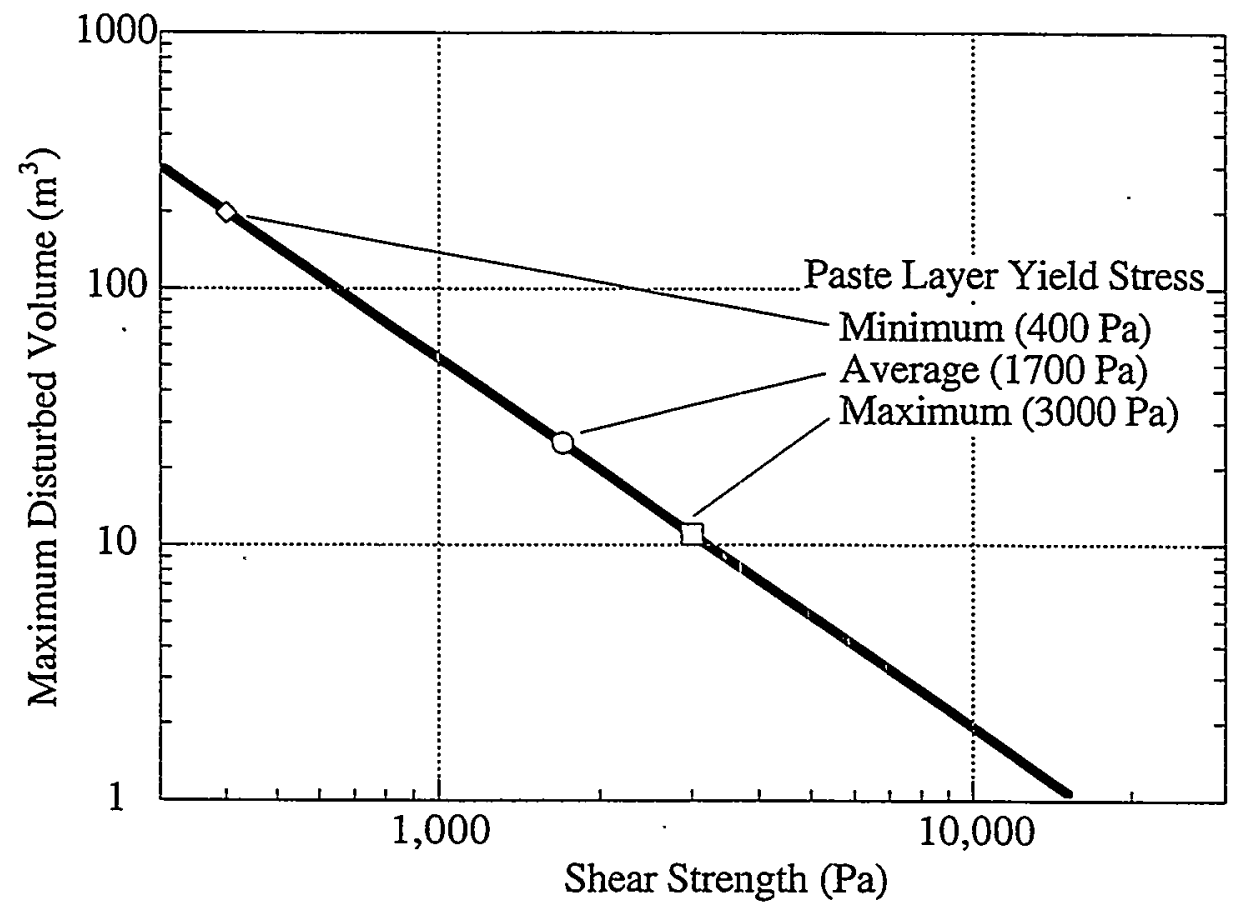

Figure 4.2.2. Volume Disturbed by Mixer Pump Operation as a Function of Waste Shear Strength

disturbed volume, we have assumed a uniform value for the crust strength in the path of the jet. In reality, of course, the crust strength varies significantly with depth. The amount of the crust that is actually disrupted by the jets will depend on the local crust strength in the volume where the jets actually impinge upon it. Even in the conservative scenario, where the sunken crust is assumed composed entirely of weak paste, gas release volumes are not a concern. Using an average gas fraction of 0.21 in the layer, the $200 \mathrm{~m}^{3}$ disturbed volume corresponds to a $\sim 40 \mathrm{~m}^{3}$ gas release. If released suddenly, this volume of hydrogen-containing gas is much less than that necessary to reach the lower flammability limit in the tank headspace for any practical dome volume (Section 6.5.2). In reality, the gas release would be spread over the time of the pump run, further reducing the maximum hydrogen concentration in the domespace.

\subsection{Buoyant Displacement Gas Release from Sunken Crust}

While it is highly unlikely that the floating crust layer will sink to the bottom of the tank as a cohesive unit, the possibility of substantial pieces of the crust sinking and remaining intact does exist. It has been hypothesized that these crust pieces may have the potential to participate in BD GREs like those that occurred before the mixer pump was installed in 1993. A BD GRE may be thought of as a volume of settled material retaining enough gas to become buoyant, rising to the waste surface, breaking up, and releasing a fraction of its stored gas, possibly creating a flammability hazard in the tank headspace. Models have been developed to explain and predict these phenomena. A detailed description of historic BD GRE activity in the tank, as well as 
development of the models, can be found in Meyer et al. (1997). It will be assumed for this analysis that the sunken crust piece can retain enough gas to become buoyant as a unit and that a $\mathrm{BD}$ of the piece is energetic enough to cause it to release. a fraction of its retained gas.

The gas volume available to be released from a buoyant piece of crust is dependent on the size of the crust piece and the gas void fraction required to make the piece neutrally buoyant. The volume of gas available to be released from the buoyant crust piece is determined from

$$
\mathrm{V}_{\text {rel }}=\mathrm{f}_{\text {rel }} \mathrm{V}_{\text {gas }}
$$

where

$$
\mathrm{f}_{\mathrm{rel}}=1-\frac{1}{\mathrm{P}_{\mathrm{S}}}
$$

and

$$
\mathrm{V}_{\mathrm{gas}}=\mathrm{P}_{\mathrm{S}} \mathrm{V}_{\mathrm{C}} \alpha_{\mathrm{NB}}
$$

The neutral buoyant void is given by

$$
\alpha_{\mathrm{NB}}=1-\frac{\rho_{\mathrm{L}}}{\rho_{\mathrm{C}}}
$$

where $\rho_{\mathrm{L}}$ is the liquid density, and $\rho_{\mathrm{C}}$ is the sunken crust material density. $\mathrm{V}_{\mathrm{C}}$ is the volume of the crust piece in situ, and $\mathrm{P}_{\mathrm{S}}$ is the dimensionless in situ gas pressure:

$$
\mathrm{P}_{\mathrm{s}}=1+\frac{\rho_{\mathrm{L}} \mathrm{g}}{\mathrm{P}_{\mathrm{A}}}\left(\mathrm{h}_{\mathrm{CP}}\right)
$$

with $h_{\mathrm{CP}}$ equal to the depth of the centroid of the crust piece below the waste surface. The acceleration due to gravity is denoted by $g$, and $\mathrm{P}_{\mathrm{A}}$ is atmospheric pressure. The fraction of the LFL reached in the tank headspace due to gas release (assuming instantaneous release) is computed assuming that the hydrogen fraction of the gas is 0.38 (Mahoney et al. 1999). The LFL fraction in the headspace as a function of the thickness and diameter of the sunken crust piece is shown in Figure 4.3.1. (Gas release and domespace flammability are addressed further in Section 6.) It is assumed that the tank waste level is $10.3 \mathrm{~m}$ (406 in.) at the time of the release (back-dilution volume equals transfer volume). To reach flammability (LFL fraction equals 1.0), it is apparent that a piece of crust approaching the current extent of crust in thickness (see Section 2.4) and of a diameter approaching that of the tank must become buoyant and release its gas.

It is uncertain what the configuration (thickness and diameter) of a sunken crust piece would be. However, it is almost certain, due to the dilution activities and associated waste behavior that must occur for the crust to sink (see Section 2.4), that the crust will not be in a configuration that approaches the current size. Based on these limitations, assumptions can be made that limit its volume, which is approximated as a right circular cylinder. The maximum horizontal extent of a 


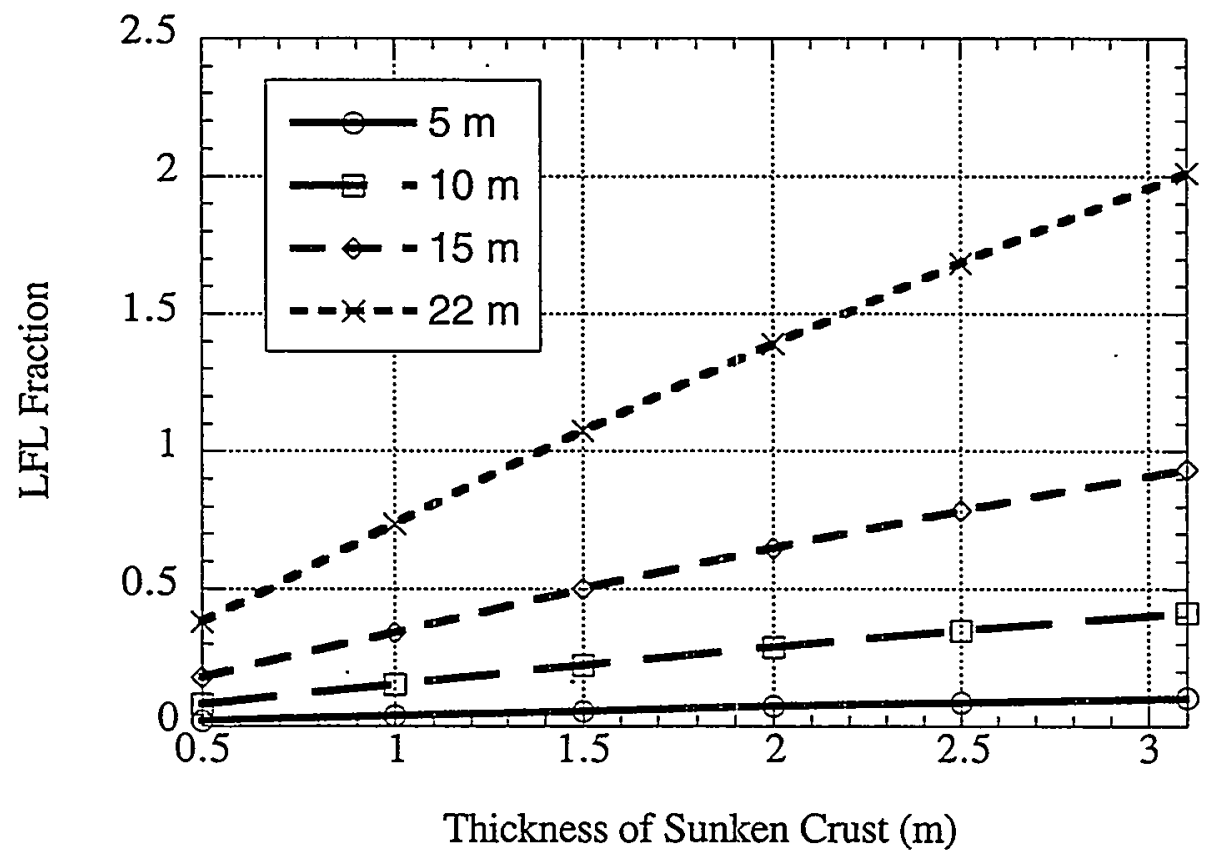

Figure 4.3.1. LFL Fraction in Tank Headspace Due to a BD GRE of a Sunken Crust Piece. The separate lines denote the diameter of the piece, as specified in the legend.

piece of sunken crust is assumed to be limited by 1) the location of permanent paths and intrusive activities through and into the crust layer (see Section 6.5.2) and 2) the horizontal aspect ratio of the crust piece, which will be approximately 1.0. The size of the piece is also conservatively maximized by assuming the mixer pump will not affect it. Based on these assumptions, the maximum diameter of the sunken crust piece is estimated to be approximately $10 \mathrm{~m}$. The maximum thickness of the crust must be $3.1 \mathrm{~m}$ at the time of sinking (Section 2.4). But as discussed, it is highly unlikely that the crust will be at its current size at the time of sinking, so a thinner crust (on the order of $1.0 \mathrm{~m}$, as determined from Section 2.4) can be expected.

It is shown in Figure 4.3.1 that the LFL fraction in the headspace due to instantaneous gas release from a buoyant crust piece $3.1 \mathrm{~m}$ thick with a horizontal diameter of $10 \mathrm{~m}$ will be approximately 0.42 . In addition, the LFL fraction for the reduced crust thickness of $1.0 \mathrm{~m}$, again with an expected diameter of $10 \mathrm{~m}$, is approximately 0.15 . The gas release volumes used to compute LFL fractions in Figure 4.3.1 were determined from Equation (4.3.1). The results indicate that a flammability hazard from a BD GRE of a sunken crust piece is very unlikely. 


\subsection{Dissolution Mechanisms and Rates}

Adding a large volume of water to SY-101 after transferring a comparable or greater waste volume out of the tank will result in dissolution of solids in the nonconvective, mixed slurry, and crust layers. Dissolution will free gas trapped within the solids-liquid-gas waste matrix. The rate and volume of hydrogen-containing gas release to the tank domespace are important from a potential flammability standpoint. Section 6 addresses tank-scale gas release issues; here we are interested in understanding the mechanisms and rates of waste solids dissolution as they impact the tank-waste configuration and gas release.

While all solids in the tank are targeted in dilution processes, special emphasis is given in this analysis to dissolution of the crust because of the large gas repository contained therein. Two hypothetical mechanisms of crust dissolution that may affect large-scale features of the crust layer and gas release pathways are addressed in Section 5.1. Included are results of a simple water spreading experiment with a simulated crust layer that complements a theoretical analysis for top-down tank dilution. In Section 5.2, rates of waste solids dissolution are analyzed. The section includes a brief review of limited actual waste and other solids dissolution rate data. Analytically determined rates of mass transport-limited dissolution of free particles in the mixed slurry layer and dissolution at the interface of the floating crust layer in the presence of unsaturated diluent are also presented. Section 5.3 summarizes dissolution and gas release mechanisms and rates observed in experiments using crusts prepared from tank-waste chemical simulant.

\subsection{Dissolution Mechanisms}

Two primary approaches of water back-dilution are planned in SY-101. In one, water is to be added on top of the floating crust layer, most likely in a stream at a single location. The analysis and experiments discussed below show that top-down dilution results in significant spreading of centrally added water, and the force of the water "jet" is insufficient to erode a hole through a massive crust layer.

Conversely, bottom-up dilution reflects plans to add water below the crust surface, most likely through the transfer pump inlet at the 96-inch $(2.4-\mathrm{m})$ elevation. While water added at this location is expected to mix quite effectively with the slurry layer (Section 3.1), less saturated and lower-density diluent will buoy to the base of, and potentially through, the crust. A mechanism is described whereby the unsaturated diluent preferentially infiltrates the larger pores and channels of the floating layer.

\subsubsection{Top-Down Dilution-Spreading}

A discussion of results from simple water spreading experiments using sugar and molasses to simulate dry and wet crust layers follows an analysis of a vertical water jet plunging down into a more dense material. 


\subsubsection{Analysis of Plunging Jet Penetration}

The plan is to introduce some water on top of the floating layer of SY-101 through a pipe in a $10.2-\mathrm{cm}$ (4-inch) riser. The water falls $3-5 \mathrm{~m}$ through the domespace onto the waste surface. With no nozzle to direct the flow, the water is expected to "dribble" off the inner walls of the riser as large drops. The flow rate of water may be less than $30 \mathrm{gpm}$, but flow rates between 30 and $100 \mathrm{gpm}(110$ to $380 \mathrm{~L} / \mathrm{min}$ ) are conservatively considered in this analysis. There is interest in understanding whether the waterfall will create a cavity deep enough to penetrate through the thick crust layer or will simply spread across the top. In this section, a conservative estimate is made to determine the depth of crust penetration by assuming a coherent plunging jet instead of the expected droplet impact. The approximate shape of the depression is also calculated.

To be conservative, it is assumed that the water flows from a $2.54-\mathrm{cm}$ diameter nozzle from the riser. This water into air jet is assumed to be perfectly coherent with no breakup into droplets. It impinges on the dry freeboard crust, which is approximately $0.5-\mathrm{m}$ thick. (This base case considers pre-first-back-dilution conditions of the crust; other crust configurations are also analyzed.) In this conservative calculation, the freeboard is assumed to be a water layer overlying a second liquid layer of higher density $\left(1490 \mathrm{~kg} / \mathrm{m}^{3}\right) 2.5 \mathrm{~m}$ (100 inches) deep. The denser layer represents liquid-saturated crust layers ("wet clay" and "paste"), conservatively, with no strength. Figure 5.1.1 is a schematic of the plunging jet model with the appropriate parameters.

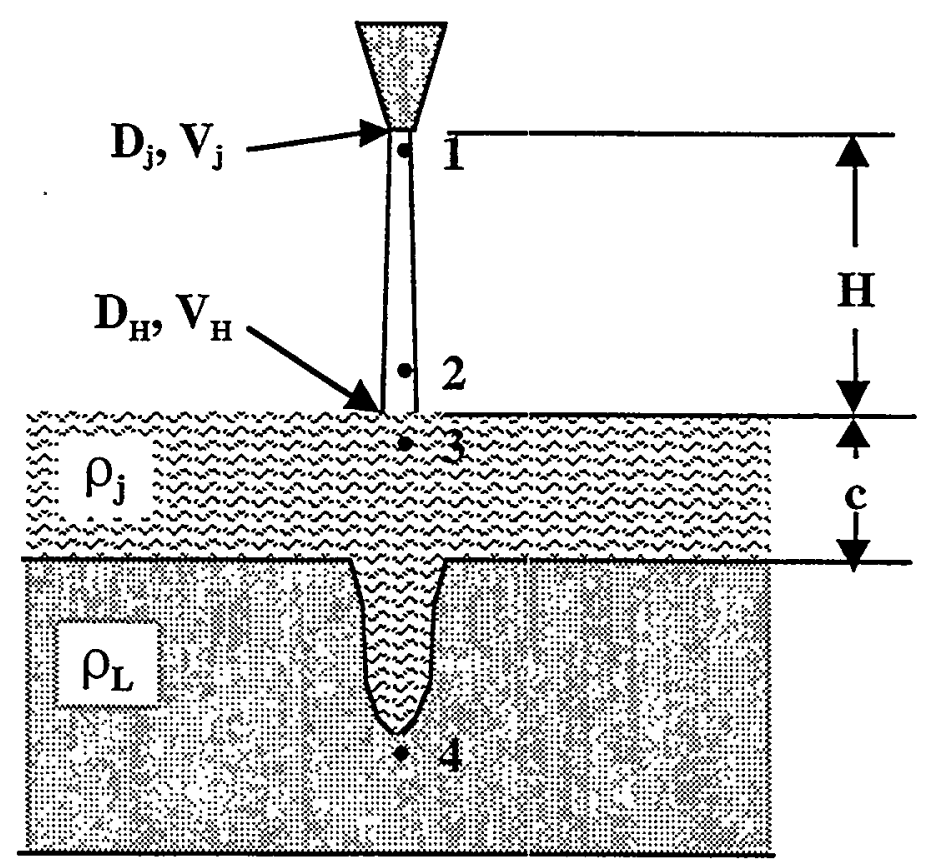

Figure 5.1.1. Schematic of the Plunging Jet Model 
Applying the Bernoulli equation between points 1 and 2, the velocity of impingement $V_{H}$ on the crust layer a distance $\mathrm{H}$ away is readily obtained in terms of the flow rate $\mathrm{Q}$ and the nozzle diameter $\mathrm{d}_{\mathrm{j}}$ :

$$
V_{H}=\sqrt{\frac{16 Q^{2}}{\pi^{2} d_{j}^{4}}+2 g H}
$$

The relationship between $d_{j}$ and the idealized diameter of the coherent jet cross sectional area $d_{H}$ at point 2 is obtained from the continuity equation:

$$
\text { . } \mathrm{d}_{\mathrm{H}}=2 \sqrt{\frac{\mathrm{Q}}{\pi \mathrm{V}_{\mathrm{H}}}}
$$

Once the jet is submerged, its centerline velocity $\mathrm{V}$ will decay inversely proportional to the distance regardless of the density of the fluid. It is assumed that the virtual origin of the submerged jet is located at point 3 . Point 4 denotes the location of maximum plunging depth, which is distance $h$ below the crust layer. Thus between points 3 and 4 Bernoulli's equation yields

$$
\frac{\rho_{j} V^{2}}{2}+\rho_{j} g(c+h)=\rho_{L} g h+\rho_{j} g c
$$

where $\mathrm{h}$ is the depth of penetration in the more dense liquid. For a round axisymmetric jet, $\mathrm{V}$ can be written as

$$
V=K \frac{V_{H} d_{H}}{c+h}
$$

where $\mathrm{K}$ is an experimentally determined constant for submerged turbulent jets (Rajaratnam 1976). Combining Equations (5.1.1) through (5.1.4), the plunging depth is obtained by

$$
h(h+c)^{2}\left(\frac{\rho_{L}}{\rho_{j}}-1\right)=\frac{2 K^{2} Q}{\pi g} \sqrt{\frac{16 Q^{2}}{\pi^{2} d_{j}^{4}}+2 g H}
$$

Equation (5.1.5) is cubic in $\mathrm{h}$ and its solution was carried out numerically. The plunging zone scales with the radial pressure distribution on a flat surface where the point of maximum plunging is considered as the impingement point. Thus, the arbitrary depth $z(z \leq h)$ as a function of the radial coordinate $r$ is

$$
z(r)=h \exp \left[-2\left(\frac{K r}{c}\right)^{2}\right]
$$

Figure 5.1.2 shows the extent of the penetration zone for a plunging jet with the following parameters: 


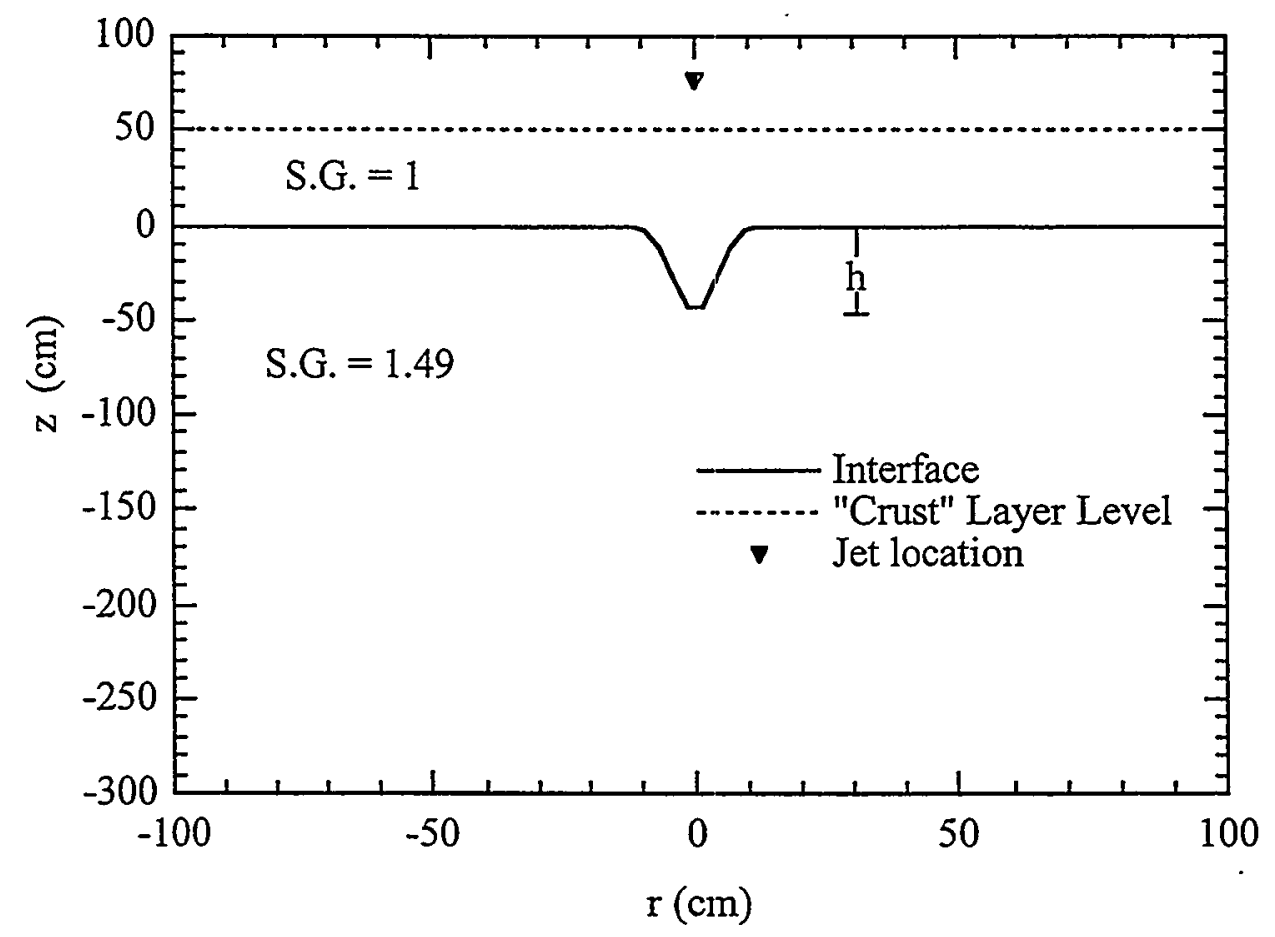

Figure 5.1.2. Extent of the Penetration Zone for a Plunging Jet

$$
\begin{aligned}
& \mathrm{Q}=378.5 \mathrm{~L} / \mathrm{min}(100 \mathrm{gpm}) \\
& \mathrm{H}=0.254 \mathrm{~m}(10 \mathrm{in}) \\
& \rho_{\mathrm{j}}=1000 \mathrm{~kg} / \mathrm{m}^{3} \\
& \mathrm{~K}=6.3
\end{aligned}
$$

$$
\begin{array}{ll}
\mathrm{d}_{\mathrm{j}} & =2.54 \mathrm{~cm}(1 \mathrm{in}) \\
\mathrm{c} & =0.508 \mathrm{~m}(20 \mathrm{in}) \\
\rho_{\mathrm{L}} & =1490 \mathrm{~kg} / \mathrm{m}^{3} \\
\mathrm{~g} & =9.81 \mathrm{~m} / \mathrm{s}^{2}
\end{array}
$$

The interface between the freeboard and the dense layer is taken at $\mathrm{z}=0$.

For this case, the maximum plunging depth $\mathrm{h}$ is $0.46 \mathrm{~m}$ (18 inches) with a maximum horizontal extent of $0.25 \mathrm{~m}$ (10 inches). Figure 5.1.3 shows the variation of $\mathrm{h}$ as a function of the crust thickness $\mathrm{c}$. The rest of the parameters are the same as those used for Figure 5.1.2. These conservative calculations indicate that the water creates a depression below the crust's free liquid level. Starting with the base-case freeboard crust, the upper bound on the maximum plunging depth is on the order of about $0.5 \mathrm{~m}$ (20 inches). Because of the lower density of the water, it will tend to spread above the extent of depression zone.

Even in the worst case of no upper crust with a perfectly collimated jet at $100 \mathrm{gpm}$, the upper bound on the maximum plunging depth cannot be larger than $80 \mathrm{~cm}$ (Figure 5.1.3). As indicated by Equation (5.1.5), the depth of penetration falls off significantly as the water flow rate decreases and the jet diameter increases (or jet coherence decreases). Viscous dissipation was also neglected in this analysis. The depth of penetration into a viscous fluid or a material of finite yield strength, like the actual tank crust (Section 2.3), would be more limited. 


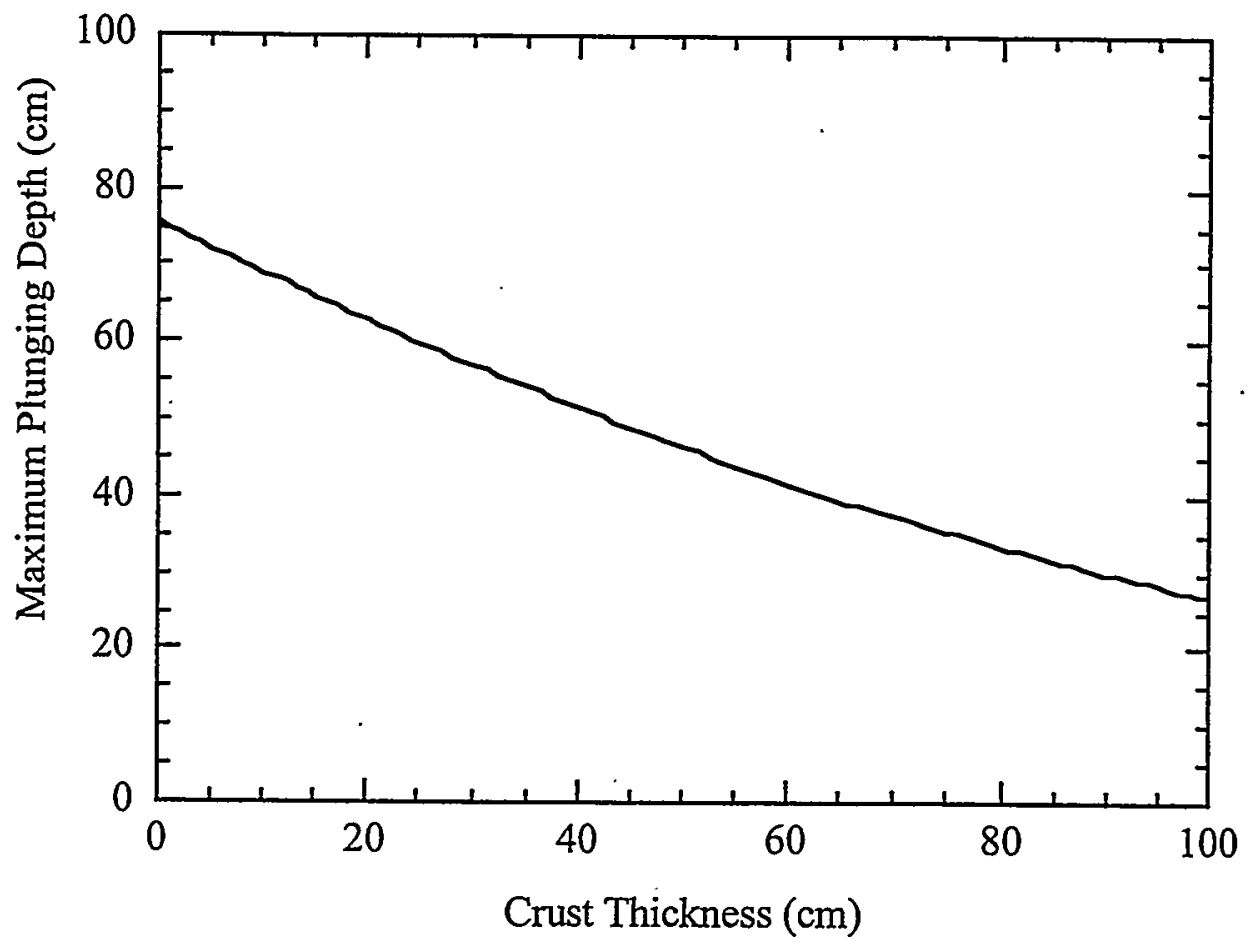

Figure 5.1.3. Plunging Depth as a Function of the "Crust" Thickness

\subsubsection{Experiments-Sugar as Simulated Crust}

A few simple laboratory experiments were performed to better understand the mechanisms of dissolution associated with water addition on the top of the crust. The simulated crust was composed of two layers. Granulated sugar simulated the dry freeboard layer (pre-back-dilution condition, Section 2.4), while a highly viscous molasses and sugar mixture represented the wetted, submerged crust layer. Water was added to the top of the crust in a single location to determine if a hole would be eroded through the wetted crust or if it would spread readily across the entire crust surface as expected.

\section{Experimental Approach}

The experiments were performed in a clear Pyrex glass container with a 17.4-cm inside diameter, corresponding to roughly $1 / 130$-tank scale. The overall thickness of crusts in the experiments were 2.5 and $5.1 \mathrm{~cm}$; the thinner crust is $\sim 1 / 120$-tank scale and the thicker is $\sim 1 / 60$ tank scale using the current 120 inches $(3 \mathrm{~m})$ estimate of tank crust thickness. The simulated crust comprised two layers; the bottom layer a dark molasses $(1.40 \mathrm{~g} / \mathrm{mL}$ measured) and granulated sugar (sucrose, true density $1.58 \mathrm{~g} / \mathrm{mL}$ ) (Weast 1985) thoroughly mixed in a 2:1 ratio. The overall density of this layer $(\sim 1.2 \mathrm{~g} / \mathrm{mL})$ was lower than expected $(\sim 1.46 \mathrm{~g} / \mathrm{mL})$ indicating a significant fraction of gas bubbles entrained during preparation. Observations support this conclusion, and the estimated gas fraction in the layer was 0.18. A layer of dry granulated sugar was carefully spread across the molasses/sugar layer. The mass and thickness of each layer was recorded along with the rate and mass of added dilution water. Table 5.1.1 summarizes crust properties and other experimental conditions. 
Table 5.1.1. Conditions for Sugar Dissolution Experiments

\begin{tabular}{|c|c|c|c|c||c|c|c|}
\hline & \multicolumn{2}{|c|}{ Wet Crust Layer } & Dry Crust Layer & \multicolumn{3}{|c|}{ Dilution Water } \\
\hline Test \# & $\begin{array}{c}\text { Thickness } \\
(\mathrm{cm})\end{array}$ & $\begin{array}{c}\text { Mass } \\
(\mathrm{g})\end{array}$ & $\begin{array}{c}\text { Thickness } \\
(\mathrm{cm})\end{array}$ & $\begin{array}{c}\text { Mass } \\
(\mathrm{g})\end{array}$ & $\begin{array}{c}\text { Flow Rate } \\
(\mathrm{mL} / \mathrm{min})\end{array}$ & $\begin{array}{c}\text { Added } \\
(\mathrm{mL})\end{array}$ & $\begin{array}{c}\text { To Dissolve } \\
\text { Top (mL) }\end{array}$ \\
\hline 1 & 2.0 & 1262 & 0.5 & 253 & 3.4 & 86 & 126 \\
\hline 2 & 3.8 & 2523 & 1.25 & 579 & 5.2 & 195 & 290 \\
\hline 3 & 3.8 & 2523 & 1.25 & 581 & 5.3 & 317 & 290 \\
\hline
\end{tabular}

The water was added continuously onto the crust surface through a small bore tube $(0.08-\mathrm{cm}$ I.D. $\mathrm{x}$ 0.4-cm O.D.) at rates of 3.4 to $5.3 \mathrm{~mL} / \mathrm{min}$ using a peristaltic pump (MasterFlex ${ }^{\mathrm{TM}}$ ). The total water volume added in two experiments was not sufficient to dissolve the top sugar layer, and in another, a slight excess of water was added. The water addition tube was held $\sim 0.18 \mathrm{~m}$ above the crust surface, and at these low flow rates the water dripped on the surface and was clearly not a jet. The tank-scale equivalent flow rate, normalized by vessel cross-sectional area, was 15 or $24 \mathrm{gpm}$.

Two video cameras were used to monitor and record the dissolution process. One camera was used in a profile view to record the development of changes in the surface contours of the dry freeboard crust and the lower molasses layer as water was added. The second camera was used in a top view. This view recorded the direction and location of the spreading of the water added to the top of the crust. Depth of water penetration into the crust was determined qualitatively by visual observation.

\section{$\underline{\text { Results }}$}

Three experiments were performed in which a diluent (water) was added at a single location to the simulated crust surface. The addition of water on top of the upper dry crust layer in these tests resulted in lateral spreading of the diluent across the more viscous (stronger) wet crust layer as well as dissolution of the dry crust layer. Similar qualitative results were exhibited in all the experiments, and visual observations of a representative experiment are presented.

Figure 5.1.4 shows a time progression for simulated crust dissolution during a one-hour addition of water (experiment \#3,5.3 $\mathrm{mL} / \mathrm{min}$ ). As depicted in the first several frames, lateral spreading was observed almost immediately after diluent was added to the dry crust layer. The first photo was taken less than a minute after the start of water flow. Approximately 11 minutes into the addition (Figure 5.1.4c), liquid reached the edge of the vessel. An interesting series of channels developed shortly after the start of the experiment (Figure 5.1.4b), and once they were established, diluent flowed in these paths, accessing fresh dry crust. Once the crust was submerged in liquid (Figure 5.1.4d), the channels and ridges were no longer apparent. This may be due to preferential dissolution at the ridge tops after submergence, because the least saturated, lowest-density diluent is available at the higher elevations. Penetration. of the white dry crust layer to the dark "wet" crust layer is noted in the third and fourth pictures of the sequence. They indicate enhanced sugar dissolution in the vicinity of water addition, not necessarily "jet" penetration through it. Although it's difficult to make out in the photographs, visual analysis indicated very little diluent penetration, perhaps on the order of a few millimeters, into the 
a $\mathbf{b}$
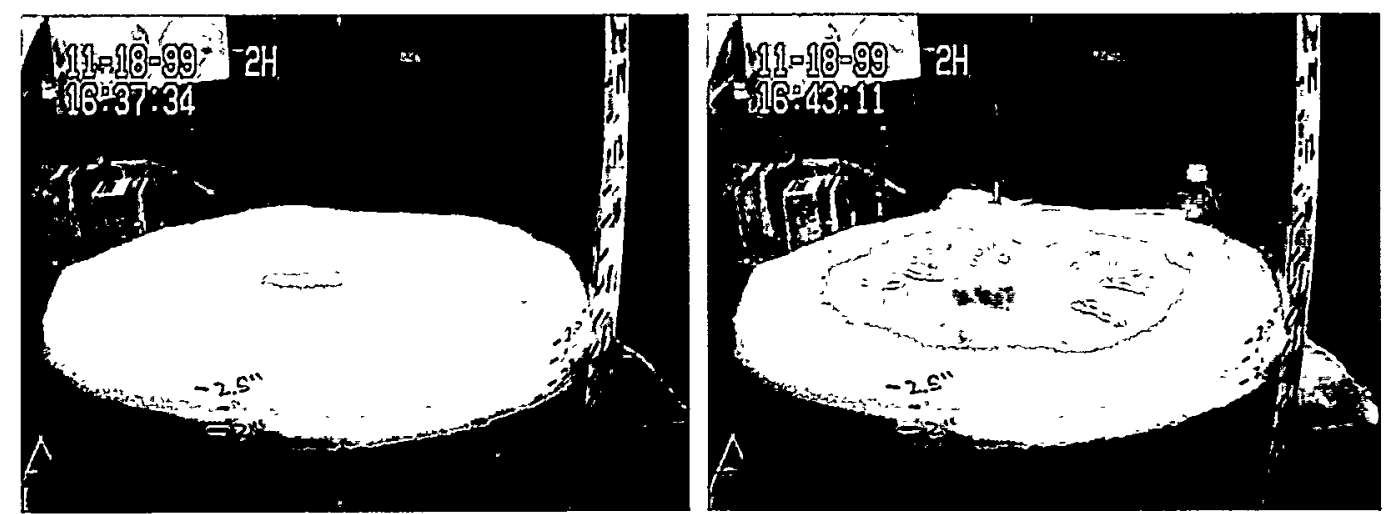

c d
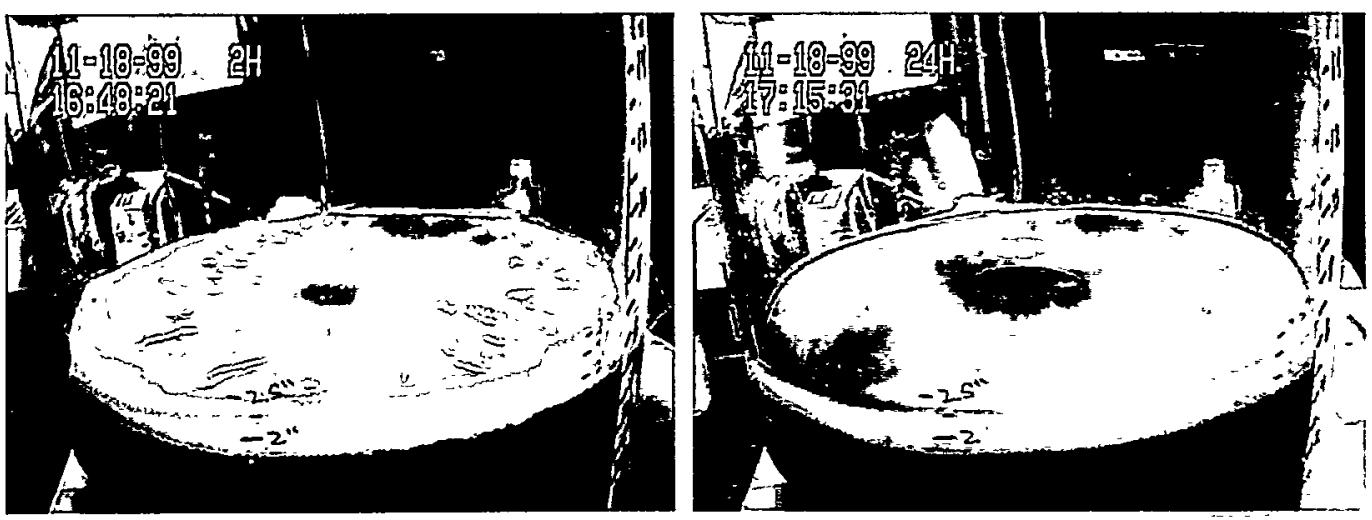

e $\mathbf{f}$
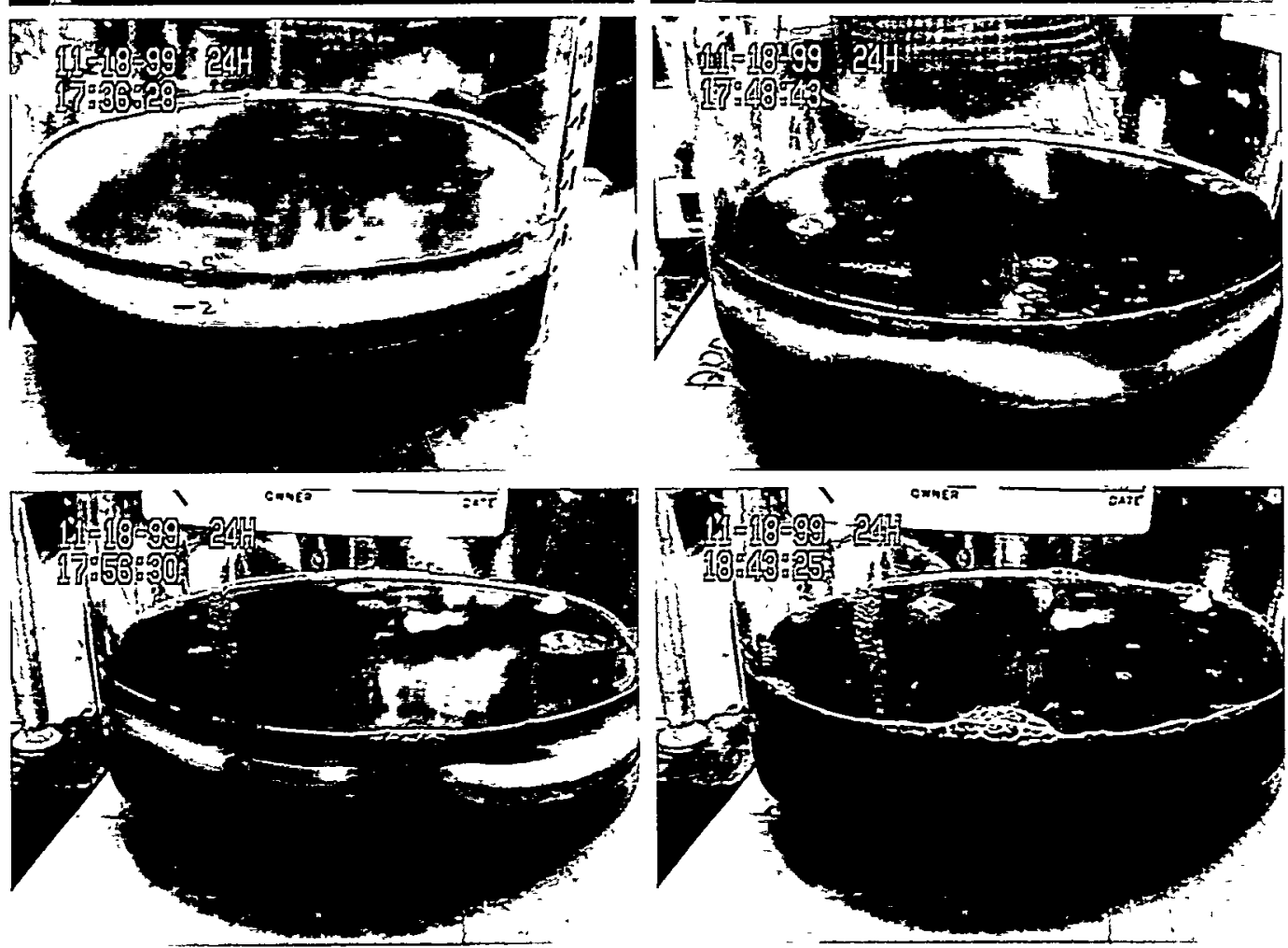

Figure 5.1.4. Water Spreading and Dissolution of Simulated Crust of Sugar and Molasses/ Sugar Layers: (a) water addition just started; (b) 6-min elapsed; (c) 11-min elapsed (d) 40-min elapsed; (e) near end of water addition (1 h elapsed); ( $f$ ) $\sim 1.2$ h elapsed; $(\mathrm{g}) \sim 80$ min elapsed; and (h) just over $2 \mathrm{~h}$ elapsed 
molasses layer. Discoloration of liquid after one-half hour (Figure 5.1.4d) reflects some dissolution of the lower crust layer, most likely in the regions exposed by complete sugar dissolution.

After water addition was completed ( $\sim$-hour elapsed, Figure 5.1.4e), the dry crust layer continued to dissolve. Complete dissolution of the upper layer was noted shortly after the last photo in the sequence, approximately 2.2 hour after the start of water addition. The solubility of sucrose in water at $20^{\circ} \mathrm{C}$ is $200 \mathrm{~g}$ in 100-g water (Dean 1992). In the third experiment, a $9 \%$ excess of water was added. As noted above, the sugar dissolution rate was somewhat slower than the water addition rate, indicating that the dissolution process becomes mass-transport limited. Any dissolution of the lower molasses/sugar layer would obviously impact the water available to dissolve the upper crust.

The last several photographs in Figure 5.1.4 provide evidence of gas release from the lower crust layer. Several patches of foam are seen on the liquid surface, and volcano-like protrusions of lower crust mass into the liquid layer are observed (Figure 5.1.4f, g). Many small bubbles were freed from the molasses/diluent interface when material around the bubbles dissolved. The larger volcanoes are probably the result of buoyancy effects. As the upper liquid layer becomes saturated in sucrose $(1.33 \mathrm{~g} / \mathrm{mL}$ density estimated at saturation), the lower density molasses/ sugar layer $(\sim 1.2 \mathrm{~g} / \mathrm{mL})$ pushes upward. After top back-dilution in SY-101, it is expected that entire crust mass will buoy upward as more saturated liquid is created through solids dissolution near the crust/diluent interface, limiting the thickness of the overlying liquid layer.

\subsubsection{Bottom-Up Dilution-Preferred Channels}

When water is added below the crust and mixed in the slurry layer, it is certain that any lowdensity liquid will buoy upward to the crust base. It is less clear whether and where unsaturated liquid would penetrate into or through the floating crust layer. For example, if a layer of pure water could be delivered just beneath the crust, buoyancy dictates it should seek the upper crust surface by any available path because it has a much lower density than the bulk crust. The questions are how would it get there and what impacts might it have on the crust structure. Intuitively, the paths of least resistance for liquid flow through the crust are larger-diameter pores or channels, analogous to fluid flow through pipes. However, the story is complicated because the ability of lower-density liquid to displace the high-density saturated liquid existing within the crust matrix is also a function of the pore diameter.

The submerged floating crust is a matrix of solids, liquids, and gas bubbles. The solid and liquid portion can be viewed as a porous network. In its most compact state, where solid particles are in contact, the size of pore-throat diameters are expected to be on the order of the typical waste particle diameters, 1 to $100 \mu \mathrm{m}$ (Herting 1992). Because gas is released to the domespace during mixer pump runs, we suspect that reliable "fast paths" of larger diameter exist through the crust surface. In this simplified analysis, the pores and paths through the crust are modeled as a series of vertically oriented tubes. The tubes are initially filled with saturated liquid (1490 kg/m $\mathrm{m}^{3}$ and $100-\mathrm{cP}$ viscosity assumed) and contacted from below with a pool of unsaturated liquid of correspondingly lower density and viscosity. More complex and realistic models of the crust as a fine-particle porous media with some larger channels lead to the same 
qualitative conclusions. Given our lack of knowledge of the pore and larger-path size distribution in the tank crust, the additional analysis complexity is not warranted.

Consider the arrangement shown in Figure 5.1.5. This system will be stable if and only if the density beneath the crust is greater than or equal to the density of the liquid filling the tube, $\rho_{2} \geq \rho_{1}$. However, if the system is unstable, there is a radial length scale for which the system will become unstable the fastest. According to the Rayleigh-Taylor stability problem in cylindrical coordinates (Yih 1977), it can be shown that the length scale is

$$
L=7.4\left[\frac{\left(\mu_{1}+\mu_{2}\right)^{2}}{\left(\rho_{1}^{2}-\rho_{2}^{2}\right) g}\right]^{\frac{1}{3}}
$$

This means that tubes that have a diameter larger than $L(D>L)$ will easily be able to accommodate disturbance modes whose wavelength is $L$ (or larger) and become unstable very fast. However, if the tube diameter $\mathrm{D}<\mathrm{L}$ the system will take "longer" to destabilize. Note that the stability length scale is independent of fluid surface tension. However, if the fluid in the tube is displaced by new liquid, the change in surface tension could result in a change in the maximum liquid level in the pore due to capillary rise.

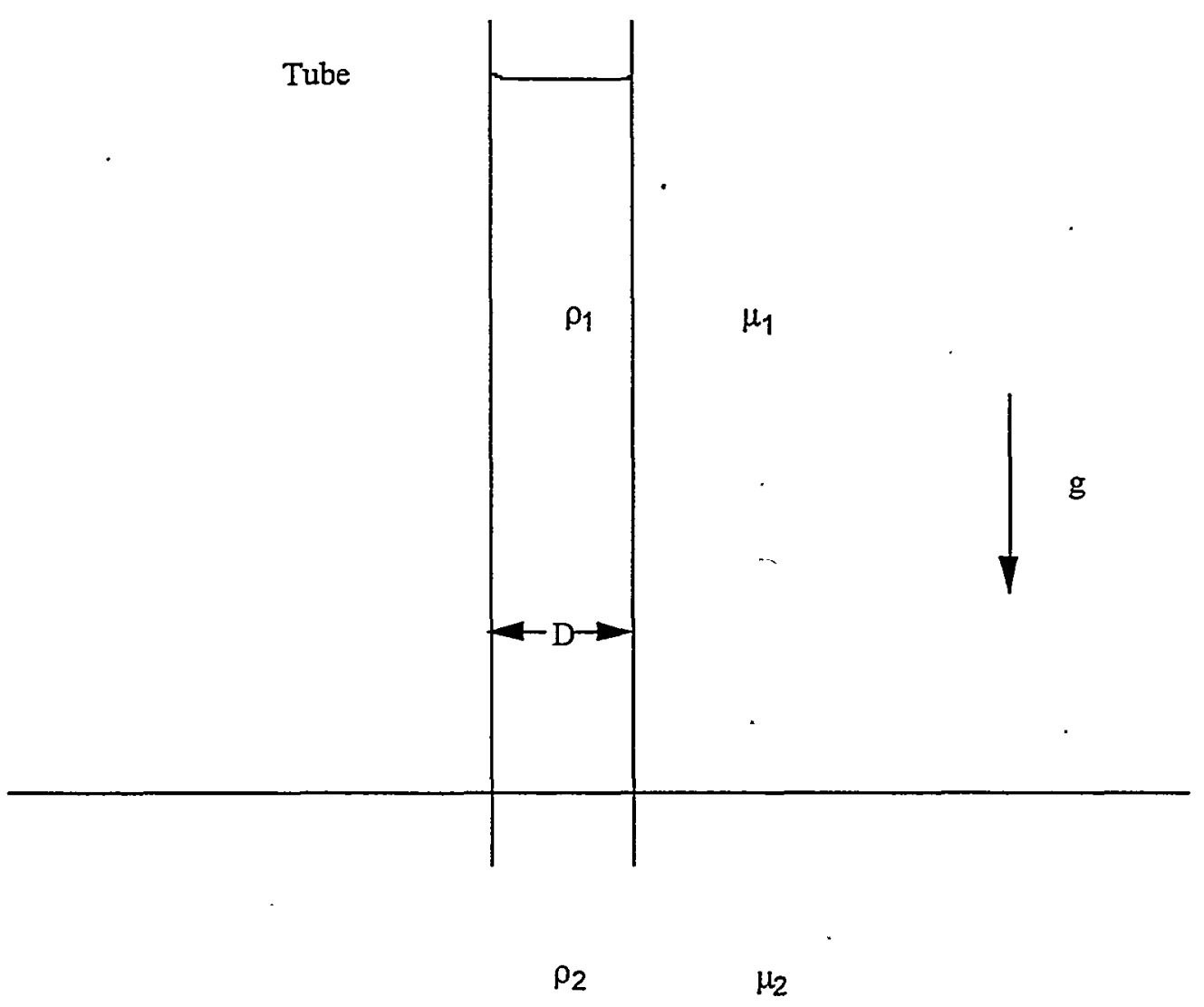

Figure 5.1.5. Schematic of Stability Analysis for Liquid Displacement in a Tube 
Figure 5.1.6 shows the variation of this length scale as a function of the lower liquid density. In analyzing the length scale from Equation (5.1.7), the lower liquid viscosity was determined from an exponential fit assigning a viscosity of $1 \mathrm{cP}$ for water and either 100 or $500 \mathrm{cP}$ for saturated liquid at $1490 \mathrm{~kg} / \mathrm{m}^{3}$. This fit approach is based on handbook values that indicate exponential viscosity variation with density for pure salt solutions (Weast 1985). For diluent density of $1000 \mathrm{~kg} / \mathrm{m}^{3}$, the stability length scale is $0.7 \mathrm{~cm}$, assuming the lower viscosity range and $2 \mathrm{~cm}$ for higher viscosity limits. ${ }^{(\mathrm{a})}$ In other words, the preferred tubes for fluid replacement are those with diameters larger than stability length scale values. Even with pure water, the pore diameter must be substantially larger than typical particle (pore) diameters for the liquid to displace saturated liquid quickly. The unstable length scale does, however, approximate the largest retained gas bubbles. As the lower liquid approaches saturation, the size of pores stable to the density inversion increases. At a liquid density of $1480 \mathrm{~kg} / \mathrm{m}^{3}$, pores $<3.7 \mathrm{~cm}(100-\mathrm{cP}$ limit) or $<10.7 \mathrm{~cm}$ (500-cP limit) are relatively stable. Thus, in a typical back-dilution scenario where water is added low in the tank and well mixed with slurry, creating a substantially saturated diluent, little (or slow) penetration of the liquid through the crust may occur unless fairly large preferred paths exist.

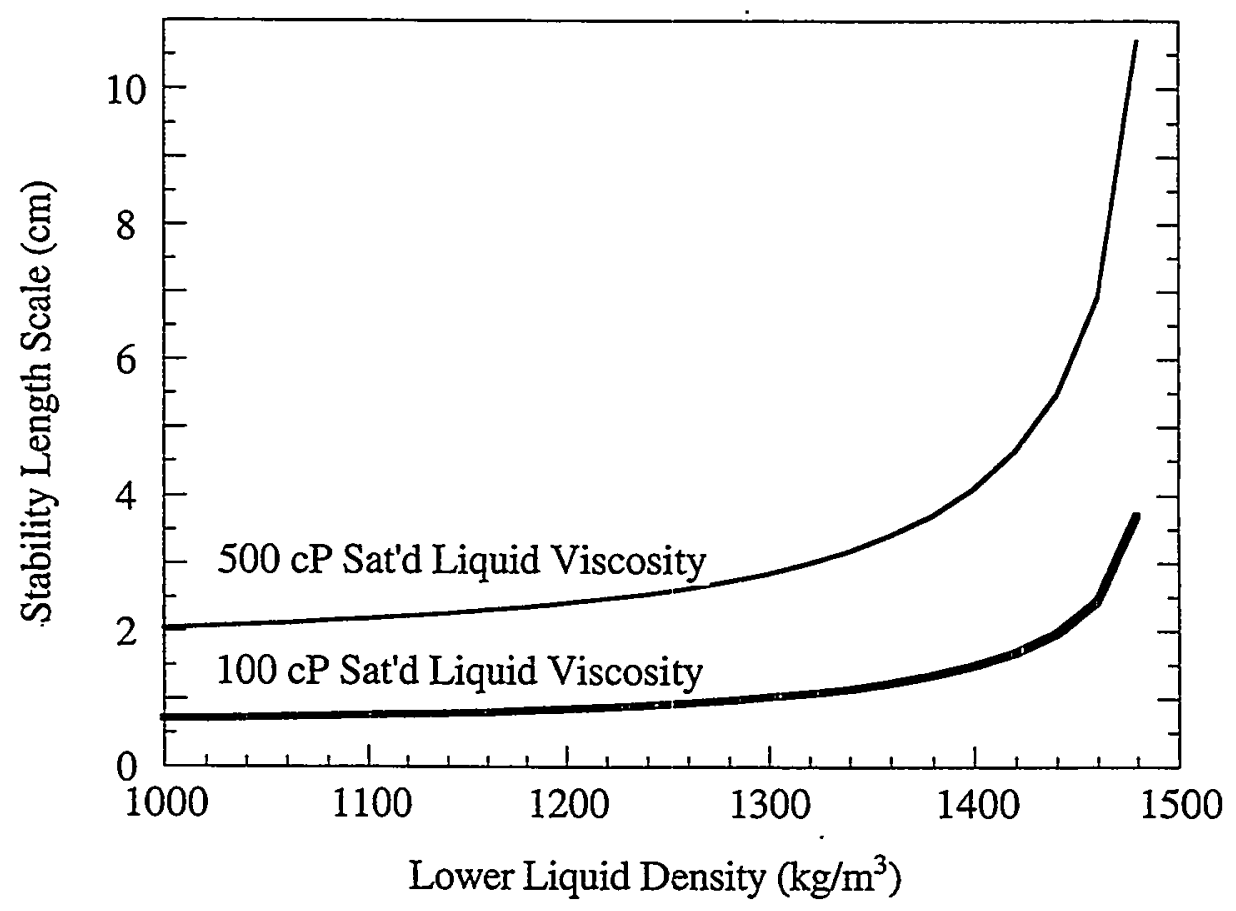

Figure 5.1.6. The Stability Length Scale as a Function of Liquid Density at the Lower Pore Entrance

(a) Throughout the remainder of the document, water, when considered as a pure (completely unsaturated) diluent, is assumed to have a density of $1000 \mathrm{~kg} / \mathrm{m}^{3}$. Since pure water is not mixed with waste, its density is different than that of water in the dissolved state $\left(1050 \mathrm{~kg} / \mathrm{m}^{3}\right)$, as presented in Section 2.1. Using the lower density value is more conservative for dissolution analyses because the potential for dissolving solids is higher. 
The analysis above quantifies the length scale of stability for an inverted liquid density scenario (Figure 5.1.5) in which the fluids are initially quiescent. Under actual tank conditions, the creation of an inverted density profile with water addition below the floating crust will lead to a change in crust submergence. The sinking (or buoying) of crust through some distance $h$ results in flow of fluid through. (or around) the crust at some volumetric rate $\mathrm{Q}$. This does not represent the rate of water addition to the tank but may be a function of it. A change in liquid density $\Delta \rho_{L}$ that the crust is submerged in changes the buoyant hydrostatic load imparted on the floating mass. The net result is a pressure driving force $\Delta P\left[=f\left(\Delta \rho_{L} g h\right)\right]$ needed to impart fluid flow through the crust structure. Applying the tube analogy for the pores and channels within the crust and assuming laminar flow, the flow rate $Q_{t}$ through an individual tube can be determined from the Hagen-Poiseuille equation. ${ }^{(a)}$

$$
\frac{\mathrm{Q}_{\mathrm{t}}}{\Delta \mathrm{P}}=\frac{\pi \mathrm{D}^{4}}{128 \mu \mathrm{L}_{\mathrm{t}}}
$$

The right-hand term of Equation (5.1.8) reflects the conductivity to fluid flow through a tube of length $L_{t}$ and diameter $D$. The fourth-power dependence on tube diameter $D$ clearly demonstrates the significant resistance to flow through pores of small diameter. For example, the resistance to flow in a $1-\mu \mathrm{m}$ diameter pore (tube) is $10^{12}$ times greater than for a $1-\mathrm{mm}$ diameter path or $10^{16}$ times greater than for a $1-\mathrm{cm}$ channel.

These results are qualitatively consistent with the stability length scale analysis. Larger paths are preferred over smaller for the transport of unsaturated, low-density liquid into or around the floating crust. The entry of unsaturated liquid into larger channels would expectedly lead to dissolution of solids along the channel walls, and widening of the channels would create paths more susceptible to additional penetration of low-density liquid from below.

For top-down dilution, a qualitative argument reveals that preferred channels are less likely to be formed and maintained, and in fact, an opposite effect may occur. Consider, for example, the sugar dissolution experiments of the previous section. Initially, water addition created a series of dry ridges and liquid-filled valleys (a type of preferred path). Once enough water was added to cover the ridges and as solids continued to be dissolved, the ridges became imperceptible and the sugar surface became more uniform. This self-leveling effect is rationalized by considering the natural liquid density gradient for liquid layered on top of the crust surface. The most saturated and dense liquid falls to the "preferred" channels (and settles atop dense liquid or crust below) while the low-density, least saturated liquid is nearer the elevated crust features. Dissolution rates are faster in less saturated diluent (Section 5.2), and therefore ridges or other raised top crust features should dissolve more quickly than low valleys or channels. This is not to say that paths running through the crust from bottom to top will become more filled with solids during top-down dissolution; rather, top-down dissolution is more likely to create a planar dissolution front that does not preferentially open the paths.

(a) The Blake-Kozeny relationship, similar in form to the Hagen-Poiseuille equation, applies to packed beds or porous networks (Bird et al. 1960). Therefore, qualitatively, the analysis of flow through the porous crust structure as a simple series of tubes holds. 


\subsection{Dissolution Rates}

Dissolution rates for waste solids in the floating crust layer and for "free" particles transported in the mixed slurry layer are determined analytically. These theoretical results are evaluated assuming mass-transport-limited, not solids dissolution-kinetics-limited, dissolution processes. This assumption is justified with limited actual waste and waste simulant dissolution rate data and analysis of complementary dissolution and crystallization processes for salt solutions.

\subsubsection{Actual Waste and Other Salt Data}

There are limited dissolution kinetics data available from actual and simulated tank waste dilution tests. The dilution studies reported by Person (1999) on SY-101 waste samples showed that the weight fraction of dissolved solids at a 1:10 volume dilution with water after three hours of contact time was only 5\% more than samples contacted for seven days, both at tank temperature. These data suggest that the majority of the solids dissolution occurred within the first three hours in the well-mixed samples. Another dilution study on actual AN-103 waste, a double-shell slurry waste with chemical components similar to SY-101, showed that only $40 \%$ of solids were dissolved within the first 96 hours after water addition to a 1:1 dilution ratio if the sample was not agitated. ${ }^{(a)}$ Agitation of a comparably diluted AN-103 waste sample greatly increased the rate of dissolution to approximately $80 \%$ of solids dissolved in less than two hours (estimated from plot). In the same memo, Herting reviewed results of earlier dissolution kinetics studies on vortex mixed samples of Tank AN-105 waste (Herting 1997). He noted little difference in the fraction of solids remaining in samples mixed for $15 \mathrm{~s}, 1 \mathrm{~min}$, and $5 \mathrm{~min}$, again suggesting rapid dissolution with agitation. A similar effect of agitation was observed during the dissolution of SY-101 chemical simulant samples as described in subsection 5.3.3.3. Consistent in these studies, intimate contact of diluent and waste or simulated-waste solids as a result of mixing or agitation greatly increased dissolution rates.

These data suggest that the dissolution rate is limited by transport away from the dissolving solid and is not controlled by the kinetics of solids dissolution. In other words, equilibrium prevails at the solid/solution interface. The basis for this assumption is discussed and elaborated on in this section. The two main steps in a dissolution process are 1) dissolution of the solid at the solid/liquid interface and 2) transport of the dissolved solid away from the surface. Either or both of these processes can control the overall rate of dissolution. The case in which the dissolution at the solid/solution interface dominates is the simplest to identify experimentally because any degree of agitation should not affect the overall dissolution rate (Adamson 1990). Cases in which the overall rate is controlled by both dissolution kinetics and transport away from the interface or simply by the transport of dissolved solids away from the surface are more difficult to differentiate. We present an argument that the solid/liquid interface during dissolution of readily soluble salts is maintained at equilibrium; implying that transport limits the rate of solids dissolution. Comparing available experimental data for dissolution and crystallization, which are reverse processes, makes this argument.

(a) Results are summarized in a memo from DL Herting to NW Kirch in May 1999. Double-Shell Slurry Dissolution Kinetics. Numatec Hanford Corporation, Richland, Washington. 
It is generally accepted that crystallization processes are controlled by crystallization kinetics and mass transport from the bulk liquid phase to the solid/liquid interface (Mullin 1972; Wankat 1990). Given that crystallization is both kinetics and mass-transport limited, comparing crystallization and dissolution rate data indicates whether the rate of dissolution is dominated by the combination of the two or just mass transport rate. Mullin and Gaska (1969) studied the dissolution and crystallization of potassium sulfate. They showed the dissolution and crystallization rates as a function of a concentration driving force (defined by the difference between the solution concentration and the saturation concentration) at various temperatures from which mass-transfer coefficients are determined. The data indicate that crystallization mass-transfer coefficients depend on both temperature and concentration driving force, while dissolution masstransfer coefficients are only temperature dependent. Because dissolution mass-transfer coefficients were independent of the concentration driving force, we conclude that the dissolution process was only limited by mass transport. We expect that dissolution of actual waste solid species such as sodium nitrate and sodium nitrite, which are more soluble than alkali sulfate salts, is also limited by mass transport alone and not dissolution kinetics.

\subsubsection{Analytical Results}

A theoretical analysis of crust layer dissolution rates follows an analysis of dissolution times for solid particles in the mixed slurry layer. Lacking mass-transfer correlations for actual waste under the conditions of interest, we resort to mass-transfer correlations presented in the literature to estimate dissolution rates. Strictly speaking, the correlations as applied are most appropriate for dilute systems (sparingly soluble salts). In fact, many of the actual waste salts are highly soluble and solutions are concentrated. Concentration effects can be estimated using mass boundary layer theory, and for concentrated tank waste solutions, we estimate that the mass transfer rates could be about 1.5 to 2 times faster because of convection induced by diffusion (Cussler 1984). We do not apply the concentration corrections because there is already a significant uncertainty in many of the actual waste parameters (e.g., diffusion coefficients) used to analyze mass transfer rates. The analysis provides soundly based order of magnitude estimates of dissolution rates.

\subsubsection{Free Particle Dissolution}

Addition of water in the mixed slurry layer will dissolve solid particles carried in the fluid. The rate of particle dissolution impacts the rate of release for gas "retained" in the mixed slurry layer (Section 6.2.1), and it could also impact crust buoyancy as follows. The analysis of Section 3.1 showed that water added low in the tank is mixed quite effectively with the mixed slurry above the addition point. This was determined from differences in slurry bulk density as a measure of concentration, and particle dissolution processes were conservatively neglected. If particle dissolution rates are fast and added water volumes are moderate (less than necessary to dissolve all mixed slurry solids), slightly lower-density diluent stratified under the crust will be saturated and unable to dissolve solids in the gaseous bubble slurry layer of the crust. This is the desired result of addition processes where the goal is to float the crust higher in the tank (Section 2.4).

As shown below, the time to dissolution is a function of the degree of diluent saturation, particle size and density, and other waste properties. Two types of "free" particles are 
considered. The first are pure solid particles with a density of $2200 \mathrm{~kg} / \mathrm{m}^{3}$ (Section 2.1). Particle size analysis of SY-101 waste samples from the Window $\mathrm{C}$ and Window $\mathrm{E}$ core samples indicated that a large volume fraction $(>97 \%)$ of solid species in the settled layer were smaller than $100-\mu \mathrm{m}$ diameter, and a significant fraction ( $>50 \%$ ) was less than $10-\mu \mathrm{m}$ diameter (Herting et al. 1992). For completeness, dissolution times for particle sizes ranging from $1 \mu \mathrm{m}$ to $1 \mathrm{~cm}$ are analyzed.

A second type of "free" particle is a waste agglomerate (gob) containing solids, liquid, and gas bubbles (Section 6.2 .1 has additional discussion). These lower-density particles $\left(1500 \mathrm{~kg} / \mathrm{m}^{3}\right.$ assumed) may be created, for example, through jet mixer pump disturbance of the nonconvective layer and are necessarily larger than the smallest individual solid particles noted above. They are treated as a homogeneous distribution of saturated liquid $\left(\rho_{\mathrm{L}}=1490 \mathrm{~kg} / \mathrm{m}^{3} ;\right.$ Section 2.1$)$, gas, and 30 volume \% solids $\left(\rho_{S}=2200 \mathrm{~kg} / \mathrm{m}^{3}\right)$. Because the density of the gob is lower than for a pure solid, the settling velocity and hence the mass-transfer rate from a gob is smaller than for a pure solid of the same size.

\section{Method of Analysis}

Assuming fast dissolution kinetics per the analysis in Section 5.2.1, dissolution rates for free particles in unsaturated liquid are mass-transfer limited. The time for dissolution will be at a maximum if pure diffusive transport is assumed and convection is ignored. We determine particle dissolution rates for both diffusion-limited and convective mass-transfer conditions. Convection associated with particle settling is considered, and other sources of convection, such as fluid motion during mixer pump operations, are ignored.

The mass flux $\mathrm{N}$ for a particle dissolving in a bulk solution containing dissolved solid species at a concentration $\mathrm{C}_{\text {bulk }}\left(\mathrm{kg}\right.$ dissolved solids $/ \mathrm{m}^{3}$ solution) can be expressed as follows (Cussler 1984):

$$
\mathrm{N}=\mathrm{k}_{\mathrm{c}}\left(\mathrm{C}_{\text {sat }}-\mathrm{C}_{\text {bulk }}\right)
$$

In this equation, $\mathrm{C}_{\mathrm{sat}}$ is the saturation concentration of the dissolved species in the solvent, and $\mathrm{k}_{\mathrm{c}}$ is the mass-transfer coefficient $(\mathrm{m} / \mathrm{s})$. For individually dissolving spherical particles of diameter $\mathrm{d}_{\mathrm{p}}$, the mass-transfer coefficient may be estimated from a Sherwood (Sh) number correlation:

$$
\mathrm{Sh}=\frac{k_{c} d_{p}}{D_{A B}}=2+0.6 \operatorname{Re}^{1 / 2} \operatorname{Sc}^{1 / 3}
$$

where Sc is the dimensionless Schmidt number and Re is the particle Reynolds number (Sherwood et al. 1975)

$$
\begin{aligned}
& S c=\frac{\mu}{\rho_{L} D_{A B}} \\
& \operatorname{Re}=\frac{\rho_{L} d_{p} U_{p}}{\mu}
\end{aligned}
$$


Re is a function of particle properties (diameter and velocity relative to the surrounding fluid, $U_{p}$ ) and fluid properties (viscosity and density, $\rho_{L}$ ). In the absence of convection around the sphere, $R e$ is 0 and Equation (5.2.2) then gives the diffusive mass-transfer coefficient. In cases where convection was considered, the Re number was calculated using the settling velocity obtained from expressions for the drag coefficient. Three forms of the velocity expression are used to cover distinct Re number regimes (Denn 1980). Since Re is a function of the settling velocity, an iterative process is necessary to ensure the proper velocity expression is selected.

The diffusion coefficient $D_{A B}$ for dilute liquid solutions of solute $A$ in solvent $B$ is typically of the order $1 \times 10^{-9} \mathrm{~m}^{2} / \mathrm{s}$. Because the tank-waste chemistry is complex and lacking experimental values for waste diffusion coefficients, we assign the typical value in the limit that our solvent is pure water. The diffusion coefficient is expected to vary with solution properties, and many theoretical expressions for liquid diffusion coefficient are derived from the Stokes-Einstein equation (Hines and Maddux 1985) and take the form

$$
\mathrm{D}_{\mathrm{AB}}=\frac{\mathrm{K}}{\mu}
$$

In Equation (5.2.5), $\mathrm{K}$ is a grouping of other terms, and here it is taken as constant. As noted in Section 5.1.2, the viscosity of the liquid slurry is assumed to vary exponentially with liquid density from $1 \mathrm{cP}$ for water to $100 \mathrm{cP}$ (arbitrary) for saturated liquid at $1490 \mathrm{~kg} / \mathrm{m}^{3}$. This approach leads to a reduction in diffusion coefficient by about two orders of magnitude when the solution approaches saturation. Some literature results for aqueous salt solutions indicate changes in diffusion coefficient closer to $50 \%$ over the concentration range of 0.01 to $3 \mathrm{M}$ (Koryta et al. 1993). Thus the viscosity correction used here may result in underestimation of the diffusion coefficient and overestimation of the dissolution time in nearly saturated solutions.

Equation (5.2.2) defines the mass-transfer coefficient at a given particle diameter. As the particle dissolves, the particle diameter is reduced, and consequently, the mass-transfer coefficient also changes. For a small enough volume change, the particle diameter can be assumed to be constant. Therefore, the shrinking particle can be simulated using discrete volumetric changes. The time interval $\Delta t$ for dissolution of an outer spherical shell of a particle is given by

$$
\Delta t=\frac{\Delta \dot{\mathrm{V}}_{\mathrm{s}} \rho_{\mathrm{s}}}{\mathrm{A}_{\mathrm{p}} \mathrm{N}}
$$

where $\Delta V_{s}$ is the volume of shell solids dissolved, $A_{p}$ is the initial surface area of the particle shell, and $\rho_{\mathrm{S}}$ is the density of dissolving solids. The mass flux $\mathrm{N}$ in Equation (5.2.6) is determined by combining Equations (5.2.1) through (5.2.5). The shell approximation strictly holds in the limit of infinitesimal time steps, but reasonable results are obtained for small finite steps. In this analysis, input parameters for a given time step were evaluated and the time to reduce the particle diameter by $2 \%$ of its current value was calculated. A series of calculations like this were carried out until the particle diameter was reduced to $1 \%$ of its initial value. The cumulative dissolution time was summed from the successive shell dissolution times. 


\section{Analytical Results - Free Particle Dissolution Times}

In the analysis of free particle dissolution, solutions of varying density (dissolved solids concentration) ranging from pure water to near saturation were considered. ${ }^{\left({ }^{2}\right)}$ With water addition low in the tank and because of the high degree of mixing for this process (Section 3.1), the solution density will quickly increase above that of water. Pure water cases are included to cover the possible range of dissolution rates as the water is mixed into the slurry. If solids are not readily dissolved during water addition, the liquid portion of the slurry would decrease from the saturation density $\left(1490 \mathrm{~kg} / \mathrm{m}^{3}\right)$ with any water addition. For example, a water addition of only 8,600 gal into 500,000 gal of the pre-back-dilution mixed slurry $\left(1553 \mathrm{~kg} / \mathrm{m}^{3}, 2.7 \mathrm{vol} \%\right.$ gas and $15 \mathrm{vol} \%$ solids; Section 2.4 .4 ) would reduce the effective liquid density to $1480 \mathrm{~kg} / \mathrm{m}^{3}$ and the bulk mixed slurry density to $1540 \mathrm{~kg} / \mathrm{m}^{3}$ (assuming no gas release). A similar analysis for proposed post-first transfer back-dilution volumes of 35,000 or 72,000 gal (Section 2.4.4) results in effective liquid densities of $1452 \mathrm{~kg} / \mathrm{m}^{3}$ or $1417 \mathrm{~kg} / \mathrm{m}^{3}$, respectively. Therefore, even with efficient mixing, it is important to consider dissolution rates at liquid density less than the nearsaturation condition.

Figure 5.2 .1 shows the time to reduce $2200 \mathrm{~kg} / \mathrm{m}^{3}$ particles to $1 \%$ of their initial diameter in solutions of varying density. The results include convective mass-transfer effects associated with particle settling. The particle dissolution times for two liquid densities, 1360 and $1480 \mathrm{~kg} / \mathrm{m}^{3}$, are summarized in Table 5.2.1. As would be expected, dissolution times increase significantly for larger particles and with increasing concentration of dissolved solids in solution. As noted previously, more than half of the pure high-density solids are expected to be smaller than $10-\mu \mathrm{m}$ in diameter. In nearly saturated diluent $\left(1480 \mathrm{~kg} / \mathrm{m}^{3}\right)$ the time to dissolution for a $10-\mu \mathrm{m}$ particle is estimated at 2.8 minutes, and in $1360 \mathrm{~kg} / \mathrm{m}^{3}$ liquid the time is reduced to about seven seconds. For $1-\mu \mathrm{m}$ particles, the solids dissolve in less than two seconds in almost saturated solution and in a fraction of a second $(<0.1 \mathrm{sec})$ in the more dilute liquid $\left(1360 \mathrm{~kg} / \mathrm{m}^{3}\right)$. These data suggest that moderate amounts of added water that is well mixed with slurry containing typical small diameter particles will quickly reach saturation.

Dissolution is faster when convection, not diffusive mass transport alone, is considered. This is especially true for larger high-density particles and lower solution concentrations. Neglecting convection, calculated dissolution rates were just over 2 orders of magnitude slower than those shown in Figure 5.2.1 and Table 5.2.1 for 1-cm particles, while the rates were between 1.3 and 2.8 times slower for $100-\mu \mathrm{m}$ particles. Differences in diffusive-only and convective-plusdiffusive mass transfer for 1 and $10-\mu \mathrm{m}$ particles are negligible because the particle-settling velocities are so small.

The time for dissolution of larger solid particles, even when convection is accounted for, is estimated to be significantly longer than the settling time for the particle (without dissolution and neglecting fluid convection) in nearly saturated liquid. The estimated times for particles to settle

(a) A more complete analysis, accounting for changes in solution properties and mass-transfer rates as dissolution occurs, is possible. The extra effort is not warranted given our limited knowledge of actual waste mass-transfer coefficients and concentration-dependent variation of physical properties. The purpose of this and the following analysis of dissolution rates from crust surfaces is to capture the range of expected behavior. 


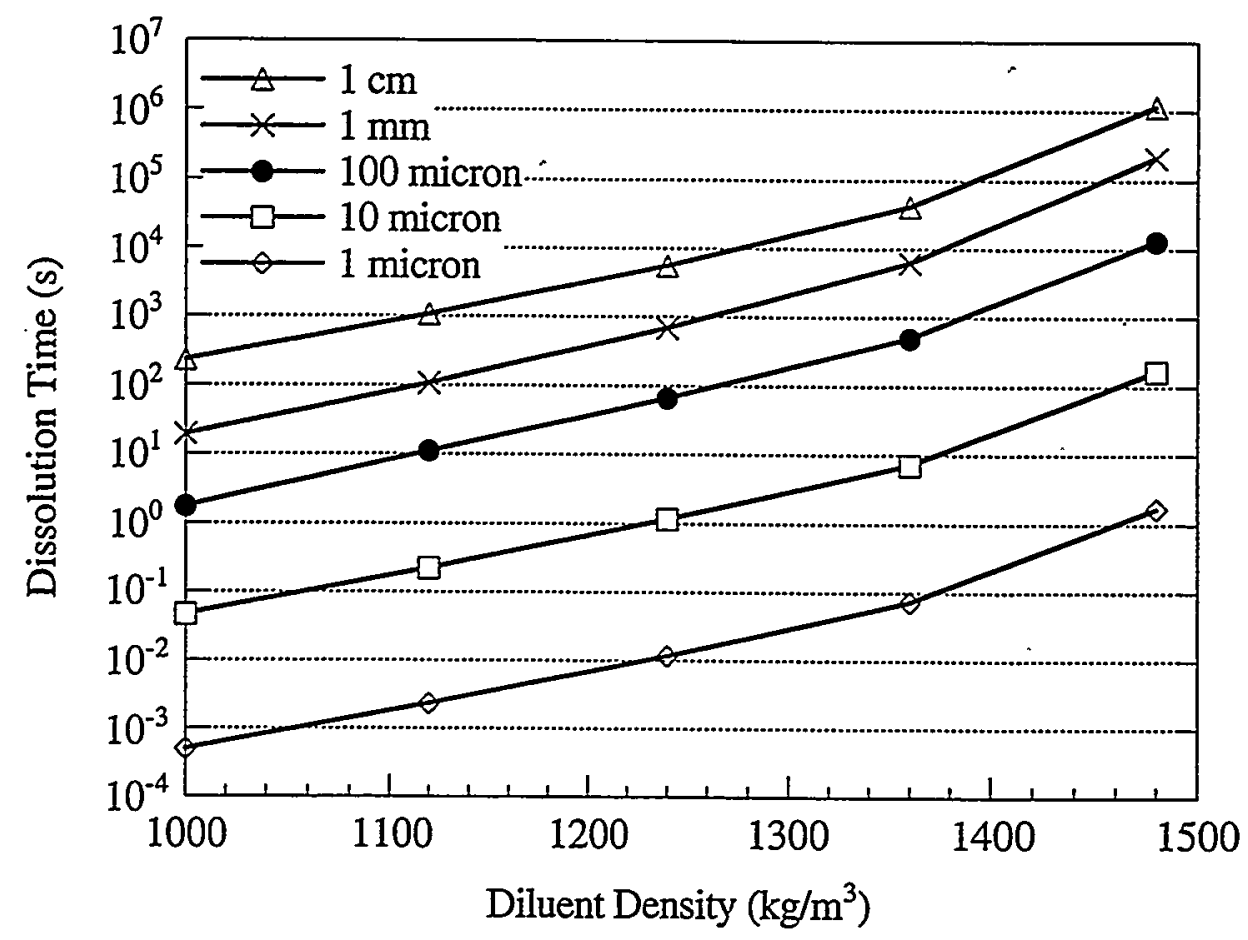

Figure 5.2.1. Time to Dissolve Solid Spheres $\left(\rho_{\mathrm{p}}=2200 \mathrm{~kg} / \mathrm{m}^{3}\right)$ to $1 \%$ of Initial Diameter in Solutions of Varying Concentration (density)

Table 5.2.1. Comparison of Dissolution Time and Estimated Settling Time in Slurry for $2200-\mathrm{kg} / \mathrm{m}^{3}$ Particles

\begin{tabular}{|c|c|c|c|}
\hline $\begin{array}{c}\text { Particle } \\
\text { Diameter }\end{array}$ & $\begin{array}{c}\text { Dissolution Time } \\
1360 \mathrm{~kg} / \mathrm{m}^{3} \text { Liquid }\end{array}$ & $\begin{array}{c}\text { Dissolution Time } \\
1480 \mathrm{~kg} / \mathrm{m}^{3} \text { Liquid }\end{array}$ & $\begin{array}{c}\text { Est. Settling Time in } \\
1480 \mathrm{~kg} / \mathrm{m}^{3} \text { Liquid }\end{array}$ \\
\hline $1 \mu \mathrm{m}$ & $0.07 \mathrm{~s}$ & $1.7 \mathrm{~s}$ & 52 years \\
\hline $10 \mu \mathrm{m}$ & $7.1 \mathrm{~s}$ & $2.8 \mathrm{~min}$ & 190 days \\
\hline $100 \mu \mathrm{m}$ & $8.2 \mathrm{~min}$ & $3.6 \mathrm{~h}$ & $45 \mathrm{~h}$ \\
\hline $1 \mathrm{~mm}$ & $1.7 \mathrm{~h}$ & $60 \mathrm{~h}$ & $27 \mathrm{~min}$ \\
\hline $1 \mathrm{~cm}$ & $11.4 \mathrm{~h}$ & $330 \mathrm{~h}$ & $45 \mathrm{~s}$ \\
\hline
\end{tabular}

through $7 \mathrm{~m}$ of $1480 \mathrm{~kg} / \mathrm{m}^{3}$ slurry liquid are summarized in Table 5.2 .1 along with calculated dissolution times. If a pure solid particle $1 \mathrm{~cm}$ in diameter fell from the bottom of the crust, it would travel $7 \mathrm{~m}$ in less than one minute, many orders of magnitude less time than is needed for the particle to dissolve. One-millimeter particles also settle much more quickly than the dissolution time even for more rapid dissolution in less saturated liquid $\left(1360 \mathrm{~kg} / \mathrm{m}^{3}\right)$. (Settling times in less dense and less viscous fluid would be less than the values presented in Table 5.2.1 for a $1480 \mathrm{~kg} / \mathrm{m}^{3}$ and $91 \mathrm{cP}$ liquid.) On the other hand, particles smaller than $10 \mu \mathrm{m}$ dissolve much more quickly than their settling rates, while for a $100-\mu \mathrm{m}$ particle dissolution is minimally 10 times faster than settling. The settling data suggest that the majority of solid particles "retained" in the mixed slurry are on the order of $100-\mu \mathrm{m}$ diameter or smaller, those most 
susceptible to rapid dissolution. A $10-\mu \mathrm{m}$ particle is estimated to take more than one-half year to settle through diluted slurry and even longer in the pre-back-dilution mixed slurry.

Of course, larger solid-liquid-gas bubble agglomerates near neutral buoyancy could be retained in the mixed slurry (Section 6.2.1) for long periods of time. Therefore, dissolution rates of waste gobs, modeled as spheres, are worth considering. Dissolution time results for $100-\mu \mathrm{m}$ and $1-\mathrm{cm}$-diameter agglomerates $\left(1500-\mathrm{kg} / \mathrm{m}^{3}\right.$ particle density) are compared in Table 5.2 .2 with results for true solids particles of the same sizes. In all cases, the lower density agglomerates are dissolved more slowly than comparably sized solid particles at any given diluent concentration (liquid density). This is a result of reduced convective mass transport for these slower settling gobs. At $100-\mu \mathrm{m}$ diameter, the solid particle dissolution times are less than two times faster than for agglomerates. Convection has little effect on dissolution rates for particles $100 \mu \mathrm{m}$ and smaller; however, the impact of convection is more noticeable for 1-cm particles in denser liquid diluent. In $1480 \mathrm{~kg} / \mathrm{m}^{3}$ liquid, the dissolution time for $1-\mathrm{cm}$ agglomerates exceeds that for solid particles by about five times, taking about two months to dissolve.

Table 5.2.2. Time to Reduce Dissolving Spheres to $1 \%$ of Initial Diameter

\begin{tabular}{|c|c|c|c|c|}
\hline & $2200 \mathrm{~kg} / \mathrm{m}^{3}$ Particle Density & \multicolumn{2}{|c|}{$1500 \mathrm{~kg} / \mathrm{m}^{3}$ Agglomerate Density } \\
\hline $\begin{array}{c}\text { Liquid Density } \\
\left(\mathrm{kg} / \mathrm{m}^{3}\right)\end{array}$ & $\begin{array}{c}\text { Time } 100-\mu \mathrm{m} \\
\text { Particles (s) }\end{array}$ & $\begin{array}{c}\text { Time 1-cm } \\
\text { Particles (s) }\end{array}$ & $\begin{array}{c}\text { Time } 100-\mu \mathrm{m} \\
\text { Particles (s) }\end{array}$ & $\begin{array}{c}\text { Time 1-cm } \\
\text { Particles (s) }\end{array}$ \\
\hline 1000 & 1.7 & 231 & 2.5 & 352 \\
\hline 1120 & 11 & 1050 & 15 & 1,720 \\
\hline 1240 & 67 & $5,580(1.5 \mathrm{~h})$ & 88 & $1.07 \times 10^{4}(3.0 \mathrm{~h})$ \\
\hline 1360 & 493 & $4.12 \times 10^{4}$ & 621 & $9.68 \times 10^{4}$ \\
& $(11.4 \mathrm{~h})$ & $26.9 \mathrm{~h})$ \\
\hline 1480 & $1.29 \times 10^{4}$ & $1.19 \times 10^{6}$ & $1.60 \times 10^{4}$ & $6.25 \times 10^{6}$ \\
& $(3.6 \mathrm{~h})$ & $(330 \mathrm{~h})$ & $(4.4 \mathrm{~h})$ & $(1,740 \mathrm{~h})$ \\
\hline
\end{tabular}

\subsubsection{Dissolution at Crust Surfaces}

An analysis was completed of dissolution rates at crust surfaces similar to the free particle dissolution analysis described above. Two crust dissolution scenarios were considered. In one, water is added atop the crust and in the other, the diluent was added below. Both are planned following waste transfers in an attempt to dissolve solids and release trapped gases within the waste matrix. In top-down dilution it is possible to contact the crust with pure water, at least initially. In bottom-up dilution, mixing of the diluent with slurry below the crust will increase the density of the liquid and at least partially saturate it. The state of saturation of liquid buoying to the base of the crust will depend on where and how the water is added (Section 3.1). As we demonstrate here, the degree of liquid saturation greatly impacts the rate of crust dissolution.

In the discussion in Section 5.2.1, the rate of dissolution of crust solids is assumed to be mass transport-limited, not limited by dissolution kinetics. The dissolution-rate-limiting mechanisms are diffusion and convection in the water/waste mixture that bring fresh, less-saturated liquid in contact with the crust surface and carry dissolved salt species away from the saturated solid/liquid interface. In the particle dissolution analysis, particle-settling velocities provided a 
clear choice for evaluating convective effects, and mass-transfer rates were readily calculated using the Sherwood number correlation (Equation 5.2.2). To describe mass transport adjacent to the crust surfaces, which are assumed planar for this analysis, it was appropriate to draw on the frequently used analogy between heat and mass transfer. For the present analysis, we used solutions from free-convection heat transfer from flat plates to calculate mass-transfer rates from a solid crust surface by replacing the relevant heat transfer terms with the analogous masstransfer groups.

The potential for increased convection driven by bubble release and liquid drag near the crust surface was neglected. The contribution of this mechanism to overall mass transfer is thought to be very small if bubbles are only released intermittently (e.g., through surface dissolution of a homogeneous bubble-waste matrix), even if the releases are broadly distributed over the crust surface. Sparse but highly concentrated "streams" of bubbles might increase convection locally, but the net overall effect on mass transfer across the crust surface would be small.

\section{Method of Analysis}

The analogy between heat and mass transfer is well documented in the literature (Rousseau 1987; Bird et al. 1960). This analogy allows one to calculate mass-transfer rates from analogous heat-transfer conditions and vice-versa, when the mass-transfer rates are low. Here, the masstransfer analogy for free-convection heat transfer from flat plates provided correlations from which mass-transfer coefficients were determined (see below).

The mass-transfer correlation approach for crust surfaces is similar to the application of Equation (5.2.2) to evaluate spherical particle dissolution rates. After determining a masstransfer coefficient, the mass flux from a crust surface was calculated (Equation 5.2.1) and used to obtain crust dissolution rates. In both top-down and bottom-up dissolution, the dissolution rates for a range of diluent solution concentrations (represented by liquid density) were analyzed. The crust was treated as a right cylinder with planar solid upper and lower surfaces equivalent in area to the tank cross-sectional area $\left(410 \mathrm{~m}^{2}\right)$. Treating the crust as a pure solid $\left(2200 \mathrm{~kg} / \mathrm{m}^{3}\right)$ instead of a solid-liquid gas-bubble matrix has no bearing on the dissolution rates obtained in this analysis approach. Any gain in dissolution effectiveness because of the reduced amount of solids needing to be dissolved (volumetric basis) is countered by a comparable decrease in effective solids surface area available for dissolution. Gas releases corresponding to the crust dissolution rates presented below are evaluated separately in Section 6.

For dissolution of crust from the bottom up, where buoyancy-driven convection would tend to replace the saturated liquid generated at the solid/liquid interface with less dense and less saturated fluid, the following mass-transfer correlation applies

$$
\mathrm{Sh}=\frac{k_{\mathrm{c}} \mathrm{L}}{\mathrm{D}_{\mathrm{AB}}}=0.13(\mathrm{GrSc})^{1 / 3}
$$

The result is analogous to natural-convection heat transfer from a flat plate that is heated from below (Kreith and Bohn 1986). In this, the mass (or heat) transfer vector is aligned with the gravity vector, maximizing the transfer rate. In Equation (5.2.8), the heat transfer dimensionless groups have been replaced with the relevant mass-transfer groups (e.g., Schmidt 
number for the Prandtl number and the Sherwood number for the Nusselt number) as documented by Bird et al. (1960). The Grashof number Gr accounts for convection due to density differences

$$
\mathrm{Gr}=\frac{\mathrm{L}^{3} \mathrm{~g} \rho_{\mathrm{L}} \Delta \rho}{\mu^{2}}
$$

In this, $\mathrm{g}$ is the acceleration due to gravity, and $\Delta \rho$ is the density difference between saturated liquid formed adjacent to the dissolving solid surface $\left(1490 \mathrm{~kg} / \mathrm{m}^{3}\right)$ and the bulk diluent a vertical distance $\mathrm{L}$ from the dissolution front. Because of the one-third-power scaling of Gr in Equation (5.2.8) and the third-power dependence on the mass-transfer length scale $\mathrm{L}$ in Equation (5.2.9), the mass-transfer coefficient $k_{c}$ is independent of $L$ for bottom-up dissolution.

Dissolution of the crust from the top down by a layer of diluent on top of the crust is analogous to natural-convection heat transfer from a flat plate that is heated from above. The heat-transfer correlation (Kreith and Bohn 1986) has the following mass-transfer analogue:

$$
\mathrm{Sh}=\frac{\mathrm{k}_{\mathrm{c}} \mathrm{L}}{\mathrm{D}_{\mathrm{AB}}}=0.58(\mathrm{GrSc})^{1 / 5}
$$

In this situation, the mass (or heat) transfer vector is $180^{\circ}$ out of alignment with the gravity vector, reducing the rate of transfer. The mass-transfer coefficient depends on the length scale in this case. To obtain more conservative (fast) dissolution rate estimates, a thin 0.1-m (L) layer of overlying liquid was typically assumed. The smaller power dependence of the Grashof-Schmidt product indicates decreased relative contribution of convection and increased diffusive character.

Some relevant conditions applied in the analyses are density of water, $1000 \mathrm{~kg} / \mathrm{m}^{3}$; saturated slurry density, $1490 \mathrm{~kg} / \mathrm{m}^{3}$; and slurry viscosity, varying exponentially as a function of density between $1 \mathrm{cP}$ (water) and $100 \mathrm{cP}$ (saturated liquid). As in the free particle dissolution analysis (Section 5.2.2), a typical liquid diffusion coefficient was assigned for dilute solutions $\left(1 \times 10^{9} \mathrm{~m}^{2} / \mathrm{s}\right)$. The viscosity-dependent diffusion coefficient Equation (5.2.5) was applied in some cases, and in others the typical liquid value was applied for all solution concentrations.

\section{Analytical Results for Crust Surface Dissolution Rates}

The analytical approach described above was used to calculate crust dissolution rates in units of thickness dissolved per unit time $(\mathrm{cm} / \mathrm{h})$. This form is useful for comparison to chemical simulant crust dissolution experiment results (Section 5.3) and is convenient for analysis of gas release rates (Section 6). In units of $\mathrm{cm} / \mathrm{h}$, the dissolution rate is independent of surface area, but area is critical for determining volumetric rates. A result in $\mathrm{cm} / \mathrm{h}$ is readily converted to a volumetric dissolution (and gas release) rate by multiplying it by the appropriate solids contact area (Equation 6.3.1).

Figure 5.2.2 shows the estimated dissolution rates as function of diluent liquid density in the case of bottom-up dissolution, and Figure 5.2.3 shows the analogous results for top-down 


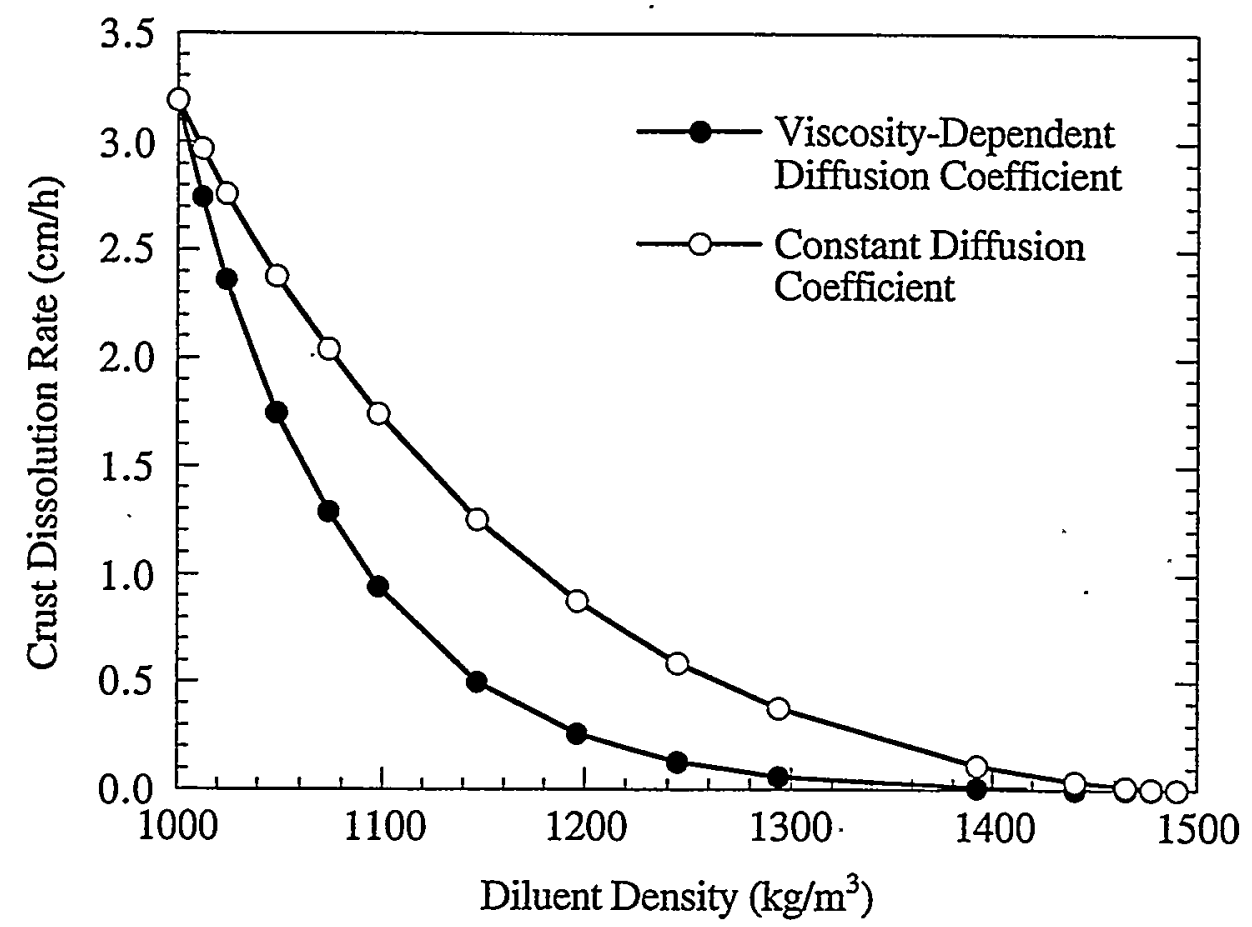

Figure 5.2.2. Crust Dissolution Rates for Bottom-Up Crust Dissolution

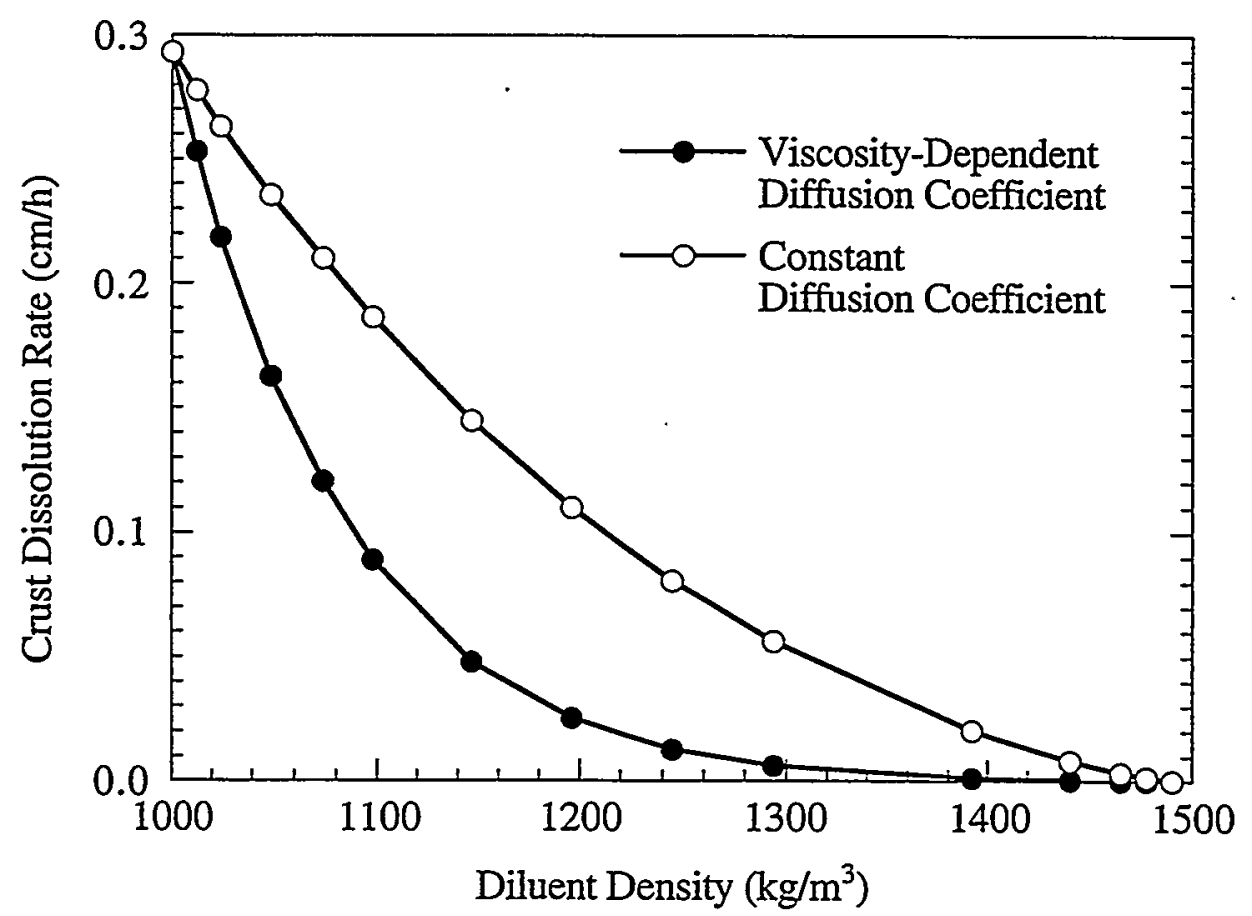

Figure 5.2.3. Crust Dissolution Rates for Top-Down Crust Dissolution 
dissolution. As would be expected, due to increased natural convection, dissolution rates are greater for bottom-up dissolution. In the hypothetical case in which pure water is introduced (and held) under the crust, a maximum dissolution rate of $\sim 3 \mathrm{~cm} / \mathrm{h}$ is estimated. For more realistic situations, where water is added low in the tank and mixes with slurry to produce more saturated diluent $\left(>1400 \mathrm{~kg} / \mathrm{m}^{3}\right.$ ), the bottom crust dissolution rates fall well below $0.2 \mathrm{~cm} / \mathrm{h}$. Over time, the mixing (natural convection) of saturated diluent created at the solids/liquid interface with diluent below it causes the bulk dissolved solids concentration to increase, further limiting the dissolution rate.

Top-down dissolution rates are considerably lower, even when contacted with pure water $(0.3 \mathrm{~cm} / \mathrm{h})$. This is attributed to the lack of convective transport to refresh diluent at the crust surface; the most saturated liquid falls toward, not away from, the crust surface as in the bottomup case. (Note that this case addresses a layer of diluent in place on top of the crust surface and does not consider convective effects during the water addition process.) However, an advantage may be gained in top-down dissolution if the crust buoys higher due to increased liquid saturation and pushes the crust surface into less-saturated liquid above. The results shown in Figure 5.2 .3 are for a liquid layer thickness of $0.1 \mathrm{~m}$. If the layer is reduced to $0.01 \mathrm{~m}(1 \mathrm{~cm})$, the calculated dissolution rate increases to $0.7 \mathrm{~cm} / \mathrm{h}$. This is in very good agreement with maximum dissolution rates observed in chemical simulant experiments $(-1 \mathrm{~cm} / \mathrm{h})$ where the water layer thickness was typically on the order of $1 \mathrm{~cm}$ (Section 5.3).

Figures 5.2.3 and 5.2.4 plot crust dissolution rate results for constant and viscosity-dependent diffusion coefficient cases. As anticipated, the dissolution rates decrease when the lower value of the variable diffusion coefficient is applied. Visually, the differences are most apparent in the middle of the density range, where dissolution rates on the two curves vary by as much as 10 times. However, the maximum differences ( $>30$ times) actually occur nearer the high-density end, where the largest differences in diffusion coefficient are applied. The greater separation of variable and constant diffusion coefficient plots for top-down dilution (Figure 5.2.3) is indicative of a greater contribution of diffusive mass transport in that system.

\subsection{Chemical Simulant Crust Dissolution Tests}

This section presents laboratory experimental results for the dissolution of small-scale crusts prepared from chemical simulants of SY-101 tank waste. (a) The experiments had three specific purposes. First, to identify mechanisms of crust dissolution and gas release; second, to determine the rate of crust dissolution and resulting gas release; and third, to observe whether there are differences in the rates and mechanisms of dissolution and gas release when water is added on top of or just below the crust surface. While the primary focus of this section is dissolution mechanisms and rates, it is not practical to discuss the chemical simulant experiments without describing the complementary gas release mechanisms and rates. Additional emphasis on gas release mechanisms and tank-scale gas release rates is given in Section 6.

(a) This section is developed from PNNL letter report TWS00.01, Crust Dissolution by Water: Experimental Results for Chemical Simulant Crusts, by SD Rassat, VV Viswanathan, DP Mendoza, and SA Bryan. Pacific Northwest National Laboratory, Richland, Washington. 
The chemical simulant crust dissolution experiments and results are discussed in three major subsections. In Section 5.3.1, the chemistry of the waste simulant and the methods of crust formation from the simulant are described. The experimental apparatus and methods used in crust dissolution studies are noted in Section 5.3.2. The experimental results are presented in Section 5.3.3; included are discussions of observed gas release mechanisms, rates of crust dissolution and gas release, and bulk sample dilution (larger water additions) as it relates to diffusion-limited solids dissolution.

\subsubsection{Chemical Simulant Crusts}

Chemical simulant waste samples were conditioned in the laboratory to create crusts for studies of dissolution resulting from water addition. To best represent expected dissolution behavior in SY-101, the composition of the chemical simulant was similar to actual tank waste. The simulant chemistry and method and mechanism of simulated crust formation are described.

\subsubsection{Simulant Chemistry and Batch Preparation}

Historically, chemical simulants of SY-101 waste have been used to gain understanding of gas generation, retention, and release in the tank (Bryan et al. 1992; Bryan and Pederson 1994; Rassat and Gauglitz 1995). Bryan and his coworkers (Bryan et al. 1992; Bryan and Pederson 1994) evaluated available information on the composition of SY-101 waste and developed a series of nonradioactive chemical simulants. In their earlier work, they show that variations in aluminate $\left(\mathrm{NaAlO}_{2}\right)$ and organic $\left(\mathrm{Na}_{4} \mathrm{EDTA}\right.$ and $\left.\mathrm{Na}_{3} \mathrm{HEDTA}\right)$ composition, relative to a "reference recipe," result in dramatic changes in the formation of strata within thermally treated samples. In some cases, relatively thick crusts were formed, and in others, relatively thick nonconvective or slurry layers formed. A 15-L batch of simulant based on the reference recipe was prepared.for this current work. The composition of this batch is shown in Table 5.3.1. A batch of "low aluminate, low organic" simulant was also prepared because it was shown in the earlier tests to create relatively thick crusts. Recent attempts to recreate these resulted in only very thin crusts, and it is still unclear what differences in chemistry and/or sample handling caused this.

A new best-basis composition was recently determined for SY-101 waste. ${ }^{(a)}$ This information was used to create a 15-L batch of the new nonradioactive chemical simulant SY1-SIM99A. The composition of this simulant is also shown in Table 5.3.1. Attempts to create crusts with this simulant were unsuccessful. Several composition variations were attempted, including preparations with and without the transition metal species ( $\mathrm{Cr}, \mathrm{Fe}$, and $\mathrm{Ni}$ ) and samples with increased levels of organic material (as $\mathrm{Na}_{3} \mathrm{HEDTA}$ ). Thermal conditioning protocols used to generate crusts from samples of the reference recipe and SY1-SIM-99A simulants were similar. Therefore, differences in crust formation in these simulants are apparently due to chemical composition. Without further investigation it is not possible to attribute the variation in observed properties to specific components. Species to consider first are those with the largest differences. The new simulant SY1-SIM-99A has more hydroxide $(\mathrm{OH})$, carbonate $\left(\mathrm{CO}_{3}\right)$, nitrite $\left(\mathrm{NO}_{2}\right)$, and

(a) LA Mahoney (PNNL) evaluated SY-101 best-basis data available in the TWINS database and other sources (e.g., Window $\mathrm{E}$ analysis) and reconciled the data to create the simulant composition. DL Herting (NHC) further evaluated the proposed composition. Appropriate changes were incorporated in the final composition provided by LA Mahoney in a personal communication on April 22, 1999. 
Table 5.3.1. Composition of SY-10I Waste Chemical Simulants

\begin{tabular}{|c|c|c|}
\hline Chemical Species & $\begin{array}{c}\text { Simulant } \\
\text { SY1-SIM-99A } \\
\text { Composition, wt\% }\end{array}$ & $\begin{array}{c}\text { "Reference Recipe" } \\
\text { Simulant Composition, } \\
\text { wt\% }\end{array}$ \\
\hline Total organic C & 1.483 & 3.878 \\
\hline organic + aluminate $\mathrm{O}$ & 3.355 & 7.230 \\
\hline organic N & 0.167 & 0.905 \\
\hline organic $\mathrm{H}$ & 0.189 & 0.561 \\
\hline $\mathrm{Na}$ & 19.851 & 21.277 \\
\hline $\mathrm{Al}$ & 3.129 & 2.903 \\
\hline $\mathrm{Cr}$ & 0.351 & 0.005 \\
\hline $\mathrm{K}$ & 0.326 & 0.000 \\
\hline $\mathrm{Ca}$ & 0.034 & 0.000 \\
\hline $\mathrm{Cu}$ & 0.000 & 0.001 \\
\hline $\mathrm{Fe}$ & 0.030 & 0.007 \\
\hline $\mathrm{Ni}$ & 0.015 & 0.011 \\
\hline $\mathrm{NO}_{3}$ & 12.133 & 12.012 \\
\hline $\mathrm{NO}_{2}$ & 10.619 & 8.863 \\
\hline $\mathrm{OH}$ & 5.868 & 3.565 \\
\hline $\mathrm{CO}_{3}$ & 3.597 & 1.492 \\
\hline $\mathrm{Cl}$ & 0.805 & 0.772 \\
\hline $\mathrm{PO}_{4}$ & 0.637 & 1.181 \\
\hline $\mathrm{SiO}_{4}$ & 0.576 & 0.000 \\
\hline $\mathrm{SO}_{4}$ & 0.379 & 0.000 \\
\hline $\mathrm{F}$ & 0.101 & 0.118 \\
\hline $\mathrm{H}_{2} \mathrm{O}$ & 36.370 & 35.221 \\
\hline Total & 100.0 & 100.0 \\
\hline $\begin{array}{l}\text { Measured Bulk Density, } \\
\mathrm{g} / \mathrm{mL}\end{array}$ & 1.54 in 1-L PMP jar & $\begin{array}{l}1.56 \text { in 1-L PMP jar } \\
1.51 \text { in } 0.5-\mathrm{L} \text { grad. cyl. }\end{array}$ \\
\hline
\end{tabular}

aluminate, significantly lower organic content, and moderately lower phosphate $\left(\mathrm{PO}_{4}\right)$. The organic species used in the two simulants are also different. $\mathrm{Na}_{4} \mathrm{EDTA}$ and a large fraction of $\mathrm{Na}_{3} \mathrm{HEDTA}$ are used in the reference recipe, while $\mathrm{Na}_{4} \mathrm{EDTA}$, sodium oxalate $\left(\mathrm{Na}_{2} \mathrm{C}_{2} \mathrm{O}_{4}\right)$, and tributyl phosphate (TBP) are used in SY1-SIM-99A. While no crust formed in the SY1-SIM99A simulant samples, gas bubbles were clearly generated, indicating thermal decomposition of some organic components.

\subsubsection{Formation of Chemical Simulant Crusts}

Simulant chemistry is a factor in the formation of crusts in these materials. The physical handling of simulant samples is also important. In these studies, each simulant sample was conditioned at temperatures between 50 and $90^{\circ} \mathrm{C}$ in air ovens to form floating layers, or crusts. We show that temperature history and sample dryout play a significant role in the crust properties. 
Two types of chemical simulant sample containers were used in these studies, 1-L clear plastic (polymethyl pentene, PMP) jars and 0.5-L glass (Pyrex) graduated cylinders. The plastic containers were $\sim 11 \mathrm{~cm}$ in diameter, corresponding to just over $1.0 \mathrm{~cm}$ for each $100 \mathrm{~mL}$ of sample volume. Gradations of $100 \mathrm{~mL}$ were marked on the outer walls of the containers using a permanent marker. A 1/8-inch $(\sim 0.3-\mathrm{cm})$-diameter hole was drilled in each plastic screw closure (lid) to vent and prevent pressure buildup during gas generation. In some cases the lids were removed completely during thermal conditioning. All the graduated cylinder samples were uncovered during conditioning. The graduated cylinders were considerably narrower $(\sim 4.7 \mathrm{~cm})$, corresponding to a much larger level change per unit volume, $\sim 5.8 \mathrm{~cm}$ per $100 \mathrm{~mL}$. This leads to thicker crust formation per unit volume of chemical simulant. It also corresponds to more significant wall effects in dissolution experiments because of the high surface contact area per unit volume of crust (simulant).

Aliquots of the bulk chemical simulant batch ( $15 \mathrm{~L}$ initially) were transferred to appropriate containers. First, the bulk simulant in a $20-\mathrm{L}$ plastic carboy was mixed thoroughly with a propeller/impeller stirrer. The laboratory vacuum system was used to siphon sample from the carboy through a $\sim 0.5$-inch-diameter tube into 1-L plastic containers. Sample was poured from a $1-\mathrm{L}$ plastic container into the graduated cylinders when used. About $400 \mathrm{~mL}$ of simulant were dispensed to each graduated cylinder and roughly $700-800 \mathrm{~mL}$ were transferred to each 1-L plastic container. Initial sample masses and volumes (levels) were recorded. The calculated average bulk densities for these unconditioned simulant samples are shown in Table 5.3.1. The densities for the reference recipe simulant were different for samples in 1-L plastic jars $(1.56 \mathrm{~g} / \mathrm{mL})$ and $0.5-\mathrm{L}$ graduated cylinders $(1.51 \mathrm{~g} / \mathrm{mL})$. The higher-density samples were transferred nearly six months before the others, and the discrepancies may be due to differences in the effectiveness of mixing before transfer. The density of SY1-SIM-99A samples, in which crust formation was not observed, was comparable at $1.54 \mathrm{~g} / \mathrm{mL}$.

Thermal conditioning was used to generate crusts on the chemical simulant samples. A key step was the initiation of crust formation at relatively high temperature $\left(90^{\circ} \mathrm{C}\right)$. The high temperature promotes dissolution and equilibration of the various chemical phases used in the simulant batches. Additionally, gas is generated at an accelerated rate at high temperature through thermal decomposition of various simulant species. Gas bubbles generated in and subsequently released from the nonconvective layer often carry some solids and liquid to the upper surface, the floating precursors of crust. A frothy initial layer limits the migration of bubbles and waste gobs (a matrix of many bubbles, solids, and liquid) released at later times from below. The upper crust develops strength as it dries in the air above it, and the solids below may act as nucleation sites for additional solids deposition (crystallization) as evaporation of the bulk sample takes place.

The simulant samples were heated in ovens from 2-4 months to grow and "cure" the crusts before dissolution experiments were run. Using the most recent thermal conditioning protocols, chemical simulant crust samples can be prepared in as little as 1-2 weeks. In the recent procedure, the sample is heated to $90^{\circ} \mathrm{C}$ from one to four days, and then the temperature is lowered, typically to $50^{\circ} \mathrm{C}$, for the remainder of conditioning. This approach was applied to graduated cylinder samples with $\sim 2$ months of final conditioning. Several variations of this were used with the other samples including preconditioning at $60^{\circ} \mathrm{C}$ before heating to $90^{\circ} \mathrm{C}$, followed by conditioning at $60^{\circ} \mathrm{C}$ for extended periods before final conditioning at near SY-101 tank 
temperature $\left(50^{\circ} \mathrm{C}\right.$ ). These variations and using (or not using) sample closures to minimize evaporation affect the crust thickness, dryness, and other physical characteristics.

Some significant differences in crust properties due to sample conditioning variations are noted in Figures 5.3.1 and 5.3.2. The figures are a series of photographs for two different samples of the same (reference) simulant, following somewhat different conditioning schemes. Both samples were initially treated at $60^{\circ} \mathrm{C}$, followed by a short increase to $90^{\circ} \mathrm{C}$, with the bulk of the conditioning at $60^{\circ} \mathrm{C}$ before the final temperature reduction to $50^{\circ} \mathrm{C}$. The sample shown in Figure 5.3.1 had the lid off for about three months at $60^{\circ} \mathrm{C}$, and the sample in Figure 5.3.2 had the lid off only for the final stages at $50^{\circ} \mathrm{C}$. Each figure shows side (upper photos) and top (lower photos) views one day after the temperature reduction from 60 to $50^{\circ} \mathrm{C}$ (left-hand photos) and more than a week after the change (right-hand photos). The transformation of crust properties resulting from lowering the temperature was noted as soon as four days (over a weekend) after the oven was adjusted, but no change was detected after the first day. The
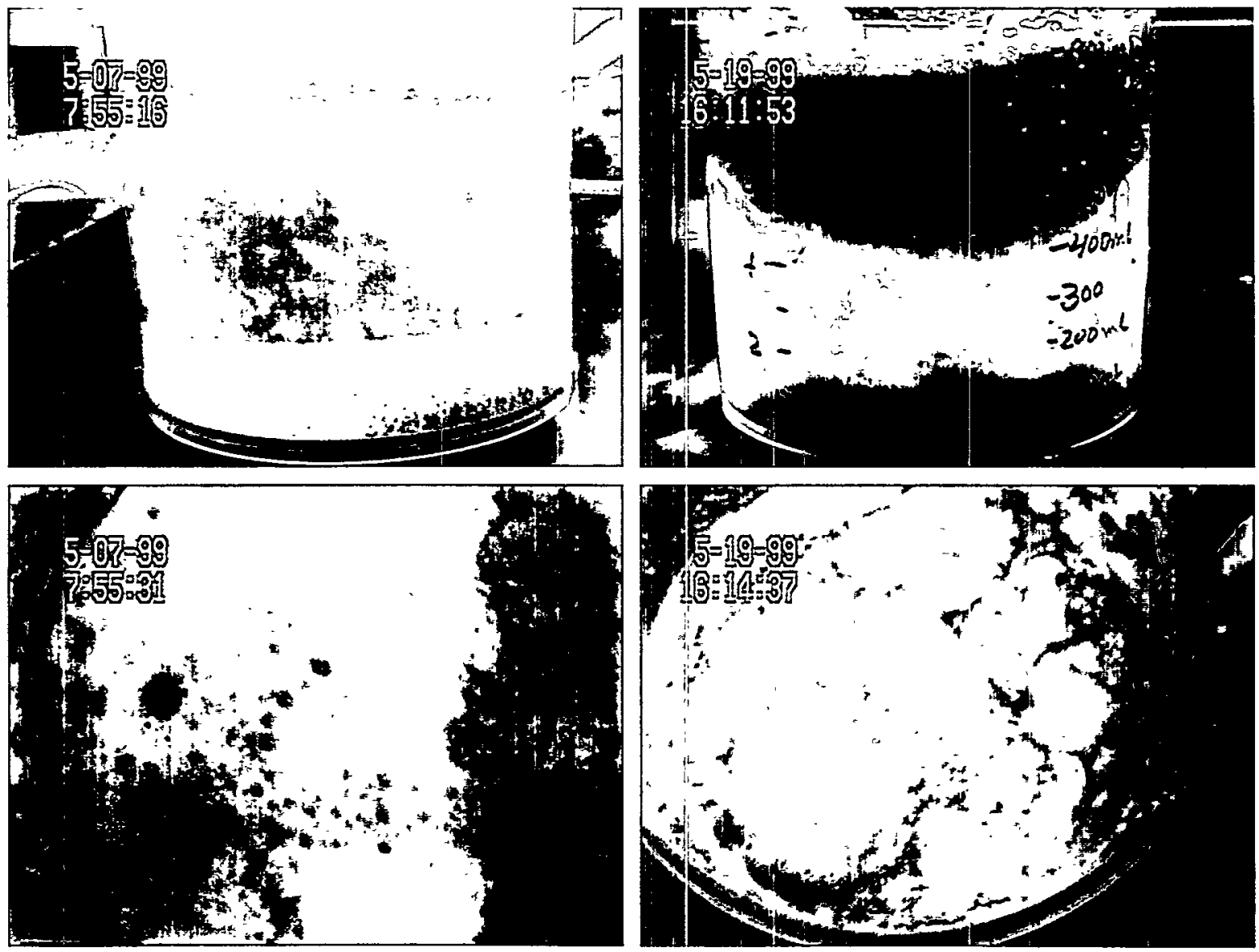

Figure 5.3.1. Changes in Crust Properties with Temperature Reduction in a Chemical Simulant Sample with Greater Evaporation: (a) upper left-little change one day after temperature lowered from 60 to $50^{\circ} \mathrm{C}$; (b) upper right-significantly thicker crust after several days at $50^{\circ} \mathrm{C}$; (c) lower left-top view of (a); (d) top view of (b) showing cauliflower-like growths 

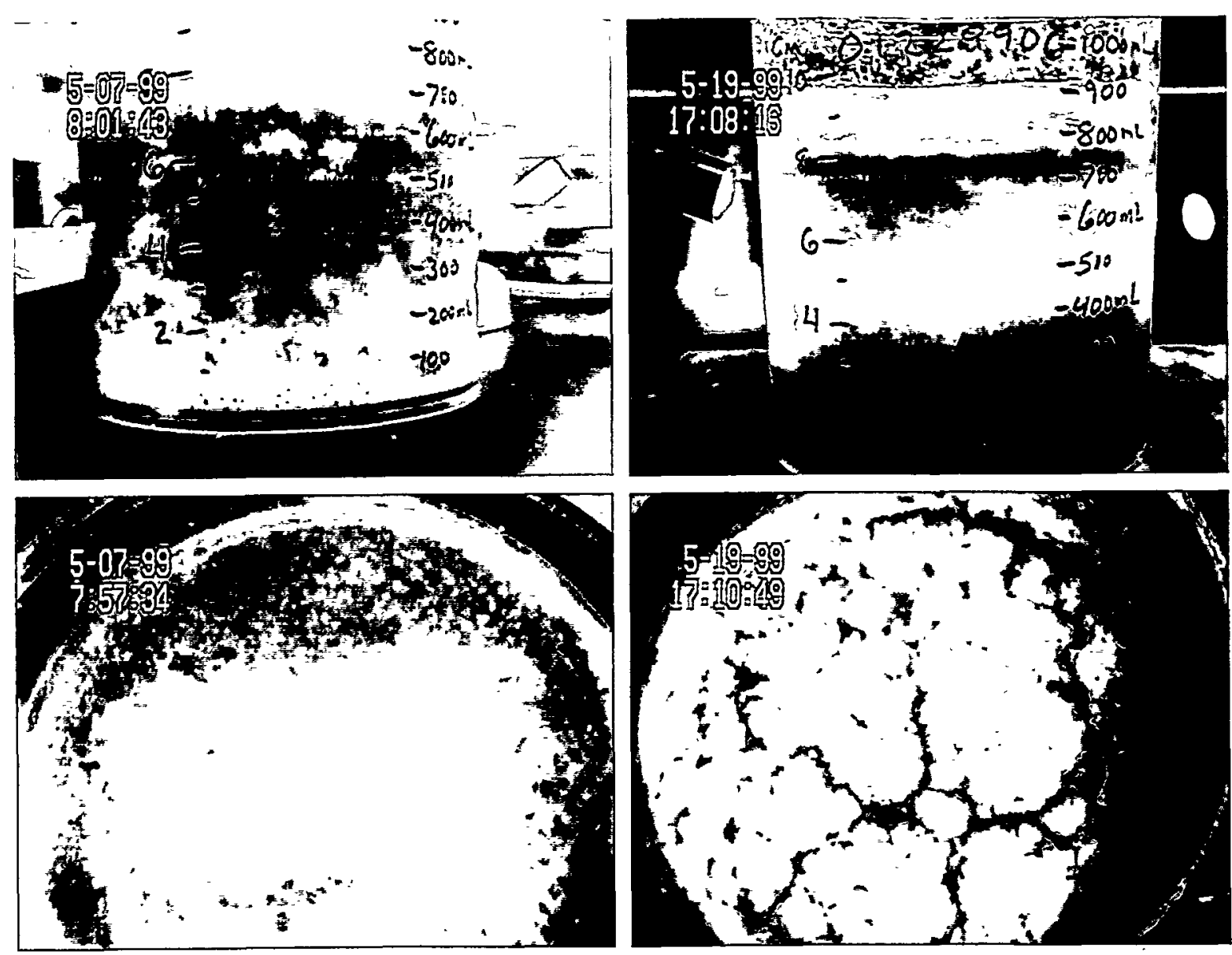

Figure 5.3.2. Changes in Crust Properties with Temperature Reduction in a Chemical Simulant Sample with Less Evaporation: (a) upper left-little change one day after temperature lowered from 60 to $50^{\circ} \mathrm{C}$; (b) upper right-little change in crust thickness after several days at $50^{\circ} \mathrm{C}$; (c) lower left - top view of (a); (d) top view of (b) showing increased surface roughness

increase in crust thickness on one sample (Figure 5.3.1) is likely due to greater evaporation, supersaturation of salts in the slurry, and subsequent crystallization after the temperature reduction. Approximately $130 \mathrm{~g}$ evaporated from the sample shown in Figure 5.3.1, and $<70 \mathrm{~g}$ was lost from a sample comparable to that shown in Figure 5.3.2. In some samples, gas pockets were visible just below the crust layer, possibly as a result of evaporation and the crust sticking to the container walls. In addition to changes in crust thickness, the surface morphology of both samples changed dramatically after the temperature reduction. The roughness of the surface increased, possibly due to wicking of the saturated salt solution to the upper surface and crystallization or dryout of certain species. This is most spectacular in the cauliflower-like protrusions observed in the photo on the lower right in Figure 5.3.1. 
For comparison, no crust layer was observed on samples of SY1-SIM-99A. Of the many samples tested, including variations in organic content, the conditioned samples had only two layers, a loose, floc-like, settled solids layer (nonconvective) occupying $>50 \%$ and up to $90 \%$ of the sample volume and an upper convective layer.

\subsubsection{Crust Dissolution Experiment Approach and Apparatus}

Several thermally conditioned chemical simulant samples were used in crust dissolution experiments. Water was added to these samples, either below or on top of the crust, and the solids dissolution and gas release process was monitored. Figure 5.3.3 is a schematic depiction of the dilution monitoring and temperature control system.

Throughout the dilution process, the sample was held at $\sim 50^{\circ} \mathrm{C}$ in a laboratory-fabricated water bath consisting of a large glass vessel partially filled with water and heated from below by a hot plate. The duty cycle of the hot plate was controlled with a Cole-Parmer Digi-Sense(B) temperature controller, which was set to $50^{\circ} \mathrm{C}$ and measured the bath temperature using a type- $\mathrm{K}$ thermocouple. The water in the bath was mixed with a propeller stirrer to maintain a relatively uniform temperature. About 14-20 hours after adding water to the sample, it was transferred to an air oven at $50^{\circ} \mathrm{C}$. Measurements and observations were made intermittently thereafter.

Typically, two video camera recording systems were used to monitor the progress of dissolution. As shown in Figure 5.3.3, one camera (VAI model CV-755 remote head color micro CCD camera) was set to view the top surface of the sample. From this view, gas releases (through liquid) and the surface coverage of crust were observed. When the top view camera was used, the sample was uncovered and therefore subject to increased evaporation. The other

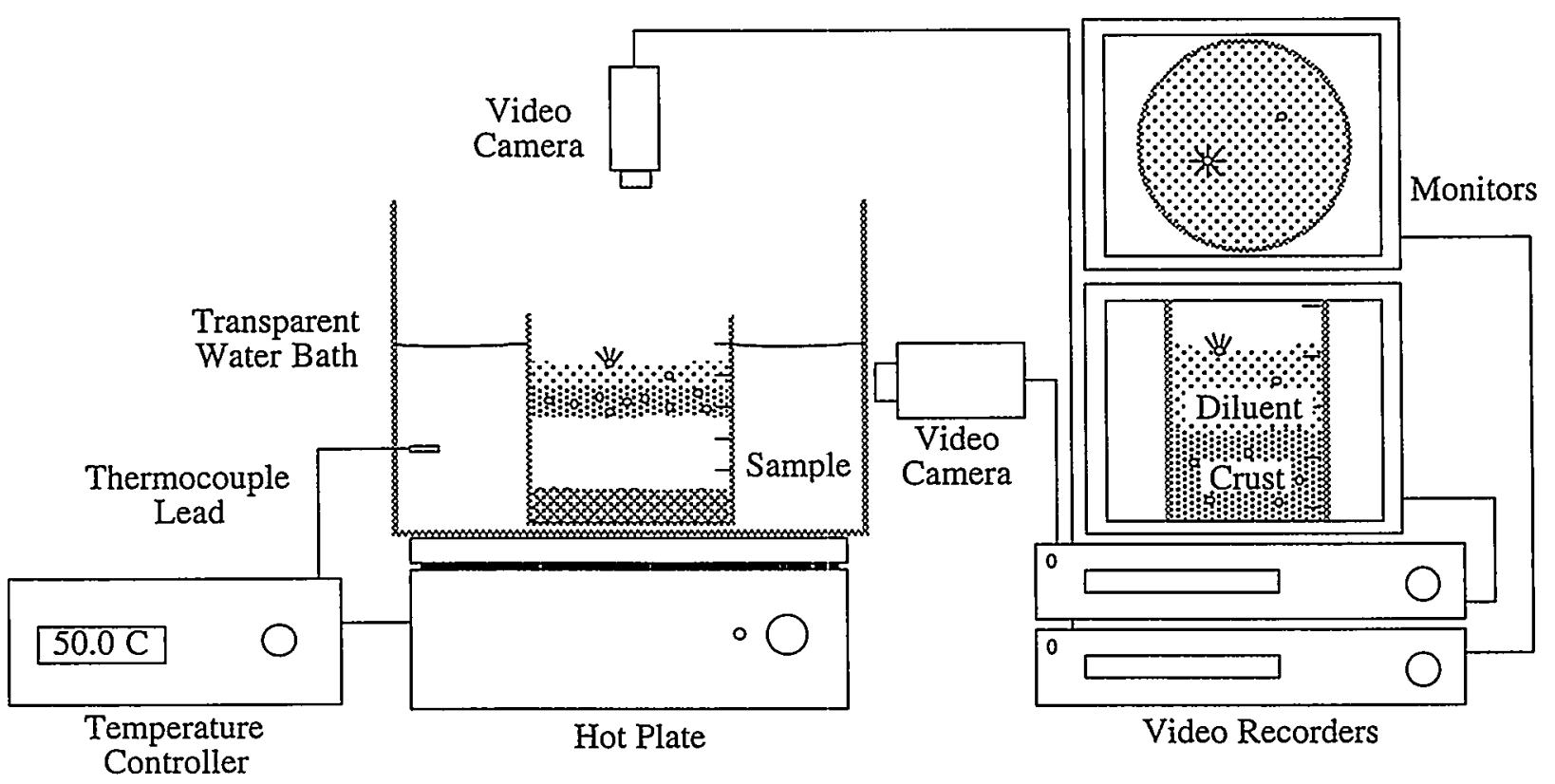

Figure 5.3.3. Temperature Control and Monitoring System for Crust Dissolution Tests 
camera (Sekai ISC-800A with autofocus and remote-controlled zoom) was set to view the side of the sample. This camera tracked changes in layer thickness and waste level, with particular focus on the crust region, and migration of the dilution water in the sample. The side camera was also used to observe gas releases when in view. The output of each video camera was recorded on an S-VHS videocassette recorder (Mitsubishi HS-S5600 and Panasonic AG-6760) and was displayed on a color video monitor (Sony PVM-1353MD). The 24-hour time-lapse record mode was used for overnight observation. Video images were printed on a Sony UP-5600 $\mathrm{MD}$ color video printer.

Prior to water addition, sample mass and volumes and the levels of various waste strata (crust, slurry, and nonconvective layers) and features were recorded. In the crust dissolution tests, water equivalent to $10 \%$ of the total sample volume was added on or below the crust. The diluent water was preheated to $50^{\circ} \mathrm{C}$ to match the sample temperature, and $0.1 \mathrm{wt} \%$ sodium fluorescein dye was added to the water to help monitor migration of the diluent in the samples. The dyed water is orange-red with transmitted light and fluorescent green-yellow with reflected light. After several hours contact with the simulant samples, the dye turned to a much darker brownish color and was more opaque.

The diluent was added in each test at roughly $4 \mathrm{~mL} / \mathrm{min}$, and the total mass of water added was recorded. In the graduated cylinder samples, $\sim 40 \mathrm{~mL}$ water was added over $\sim 10$ minutes to $\sim 400 \mathrm{~mL}$ total waste, and in the plastic containers, $\sim 80 \mathrm{~mL}$ water was added over $\sim 20$ minutes to $750-800 \mathrm{~mL}$ total waste. The water was delivered to each sample using a Cole-Parmer Master ${ }^{\circledR}$ peristaltic pump, except for one test in which a manual spray-mist bottle was used to cover the entire crust surface. The rate of addition was less consistent in the latter case. In other top-crust dissolution tests, the water was dispensed through a tube onto the wall of the container above the crust to minimize convection. To add water below the crust, a $1 / 8$-in $(0.3 \mathrm{~cm})$ outside diameter tube was run through the crust and into the convective liquid layer at least $1 \mathrm{~cm}$ below the crust. For one sample with a thick hard crust, a $1 / 8$-in $(0.3 \mathrm{~cm})$ drill bit was used to clear a path through the crust for the diluent feed tube. A stainless steel tube was set in place prior to thermal conditioning of the graduated cylinder samples so the crust would form around the tube and not be disturbed prior to water addition.

Following crust dissolution testing, more water was added to two samples in 1-L plastic containers to dissolve additional solids. The temperature control and video observation system shown in Figure 5.3.3 was used during the addition of $\sim 300 \mathrm{~mL}$ water to $725-775 \mathrm{~mL}$ of partially diluted simulant. In one case, the sample was mixed thoroughly with a metal spatula after water addition; in the other, care was taken to minimize post-addition mixing. Water was added with the peristaltic pump at $\sim 5 \mathrm{~mL} / \mathrm{min}$ to the unmixed sample and at a faster rate to the mixed sample.

\subsubsection{Results of Chemical Simulant Dissolution Experiments}

Crust dissolution experiments were conducted on six chemical simulant samples to probe dissolution and gas release mechanisms (subsection 5.3.3.1) and rates (subsection 5.3.3.2). Differences resulting from water addition above or below the crust and variations in crust properties were investigated. Table 5.3.2 summarizes the various crust samples used and the dissolution experiments performed. Thin crusts are defined as $<1-\mathrm{cm}$ deep and thick crusts $>2 \mathrm{~cm}$ deep. 
Table 5.3.2. Summary of Crust Dissolution Experiments

\begin{tabular}{|l|l|l|l|l|}
\hline Sample \# & \multicolumn{1}{|c|}{ Container } & $\begin{array}{l}\text { Type of } \\
\text { Addition }\end{array}$ & Crust Properties & \multicolumn{1}{c|}{ Comments } \\
\hline 01229903 & 1-L Plastic & Bottom & Thick & $\begin{array}{l}\text { Hole drilled in the crust to insert } \\
\text { tube for diluent addition }\end{array}$ \\
\hline 01229904 & 1-L Plastic & Bottom & Thin & $\begin{array}{l}\text { Diluent added by tube inserted } \\
\text { through crust }\end{array}$ \\
\hline 01229905 & 1-L Plastic & Top & Thin & Diluent sprayed on crust \\
\hline 07099901 & $\begin{array}{l}0.5-\mathrm{L} \\
\text { Cylinder }\end{array}$ & Top & Thick, Compact & $\begin{array}{l}\text { Diluent added by pumping along } \\
\text { container wall }\end{array}$ \\
\hline 07099902 & $\begin{array}{l}0.5-\mathrm{L} \\
\text { Cylinder }\end{array}$ & Top & $\begin{array}{l}\text { Thick, Large } \\
\text { Gas Pockets }\end{array}$ & $\begin{array}{l}\text { Diluent added by pumping along } \\
\text { container wall }\end{array}$ \\
\hline 07099903 & $\begin{array}{l}0.5-\mathrm{L} \\
\text { Cylinder }\end{array}$ & Bottom & $\begin{array}{l}\text { Thick, Small } \\
\text { Gas Pocket }\end{array}$ & $\begin{array}{l}\text { Diluent added through tube (in } \\
\text { place during crust formation) }\end{array}$ \\
\hline
\end{tabular}

Crusts prepared under similar conditions sometimes developed unique features such as gas pockets within or adjacent to the crust structure. This led to a variation in dissolution and gas release behavior for otherwise identical conditions (e.g., samples 07099901 and 07099902).

After dissolution of thin crust samples (01229904 and 01229905), more water was added to dissolve more solids in the nonconvective layer. As described in subsection 5.3.3.3, one sample was mixed and the other unmixed to probe the diffusion limitations of this dissolution process.

\subsubsection{Dissolution and Gas Release Mechanisms}

Adding a large volume of diluent (water) on or near the crust in SY-101 is expected to result in gas release from the crust via an obvious mechanism-dissolution of solids-freeing gas bubbles from the waste matrix. This mechanism was observed in dissolution experiments for both thin and thick crusts. More subtle distinctions in gas release mechanisms, attributed to differences in crust properties and the location of the added water, were observed in thicker crusts.

\section{Observations for Thin Crusts}

The disintegration of crust resulting from water addition is a function of solids dissolution and gas release as well as naturally occurring mechanical breakup of crust leading to the sinking of denser crust fragments and individual solid particles. Figure 5.3.4 captures the disintegration of a chunk of crust roughly $1.5 \mathrm{~cm}$ long and $0.7 \mathrm{~cm}$ in diameter floating in a diluent layer created by a top spray. The crust is floating near the top of the liquid adjacent to the container wall. Above the crust chunk, there is a series of released gas bubbles at the interface of the wall and liquid layer, and below the chunk there is a thin layer of solids and gas adhering to the wall. The first picture in Figure 5.3.4 was obtained 20 minutes after top-spray water addition began; no diluent was added during the photo sequence. A lighting change between the first and second photos caused the floating chunk to appear darker at later times. The piece of crust completely disintegrated $\sim 10$ minutes after the initial time shown in the figure. 

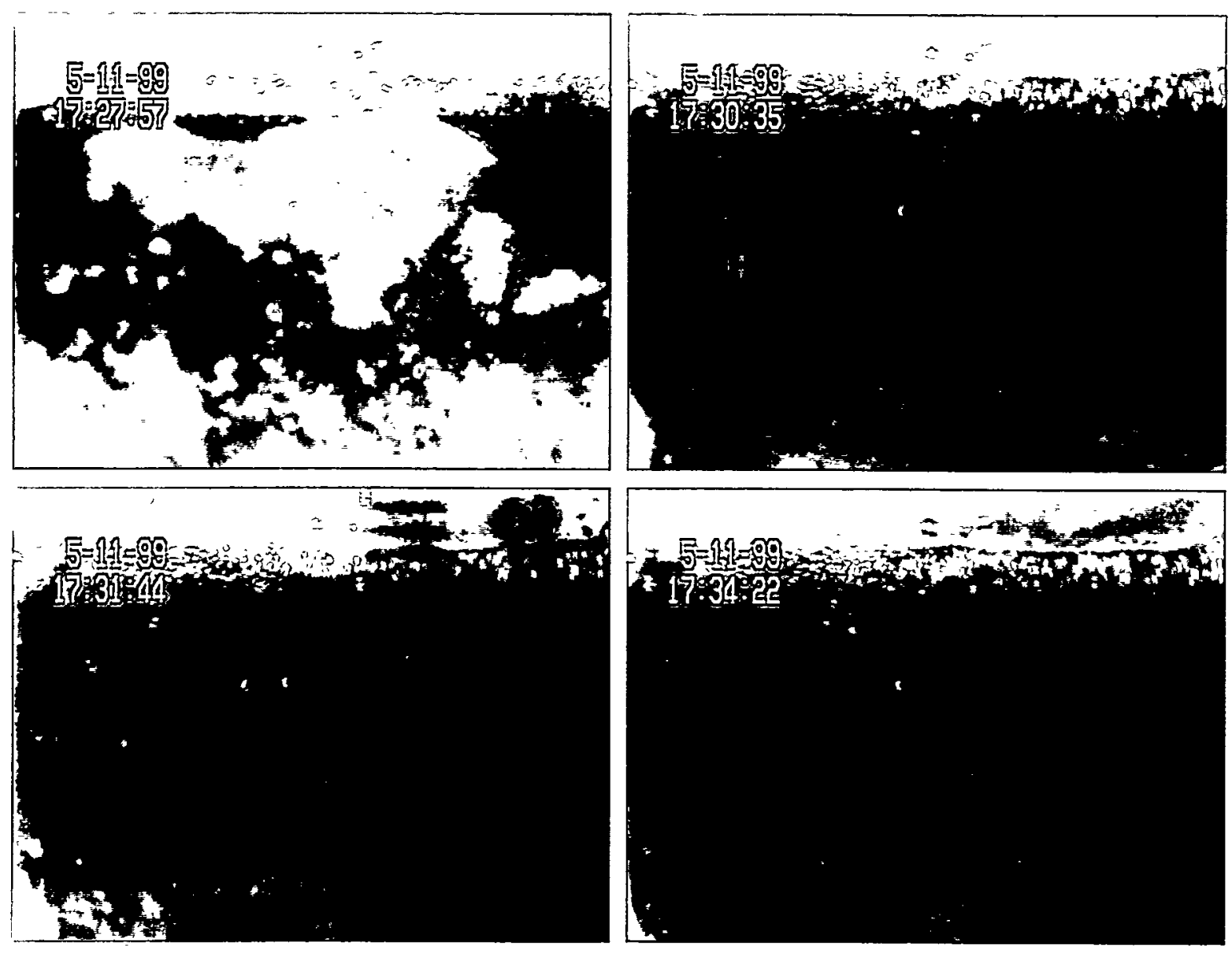

Figure 5.3.4. Dissolution and Gas Release from Small Piece of Free-Floating Crust just after Diluent Addition: (a) upper left- $0.7-\mathrm{cm}$ tall by $\sim 1.5-\mathrm{cm}$ wide buoyant chunk of crust (lighting conditions change in subsequent photos); (b) upper right-a bubble with a sheath of solids released from the chunk is about to drop its solids (upper right of photo), and another fragment is about to set free at the left tip of the chunk; (c) lower left-chunk becoming smaller because of dissolution and sloughing (each ruler mark is spaced $1 \mathrm{~mm}$ ); (d) further decay of crust chunk exposes more small $(<0.5 \mathrm{~mm})$ gas bubbles

During the decay of the piece of crust shown in Figure 5.3.4, several release mechanisms common to nearly all the dissolution experiments were observed. In many cases, individual bubbles from $<0.1 \mathrm{~mm}$ to several $\mathrm{mm}$ in diameter sloughed or released directly from the crust without any attached solids. Apparently these bubbles were freed by dissolution of adjacent waste particles. In other cases, bubbles within a matrix of solids (and liquid) broke away from the larger floating crust. The buoyant rise (or fall) of the new small waste chunk often caused solid particles to shear from the new chunk and sink. Sometimes individual bubbles sheathed in solids rose to the surface, the impact and protrusion of the top of the bubble out of the liquid causing the sheath to collapse (see the upper right photo and the description in Figure 5.3.4). 
Gas releases from the larger floating piece caused it to move, creating convection of the diluent relative to the crust. In some cases, the individual floating piece simply rotated to a new balance position. However, if the separated fragment was particularly buoyant (gas loaded), then the larger parent chunk moved down. Some fragments breaking free of the large chunk were apparently denser, which allowed the large chunk to float higher. This was observed less frequently. Increased saturation of the diluent during dissolution would also cause the chunks to float higher. Overall, the piece of crust shown in Figure 5.3.4 and many others observed in these tests tended to sink somewhat farther into the convective layer as it disintegrated.

The gas release processes for thin crusts were relatively consistent for both top-sprayed and below-crust added water. (This is discussed further in subsection 5.3.3.2.) Because the crusts were so thin, liquid quickly rose atop the crust surface when the diluent was added below. Individual gas bubbles released underneath the crust could not rise directly to the surface, but because numerous liquid-filled release paths were established in the crust structure, no significant buildup of gas was observed below the crust. Gas bubbles were readily released around the crust fragments. The motion of the bubbles along crust surfaces can cause further erosion of and bring fresh liquid to the crust surface.

\section{Observations for Thick Crusts}

The fundamental release mechanisms described for thin crusts were also observed during the dissolution of thicker crusts. Other mechanisms were unique to the thicker samples. Differences in release mechanisms were observed in each of the crust samples formed in graduated cylinders, particularly during diluent addition.

Table 5.3.3 summarizes waste and crust volumes just before and just after adding water. The difference between the initial waste volume plus added water and the volume measured just after water addition was completed is a measure of the gas volume displaced and released during water addition. Here, gas displacement is distinguished from gas release. Displacement occurs, for example, if the crust structure is somewhat porous or contains gas pockets, and this gas is pushed to the tank domespace as water is added. Effectively, the volume of gas displaced is replaced with liquid. Gas release is the process wherein void (gas) trapped within the crust waste matrix (not open to the headspace) is freed from the crust through dissolution and associated release mechanisms. Table 5.3.3 indicates a significant variability in the gas volume released and displaced $(0,16$, or $44 \mathrm{~mL})$ by the three samples during water addition, even though the initial crust volume varied less substantially $(60-80 \mathrm{~mL})$.

Most surprising are the results for the two samples with top-added water. In one (07099901) essentially all the added water was retained on top of the crust, and apparently no gas was released or displaced in the addition process. On the other hand, there was no net increase in sample volume with water addition in the other sample (07099902), indicating that an equivalent volume $(44 \mathrm{~mL})$ of gas was displaced or released. This is more than $50 \%$ of the initial estimated crust volume. Video review indicated that a very thin layer of solids at the top of this crust sample quickly dissolved, exposing a large gas pocket. It is unclear whether the gas pocket was actually trapped beneath the crust sheath or connected through pores in the crust to the vessel displaced or released during the addition. It is unclear whether the gas pocket was actually trapped beneath the crust sheath or connected through pores in the crust to the vessel 
Table 5.3.3. Waste, Crust, and Water Volumes in the Early Stages of Graduated Cylinder Crust Dissolution Experiments

\begin{tabular}{|l|c|c|c|c|c|}
\hline \multicolumn{1}{|c|}{ Experiment } & $\begin{array}{c}\text { Initial Waste } \\
\text { Volume } \\
(\mathrm{mL})\end{array}$ & $\begin{array}{c}\text { Initial Crust } \\
\text { Volume } \\
(\mathrm{mL})\end{array}$ & $\begin{array}{c}\text { Est. Max. Waste } \\
\text { Volume (initial } \\
\text { waste + water) } \\
(\mathrm{mL})\end{array}$ & $\begin{array}{c}\text { Measured } \\
\text { Maximum } \\
\text { Volume } \\
(\mathrm{mL})\end{array}$ & $\begin{array}{c}\text { Volume Gas } \\
\text { Displaced or } \\
\text { Released } \\
(\mathrm{mL})\end{array}$ \\
\hline $\begin{array}{l}\text { Bottom Addition } \\
\text { 07099903 }\end{array}$ & 390 & 65 & 431 & 415 & 16 \\
\hline $\begin{array}{l}\text { Top Addition \#1 } \\
\text { 07099902 }\end{array}$ & 430 & 80 & 474 & 430 & 44 \\
\hline $\begin{array}{l}\text { Top Addition \#2 } \\
\text { 07099901 }\end{array}$ & 395 & 60 & 434 & 436 & 0 \\
\hline
\end{tabular}

headspace. Therefore, it is unknown whether the large initial volume reduction should be classified as a gas release or displacement. In any case, the large discrepancy in initial gas releases for these otherwise identically treated samples is apparently due to distinct crust structure. ${ }^{(a)}$ We surmised that the crust sample with no initial gas release volume is denser, more compact, and relatively pore/void free near the upper crust surface. The rate of subsequent gas releases from these samples was monitored and is discussed in subsection 5.3.3.2.

Differences in the two samples before and one hour after top water addition are shown in Figure 5.3.5. The photographs reiterate the observations made above. After one hour, the liquid level of the 07099901 sample was still $\sim 434 \mathrm{~mL}$, about $40 \mathrm{~mL}$ greater than the initial waste volume. A film of waste on the glass above the crust surface, possibly resulting from the collapse of a gas pocket during thermal conditioning, makes it difficult to see the top of the crust near $395 \mathrm{~mL}$ in the photo. Gas bubbles are seen throughout the lower half of the crust. The middle row of photos in Figure 5.3.5 shows the sample with large initial gas release or displacement. One hour after water addition, the crust above $\sim 385 \mathrm{~mL}$ to $\sim 425 \mathrm{~mL}$ (below the original waste level of $\sim 430 \mathrm{~mL}$ ) was liquid-filled. Again, the key difference was the bubble pocket hidden just below a thin crust surface of this sample.

Figure 5.3.5 and Table 5.3.3 also include results for a sample (07099903) in which diluent was added $\sim 9 \mathrm{~cm}$ below the crust surface. The diluent quickly rose to the base of the crust and, as indicated in the photos, some diluent passed through the crust and onto the crust surface. The transport of water to the surface occurred $\sim 8$ minutes into the water addition. The path by which water was transported was subsequently observed to be the conduit for all gas released from below the crust. (Somewhat surprisingly, the stainless steel feed tube was not the preferred channel.) A gas bubble pocket near the bottom of the crust layer before water was added was displaced or released during the addition. It is unclear whether the path through which this gas

(a) One known difference in treatment of these samples was the inclusion of a stainless steel tube through the crust in the 07099902 sample. The tube was placed before crust formation, anticipating the sample would be used to investigate below-crust water addition. 

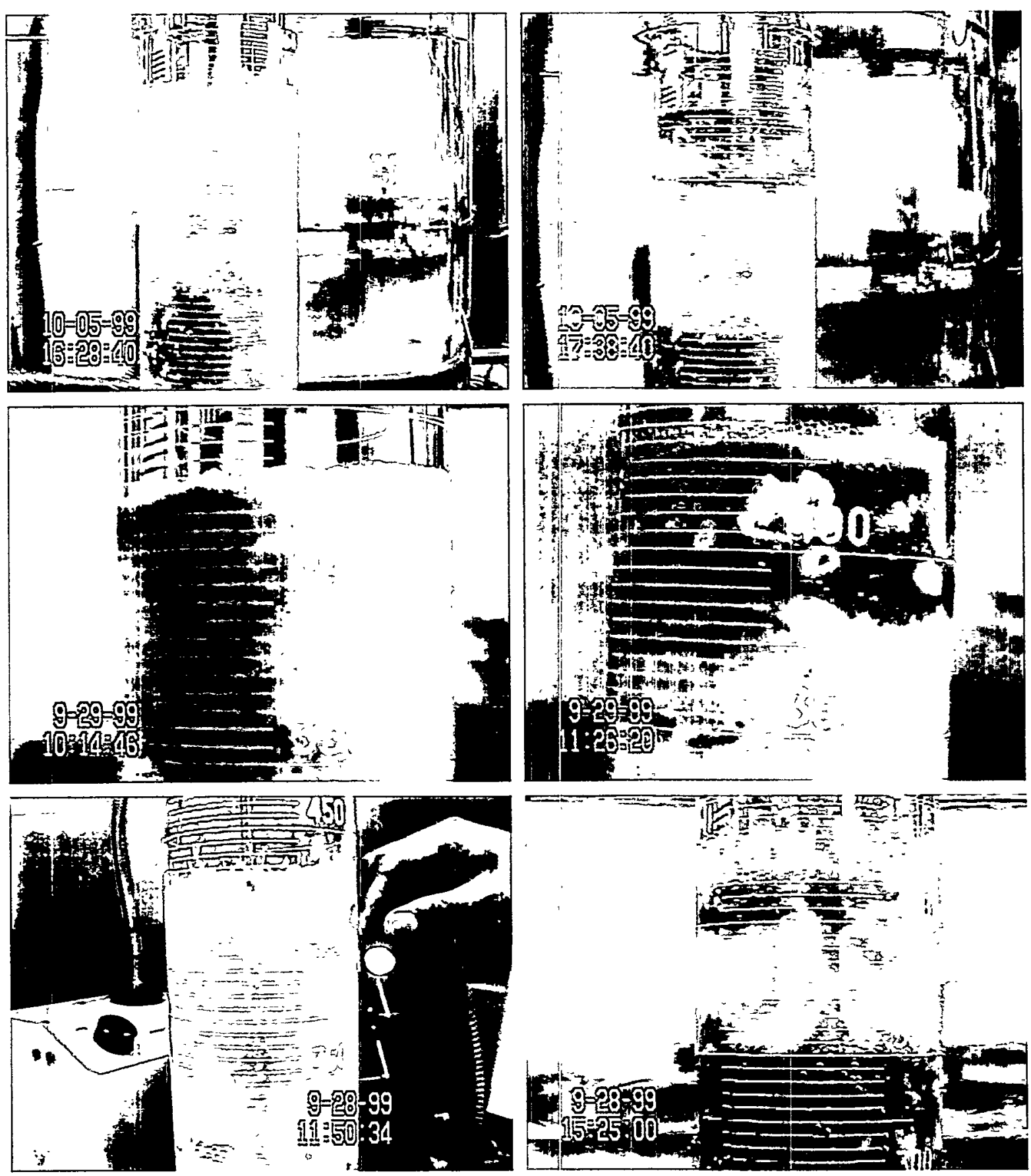

Figure 5.3.5. Three Thick Crust Samples and the Location of Diluent One Hour After Addition. Left side shows initial condition; right is $\sim 1 \mathrm{hr}$ after water addition: (a) top row-top water addition to sample 07099901 with no apparent gas pockets; (b) middle row-top water addition to sample 07099902 with large bubble pockets below a thin upper crust layer; and (c) bottom row-water added below the crust of sample 07099903 spills onto the crust surface. 
dissipated was connected to the pocket before water was pumped. It is conceivable that the hole was blown through the crust because of gas pressurization in the addition process or was dissolved by water. The gas or liquid pressure could not lift the entire crust because it adhered to the cylinder walls; it was not free-floating. As shown in Table 5.3.3, $16 \mathrm{~mL}$ of gas, most from the sub-crust bubble pocket, was displaced or released while water was added.

The gas releases from below the crust in sample 07099903 terminated at a single location at the top liquid surface, and over time a froth layer formed. The layer spread across the surface over many hours and appeared to provide some resistance to bubble popping and the final release of gas to the headspace. The froth was opaque, indicating it contained solids. Later in the experiment, evaporation caused the froth to harden in an unsealed layer suspended above the liquid.

\subsubsection{Crust Dissolution and Gas Release Rates}

Visual observations were used to qualitatively infer dissolution and gas release rates for crust samples in 1-L plastic containers. Quantitative gas release rate data were obtained in the graduated cylinder experiments. This was possible because of the higher resolution in level change per unit volume in the narrower containers.

\section{Visual Comparison of above and below Crust Water Addition-Thin Crusts}

Crust dissolution experiments were conducted on two samples in 1-L plastic containers with relatively thin $(\sim 0.7-0.8 \mathrm{~cm})$ chemical simulant crusts. In one case (01229904), the water was pumped slowly subsurface, and in the other the water was sprayed on top with a spray bottle (01229905). Figures 5.3.6 and 5.3.7, respectively, show a time sequence for these dissolution experiments. In each case, significant dissolution of the crust ( $>50 \%$ estimated) occurred in the first hour, and the bulk of the crust solids were dissolved or lost buoyancy in four to eight hours.

Crusts were not sufficiently thick to create a barrier to rapid water migration between the top and bottom of the crust (e.g., through cracks). For sample 01229904 (Figure 5.3.6), water made . its way through the gap around the tube through which diluent was introduced within 1.5 minutes of initial water flow. The crust crumbled around the tube and bubbles were released, causing crust pieces to sink. The largest of these bubbles was about $0.5 \mathrm{~cm}$ in diameter. Within 10 minutes the crust in the central portion of the container was submerged, although part of the crust was still attached along the container wall away from the tube. Dissolution detached a large chunk of crust from the wall, allowing it to float freely after $20 \mathrm{~min}$. Additional crust decay and gas release proceeded in accordance with the mechanisms described in Section 5.3.3.1.

When diluent was sprayed on to the crust of sample 01229905 (Figure 5.3.7), the crust pieces moved around because of the force of the spray. The crust proceeded to dissolve, release gas bubbles, and sink. Within 15 minutes, all the crust pieces were submerged below the liquid surface. Because spraying broke up crust pieces quite easily, dissolution proceeded faster in this top-sprayed sample than in bottom addition. This is apparent by comparing Figures 5.3.6 and 5.3.7. After 20 minutes, more than half of the crust on the surface had crumbled and/or dissolved for the top-sprayed sample 01229905 , while about $80 \%$ of the crust remained intact for 01229904. The discrepancy in the fraction of crust eroded decreased over time but was still apparent after four hours. The visual difference was negligible at 8 to 12 hours. 
a $\mathbf{b}$
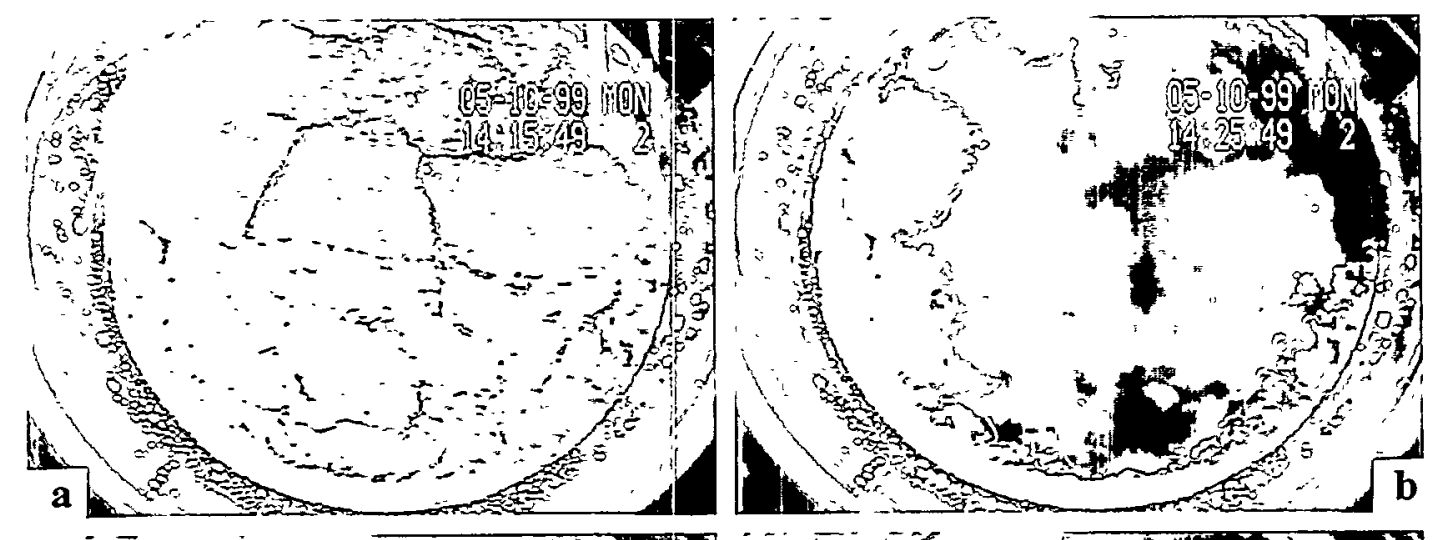

c d

e $\mathbf{f}$
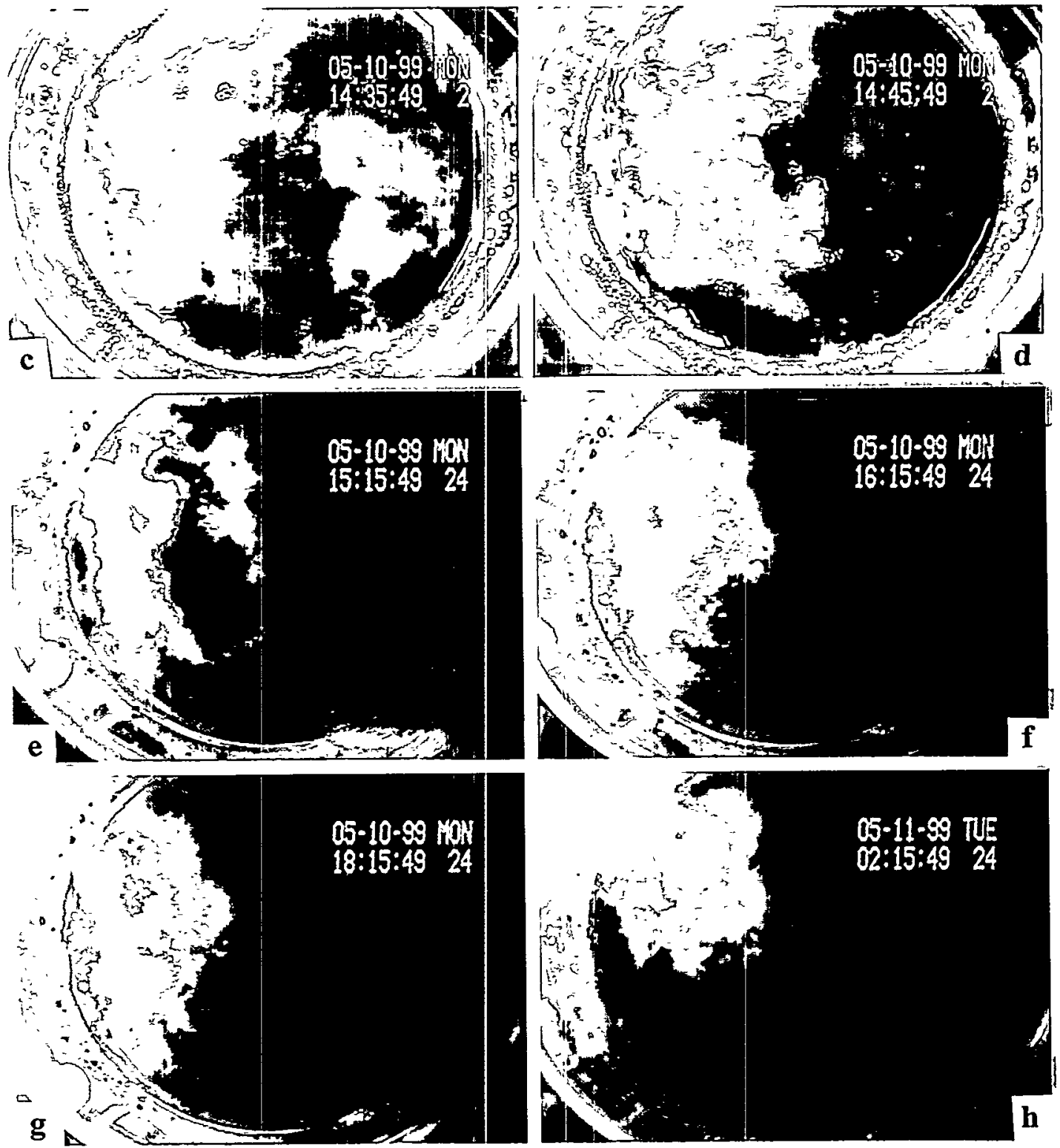

g h

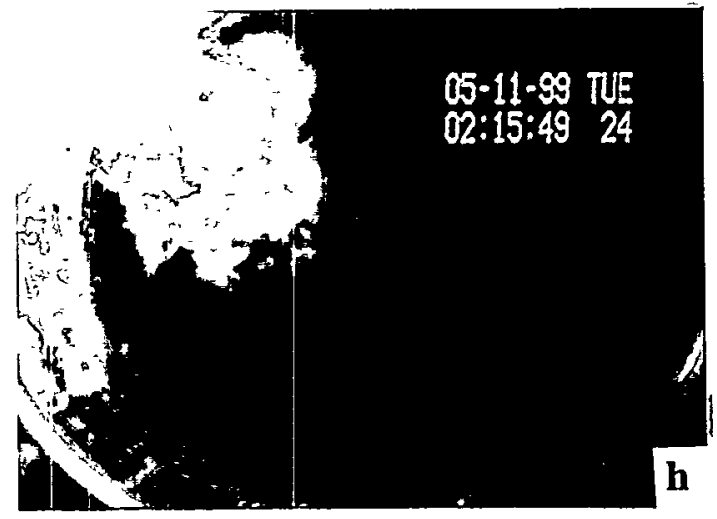

Figure 5.3.6. Dissolution of Thin Crust with Water Added below Crust Surface: (a) before water addition (time 0); (b) 10 min into water addition; (c) near end of water addition ( $20 \mathrm{~min}$ ); (d) 30 min elapsed; (e) $1 \mathrm{~h}$ elapsed; (f) $2 \mathrm{~h}$ elapsed; (g) $4 \mathrm{~h}$ elapsed; (h) $12 \mathrm{~h}$ elapsed; bright light shows on left or upper left corner of photos 
a b
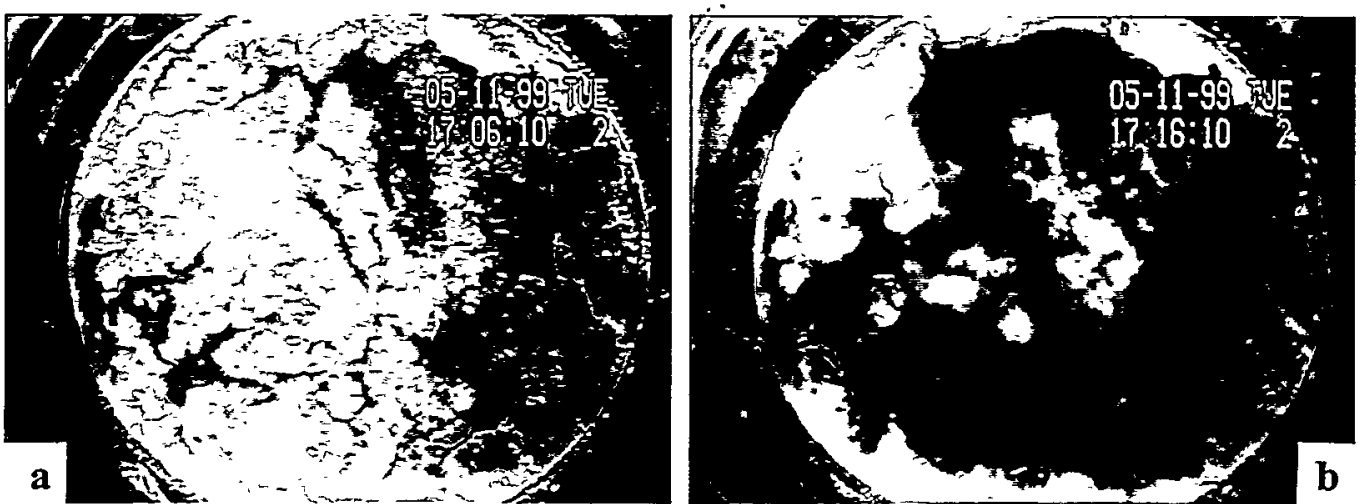

c d
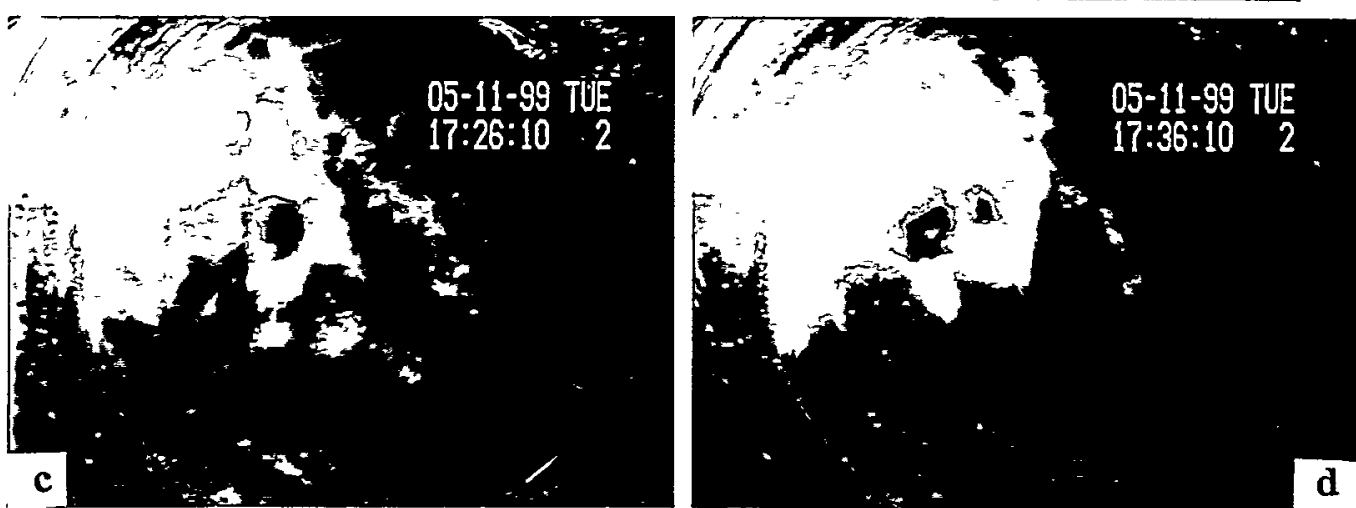

e $\mathbf{f}$

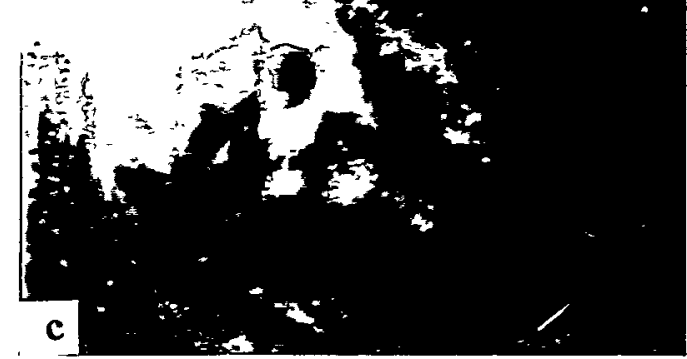

$\mathbf{g} \mathbf{h}$
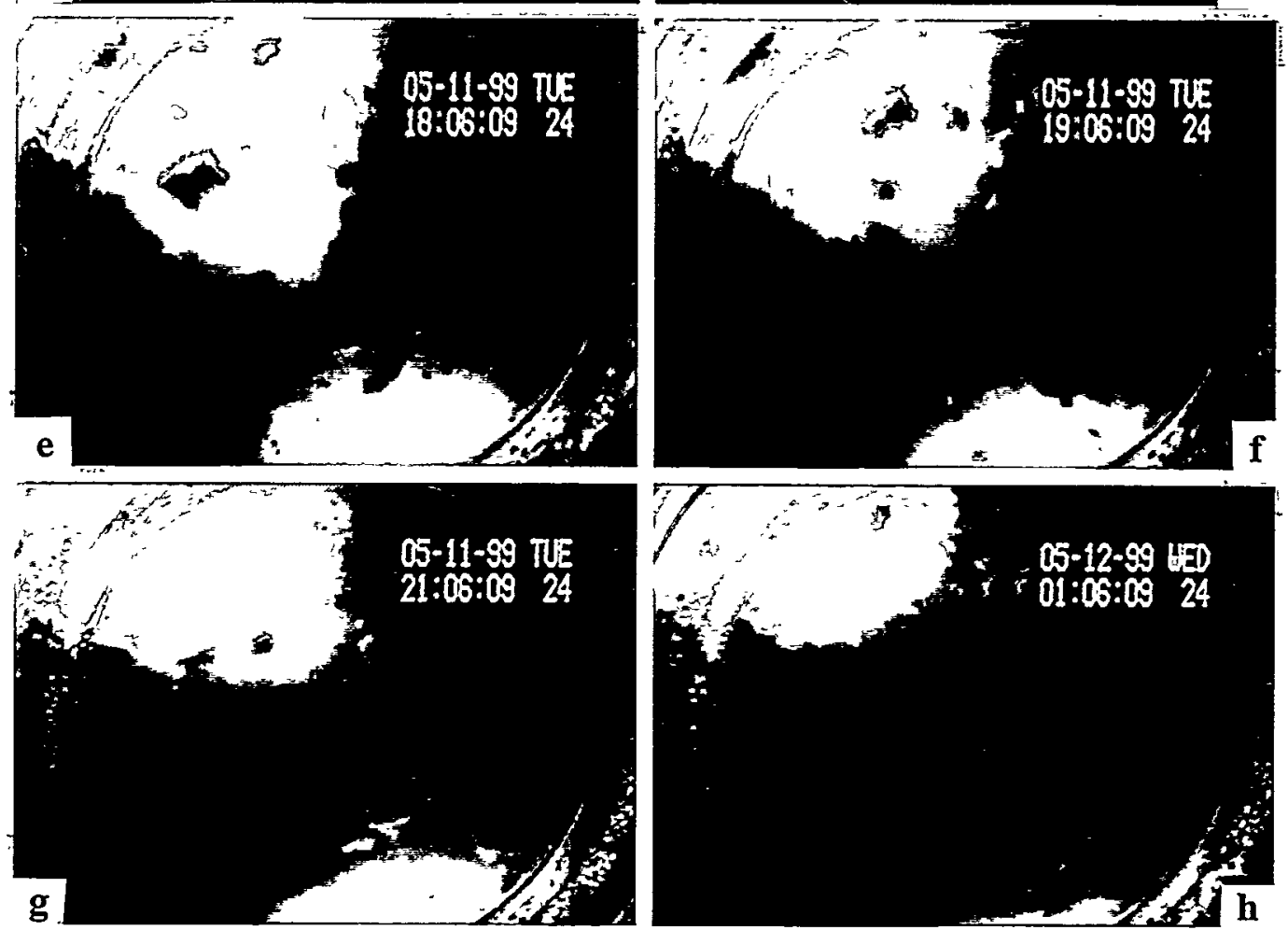

Figure 5.3.7. Dissolution of Thin Crust with Water Sprayed on Top of Crust Surface: (a) before water addition (time 0); (b) 10 min into water addition; (c) near end of water addition ( $20 \mathrm{~min}$ ); (d) 30 min elapsed; (e) $1 \mathrm{~h}$ elapsed; (f) $2 \mathrm{~h}$ elapsed; (g) $4 \mathrm{~h}$ elapsed; (h) $8 \mathrm{~h}$ elapsed. Bright light shows in upper left corner of photos. 


\section{Comparison of Below Crust Water Addition for Thin and Thick Crusts}

A dissolution experiment was initiated on a thicker $(\sim 3-\mathrm{cm})$ chemical simulant crust in a 1-L plastic container (sample 01229903). Eighty milliliters of diluent was added below the crust surface. About half way through the addition, some water flowed back up around the liquid feed tube and onto the surface (shown in photo sequence in Figure 5.3.8). The upper crust features were too tall to be completely submerged given the limited diluent volume. The data indicate $\sim 100 \mathrm{~mL}(\sim 1 \mathrm{~cm})$ at the bottom of the $\sim 300 \mathrm{~mL}$ crust dissolved over about three hours, the rate of dissolution dramatically decreasing at still later times. The bulk of the crust $(\sim 200 \mathrm{~mL})$ remained intact for more than two months (when observations ceased), although it appeared significantly softened with the pooled liquid on top. Figure 5.3.8 shows the "final" condition of the sample about two days after water addition. It appears in this case that the diluent was saturated well before the bulk of the crust could be dissolved. A lid on the sample minimized evaporative losses and potential dryout.

For comparison, an equivalent amount of water added below a thin crust (Figure 5.3.6) resulted in complete submergence of the crust during the 20-minute diluent addition. More than $50 \%$ of the crust dissolution/disintegration and the most significant gas release occurred within about two hours. Ultimately, most of the crust in this sample was dissolved or disintegrated and gas released according to the mechanisms described in subsections 5.3.3.1 and 5.3.3.2.

\section{Quantitative Analysis for Thick Crusts}

To obtain quantitative gas release and dissolution rate data, experiments were conducted in half-liter graduated cylinders, as described in subsection 5.3.1.2 and Section 5.3.2. Gas release mechanisms observed during these tests, with particular emphasis on initial gas release and displacement resulting from diluent addition, were discussed in subsection 5.3.3.1. Figure 5.3.5 is a photograph of each of the three experiments before and after diluent addition. The results in this subsection focus on dissolution and gas release starting from the point at which water addition was complete. Thus anomalous gas evolution from the diluent addition process is avoided.

Figure 5.3.9 shows the volume of gas released as a function of time in the first 10 hours after diluent addition. The figure includes results for three experiments, including two above-crust water additions and one below-crust addition. Gas release volume was determined by tracking changes in the free liquid level. To estimate the gas release volumes, the volume of water evaporated from the open sample at $50^{\circ} \mathrm{C}$ had to be subtracted from the total change in liquid level. Periodic weight loss data for the first 20 hours was obtained during one dissolution experiment (sample 07099901) from which the water evaporation rate was calculated. This evaporation rate was subsequently used to calculate the gas release rate for all three samples over the first 20 hours. Roughly $6 \mathrm{~mL}$ of the $\sim 40 \mathrm{~mL}$ of added diluent evaporated in four hours; the rate of evaporation decreased at longer times and with increasing diluent saturation. In the plots shown in Figure 5.3.9 (and 5.3.10), decreases in the cumulative volume of gas released is probably due to inaccuracy in estimating the water evaporation rate. Beyond 20 hours, actual weight loss data for individual samples were recorded and used to calculate gas release volumes. 

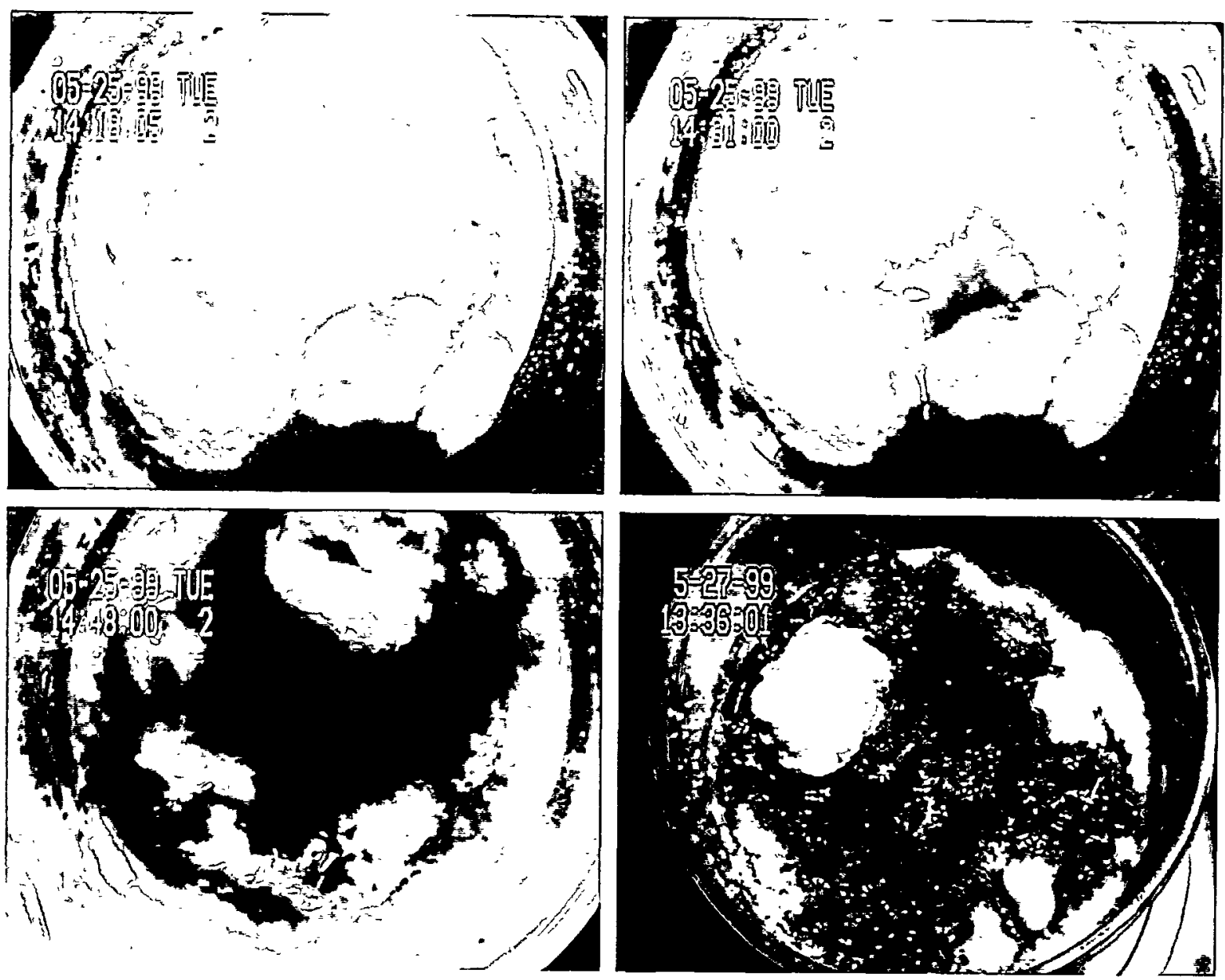

Figure 5.3.8. Dissolution of Thicker Crust with Water Added below Crust Surface: (a) upper left-before water addition; (b) upper right-during water addition; (c) lower. left-just after completing water addition; and (d) lower right-two days after water addition, the "final" state

As shown in Figure 5.3.9, the gas release volume was most substantial for the above-crust water addition in sample 07099902. Coincidentally, this sample also had the largest gas evolution during water addition (Table 5.3.3). Apparently, the initial dissolution and gas evolution process, in which significant convection was observed, created access to a somewhat gaseous crust region where relatively uniform gas release occurred over the next $\sim 10$ hours. During this $\sim 10$-hour period, higher incremental release rates were observed early in the dissolution process and during release events. In some of these events, several $\mathrm{mL}$ of gas were released in less than a minute. Overall, $\sim 15 \mathrm{~mL}$ of gas released in 10 hours, for an average release rate of $\sim 1.5 \mathrm{~mL} / \mathrm{h}$. The average release rate in the first five hours was higher, about $2.5 \mathrm{~mL} / \mathrm{h}$. The gas release volume $(\sim 15 \mathrm{~mL})$ in 10 hours was about $20 \%$ of the initial estimated crust volume $(\sim 80 \mathrm{~mL})$ or $\sim 40 \%$ of the crust volume remaining after water addition was complete $(\sim 36 \mathrm{~mL})$. Total crust volume estimates are somewhat suspect because the transition of crust and slurry layers was difficult to quantify in most cases due to solids buildup on the vessel wall. 


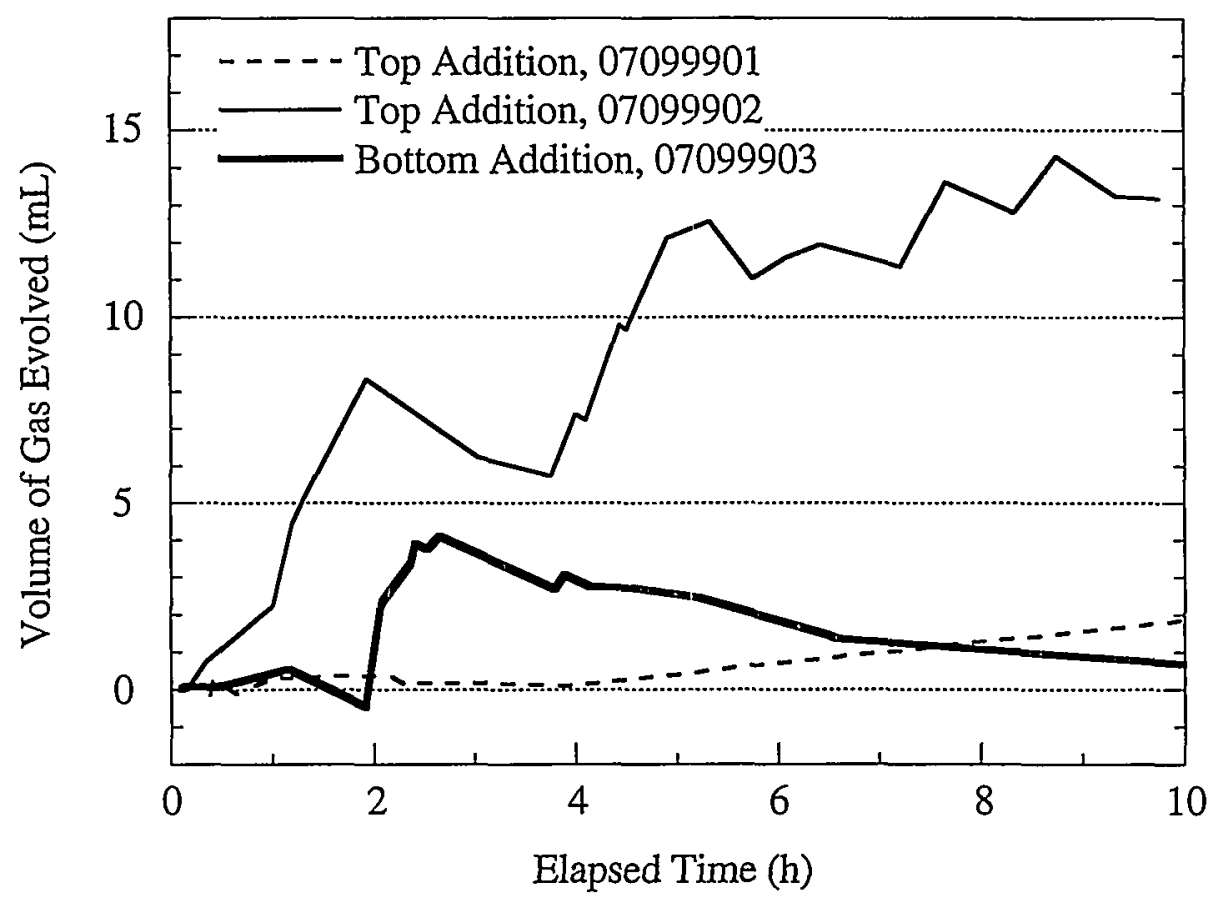

Figure 5.3.9. Apparent Crust Gas Release Volumes for Three Crust Samples in the First 10 Hours after Water Addition

The gas release rates and volumes shown in Figure 5.3.9 for the other two samples were considerably lower. In the other top-added water case (07099901), less than $2 \mathrm{~mL}$ of gas or $\sim 3 \%$ of the crust volume was released in 10 hours, the lowest release rate observed at $<0.2 \mathrm{~mL} / \mathrm{h}$. Interestingly, this sample also had the smallest $(0 \mathrm{~mL})$ gas evolution during water addition. The volume and rate of gas release for the sample (07099903) in which water was added below the crust was in between the two above-crust addition tests. In the first three hours, particularly between the second and third hours, significant gas release was observed. Figure 5.3.9 shows that $<5-\mathrm{mL}$ gas released in the three hours, corresponding to an average release rate of $<2 \mathrm{~mL} / \mathrm{hr}$. The total release volume is $\sim 10 \%$ of the crust volume remaining just after water addition. As described in subsection 5.3.3.1, gas release from this sample created froth that ultimately formed a suspended super crust. The decrease in the cumulative volume of gas evolved after three hours is probably an artifact created by evaporation of water from the newly created upper crust. The evaporation correction used assumes evaporation occurs at the liquid surface.

Figure 5.3.10 characterizes the cumulative gas release volumes for 100 hours after water addition for two of the experiments shown in Figure 5.3.9. Sample 07099901 dissolved very slowly and steadily over 40 hours, releasing $\sim 10 \mathrm{~mL}$ gas at $\sim 0.25 \mathrm{~mL} / \mathrm{h}$. The release rate is slow because the upper crust layer was relatively compact; the diluent did not readily penetrate and access the more gaseous regions of the lower crust visible in Figure 5.3.5. About 84\% of the crust was still intact after $\sim 70$ hours. Dissolution and gas release ceased at long times, most likely due to diluent saturation. Additional gas release from sample 07099902 was detected between 10 and $\sim 35$ hours, before dissolution ceased. The maximum cumulative release volume 


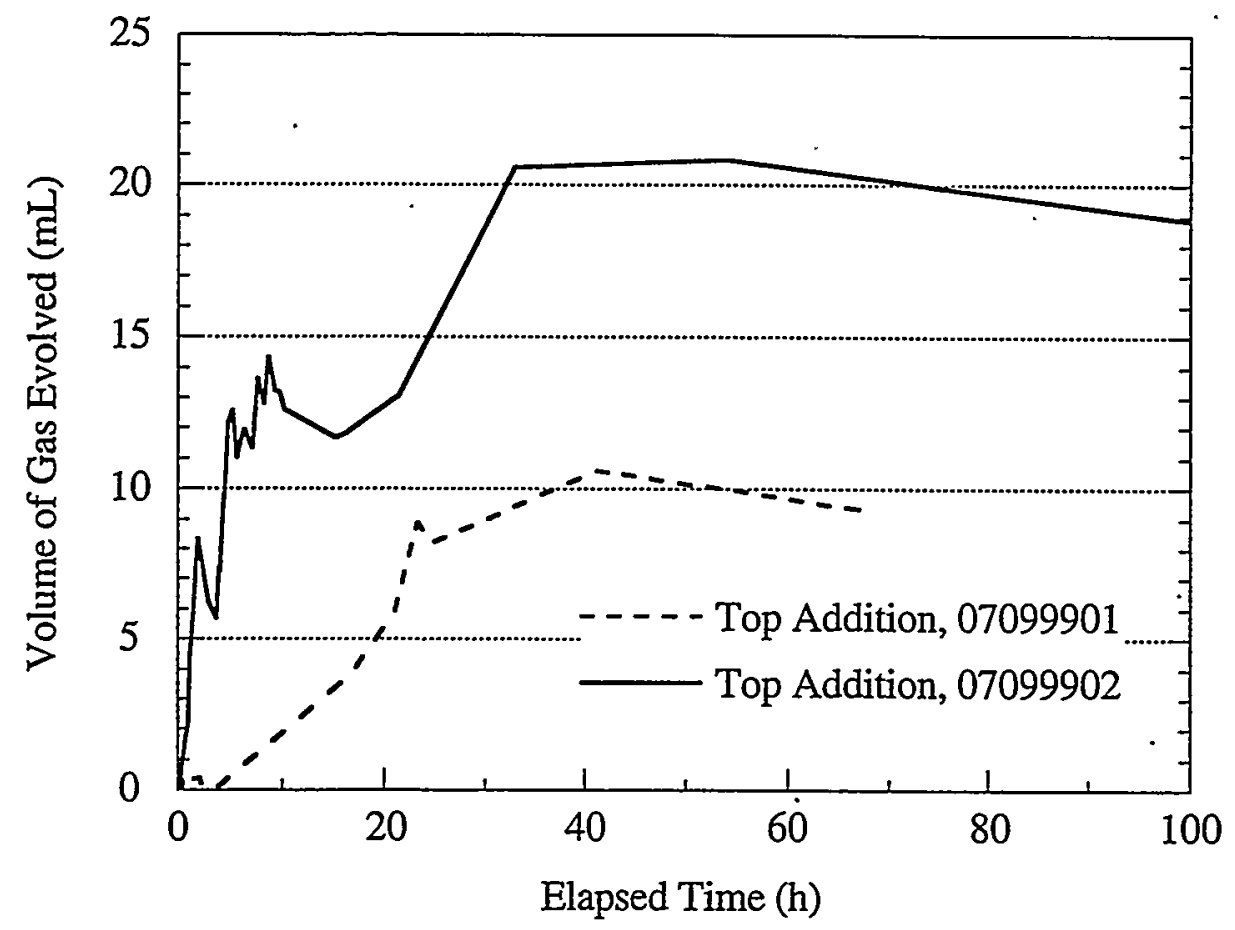

Figure 5.3.10. Apparent Crust Gas Release Volumes for Three Crust Samples in the 100 Hours Following Water Addition

$(\sim 20 \mathrm{~mL})$ was only $5 \mathrm{~mL}$ more than the 10-hour measurement, indicating a decreasing release rate at longer times. However, compared with activity between 10 and 20 hours, the release rate picked up considerably from 20 to 35 hours. This is thought to result from variation in the lower crust structure and dissolution of a relatively high gas fraction region at later times. As noted above, the release profile for 07099903 was complicated by evaporation from the suspended froth layer; therefore, the long-time results for this sample are not shown in Figure 5.3.10.

In the first few days after water addition, the diluent was primarily contained near the top of the vessel (indicated by dye in the diluent). Therefore, level changes on the time scale shown in Figure 5.3.10 are assumed to be associated with dissolution and gas releases in the vicinity of the crust, not from the lower slurry and nonconvective layers. Releases from these lower layers were not observed during the experiment, and the lower layers were intact after 150 hours.

\section{Summary of Crust Degradation Rates - Consideration for Dilution in SY-101}

Gas release rates were quantified in graduated cylinder experiments by tracking the liquid level and correcting for losses due to evaporation. Experimental crust degradation rates can be calculated from the volumetric gas release rates, $Q_{R}$, by assuming a crust void fraction, $\alpha_{C}$. In turn, the volumetric crust degradation rate is converted to a more useful crust thickness degradation rate $\left(\dot{\mathrm{H}}_{\mathrm{c}}, \mathrm{cm} / \mathrm{hr}\right)$ by factoring the cross sectional area ( $\mathrm{mL}$ per $\mathrm{cm}$ height) of the graduated cylinder, $\mathrm{A}_{\text {cyl }}$ : 


$$
\dot{\mathrm{H}}_{\mathrm{c}}=\frac{\mathrm{Q}_{\mathrm{R}}}{\mathrm{A}_{\mathrm{cyl}} \alpha_{\mathrm{c}}}
$$

This form of crust degradation and associated gas release rate is applied in Section 6 to evaluate flammability hazards of tank-scale gas releases. As noted in Section 5.2, the crust dissolution process and gas release rate (for semi-continuous releases) are likely dominated by the rate of transport of unsaturated diluent to the gas-containing waste matrix. The transport of diluent to the crust for most of the simulant experiments were not as limited by diffusion as one might expect in SY-101, because the experiment length scales were small. Conservatively, it can be concluded that the rate of transport of diluent in the tank would scale directly with the experiments. In other words, the rate of crust degradation in the tank in terms of thickness degraded per unit time may be roughly the same as in the experiments, on the order of $1 \mathrm{~cm} / \mathrm{hr}$ or less. The experimental results from which this rate was obtained are summarized below.

In one top crust water addition test (graduated cylinder, 07099902), the highest release rate averaged over a two-hour period was $\sim 4 \mathrm{~mL} / \mathrm{h}$, and over the first five hours, the average release rate was $\sim 2.5 \mathrm{~mL} / \mathrm{h}$. The maximum two-hour average release rate for the bottom addition experiment (07099903) was $\sim 2 \mathrm{~mL} / \mathrm{h}$. The very highest average gas release rate $(\sim 4 \mathrm{~mL} / \mathrm{h})$ corresponds to a crust degradation rate of $\sim 0.5 \mathrm{~cm} / \mathrm{h}$ assuming $50 \%$ void fraction in the crust (Equation 5.3.1). A lower assumed gas fraction of 0.2 is equivalent to a higher maximum average crust degradation rate of $\sim 1.2 \mathrm{~cm} / \mathrm{hr}$. These highest degradation and gas release rates were observed in the first several hours after water addition, when the diluent was less saturated.

Gas release was detected for up to $\sim 40$ hours in two thick-crust experiments $(07099901$ and 02 ), corresponding to average release rates of $\sim 0.25$ and $\sim 0.5 \mathrm{~mL} / \mathrm{h}$. Assuming a crust gas fraction of only $20 \%$, these equate to crust degradation rates of 0.08 to $0.15 \mathrm{~cm} / \mathrm{h}$. If the crust void fraction is $50 \%$, the calculated crust degradation rates are only 0.03 to $0.06 \mathrm{~cm} / \mathrm{h}$. The rate drops off at longer times presumably because of increased diluent saturation resulting from solids dissolution and evaporation effects. The decrease in rate with increasing saturation is in agreement with the theoretical results presented in Section 5.2.2.

For experiments in 1-L plastic containers, crust degradation rates were estimated from visual observations of the sample (e.g., the change in apparent surface coverage of crust with time). With these thin crusts ( $<1-\mathrm{cm}$ thick), significant decay of the crust ( $>50 \mathrm{vol} \%$ estimated) and gas release occurred in the first hour after a crust volume equivalent of water was added either below or on top of the crust. Initially, the gas release rate was higher for top-spray addition, possibly due to the convection created by spraying. Continued dissolution and gas release was noted for at least 8 to 12 hours, though the rate slowed considerably after the first hour. The thin-crust experimental results indicate maximum crust degradation rates of the order $0.5 \mathrm{~cm} / \mathrm{h}$.

\subsubsection{Nonconvective Layer Dissolution Kinetics-Mixed and Unmixed Samples}

After dissolution of the thin crusts in plastic containers with $\sim 80 \mathrm{~mL}$ of water (subsection 5.3.3.2), additional dilution water $(-300 \mathrm{~mL})$ was added to the two chemical simulant samples to evaluate dissolution rates of the remaining solids in the nonconvective layers. One sample was forcibly mixed for several minutes with a spatula after water addition, and the other was not mixed. The container lids, each with a small $\sim 0.3-\mathrm{cm}$-diameter vent hole, were placed 
on the samples after water addition to minimize evaporation. Neglecting gas retained in the samples before addition and assuming that water and simulant mixing volumes were additive, water was added to a target density of $\sim 1.38 \mathrm{~g} / \mathrm{mL}$. Actual measured bulk densities just following water addition were somewhat higher at 1.42 to $1.44 \mathrm{~g} / \mathrm{mL}$, possibly due to gas trapped in the sample prior to water addition.

In the mixed sample, most solids seemed to dissolve during mixing, and a thin settled solids layer $(\sim 10 \mathrm{vol} \%)$ formed over time. The exact amount of time required for solids dissolution is unknown because the sample remained cloudy with suspended solids for a considerable period. The solids settled within 24 hours, leaving a distinct and relatively unchanging settled layer. The change of nonconvective solids layer volume in time is depicted in Figure 5.3.11 for both the mixed and unmixed samples. The apparent increase in the mixed sample volume at 25 days is believed to be an artifact of the camera angle. In all cases, the nonconvective layer upper surface features (roughness) limit the accuracy of volume measurements to no better than $\pm 20 \mathrm{~mL}$.

As expected, the dissolution rate of the unmixed sample is considerably slower than that of the mixed sample. In the unmixed sample, water was pumped at $5 \mathrm{~mL} / \mathrm{min}$ directly into the nonconvective layer at a fixed location, disturbing solids in the immediate vicinity $(\sim 2-3-\mathrm{cm}$ diameter). The majority of the water floated to the surface immediately, and the dissolution rate of the nonconvective layer was slow, limited by diffusion. The time scale for liquid diffusion over a distance of $5 \mathrm{~cm}$, roughly the distance from top to bottom in the samples, assuming a diffusivity of $10^{-5} \mathrm{~cm}^{2} / \mathrm{s}$ is $\sim 30$ days. Therefore, the relatively slow dissolution of solids separated by a short distance from a quiescent water source is not surprising. As shown in Figure 5.3.11, the settled solids layer was $\sim 20$ vol\% $(\sim 200 \mathrm{~mL})$ of the sample after six days and still $>15$ vol\% after three weeks. Over long times ( $>50$ days), the solids fraction of the unmixed sample leveled off to $\sim 10$ vol\% solids, much like the mixed sample.

The slow dissolution rate in diffusion-limited cases must be considered when evaluating the potential effectiveness of water added to dissolve solids in the waste tank. For example, a toothick layer of water stratified atop the floating crust layer is likely to be somewhat diffusion limited. However, unlike the nonconvective layer experiments, a few factors in this scenario would tend to overcome the diffusion limitation: 1) Release of gas from the upper crust surface or through the crust from lower in the tank could create some liquid convection. The magnitude of this effect has not been evaluated, though it likely depends strongly on gas release rates. 2) The free-floating layer would tend to buoy up into less saturated diluent as the more saturated diluent near the dissolution front sinks. These phenomena, along with judicious step-wise top addition volumes, would maximize the effectiveness (rate) for top-down crust dissolution. 


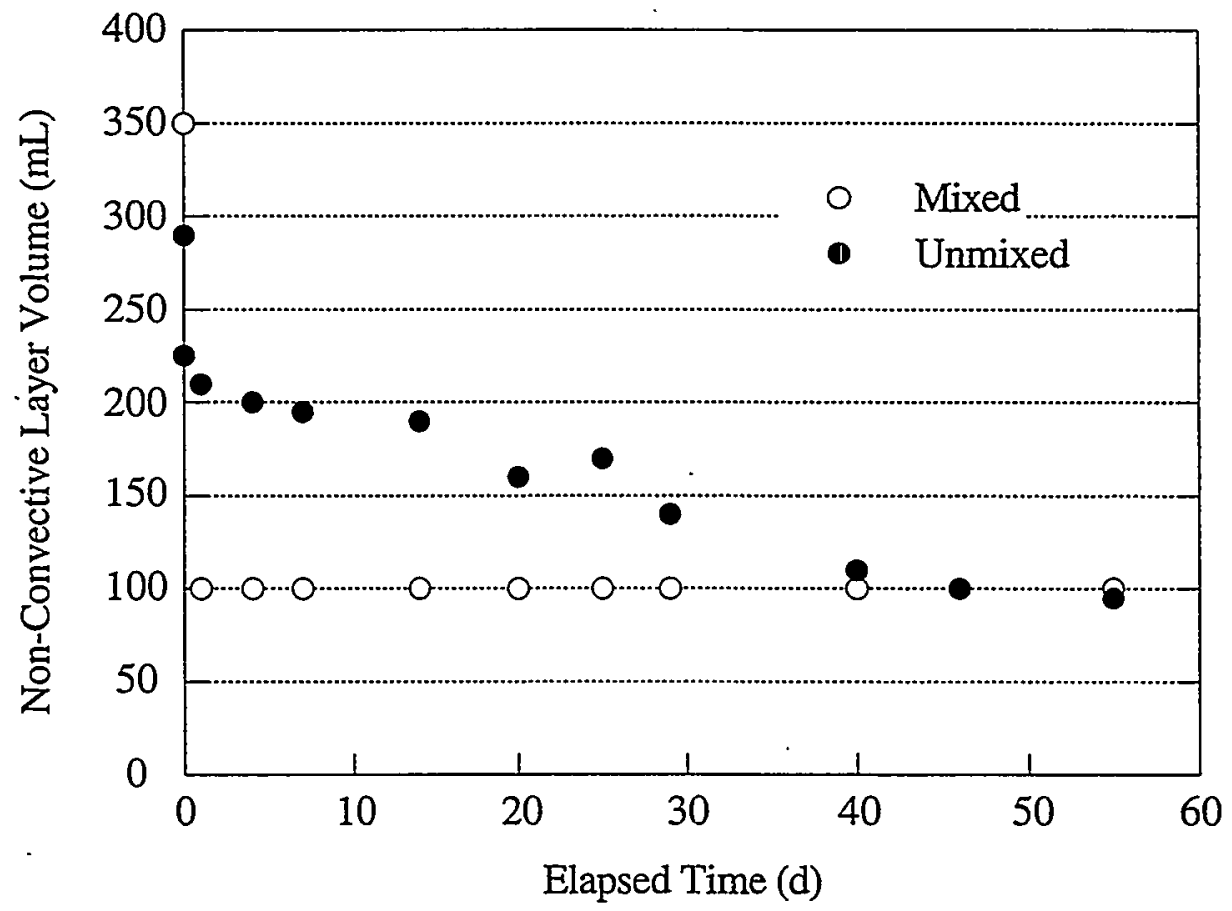

Figure 5.3.11. Dissolution Rates of Nonconvective Layers in Mixed and Unmixed Chemical Simulant Samples 


\subsection{Gas Release Mechanisms, Rates, and Analysis}

The addition of a large volume of water on or below the floating crust layer in SY-101 is expected to result in gas release from the crust via an obvious mechanism-dissolution of solids freeing gas bubbles from the waste matrix. This mechanism, unique because of the changing chemistry resulting from dilution, will likely be coupled with other postulated release mechanisms to ultimately release gas to the tank domespace. As demonstrated in Section 5, the rate of dissolution (or degradation) of gas-bearing waste is coupled to the rate gas is freed from the waste matrix. In one limit, gas is released to tank domespace at the rate it is evolved from the waste, and in the other extreme, the freed gas is held up in or below the crust temporarily and the collected volume is released suddenly. Here we postulate the mechanisms of gas retention and release particular to tank back-dilution processes, considering diluent addition on top of or below the crust. We also demonstrate through analysis of various gas release scenarios and rates that the creation of flammable concentrations of hydrogen $\left(\mathrm{H}_{2}\right)$ in the domespace from dilution activities following the $2^{\text {nd }}$ waste transfer from SY-101 are highly unlikely.

The model used to evaluate changes in domespace $\mathrm{H}_{2}$ concentration and flammability conditions is described in the first section. Mechanisms of gas retention and release from nonconvective, slurry, and crust layers are discussed in Section 6.2, with a particular emphasis on the floating crust layer as it is the conduit through which all gas must pass. Section 6.3 sets up the conditions and modeling approach for the gas release scenario analyses that follow in Sections 6.4 (continuous releases) and 6.5 (sudden releases).

\subsection{Domespace Hydrogen Concentration Model}

The concentration of hydrogen in the tank domespace, written as the molar or volume fraction in air, $\mathrm{C}_{\mathrm{H} 2}$, is typically used to determine whether the gas mixture above the waste is flammable (Sullivan 1995). The LFL for $\mathrm{H}_{2}$ in air is $\mathrm{C}_{\mathrm{H} 2 \mathrm{LFL}}=0.04$, and $\mathrm{H}_{2}$ concentrations exceeding this level (up to the upper flammability limit $\mathrm{C}_{\mathrm{H} 2 \text {,UFL }}=0.75$ ) are flammable (Beyler 1988). For continuous gas releases from the waste to the domespace, the concentration of $\mathrm{H}_{2}$ can be estimated from a mass balance about the domespace volume:

$$
\text { Rate of accumulation of } \mathrm{H}_{2} \text { in domespace }=\text { Rate } \mathrm{H}_{2} \text { in }- \text { Rate } \mathrm{H}_{2} \text { out }
$$

and this can be expressed in quantitative terms by the differential equation

$$
V_{D}(t) \frac{d C_{H 2}}{d t}=Q_{R} \chi_{H 2}-Q_{V} C_{H 2}
$$

Here, $Q_{R}$ and $Q_{V}$ are the volumetric rate of gas release from the waste at atmospheric pressure $\left(\mathrm{P}_{\mathrm{a}}\right)$ and the constant vent flow rate, respectively, and $\chi_{\mathrm{H} 2}$ is the concentration of $\mathrm{H}_{2}$ in the released gas. Although the exit flow typically increases during a release to match more closely the sum of the release rate and vent flow, it is assumed here that the exit flow is constant at the specified vent flow rate. The concentration of the gas in the outflow is defined as equal to the concentration in the domespace. This is the typical simplifying assumption of perfect, instantaneous mixing of the released gas into the domespace volume. While the released gas may exist 
as a plume for a finite duration, mixing is quite rapid (Antoniak and Recknagle 1997). Consideration of plumes is outside the scope of the current analysis, and it is believed that the simplifications made here do not change the conclusions. Making the well-mixed assumption and subject to the initial condition on the hydrogen concentration in the domespace,

$$
\mathrm{C}_{\mathrm{H} 2}(0)=\mathrm{C}_{\mathrm{H} 2,0}
$$

Equation 6.1.2 has an integrated solution of the form

$$
C_{H 2}(t)=\frac{Q_{R} \chi_{H 2}}{Q_{V}}\left[1-\exp \left(\frac{-Q_{V} t}{V_{D, o}}\right)\right]+C_{H 2, o} \exp \left(\frac{-Q_{V} t}{V_{D, o}}\right)
$$

The first term on the right accounts for increases in dome hydrogen concentration due to continuous gas releases, while the second term describes the decay in concentration of the gas initially present in the domespace.

In general, the domespace volume $V_{D}$ is a function of time due to gas releases and other factors affecting waste level. Often the dome volume is assumed constant at some initial value $\mathrm{V}_{\mathrm{D}, \mathrm{o}}$, a reasonable assumption for small releases. However, to properly account for changes in the dome volume for larger releases, Equation 6.1.2 must be reevaluated using a more general time-dependent dome volume. Assuming the dome volume changes only as a function of continuous gas releases, waste transfers, and back-dilution additions, the transient dome volume can be expressed as

$$
V_{D}(t)=V_{D, o}+\left(\frac{P_{a}}{P_{h}} Q_{R}+Q_{X}-Q_{W}\right) t=V_{D, o}+Q_{D} t
$$

where $\mathrm{Q}_{W}$ and $\mathrm{Q}_{\mathrm{X}}$ are the constant volumetric rates of water back-dilution to the tank and waste transfer from the tank, respectively. The pressure term $P_{a} / P_{h}$ corrects the released volume to an as-retained volume at depth $h$. In the situations analyzed here, releases during waste transfer are not considered; therefore, the rate of change of domespace volume $Q_{D}$ is a function of release and back-dilution rates. In many of the analyses, releases are assumed to begin only after water addition is completed, in which case $\mathrm{Q}_{\mathrm{D}}=\left(\mathrm{P}_{\mathrm{a}} / \mathrm{P}_{\mathrm{h}}\right) \mathrm{Q}_{\mathrm{R}}$.

Substituting Equation 6.1.5 into Equation 6.1.2 and integrating subject to the initial condition Equation 6.1.3, the solution for the transient domespace $\mathrm{H}_{2}$ concentration is

$$
C_{H 2}(t)=\frac{Q_{R} X_{H 2}}{Q_{V}}\left[1-\left(1+\frac{Q_{D} t}{V_{D, o}}\right)^{\frac{-Q_{v}}{Q_{D}}}\right]+C_{H 2,0}\left(1+\frac{Q_{D} t}{V_{D, 0}}\right)^{\frac{-Q_{V}}{Q_{D}}} ; Q_{D} \neq 0
$$

The transient results obtained from Equation 6.1.6 are exponential in nature, although this may not be obvious from the equation. Equation $6.1 .6 \mathrm{can}$ be written in an equivalent exponential form: 


$$
\mathrm{C}_{\mathrm{H} 2}(\mathrm{t})=\frac{\mathrm{Q}_{\mathrm{R}} \chi_{\mathrm{H} 2}}{\mathrm{Q}_{\mathrm{V}}}\left\{1-\exp \left[-\frac{\mathrm{Q}_{\mathrm{V}}}{\mathrm{Q}_{\mathrm{D}}} \ln \left(1+\frac{\mathrm{Q}_{\mathrm{D}} \mathrm{t}}{\mathrm{V}_{\mathrm{D}, \mathrm{o}}}\right)\right]\right\}+\mathrm{C}_{\mathrm{H} 2, \mathrm{o}} \exp \left[-\frac{\mathrm{Q}_{\mathrm{V}}}{\mathrm{Q}_{\mathrm{D}}} \ln \left(1+\frac{\mathrm{Q}_{\mathrm{D}} \mathrm{t}}{\mathrm{V}_{\mathrm{D}, \mathrm{o}}}\right)\right] ; \mathrm{Q}_{\mathrm{D}} \neq 0 \text { (6.1.7) }
$$

In the limit that $Q_{D}$ approaches zero, the results of Equations 6.1 .4 , in which a constant domespace volume is assumed, and 6.1.6 (or 6.1.7) are identical. Continuous and sudden gas releases from crust or other tank waste fractions result in a non-zero $Q_{D}$, and, in general, Equation 6.1.6 is useful when computing transients in the domespace $\mathrm{H}_{2}$ concentration. A sudden release can be modeled as a continuous release of very short duration. Thus Equation 6.1.6 can be used to model hydrogen concentrations for both continuous and sudden releases over the period that the release rate $\mathrm{Q}_{\mathrm{R}}$ (and $\mathrm{Q}_{\mathrm{D}}$ ) remains constant. To track $\mathrm{C}_{\mathrm{H} 2}$ after an initial release phase, Equation 6.1.6 (or 6.1.4 if $Q_{D}=0$ ) is reset with new $Q_{R}$ and $Q_{D}$ values, $t$ is reset to 0 , and $\mathrm{C}_{\mathrm{H} 2, \mathrm{o}}$ and $\mathrm{V}_{\mathrm{D}, \mathrm{o}}$ are set to their values at the end of the initial phase. This process can be repeated indefinitely and is necessary each time $Q_{R}$ or $Q_{D}$ changes. If a background release occurs in addition to any other release being considered, the combined rate of gas release from all sources must be accounted for in $\mathrm{Q}_{\mathrm{R}}$. In the following analysis, background releases are not separated or explicitly addressed because they are typically small compared to the magnitude of gas releases analyzed.

\subsection{Gas Release Mechanisms}

Mechanisms of gas retention and release from simulated and actual wastes were described by Gauglitz et al. (1994, 1995) and further refined in later work (Bredt et al. 1995; Bredt and Tingey 1996; Gauglitz et al. 1996; Stewart et al. 1996; Rassat et al. 1997, 1998). These studies focused on naturally occurring retention and release from the nonconvective. layer of DST and SST wastes on the FGWL in an effort to understand the flammability hazard and to resolve the safety issue (Johnson et al. 1997). Drawing on these earlier gas retention studies, several mechanisms of spontaneous and induced gas release from SY-101 crust were hypothesized and discussed (Rassat et al. 1999). Many of these gas retention and release mechanisms are pertinent to our understanding of how gas is released from the crust as it is dissolved and how gas is transported through the crust when evolved below it. In this section we first discuss the process of gas evolution from nonconvective and slurry layers, and then we present floating crust layer gas retention and release mechanisms.

\subsubsection{Gas Release from Slurry and Nonconvective Layers}

The gas fraction in the mixed slurry and loosely settled nonconvective waste layers is small, on the order of 2 to $3 \%$ by volume (Section 2.2). However, the large volume of combined slurry and nonconvective waste, 320 inches $(8.1 \mathrm{~m})$ deep, corresponds to about $90 \mathrm{~m}^{3}$ of retained gas assuming a gas fraction of 0.027 . For completeness, this gas source and its potential evolution during back-dilution operations are considered.

Gas is evolved from the nonconvective layer when the gas-bearing waste is disturbed in normal mixer pump operations. Domespace hydrogen concentrations increase during pump runs, indicating that at least some of the evolved gas is released through the crust. This mechanism of gas release is reasonably expected to continue after back-dilution with water as 
long as gas is retained in the waste, the mixer pump is operated, and release paths to the domespace exist. Other gas evolved from the nonconvective layer with pump operation is retained either in the crust or the mixed slurry.

Here we are concerned with dissolution-driven evolution of gas from the mixed slurry layer following addition of large volumes of water into the slurry. The configuration of gas retained within the fluid slurry layer of the tanks is not completely understood, but two distinct mechanisms of gas retention in bubble-waste agglomerates are postulated. First, the gas may be trapped in particle-armored bubbles, bubbles stabilized by a single-layer sheath of smaller solid particles. Second, the gas may be retained in small waste gobs consisting of a many-bubbleliquid-solid particle matrix. These gobs may be created by the action of the jet mixer pump on the nonconvective layer or from crust in a dissolution and gas-release process. Both types of bubble-particle agglomerates were observed in chemical simulant dissolution experiments (Section 5.3). In terms of dissolution and gas. release, the form of the bubble-particle agglomerates is potentially important.

For the bubble-waste agglomerates to truly be retained in the mixed slurry layer, they must be neutrally buoyant. Otherwise, low-density agglomerates rise into the crust where the gas (and possibly liquid and solids) is either retained or released if suitable bubble transport to the upper crust surface is possible. This phenomenon is enhanced by gas expansion as bubbles rise. If particles in the entity dissolve in unsaturated fluid and no additional solid particles are added as the entity buoys upward, its density decreases further and the rise is accelerated. Particles lost in transit settle toward the nonconvective layer, increasing the effective density of the mixed slurry. A complimentary gas transport process is also possible. Bubbles in the mixed slurry that add particles to form armor, or waste gobs that release particularly gaseous fractions, can sink to the nonconvective layer. In these ways, the formation and retention of gas retaining agglomerates in the mixed slurry is very dynamic. In fact, the "retained" gas present in the mixed slurry most likely reflects the continual transitory migration of gas bubbles and bubble-waste agglomerates.

To evaluate the typical gas fraction of retained bubble-waste agglomerates, it is assumed they are on average neutrally buoyant in the bulk mixed slurry $\left(\rho_{\mathrm{SL}}=1550 \mathrm{~kg} / \mathrm{m}^{3}\right)$. Armored bubbles coated in $2200 \mathrm{~kg} / \mathrm{m}^{3}$ particles are neutrally buoyant in the slurry when the gas and solid volume fractions are 0.29 and 0.71 , respectively. A straightforward analysis shows that the overall diameter of the neutrally buoyant armored bubbles is a few times larger than the nominal diameter of included particles. Typical waste particles are expected to range from about $1 \mu \mathrm{m}$ to $1 \mathrm{~mm}$ in diameter, and associated neutrally buoyant armored bubbles would be only slightly larger. The size of waste gobs (bubbles-liquid-solids) liberated from the nonconvective layer would be a function of the waste strength and the capacity (energy) of the jet pump to shear the material into fragments. It seems likely that waste gobs could be larger than the neutrally buoyant armored bubbles, perhaps centimeter diameter or bigger. Whether gobs result from pump action or are freed from dissolving crust, the gas fraction necessary for them to float is smaller than for armored bubbles. Assuming the bulk density of the liquid and solids in the gob matrix is $1740 \mathrm{~kg} / \mathrm{m}^{3}$, a gas fraction of $\sim 0.11$ or greater makes the gobs buoyant in the mixed slurry. However, waste gobs and armored bubbles contain the same ratio of solids and gas. Therefore, in terms of gas volume released as a result of dissolution of surrounding solids, each type of bubble-waste agglomerate could be equally affected by unsaturated diluent. 
In Section 3.1, it was shown that liquid added at the transfer pump inlet (96 inches above tank bottom) or lower was effectively mixed with the slurry volume above the addition elevation. Water added in this manner will affect the retained bubble-waste agglomerates in two ways. The decrease in bulk density of the slurry would cause agglomerates near neutral buoyancy to sink, and an opposite effect is achieved as solids at agglomerate surfaces dissolve. Assuming uniform gas distribution within waste gobs, the rate of maximum gas release is likely coupled to the rate gob matrix solids are dissolved. These rates could be estimated from analysis of free particle dissolution, treating the gobs as large particles of low density (Section 5.2.2). On the other hand, gas release rates from armored bubbles could far outstrip the general rate of solids dissolution, because convective dissolution and gas expansion during bubble rise may destabilize the armor and free the bubbles. In this way, a limited water addition may affect a large volume of gas retained in armored bubbles.

This does not imply a large instantaneous gas release to the tank domespace, however. The maximum release rate would be limited by the transport of the small bubbles through the viscous slurry. The terminal velocity of a relatively large, $\sim 1-\mathrm{mm}$-diameter bubble freed of its armor in a $500-\mathrm{cP}$ fluid is estimated at $<0.002 \mathrm{~m} / \mathrm{s}$. At this rate, bubbles released at the base of the crust take $\sim 25$ minutes to reach a liquid level some 100 inches $(2.5-\mathrm{m})$ above if unhindered, and bubbles freed near the mixer pump inlet $\sim 300$ inches $(7.5 \mathrm{~m})$ below the liquid level take $\sim 75$ minutes to reach the surface. In this worst-case scenario, the minimum domespace release duration is $\sim 50(=75-25)$ minutes. The sudden release of mixed slurry gas is considered further in Section 6.5.1, and no domespace flammability concern is identified for this scenario.

\subsubsection{Floating Crust Layer Gas Release Mechanisms}

Gas evolution, the process by which gas bubbles are freed from the waste matrix, is distinguished from gas release to the tank domespace. Gas evolved below or within the floating crust must be released through the crust, not trapped by it, to influence the domespace flammability condition. Evolution and release are both impacted by the tank dilution process. Gas evolution rates are directly linked to the rate at which waste matrix is dissolved, and dissolution of crust influences global gas release mechanisms through changes in the structure of the floating layer.

A previous analysis related mechanisms of gas retention and release to the configuration or structure of the crust, ranging from a completely homogenous gas-laden material to a more realistic heterogeneous floating mass (Rassat et al. 1999). The current crust model includes vertical heterogeneities as depicted in the layered crust structure presented in Figure 2.2.2. Additionally, video evidence of the SY-101 crust upper surface demonstrates lateral inhomogeneity. Evidence to support lateral nonuniformity throughout the floating layer mass below the visually accessible portion is less obvious. A key point is that gas continues to be released during mixer pump runs regardless of pump orientation (Section 6.5.2). This suggests that release paths, a type of lateral inhomogeneity, exist through the crust surface. Such paths are necessary if gas that evolves below or at the base of the crust is to release readily and continuously as it is liberated. Otherwise, gas may hold up under the crust and release only after a bubble or a group of bubbles attain sufficient size to push through a weak spot in the crust. Depending on the distribution of these "preferential" paths and the location and frequency with which gas is liberated, these semicontinuous gas releases may appear continuous in nature. The formation of preferred channels for gas release has been observed experimentally with simulated 
crust materials (Rassat et al. 1999, Section 5.3). Additionally, the analysis of Section 5.1.2 indicates that larger-diameter channels or paths would be filled more readily by low-density unsaturated diluent. Continued dissolution at these preferred channel surfaces would tend to open the path further for buoyancy-driven gas bubble transport.

Chemical simulant experiments provided many insights into dissolution and gas release mechanisms for water introduced near crust surfaces (Section 5.3). In these, continuous and semi-continuous gas-release mechanisms dominated. Because of the many mechanical forces contributing, experiments showed that gas release from crusts should be considered a function of crust degradation, not strictly of crust solids dissolution. Release of individual bubbles, typically $<0.5 \mathrm{~cm}$ in diameter, directly from the crust was a primary mechanism of gas release observed in the tests. This likely resulted from dissolution of the crust solids adjacent to the bubble and/or sloughing as a result of mechanical forces on the bubbles (e.g., buoyancy) and crust surfaces (e.g., liquid convection). Frequently, many bubbles within a matrix of solids (and liquid) broke away from larger pieces of crust. Motion of a bubble-solid matrix often caused the solids to erode, shear, or dissolve, further exposing the bubbles and accelerating the rise of the bubbleladen fragment. Release of bubbles and waste fragments caused the free-floating parent crust to move (rise, sink, or rotate) according to the buoyant forces exerted. With bottom addition to a thicker simulant crust, gas released from below the crust through preferred paths. Gas bubbles likely evolved across the crust bottom surface as a result of dissolution, but the gas collected at and released through the preferred channel. Gas releases resulting from a layer of diluent in contact with the upper crust surface appeared more uniform because released bubbles buoyed directly (vertically) to the surface.

These continuous and semicontinuous release mechanisms are also expected to contribute significantly in tank-scale back-dilution activities. Such releases are almost certain for water added on top of the crust where an overlying layer of liquid provides little resistance to the buoyant migration of bubbles from the crust layer. After some top dissolution, however, a layer of insoluble or slowly soluble solids (40\% of total solids content estimated; Section 2.1) is likely to build up on the upper crust surface. This layer, presumably loosely settled and weak, would lead to a barrier restricting liquid transport to fresh crust surface and bubble migration from that surface. With increasing insoluble layer thickness, the size of the particle-displacing bubbles at the fresh crust surface required to overcome the load of solids above would increase, and a semicontinuous release of coalesced bubbles is expected. Additionally, with increasing size and depth of the insoluble solids, retention of interstitial-liquid-displacing bubbles within the pore space of the solid network and subsequent percolation releases are possible (Gauglitz et al. 1995; Stewart et al. 1996). This is also considered a semicontinuous release mechanism.

The release of bubbles to the tank domespace during bottom-up dissolution, when unsaturated low-density diluent lies under the crust, is also very likely a semicontinuous process. For it to be truly continuous would require that each bubble exposed by dissolution have a conductive release path through the crust directly above it. If such paths existed, the bubbles would release in the current state of the tank, without added water. In reality, the exposed gas bubbles at the bottom surface will most likely accumulate and possibly coalesce to form a gaseous entity of moderate size that will release semicontinuously after migrating (or spreading) laterally along a nonuniform crust base (heterogeneous crust) to a preferred pathway. These paths might be filled with liquid or with weaker crust material. In the limit of a very large 
number of equally spaced, low-resistance, semi-continuous release paths through the crust, a continuous gas release model holds for bottom dissolution. The effects of continuous gas releases on tank domespace flammability are considered in Section 6.4 .

In the extreme and unlikely circumstance that a large portion of the crust layer forms a seal preventing the continuous (or semicontinuous) migration of gas to the domespace, larger sudden gas releases must be considered. In chemical simulant experiments (Section 5.3), no sudden large gas release mechanisms were observed other than initial "tapping" or exposing existing gas pockets. Relatively large volumes of gas (experimental scale) were evolved during the short (10-min) diluent addition in two tests, but this was attributed to the presence of gas pockets in the samples that were directly displaced by the added liquid or released when the liquid opened paths to the headspace. No comparable tank-scale gas-tapping phenomena have been observed in SY-101. Operational experience with crust penetrations during VFI, MMA, and other waterassisted lance deployments and water flushes have not led to any significant sudden gas releases. In fact, these operations may have produced preferred paths, minimizing the potential for gas buildup and sudden releases. Furthermore, monitoring of the tank domespace gas composition in the last few years has not indicated any substantial spontaneous releases despite the considerable increase in retained gas in the floating layer. These data suggest that large pockets of easily released gas have not formed in the tank.

In spite of this tank evidence, sudden release mechanisms are considered here. A noted concern is formation of a very large gas bubble or gas pocket in or beneath the floating layer, retained by the strength of the crust material. It is supposed that such a bubble grows until the buoyant force on the bubble allows it to overcome the waste strength and it rises or the bubble grows until it reaches a weak, open path. It is demonstrated in Section 6.5.2 that, even if such a large bubble could form, it would not create a flammable condition when released suddenly.

Many hypothetical sudden gas release mechanisms will most likely follow a period of continuous dissolution and gas release. For examples, dissolution from the top down with the preferential creation of a depression, and ultimately a hole, could provide a path through which the high gas content and relatively weak bubble slurry flows to the upper crust surface and releases gas. ${ }^{(a)}$ (Recent intrusions through the crust during MMA and lance operations have not resulted in any significant flow of bubble slurry to the crust surface.) Second, a downward dissolution front exposes a weaker and weaker paste layer (Section 2.3). At some point, larger gas bubbles from the bubble slurry layer may be able to migrate through the paste, disturbing and releasing the remaining bubble slurry and some paste layer gas as it does so. Finally, a period of continuous dissolution may ultimately lead to creation of numerous free-floating bergs (see results for thin chemical simulant crusts in Section 5.3.3). Bergs with a high-gas region trapped below a denser, low-gas material will become buoyantly unstable if the breadth of the berg is smaller than its height; if these bergs capsize or tip they could shear and release large portions of the trapped gas. The limited impacts of these types of potential sudden gas releases on domespace flammability are addressed in Section 6.5.1.

(a) This mechanism is addressed in detail in 1999 PNNL letter report TWS99.27, by PA Meyer, CW Stewart, SD Rassat, RT Allemann, G Terrones, and DP Mendoza: "Potential Gas Release by Bubble Slurry Flow Through a Hole in the Crust Layer in SY-101." 


\subsection{Approach for Modeling Gas Releases from Tank Crust}

The transient gas release model described in Section 6.1 is used in subsequent sections to evaluate domespace hydrogen concentrations. The simple two-layer crust model depicted in Figure 6.3.1 is the basis for most of the analyses. The crust consists of a relatively thick paste layer (85 in.) $\left(\alpha_{\mathrm{p}}=0.21\right)$ on top of a thinner bubble slurry layer (10 in.( $\left.) \alpha_{B S}=0.6\right)$ for a total thickness of 95 inches $(2.4 \mathrm{~m})$. This model is based on the projected condition of the crust after the initial transfer and back-dilution processes (Tables 2.4.3 and 2.4.4). In the model crust in the figure, the paste layer is 5 inches thicker than that described in. Section 2 to account for the remaining "wet clay" layer (0.08 gas fraction), conservatively increasing the amount of gas retained. The average void fraction of the model crust is $\alpha_{c}=0.251$, slightly higher than the projected value (0.244).

Corrections for gas volume expansion during release to the domespace are made considering the pressure at the average layer depth. Using the density of the crust to compute the hydrostatic load on retained gas, the estimated average pressures in the paste and bubble slurry layers are 1.14 and 1.28 atm, respectively. Applying average pressure corrections is a simplification that gives constant release rates needed in the model calculations. ${ }^{(a)}$ To account for uncertainty in parameter values (e.g., void fraction and thickness of the crust layers), the parameter space is expanded to more conservative limits. For example, the relatively low solids volume fraction of

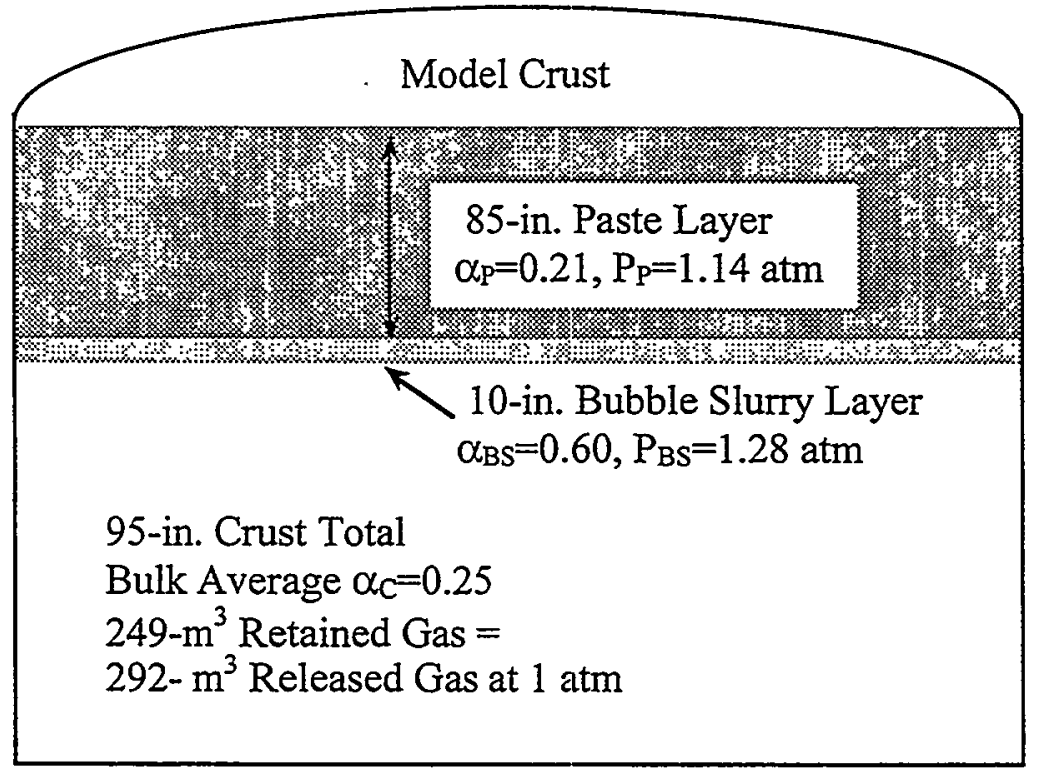

Figure 6.3.1. Simple Crust Model Used in Gas Release Analyses

(a) Equation 6.1.6 (or 6.1.7) requires a constant rate of change of domespace volume, which is a function of the gas release rate from the waste and the rate of volume changes associated with transfer and/or dilution, if they occur simultaneously. For this reason, in the model cases where the addition of dilution water is faster than the time for dissolution of the crust, it is assumed that all the dilution water is present when the dissolution begins. This is a conservative assumption because the domespace volume is initially reduced, growing at the rate of gas evolution. In reality, the domespace would not reach the initial level for the same water addition because of the gas released during the addition. 
the model crust (0.3), the resultant low gas-free crust density $\left(1703 \mathrm{~kg} / \mathrm{m}^{3}\right)$, and the relatively high fraction of insoluble solids (0.4) give a relatively high effectiveness factor for diluent water (3.19 volumes gas-free crust affected per unit volume pure water). Additionally, the specified vent flow rate $(475 \mathrm{scfm})$ is more than $10 \%$ lower than the current typical value $(530 \mathrm{scfm})$. The $\mathrm{H}_{2}$ mole fraction in the released crust gas is 0.38 , a best estimate from RGS analysis (Mahoney et al. 1999). Table 6.3.1 summarizes the constant model parameters. Other variable parameters are specified in the text corresponding to specific release scenarios.

For large and relatively fast gas releases, the domespace volume at the time of release is an important factor in determining whether a flammable domespace condition exists. The initial domespace volume must be specified for the expected condition at the time of crust dissolution and gas release associated with the second back-dilution. Tables 2.4.3 and 2.4.4 provide guidelines for the expected waste level following the first waste transfer $(88,000$ gal) and backdilution (60,000 or 97,000 gal water). A final waste level of 408 or 419 in. is projected, depending on the back-dilution volume. A larger second waste transfer is planned, but given the uncertainty in the exact volumes to be back-added after the first transfer and removed in the second transfer, a range of waste levels at the start of crust dissolution is considered. Some possible values for this initial level, following the addition of the 61,400 gal needed to dissolve the model crust, and the corresponding domespace volumes are shown in Table 6.3.2. The table

Table 6.3.1. Constant Model Parameters Used in Gas Release Analyses

\begin{tabular}{|c|c|c|c|}
\hline \multicolumn{2}{|l|}{ Solubility and Density Parameters } & \multicolumn{2}{|c|}{ Gas Release and Tank Parameters } \\
\hline $\begin{array}{l}\text { Waste solubility, mass readily } \\
\text { soluble solids/mass water }\end{array}$ & 1.267 & $\begin{array}{l}\mathrm{H}_{2} \text { fraction in trapped and } \\
\text { released gas, } \chi_{\mathrm{H} 2}\end{array}$ & 0.38 \\
\hline $\begin{array}{l}\text { Waste solubility, volume affected } \\
\text { gas-free waste/volume water }\end{array}$ & 3.19 & $\mid \begin{array}{l}\mathrm{H}_{2} \text { concentration at } \mathrm{LFL}, \\
\mathrm{C}_{\mathrm{H} 2 \mathrm{LI}}{ }^{2}\end{array}$ & 0.04 \\
\hline $\begin{array}{l}\text { Insoluble solids fraction, } \\
\text { insoluble solids/total solids }\end{array}$ & 0.4 & \begin{tabular}{|l|} 
Bubble slurry layer gas \\
fraction, $\alpha_{B S}$
\end{tabular} & 0.60 \\
\hline $\begin{array}{l}\text { Volume fraction total solids in } \\
\text { gas-free crust, } \phi_{\mathrm{S}}\end{array}$ & 0.3 & Paste layer gas fraction, $\alpha_{\mathrm{p}}$ & 0.21 \\
\hline Crust solids density, $\rho_{s}, \mathrm{~kg} / \mathrm{m}^{3}$ & 2200 & $\begin{array}{l}\text { Average pressure in bubble } \\
\text { slurry layer, } \mathrm{P}_{\mathrm{BS}} \text {, atm }\end{array}$ & 1.28 \\
\hline $\begin{array}{l}\text { Saturated liquid density, } \rho_{\mathrm{L}}, \\
\mathrm{kg} / \mathrm{m}^{3}\end{array}$ & 1490 & $\begin{array}{l}\text { Average pressure in paste } \\
\text { layer, } \mathrm{P}_{\mathrm{P}} \text {, atm }\end{array}$ & 1.14 \\
\hline $\begin{array}{l}\text { Gas-free crust density, } \rho_{\mathrm{GFC}}, \\
\mathrm{kg} / \mathrm{m}^{3}\end{array}$ & 1703 & Vent flow rate, scfm & 475 \\
\hline Water density, $\rho_{\mathrm{W}}, \mathrm{kg} / \mathrm{m}^{3}$ & 1000 & $\begin{array}{l}\text { Domespace volume at } 400 \text {-in } \\
\text { waste level, } \mathrm{m}^{3}\end{array}$ & 1167 \\
\hline & & Tank cross-sectional area, $\mathrm{m}^{2}$ & 410 \\
\hline
\end{tabular}

(a) The Safety Assessment conducted by Los Alamos National Laboratory specifies a very conservative estimate of 0.03 for the $\mathrm{H}_{2}$ fraction at the LFL to account for the presence of other fuel gases (Sullivan 1995). Justification for the use of the lower value is not evaluated in the current report. We use the standard literature value for the flammability of $\mathrm{H}_{2}$ in air (Beyler 1988), and conservatism is included in other assumptions as noted. 
Table 6.3.2. Possible Waste Levels in the Second Waste Transfer and Back-Dilution Operation

\begin{tabular}{|c|c|c|c|}
\hline \multicolumn{2}{|c|}{} & \multicolumn{2}{c|}{ Net Waste Transfer Volume (gal) } \\
$\begin{array}{c}\text { Waste Level } \\
\text { after 61,400-gal } \\
\text { Added (in.) }\end{array}$ & $\begin{array}{c}\text { Domespace } \\
\text { Volume }\left(\mathrm{m}^{3}\right)\end{array}$ & $\begin{array}{c}\text { 408-in. Initial } \\
\text { Waste Level }\end{array}$ & $\begin{array}{c}\text { 419-in. Initial } \\
\text { Waste Level }\end{array}$ \\
\hline 360 & 1584 & 193,600 & 223,900 \\
\hline 380 & 1376 & 138,500 & 168,800 \\
\hline 400 & 1167 & 83,400 & 113,700 \\
\hline 420 & 959 & 28,400 & 58,700 \\
\hline
\end{tabular}

also includes the net volume of the second waste transfer required to achieve the specified postaddition level starting with either 408- or 419-inch waste levels. In calculating the post-addition levels of Table 6.3.2, it was assumed that no gas is released during water addition, and changes in crust buoyancy due to dilution were neglected. Anticipating that the second waste transfer is at least as large as the first, a 400 -inch post-second-addition waste level is an appropriate maximum for analysis of gas release scenarios. Results for other initial waste levels, including a high 420 -inch value, are compared in several cases.

A requirement of the domespace concentration model (Equation 6.1.6 or 6.1.7) is that the release rate $Q_{R}$ and the rate of change in domespace volume $Q_{D}$ remain constant. Therefore, the parameters used in the model must be updated anytime a change in $Q_{R}$ (or $Q_{D}$ ) occurs. To successfully analyze transient dome concentrations of $\mathrm{H}_{2}$ associated with gas releases from the two-layer model crust, it is necessary to update the domespace concentration model parameters three times, creating three distinct phases of model operation. In the first and second phases, gas is released sequentially from the two crust layers, and in the final phase, after gas releases have ceased, the decay in $\mathrm{H}_{2}$ concentration is tracked. In the initial phase, the domespace $\mathrm{H}_{2}$ concentration is typically assumed negligible and the assigned gas release rate (crust degradation rate) for a layer of the crust is used to calculate the transient $\mathrm{H}_{2}$ concentration in the domespace. Choosing the appropriate first (and second) phase parameters, the model allows the crust to be dissolved top-down (paste first), bottom-up (bubble slurry first), or top and bottom simultaneously. After the first layer (phase) of crust is completely consumed (dissolution/gas release), the second crust layer begins to dissolve. This is the start of the second phase. The second phase initial dome concentration is set to the final value from phase one and a second phase crust dissolution rate (i.e., gas release rate) is specified. When the second crust layer is completely consumed, no crust remains. The transient decay of $\mathrm{H}_{2}$ is then monitored in the third phase by resetting the gas release rate to zero and the initial third phase $\mathrm{H}_{2}$ concentration to the end of phase-two value.

As described in Section 5, the gas release rate is readily cast in terms of a linear crust degradation rate $\dot{\mathrm{H}}_{c}$ and the crust gas fraction $\alpha_{c}$. Equation 5.3.1 is recast here in terms of the crust surface area affected by unsaturated diluent $\mathrm{A}_{\mathrm{w}}$ :

$$
\mathrm{Q}_{\mathrm{R}}=\dot{\mathrm{H}}_{\mathrm{C}} \mathrm{A}_{\mathrm{w}} \alpha_{\mathrm{c}}
$$


In model dissolution and gas release analyses, where either top-down or bottom-up crust dissolution is assumed to occur across the tank, the cross-sectional surface area of the tank $\left(410 \mathrm{~m}^{2}\right)$ is the appropriate value for $A_{w}$. In these cases, the quantity $\dot{H}_{c} A_{w}$ has a value of $4.1 \mathrm{~m}^{3}$ affected crust/hour for each $1 \mathrm{~cm} /$ hour of crust degradation rate. In turn, the gas release rate is the product of the volumetric rate at which crust is affected and the crust gas fraction. In cases where simultaneous top-down and bottom-up dissolution is assumed, the value of $A_{W}$ is effectively doubled.

\subsection{Analysis of Continuous Crust Degradation and Gas Release}

As discussed in the theoretical analysis of crust dissolution (Section 5.), the rate of crust degradation is expected to be transport limited. This section evaluates the magnitude of gas releases from the model crust considering both diluent transport-limited cases and extreme, ideal cases where no transport limitation exists. The absence of a transport limitation corresponds to crust dissolution at the rate of diluent addition, limited only by the saturation of the solvent.

Experimental and theoretical analysis indicates expected continuous crust degradation rates on the order of $1 \mathrm{~cm}$ crust thickness per hour in the presence of unsaturated diluent (see Section 5). This represents the upper bound of experimental observations, and the value is expected to apply directly to Tank SY-101 (i.e., scale factor of 1). The theoretical analysis provides tank crust degradation rate estimates ranging from $\sim 0.1$ to $1.5 \mathrm{~cm} / \mathrm{h}$, depending on the concentration of dissolved solids in the diluent and whether dissolution is assumed to occur at the bottom or top surface of the crust. It is demonstrated in this section that continuous degradation rates improbably greater than these expected values are needed to approach a flammable condition in the domespace.

It is assumed here that continuous crust dissolution and gas release mechanisms described in Section 6.2.2 are dominant. Gas holdup and sudden release scenarios are discussed further in Section 6.5.

\subsubsection{Expected Degradation Rates}

The theoretical and experimental "maximum" continuous crust degradation rate (on the order of $1 \mathrm{~cm} /$ hour) is used to predict gas release behavior for continuous dissolution of the model crust. Figure 6.4.1 shows the transient response of the domespace $\mathrm{H}_{2}$ concentration, in terms of the LFL fraction, resulting from the dissolution of the model crust consisting of 85 in. of paste $\left(\alpha_{\mathrm{p}}=0.21\right)$ atop 10 in. of bubble slurry $\left(\alpha_{B S}=0.6\right)$. Continuous degradation rates equivalent to $1 \mathrm{~cm} /$ hour of paste layer and $1.98 \mathrm{~cm} /$ hour of bubble slurry were assigned. The higher bubble slurry layer dissolution rate was assumed because of its higher gas content and its proportionally lower solids content. The waste level at the start of degradation was set to 400 in. (10.2 m), a high and conservative value for post-second transfer (see Table 6.3.2).

Figure 6.4.1 shows expected transient gas release behavior for continuous dissolution from the top down, where the paste layer is dissolved before the bubble slurry layer, bottom up dissolution, and simultaneous top and bottom dissolution. These cases reflect realistic "maximum" continuous gas release rates for planned water addition locations following the 


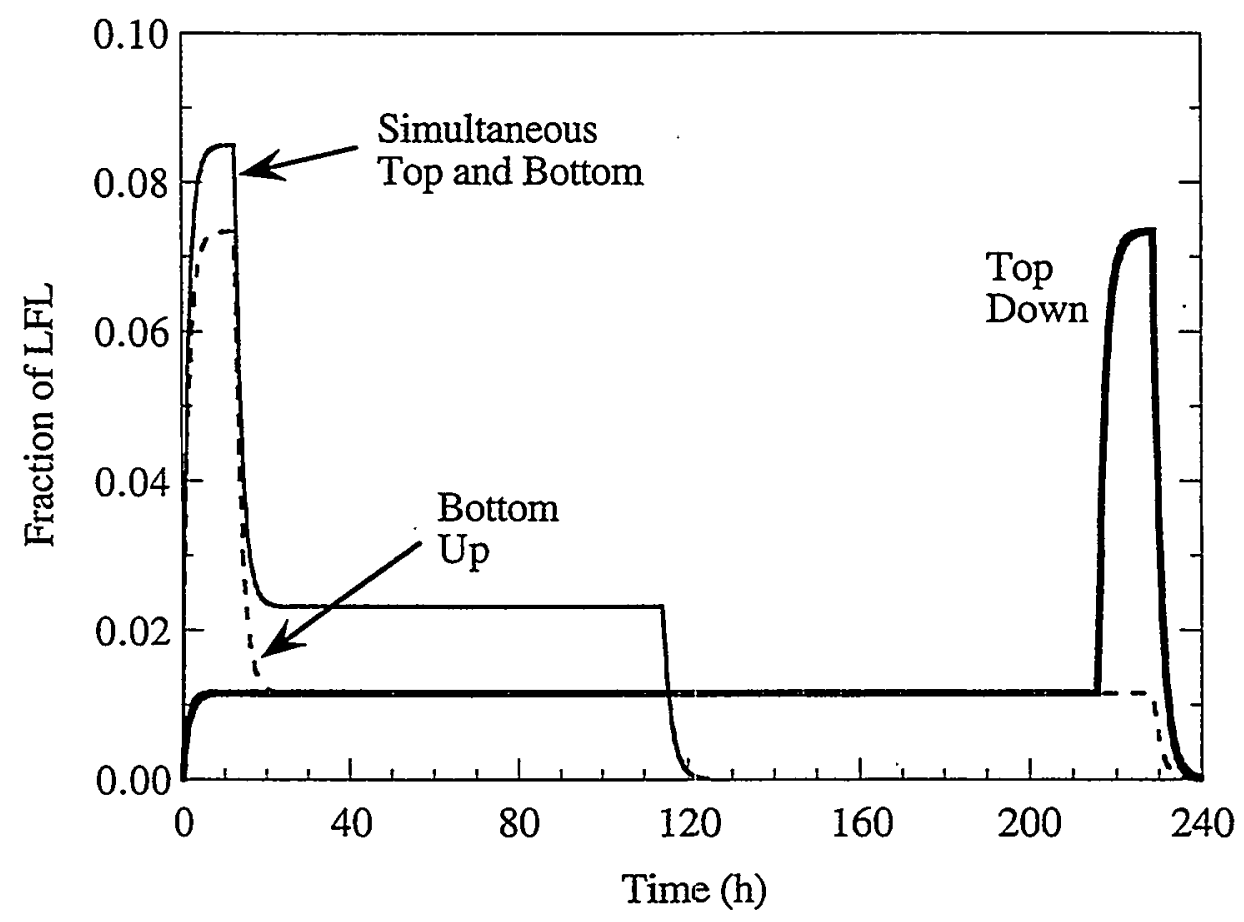

Figure 6.4.1. Transient Response of the $\mathrm{H}_{2}$ LFL Fraction Resulting from the Degradation of the Model Crust at a Rate Equivalent to $1 \mathrm{~cm}$ of Paste Layer per Hour

second waste transfer. When large volumes of water are added directly to the crust surface through a single riser (or even more so if it were added as a widely distributed spray), the diluent is expected to spread across the entire surface. While the dissolution front may be dished somewhat in the vicinity of a water addition point (Section 5.1.1), the assumption of a planar dissolution front at the top surface is not unreasonable. Increases in exposed and dissolving crust surface area in a dish or other non-planar geometry can be handled by directly increasing the surface area used in the analysis (Equation 6.3.1), or it can be indirectly analyzed by increasing the crust degradation rate. Both approaches are used. In cases where simultaneous top and bottom dissolution is modeled, the area for dissolution is effectively doubled. Bottom-up dissolution analyses cover potential gas releases from water added below the crust surface through the transfer pump or mixer pump. The saturation condition of the bottom-added diluent is strongly dependent on the addition location, with greater mixing resulting from addition low in the tank (Section 3). In turn, the theoretical dissolution rate decreases with increasing diluent saturation (Section 5.2.2). Therefore, 1 to $2 \mathrm{~cm} / \mathrm{hr}$ dissolution rates are conservatively fast, assuming nearly unsaturated diluent is always available at the crust surfaces.

The maximum LFL fraction for top only and bottom only dissolution cases in Figure 6.4.1 was identical, 0.073 . The maximum LFL fraction was slightly higher $(0.085)$ for simultaneous top and bottom dissolution because of the increased degradation and gas release rate. The overall crust degradation time for simultaneous dissolution $(\sim 114 \mathrm{~h})$ was half that of the onesided dissolution processes. 


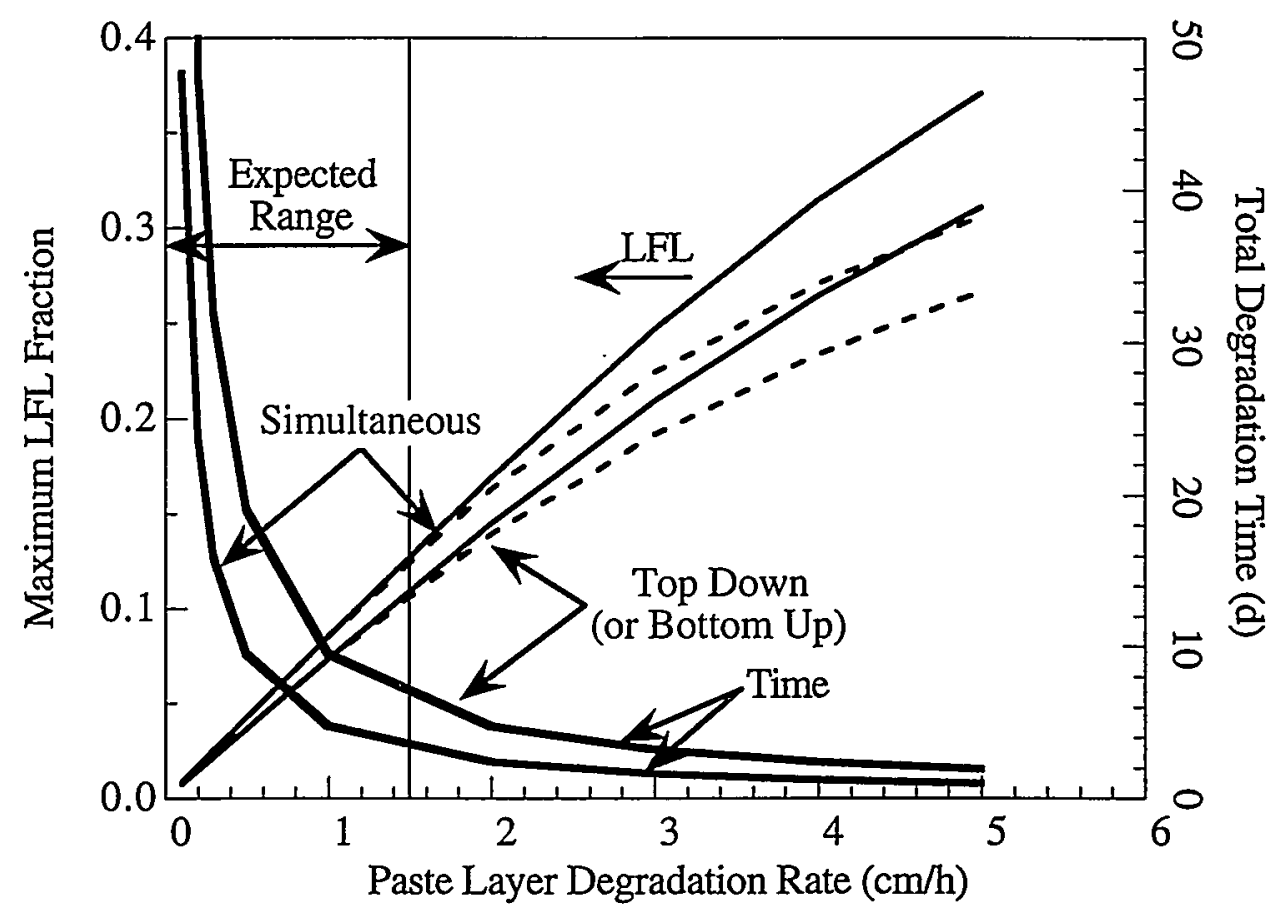

Figure 6.4.2. Maximum $\mathrm{H}_{2}$ LFL Fraction for Continuous Gas Release from the Model Crust for a Range of Realistic Dissolution Rates

The maximum LFL fractions for the cases shown in Figure 6.4.1 and other continuous release conditions in the range of expected crust degradation rates are captured in Figure 6.4.2. In all cases, the bubble slurry degradation rate is assumed to be about twice the paste layer degradation rate characterized in the plot. ${ }^{(a)}$ There is negligible difference in the maximum LFL fraction achieved for dissolution from the top down or bottom up at these modest degradation rates, because the rates are sufficiently slow that near steady state dome concentrations are reached. The domespace volume, represented in the figure by the initial waste level after water addition and at the start of degradation (360 or 420 inches), only has an appreciable affect when the equivalent paste layer degradation rates are greater than $\sim 2 \mathrm{~cm} / \mathrm{h}$. Again, this is attributed to the attainment of steady-state dome concentrations at the lower degradation rates. As the dome volume increases, more time is needed to reach a steady-state concentration at a constant release rate. At higher degradation rates, the steady state LFL fraction is more closely approached for smaller dome volumes or greater initial waste level.

The LFL fraction for simultaneous top and bottom degradation is, as expected, higher than top or bottom only dissolution. A very high degradation rate of $3.0 \mathrm{~cm} / \mathrm{h}$ or greater is required to

(a) This is simply a normalization based on the solids content of the layers, with the bubble slurry $(0.4=$ $\left.1-\alpha_{B S}\right)$ containing only half the gas-free waste of the paste $\left(0.79=1-\alpha_{\mathrm{P}}\right)$. This is a conservative assumption-there is no fundamental argument for the increased dissolution rate of the higher void material in cases where transport limits the degradation rate. In Section 5.2.2, it was noted that increased gas content may in fact reduce the degradation rate, gas bubbles blinding the migration of diluent to the crust solids. If no diluent transport limitations exist, the higher void material will degrade more readily at a given diluent addition rate due to the greater effectiveness of the diluent per unit volume gaseous waste, and the normalization used in Figure 6.4.2 strictly holds. 
exceed $25 \%$ of the LFL for initial waste levels of 420 in. or less. The time for complete crust degradation at the specified rate is also shown in Figure 6.4.2. At any given paste layer degradation rate, the time for degradation of the floating layer dissolved simultaneously from both surfaces is only half as long. In other words, the abscissa values represent the equivalent degradation rate at each crust surface.

\subsubsection{Extreme Cases-Dissolution and Gas Release at the Water Addition Rate}

Crust dissolution at the rate of water addition is considered here as an extreme situation in which no limitations of diluent transport to the crust surface and no kinetic limitations in solids dissolution exist. As such it is very unrealistic. To achieve the no-transport-limitation condition, the added water would need to be instantaneously convected to fresh crust surface and instantly dissolve the soluble solids. The extreme case could be approached, but not met, by blending the entire crust at a very high rate of speed as water is added in the top of the blender and saturated liquid is pulled off at the bottom. Thus, these analyses result in conservative maximum values for $\mathrm{H}_{2} \mathrm{LFL}$ fractions during continuous dissolution and gas release.

Figure 6.4.3 depicts the transient response of the $\mathrm{H}_{2}$ LFL fraction during the degradation of the model crust at a rate equivalent to instantaneous dissolution by water added at either $240 \mathrm{gpm}$ or $70 \mathrm{gpm}$. The lower rate is the design specification for the water transfer skid to be used in back-dilution through the transfer pump inlet, and the higher addition rate is the minimum needed to reach the hydrogen LFL. The dissolution rate was limited only by the solubility of the crust in water. For these analyses, the waste level at the start of water addition was $\sim 378$ in., corresponding to a final level of 400 in. if no crust dissolution occurred during the $\sim 61,400$-gal back-dilution required to completely dissolve the readily soluble crust solids. For both water

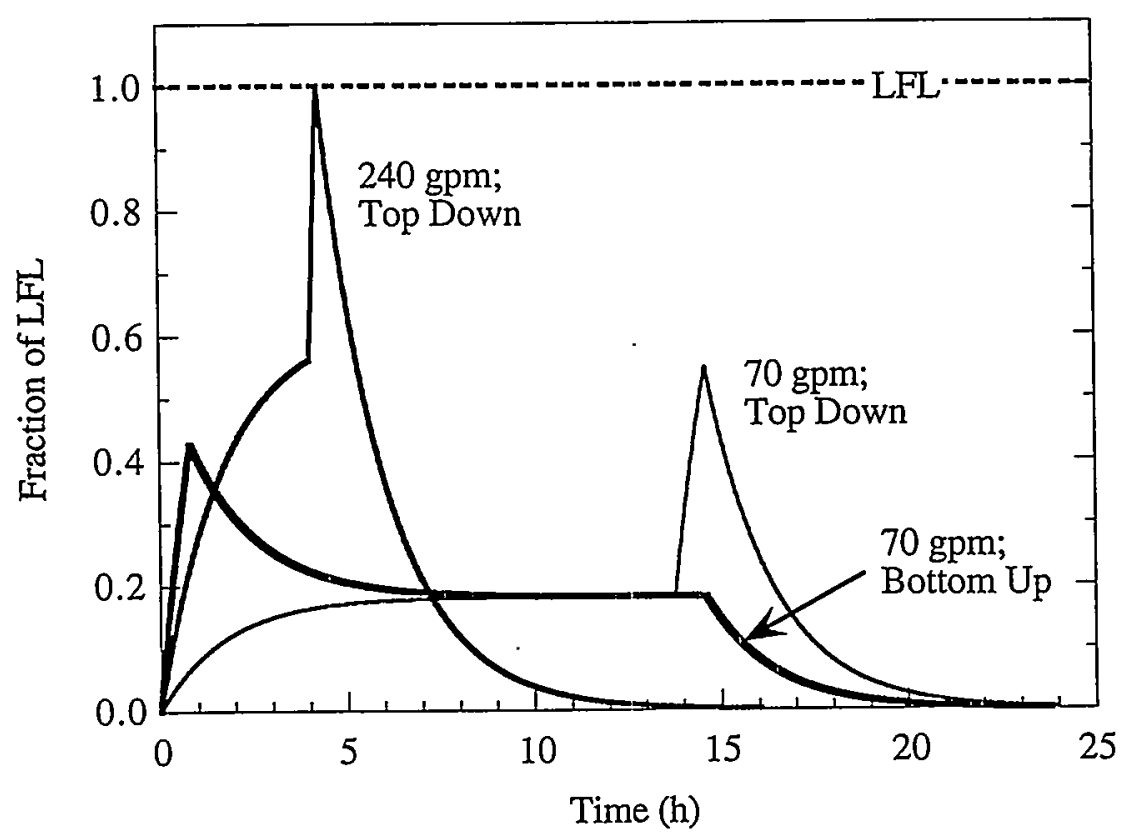

Figure 6.4.3. Transient Response of Hydrogen LFL Fraction during Degradation of Model Crust (rate equivalent to instantaneous dissolution by water added at 240 or $70 \mathrm{gpm}$ ) 
addition rates, the plot shows expected gas release behavior for dissolution from the top down (paste layer first). Dissolution from the bottom up is also depicted for the 70-gpm water-addition rate. The peak LFL fraction is lower for bottom-up cases, because the domespace is assumed hydrogen-free at the time dissolution starts. In top-down scenarios, the hydrogen concentration is built up due to paste layer dissolution by the time the gaseous bubble slurry is tapped. At 240 -gpm equivalent degradation rate, the 95 -inch $(2.4-\mathrm{m})$ crust is completely consumed in $\sim 4.2$ hours. Approximately 15 hours are needed to dissolve the crust at a 70-gpm equivalent water-addition rate, and the peak LFL fractions are 0.55 or less. The cases depicted in Figure 6.4.3 are extremely conservative.

The results of the model cases shown in Figure 6.4.3 are summarized in Figure 6.4.4, where a range of dissolution rates up to an equivalent of $500-\mathrm{gpm}$ water addition are considered. The maximum hydrogen LFL fraction for the corresponding continuous. gas release rates are shown for both dissolution from the top down (paste first) and bottom up (bubble slurry first). Because dissolution is limited by the rate of water addition, there is no increase in gas release assuming simultaneous top-down and bottom-up dissolution. In fact, the simultaneous assumption leads to results intermediate of the top-down and bottom-up cases depicted in Figure 6.4.4. In all cases, the dissolution rates needed to achieve LFL are extremely high. The worst-case scenario is $\sim 240$-gpm top-down dissolution. The 240-gpm equivalent dissolution rate corresponds to an incredible $54-\mathrm{cm} / \mathrm{h}$ crust degradation rate in the paste layer and $106 \mathrm{~cm} / \mathrm{h}$ in the bubble slurry layer. The inflection in the bottom up dissolution curve shown in Figure 6.4.4 represents a shift in the dominant release rate. At lower dilution rates, the maximum hydrogen fraction is driven by the bubble slurry release rate but, at higher dissolution rates, the gas release rate from the paste layer is sufficient to maintain or increase the dome hydrogen concentration. Note that

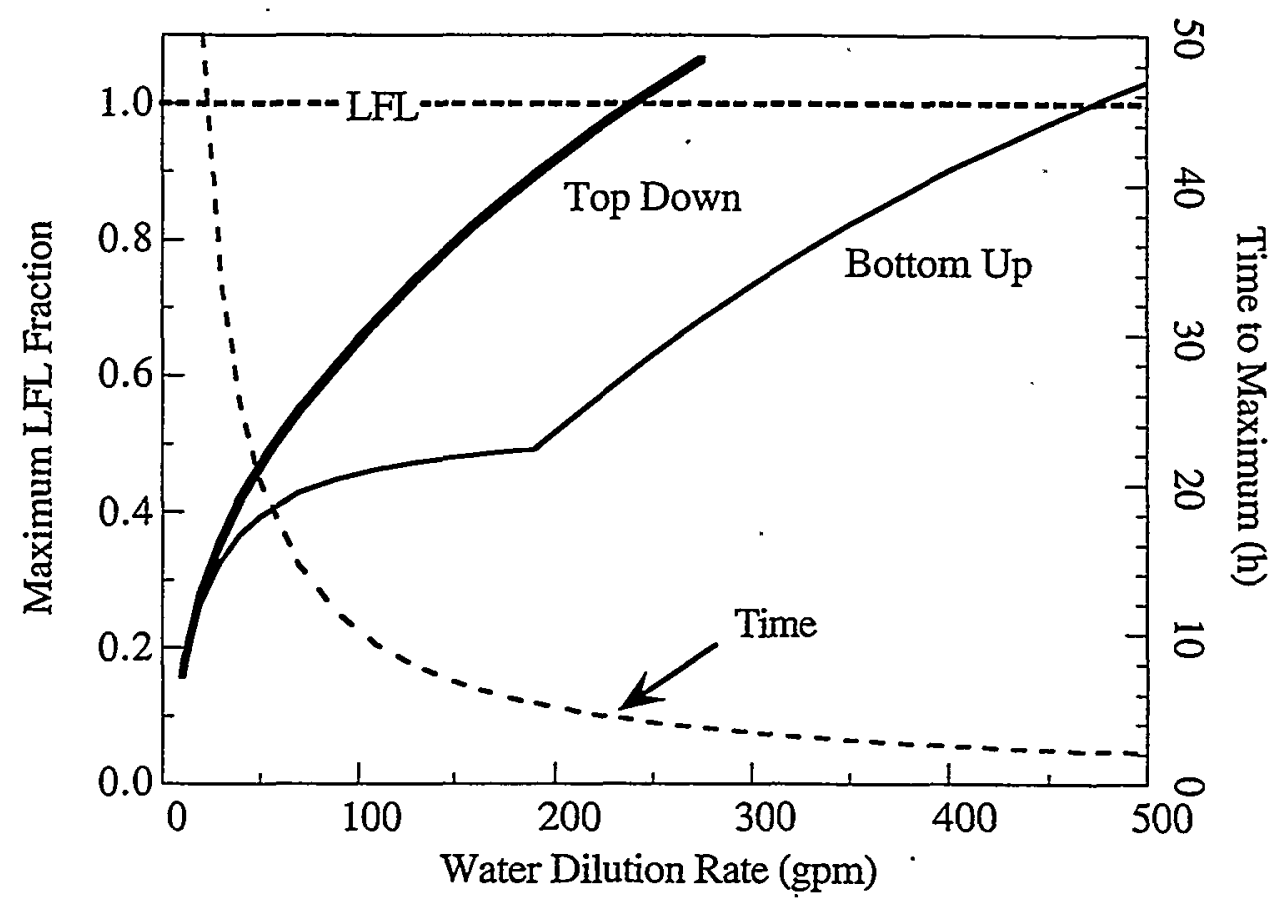

Figure 6.4.4. Maximum Hydrogen LFL Fraction for Continuous Gas Release from Model Crust Assumed to Dissolve at the Rate of Water Addition 
water-addition rates shown in Figure 6.4.4 cover a range seven times the target rate for near tank-bottom back-dilution (70 gpm). For each case shown in Figure 6.4.4, 0.25 LFL is reached with crust dissolution rates equivalent to just under 20 -gpm water addition.

A preliminary analysis of crust dissolution at the rate of water addition by Stewart indicated 1) a maximum water addition rate of $34 \mathrm{gpm}$ to stay just below the LFL and 2) the LFL would be reached in $\sim 30$ minutes at a 70 -gpm equivalent dissolution rate. ${ }^{(a)}$ When the domespace concentration model described in and used for this report is run with the parameters and conditions specified in the earlier analysis, identical time-dependent hydrogen concentration results are obtained. The differences contributing to the much more conservative limits of the earlier study are summarized in Table 6.4.1. One, the direction of dissolution, would tend to make the earlier results using bottom-up dissolution less conservative than the current model. The most critical differences making the earlier model more conservative are waste solubility, domespace volume (waste level), and thickness of bubble slurry layer. The analysis of waste solubility (Section 2.1) was not available in the earlier work, so the assumed effective dilution factor of 5 was a more reasonable estimate than the newer value of 3.2. Also, the scenarios considered in the previous task led to a much higher assumed waste level at the time of dissolution, severely limiting the domespace volume. Finally, and perhaps most important, the bubble slurry available in the crust is limited to 10 -in. thickness in the current model, whereas in the earlier study a 40 -inch thickness ( $1 \mathrm{~m}$ ) was considered; as a result, much more conservative (higher) LFL fractions were attained.

Given this critical dependence on bubble slurry volume, the current model was run with several crust configurations of varying bubble slurry and paste fractions. The results of these analyses, including the model crust results depicted in Figure 6.4.4, are shown in Table 6.4.2. In all cases, a 95 -inch $(2.4 \mathrm{~m})$ total crust thickness was assumed, a post-addition waste level of 400 inches was specified, and the pressure correction factors used in the base model case were applied (1.28 atm for bubble slurry and 1.14 for paste). Additionally, more conservative topdown dissolution was used in most cases. For a bubble slurry layer 40 inches $(1 \mathrm{~m})$ thick, a maximum LFL fraction of 1.0 is attained at a 70 -gpm equivalent dissolution rate. Even if the

Table 6.4.1. Comparison of Current and Early Dissolution Gas Release Models

\begin{tabular}{|l|l|l|}
\hline \multicolumn{1}{|c|}{ Model Parameter or Condition } & \multicolumn{1}{c|}{ Early Model } & \multicolumn{1}{c|}{ Current Model } \\
\hline Dissolution direction & Bottom up & Top down or bottom up \\
\hline Domespace volume assumption & Constant & Variable \\
\hline Waste level (in.)/domespace volume $\left(\mathrm{m}^{3}\right)$ & $458 / 566$ & $400 / 1167$ (typical) \\
\hline Vent flow rate (scfm) & 400 (minimum) & 475 (constant) \\
\hline $\begin{array}{l}\text { Waste solubility, volume affected; gas-free } \\
\text { waste/volume water }\end{array}$ & 5 & 3.19 \\
\hline $\mathrm{H}_{2}$ fraction in trapped and released gas, $\chi_{\mathrm{H} 2}$ & 0.40 & 0.38 \\
\hline $\begin{array}{l}\text { Average pressure in bubble slurry layer, } \mathrm{P}_{\mathrm{BS}} \\
\text { (atm) }\end{array}$ & 1.30 & 1.28 \\
\hline Bubble slurry thickness (in) & 40 (maximum) & 10 \\
\hline
\end{tabular}

(a) CW Stewart. 1999. Potential Gas Release from Water Addition Under the Crust Layer in SY-101. Letter report TWS99.2, Rev. 1, Pacific Northwest National Laboratory, Richland, Washington. 
Table 6.4.2. Summary of Dilution Rate Equivalent Crust Dissolution (400-in. waste level)

\begin{tabular}{|l|c|c|c|c|c|}
\hline & & \multicolumn{2}{|c|}{ 70-gpm Dilution } & \multicolumn{2}{|c|}{$\begin{array}{c}\text { Dilution to Reach } \\
\text { 1.0 LFL }\end{array}$} \\
\hline \multicolumn{1}{|c|}{ Case } & $\begin{array}{c}\text { Volume of } \\
\text { Crust Gas } \\
\text { Release (m) }\end{array}$ & $\begin{array}{c}\text { Maximum } \\
\text { LFL } \\
\text { Fraction }\end{array}$ & $\begin{array}{c}\text { Time to } \\
\text { Maximum } \\
\text { (h) }\end{array}$ & $\begin{array}{c}\text { Dilution } \\
\text { Rate (gpm) }\end{array}$ & $\begin{array}{c}\text { Time to } \\
\text { LFL (h) }\end{array}$ \\
\hline $\begin{array}{l}\text { Model Crust: 10-in bubble } \\
\text { slurry + 85-in paste; bottom up }\end{array}$ & 292 & 0.43 & 14.61 & 472.7 & 2.16 \\
\hline $\begin{array}{l}\text { Model Crust: 85-in paste + 10- } \\
\text { in bubble slurry; top down }\end{array}$ & 292 & 0.55 & 14.61 & 239.8 & 4.26 \\
\hline $\begin{array}{l}80 \text {-in paste + 15-in bubble } \\
\text { slurry; top down }\end{array}$ & 320 & 0.67 & 14.21 & 161.8 & 6.15 \\
\hline $\begin{array}{l}75 \text {-in paste + 20-in bubble } \\
\text { slurry; top down }\end{array}$ & 348 & 0.77 & 13.81 & 117.5 & 8.23 \\
\hline $\begin{array}{l}\text { 65-in paste + 30-in bubble } \\
\text { slurry; top down }\end{array}$ & 403 & 0.91 & 13.01 & 81.6 & 11.16 \\
\hline $\begin{array}{l}\text { 55-in paste + 40-in bubble } \\
\text { slurry; top down }\end{array}$ & 458 & 1.0 & 12.21 & 70.3 & 12.16 \\
\hline $\begin{array}{l}\text { 95-in bubble slurry; top down } \\
\text { or bottom up }\end{array}$ & 762 & 1.13 & 7.80 & 61.4 & 8.90 \\
\hline
\end{tabular}

entire crust mass were gaseous bubble slurry, which it clearly is not, a dissolution rate equivalent to $61.4 \mathrm{gpm}$ would be necessary to approach the LFL. These results emphasize the unrealistically extreme conditions necessary to achieve the LFL in continuous crust dissolution processes. (Section 6.4.1 analyzes crust dissolution and gas release at expected rates.)

\subsection{Analysis of Sudden Gas Release Scenarios}

By definition, sudden implies that the rate is relatively fast, or instantaneous as a limit. In this section we first describe slower sudden releases of less well-organized crust and mixed slurry gas, and then we discuss faster releases of large gas pockets or bubbles.

\subsubsection{Scenarios for Sudden Gas Release Following Continuous Release}

Several of the gas release mechanisms and scenarios described in Section 6.2 can be categorized as sudden. Many of these, should they actually occur under tank conditions, are most likely to follow a period of continuous dissolution and gas release. Examples include bubble slurry flow, fast bubble migration through a weakened paste layer, and partial wasteberg capsizing. The impact of the potential gas releases from these and related scenarios, such as sudden mixed slurry gas release, is captured within the framework of the parametric model studies presented in this section.

The release mechanisms noted above involve gas from the bubble slurry layer in all cases and some gas from the paste layer in a few. In each analysis here, the sudden gas release from a 
portion of the model crust is assumed to follow the continuous degradation and gas release of the remainder of the crust. For example, several analyses are based on the sudden release of all gas $\left(80 \mathrm{~m}^{3}\right)$ from the 10-inch bubble slurry layer of the model crust just after dissolution of the 85inch paste layer, at a specified rate, is completed. Other analyses consider a larger sudden gas release volume (143 $\mathrm{m}^{3}$ at atmospheric pressure). This gas volume is equivalent to that contained in the model crust bubble slurry layer plus 25 inches of paste layer. Nothing is magic about the volume of paste specified, but combined with the bubble slurry it represents $49 \%$ of the gas in the model crust. While it is hard to conceive of a release mechanism in which half of the entire crust gas is released suddenly, it is included here as a bounding case, and it is shown to be of no consequence to flammability concerns for expected tank conditions. In fact, the fraction of gas involved in slower sudden releases might be limited by neutral buoyancy considerations-any piece of the crust will sink if its gas release causes its density to fall below that of the slurry. For typical conditions, material with gas fractions on the order of 0.12 would sink, carrying a significant portion of the gas to the bottom of the tank. Assuming 0.12 is the critical gas fraction, a chunk of paste layer material $\left(\alpha_{\mathrm{p}}=0.21\right)$ sinks after only $\sim 40 \%$ of its gas is released, whereas a segment of bubble slurry $\left(\alpha_{B S}=0.60\right)$ must lose $80 \%$ of its gas to become subbuoyant. (See Section 4 for additional discussion of crust sinking and gas release.)

All else being equal, the maximum domespace hydrogen concentration is a function of both the dissolution rate in the continuous release phase and the duration of the sudden release. In defining duration for sudden releases, we are specifying a release rate. The effects of sudden release duration on the maximum LFL fractions for the two large release volumes summarized in Table 6.5.1 are presented in Figure 6.5.1. In these model studies, the paste layer was set to dissolve continuously at a rate of $1 \mathrm{~cm} / \mathrm{h}$, providing a realistic hydrogen background in the domespace. The sudden release of bubble slurry alone sets an upper bound for gas release in a "bubble slurry flow" scenario. The instantaneous release of gas from 10 in $(0.25 \mathrm{~m})$ of bubble slurry $\left(80 \mathrm{~m}^{3}\right.$ gas) with an initial waste level of 420 in. only approaches $0.66 \mathrm{LFL}$. This suggests that gas release and domespace flammability is not a major concern for this proposed mechanism given the expected waste levels following waste transfers and back-dilution. Additionally, experimental and theoretical analysis of bubble slurry releases indicate that the crust hole diameter and a finite yield strength in the bubble slurry will limit the fraction of the material released, and a finite duration of the release event will further limit the peak domespace $\mathrm{H}_{2}$ concentration $^{(a)}$. Furthermore, there is no evidence to date of large volume bubble slurry flow to holes created in the SY-101 crust in lance and MMA deployments.

Table 6.5.1. Summary of Sudden Gas Release Volumes

\begin{tabular}{|c|c|c|}
\hline $\begin{array}{c}\text { Sudden Release Gas } \\
\text { Volume }\left(\mathrm{m}^{3}\right)\end{array}$ & $\begin{array}{c}\text { Possible Source of Sudden } \\
\text { Release Gas }\end{array}$ & $\begin{array}{c}\text { Fraction of } \\
\text { Crust Gas }\end{array}$ \\
\hline 80 & $\begin{array}{c}10 \text {-in bubble slurry (or the } \\
\text { equivalent of 32-in paste) }\end{array}$ & 0.27 \\
\hline 143 & $\begin{array}{c}10 \text {-in bubble slurry + the } \\
\text { equivalent of 25-in paste }\end{array}$ & 0.49 \\
\hline
\end{tabular}

(a) Summarized in a 1999 letter report by PA Meyer, CW Stewart, SD Rassat, RT Allemann, G Terrones, and DP Mendoza entitled "Potential Gas Release by Bubble Slurry Flow Through a Hole in the Crust Layer in SY-101." TWS99.27, Pacific Northwest National Laboratory, Richland, Washington. 
The sudden release of gas from the combined 10-inch bubble slurry and 25-inch paste represents a severe case $\left(143 \mathrm{~m}^{3}\right.$, or $49 \%$ of the as-released crust gas). Even for instantaneous release of this larger-than-expected volume, the hydrogen LFL is only approached for instantaneous releases when the initial waste level is 400 inches or less. If the initial waste level is 420 inches, the LFL is reached in less than $\sim 30$ minutes. Figure 6.5.1 includes analyses for 400 and 420 inches to capture the upper bound. After the second waste transfer and partial backdilution to attack the crust, the waste level is not expected to exceed 380 inches (Table 6.3.2).

Because of the large tank scale and the entrapment of the gas within the crust matrix, sudden releases in the scenarios considered in this section will not be instantaneous. Releases on the order of minutes to hours are more realistic. Some sense of the time scale can be derived from historic BD GREs in DSTs. In SY-101, the duration of characterized BD-GREs was 7 to 20 minutes for gas releases of $\sim 120$ to $190 \mathrm{~m}^{3}$, and in the AN- and AW-series tanks, the release duration was typically greater than two hours (Meyer et al. 1997). As a conservative approach, we assume the duration of sudden crust gas releases to be of the order 10 minutes unless otherwise specified. Because there is less potential energy for the release of gas from the crust than from the nonconvective layer of SY-101 in a BD-GRE, it seems reasonable that large crust sudden release events would actually occur over times much longer than ten minutes. Figure 6.5.1 demonstrates that slow "sudden" gas releases of this sort, even if larger than might realistically be expected ( $143 \mathrm{~m}^{3}, 49 \%$ of crust gas), do not create a flammability hazard for expected crust dissolution rates and tank conditions.

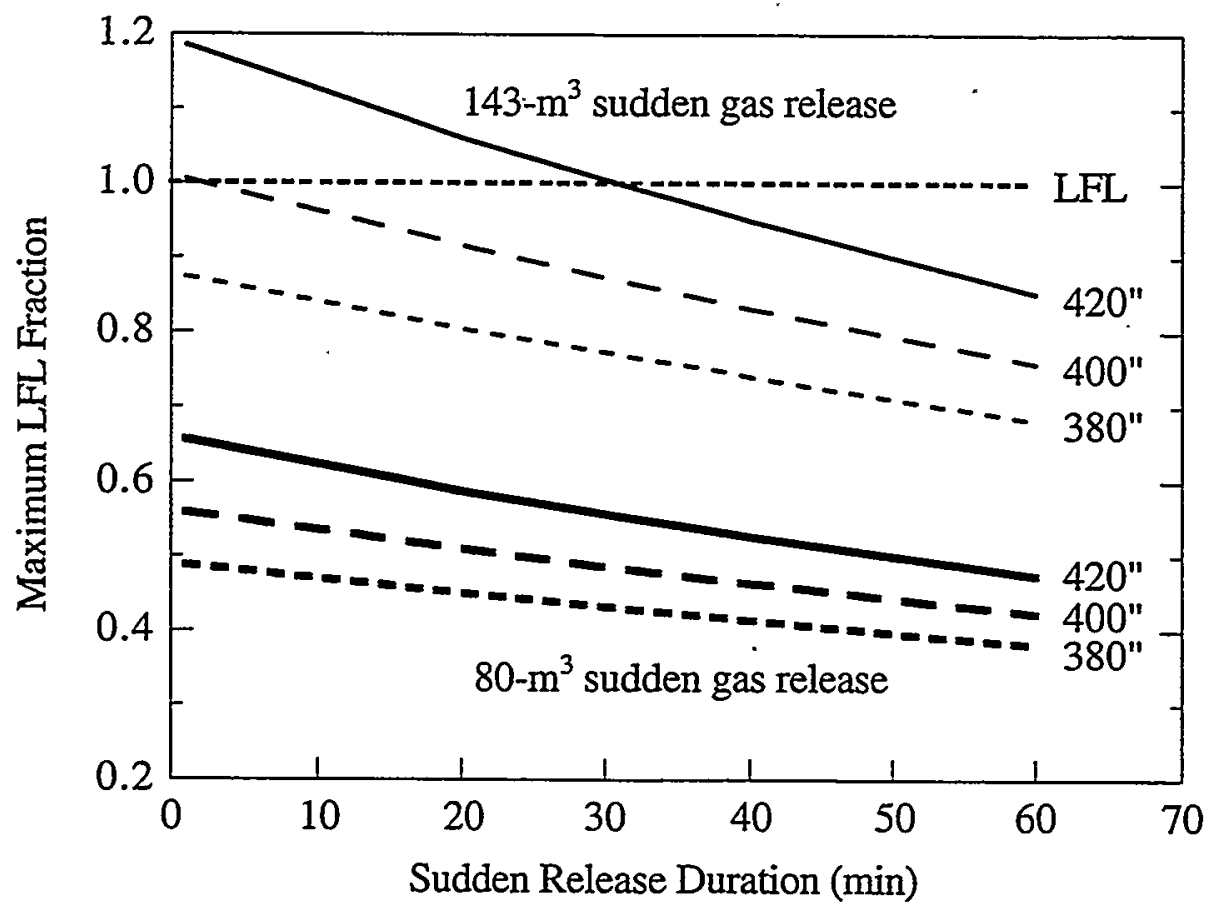

Figure 6.5.1. Effect of Sudden Release Duration on Maximum LFL Fraction for 80- and $143-\mathrm{m}^{3}$ Gas Releases 
In Section 6.2.1, a worst-case sudden release scenario was identified for gas retained in the mixed slurry. The minimum duration of the release was estimated at 50 minutes; the maximum gas volume released is estimated from the retained volume in the slurry between the addition point (96-inch elevation) and the base of the crust (assumed 320-inch elevation). At 0.027 gas fraction, this corresponds to $63 \mathrm{~m}^{3}$ gas retained or $107 \mathrm{~m}^{3}$ released using an average pressure correction of $1.7 \mathrm{~atm}$. As noted above, a sudden release volume of $143 \mathrm{~m}^{3}$ with an initial waste level of 420 inches is below the LFL for releases longer than 30 minutes. Similar calculations indicate a maximum LFL fraction of 0.74 if the $107 \mathrm{~m}^{3}$ is released over 50 minutes (420-inch initial waste level). Even if the gas release were unrealistically fast, only 10 minutes, the maximum domespace hydrogen concentration is estimated to stay below LFL ( 0.96 LFL fraction). The maximum LFL fraction decreases with lower, more realistic post-transfer waste levels.

The effect of the continuous paste layer degradation rate preceding 80 - and $143-\mathrm{m}^{3}$ sudden releases is considered in Figure 6.5.2. Here, the sudden release duration is fixed at a conservatively fast 10 minutes, and the continuous paste layer degradation rate is varied in the 1 to $16 \mathrm{~cm} / \mathrm{h}$ range. For any given initial waste level, the peak LFL fraction resulting from the sudden release falls off with the initial degradation rate. This is expected because a lower continuous gas release rate up front limits the initial hydrogen concentration of the domespace. Extreme values for the crust degradation rate were selected to conservatively bound the analysis. As noted in Section 6.4.1, selection of a continuous crust degradation rate exceeding order 1 does not appear to be warranted. A paste degradation rate of $6.7 \mathrm{~cm} / \mathrm{h}$ is equivalent to instantaneous dissolution at a $30-\mathrm{gpm}$ water addition rate and a $15.6 \mathrm{~cm} / \mathrm{h}$ degradation rate corresponds to a 70 -gpm equivalent. The waste levels after water addition and before the start of dissolution are shown in the figures. For a large, $143-\mathrm{m}^{3}$ gas release (10-inch bubble slurry +25 -inch paste), the

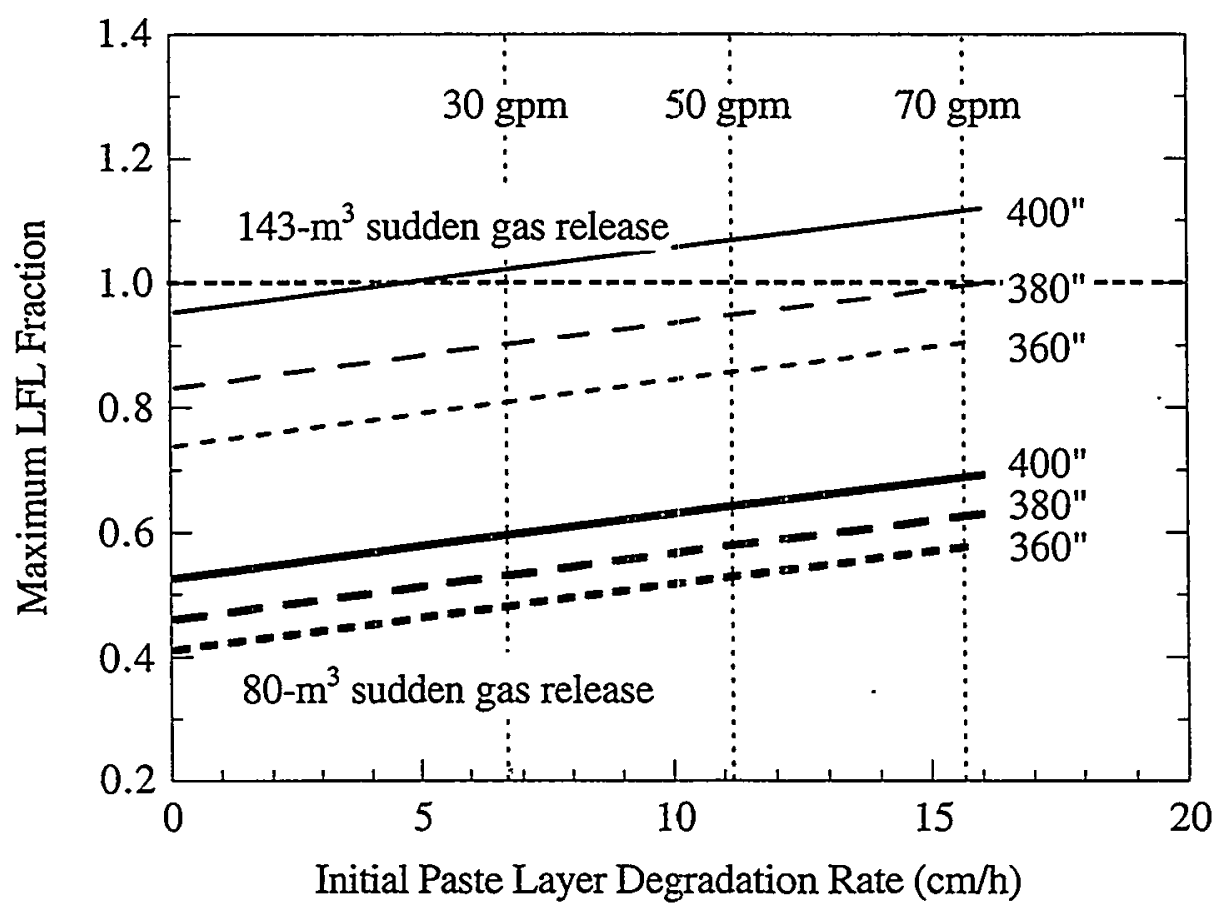

Figure 6.5.2. Effect of Continuous Paste Layer Degradation Rate on Maximum LFL Fraction for 80 - and $143-\mathrm{m}^{3}$ Sudden Gas Releases 
LFL is exceeded only for crust degradation rates $>5 \mathrm{~cm} / \mathrm{h}$ for an initial waste level of 400 in. $(10.2 \mathrm{~m})$. Given the expected waste levels and likely continuous crust degradation rates, even very large sudden gas releases do not appear to be serious threats to dome flammability.

\subsubsection{Accumulation and Sudden Release of Large Gas Pockets Beneath the Crust}

The previous discussion addressed sudden gas release scenarios in which a continuous gas release prior to the larger release event was expected and assumed. For other postulated release scenarios it is less clear whether a continuous release would precede a sudden large release. In particular, some sudden release scenarios are driven by the lack of continuous release-gas that might normally be released to the domespace in a continuous fashion is trapped below or within the crust. This gas might originate within the nonconvective or slurry layers, released by pump action or dissolution processes, or the large gas pool might generate as the crust is continuously dissolved from below. This scenario, the trapping and sudden release of a large bubble or gas pocket, is considered here first, and then the critical size of fast sudden gas releases is considered in general terms.

While it is hypothetically possible that a large gas bubble or gas pocket could be created beneath or within the crust, this scenario is deemed unlikely due to the evidence of numerous gas-release paths throughout the crust and lack of evidence of large bubbles retained in the tank. To alleviate concerns related to this mechanism of gas retention and potential sudden release, it warrants further investigation.

Tank gas release data and the physical configuration of the tank can be used to argue the existence of established gas release paths throughout the crust. The mixer-pump in SY-101 operates on a schedule that orients its opposed jets in an incremental fashion, thereby disturbing the entire tank after a number of pump operations. While the volume of gas releases associated with pump runs varies historically, all orientations of the pump result in gas release, as shown in Figure 6.5.3. The data clearly indicate that gas is being released from the waste and into the domespace of the tank, and therefore release paths through the crust must exist. Because there is no concrete evidence of enhanced gas release for any orientation of the mixer-pump, and assuming the gas is buoyed vertically from where it is first released, gas release paths appear to be somewhat uniformly located throughout the crust.

While no conclusive argument can be made about the nature and location of all the gas release paths, some specific paths can be located with confidence. In-tank video and waste level data all suggest that the crust layer is not firmly attached to the walls of the tank or to the MITs, velocity-density-temperature trees (VDTTs), and other devices that extend into the waste. It is therefore assumed that each of these locations is a permanent gas release path. Intrusive activities in the tank that penetrate the crust, such as the VFI, RGS, MMA, and lancing operations create holes in the crust that may also serve as gas release paths. The locations of the assumed gas release paths in Tank SY-101 are shown in Figure 6.5.4. 


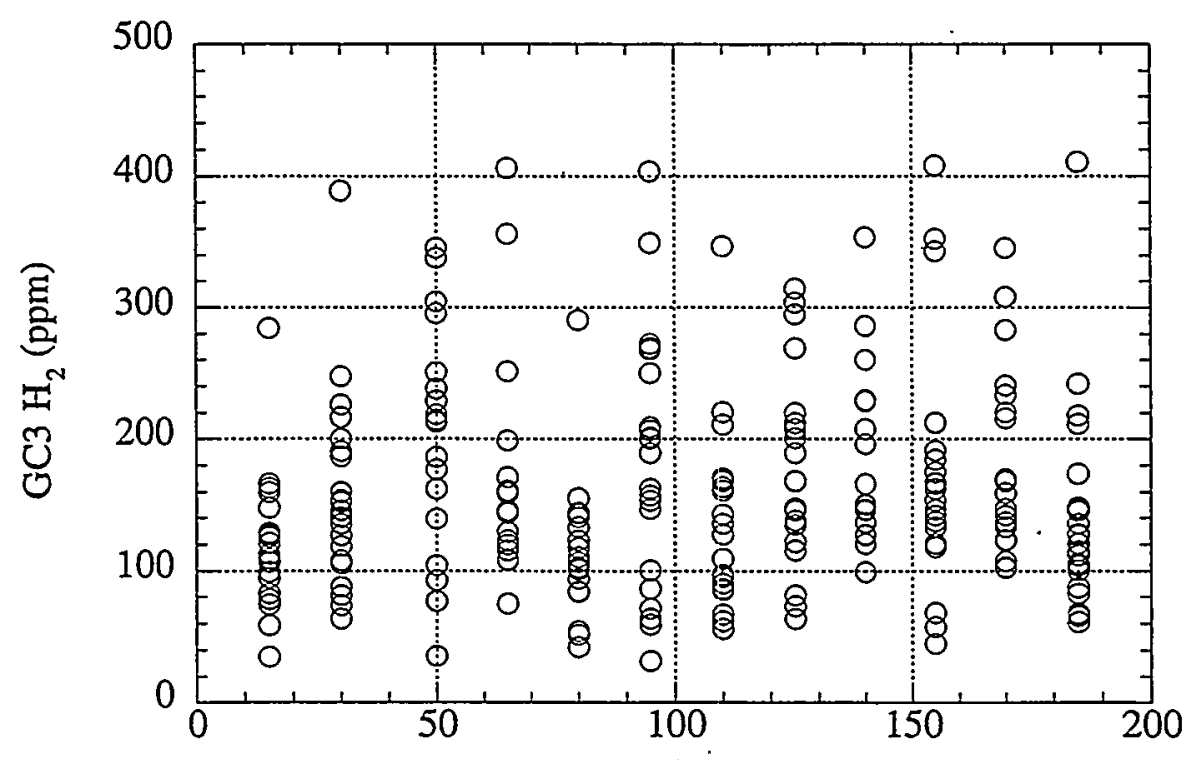

Orientation of mixer-pump in southern hemisphere of the tank (deg)

Figure 6.5.3. Gas Releases as a Function of the Angle of Mixer-Pump Orientation in SY-101 $(5 / 97-5 / 99)$

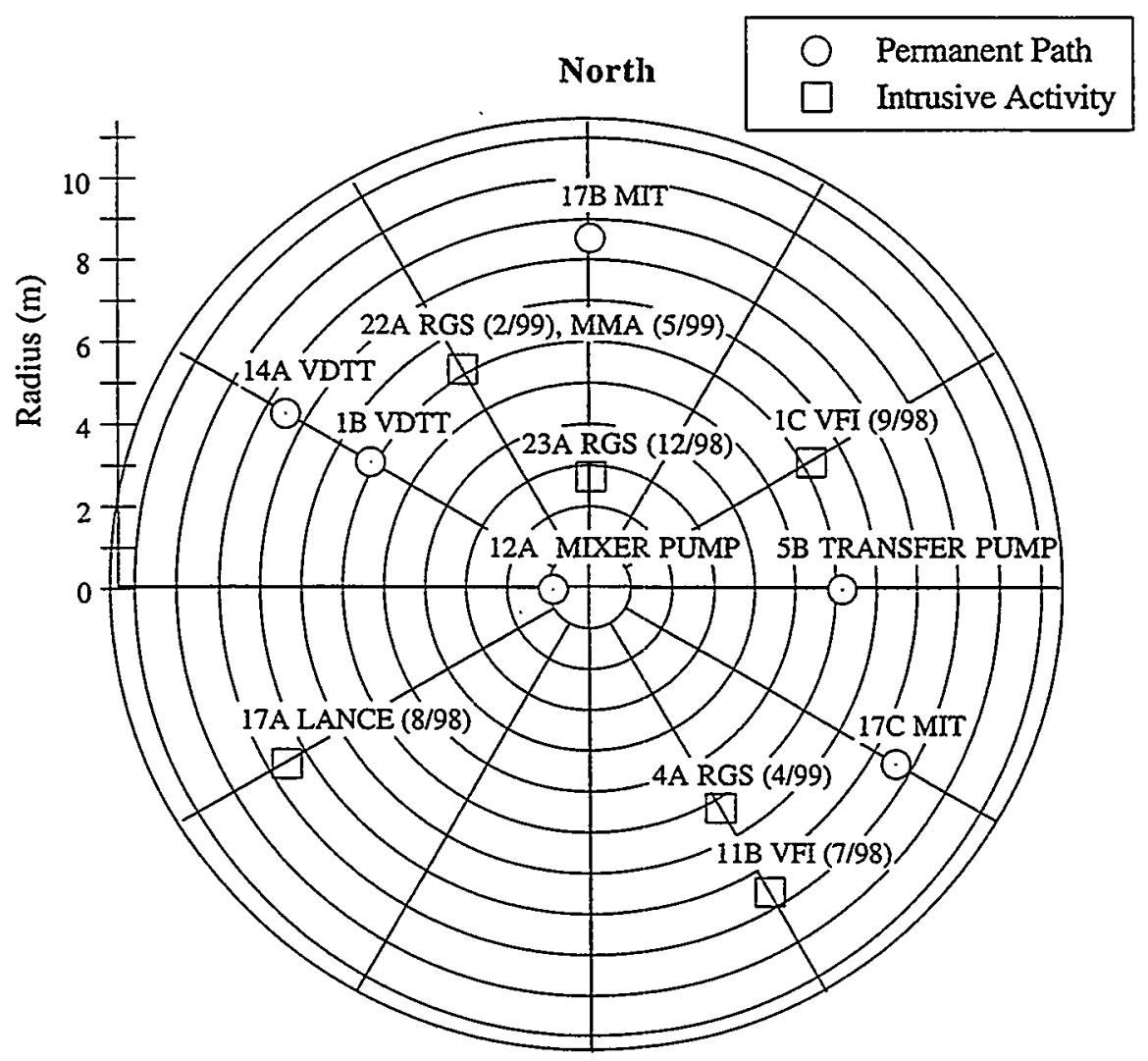

Figure 6.5.4. Location of Permanent Gas Release Paths and Intrusive Activities in SY-101 
If it is conservatively assumed that the permanent paths and possibly the sites of the intrusive activities shown in Figure 6.5.3 represent the only gas release paths through the crust, the location of the these paths in the tank limits the maximum horizontal bubble size. A bubble can only extend horizontally until it reaches a release path. For the purposes of this analysis, it is assumed that the large gas bubble is a right elliptical cylinder. A flattened ovoid shape is more physically realistic but smaller in volume than a comparably dimensioned elliptical cylinder and therefore less conservative for gas release analysis. The in situ gas pressure of a gas bubble in the crust layer is assumed to be

$$
P_{0}=P_{A}+\rho_{C} g h
$$

where $P_{A}$ is the atmospheric pressure, $\rho_{C}$ is the density of the submerged crust $\left(\rho_{c}=1340 \mathrm{~kg} / \mathrm{m}^{3}\right.$, Section 2.4.3), $\mathrm{g}$ is the acceleration due to gravity, and $\mathrm{h}$ is the depth into the waste at which the bubble is located. The gas bubble is therefore in hydrostatic equilibrium with the waste surrounding it, and the only force acting on the bubble is due to buoyancy. Assuming that the surface under which the bubble is trapped is level, there will be no horizontal forces acting on the bubble, so the maximum horizontal extent of the bubble is dictated solely by the location of the permanent release paths.

Based on the work of Stewart et al. (1996), a gas bubble forming in or just below the lower region of the crust layer in SY-101 will be hydrodendritic (a particle-displacing bubble). The vertical extent of a hydrodendritic gas bubble can be determined from

$$
h_{b}=\frac{\tau_{y}}{\rho_{C} g Y_{G}}
$$

where $\tau_{\mathrm{y}}$ is the yield stress in shear of the crust material $(1,700 \mathrm{~Pa}$ average computed from data in Section 2.3), and $Y_{G}$ is the critical gravity yield number [estimated in Stewart et al. (1996) to be 0.2]. Using Equation 6.5.2, the estimated maximum retained bubble height is $0.65 \mathrm{~m}$.

The maximum area for large bubble growth is depicted schematically in Figure 6.5.5. Considering the retention area and the bubble height, the maximum large bubble volume is estimated. The maximum retained gas bubble volume when the intrusive activities are neglected as gas release paths $\left(76 \mathrm{~m}^{3}\right)$ is significantly larger than when they are included $\left(48 \mathrm{~m}^{3}\right)$. As demonstrated below (Figure 6.5.6), these release volumes are well below the LFL even for a post-transfer waste level of $420 \mathrm{in}$. Assuming that the hydrogen concentration in the released gas is 0.38 (Table 6.3.1), the waste level at the time of the sudden release is 420 in., and the retained gas is at an average pressure of $1.25 \mathrm{~atm}$, the LFL fractions in the domespace upon instantaneous release of the large retained gas bubbles are 0.90 and 0.58 , respectively. While the creation of these large gas bubbles is speculative and unlikely, these results indicate that sudden gas releases from them would not render the domespace flammable even with conservative assumptions.

Where the sudden release of a gas pocket or a very large bubble is considered, unlike the discussion in Section 6.5.1 of large gas releases from smaller bubbles trapped within a waste-gas matrix, release duration on the order of a minute is much more realistic. A pooled source of gas is, in a sense, organized, having lower entropy and higher potential energy. Figure 6.5.6 shows 


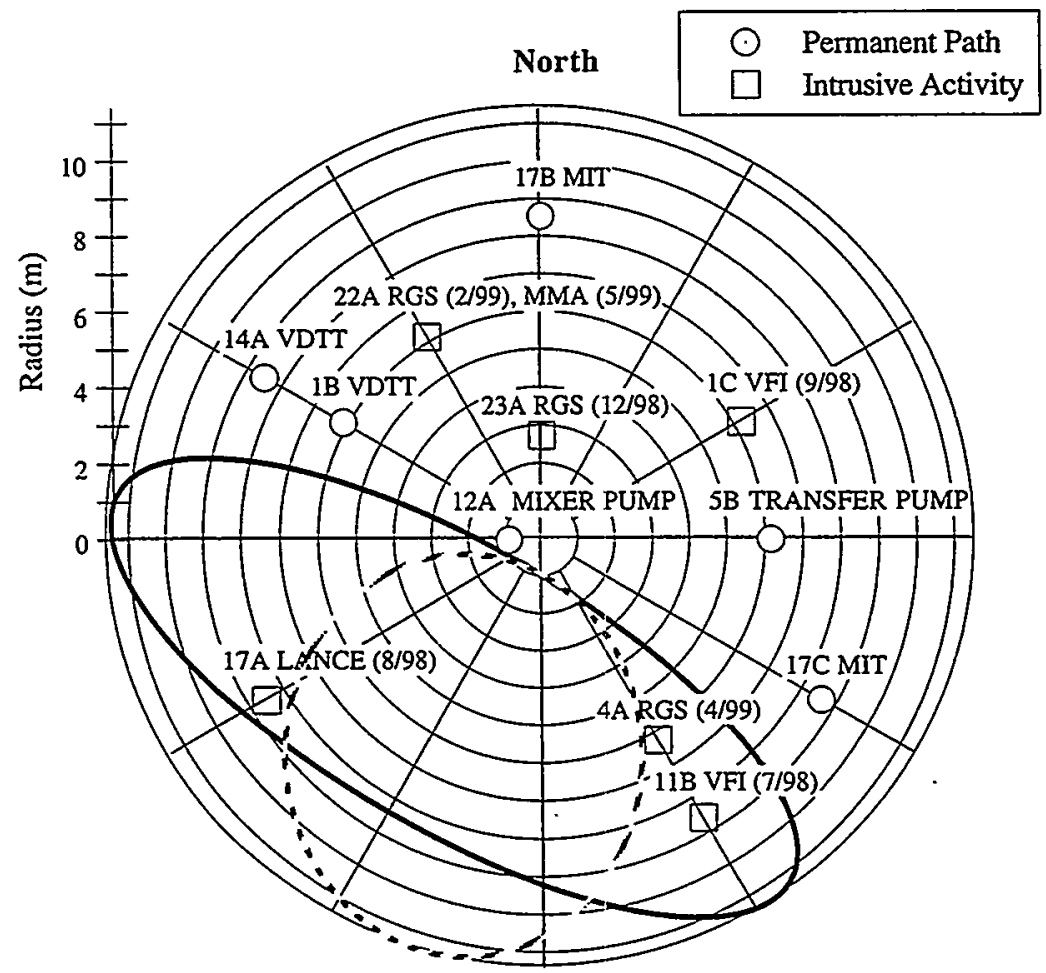

Figure 6.5.5. Maximum Gas Bubble Size in SY-101; solid line-ellipse neglects intrusive activity sites as possible release paths, and the dashed-line ellipse includes them

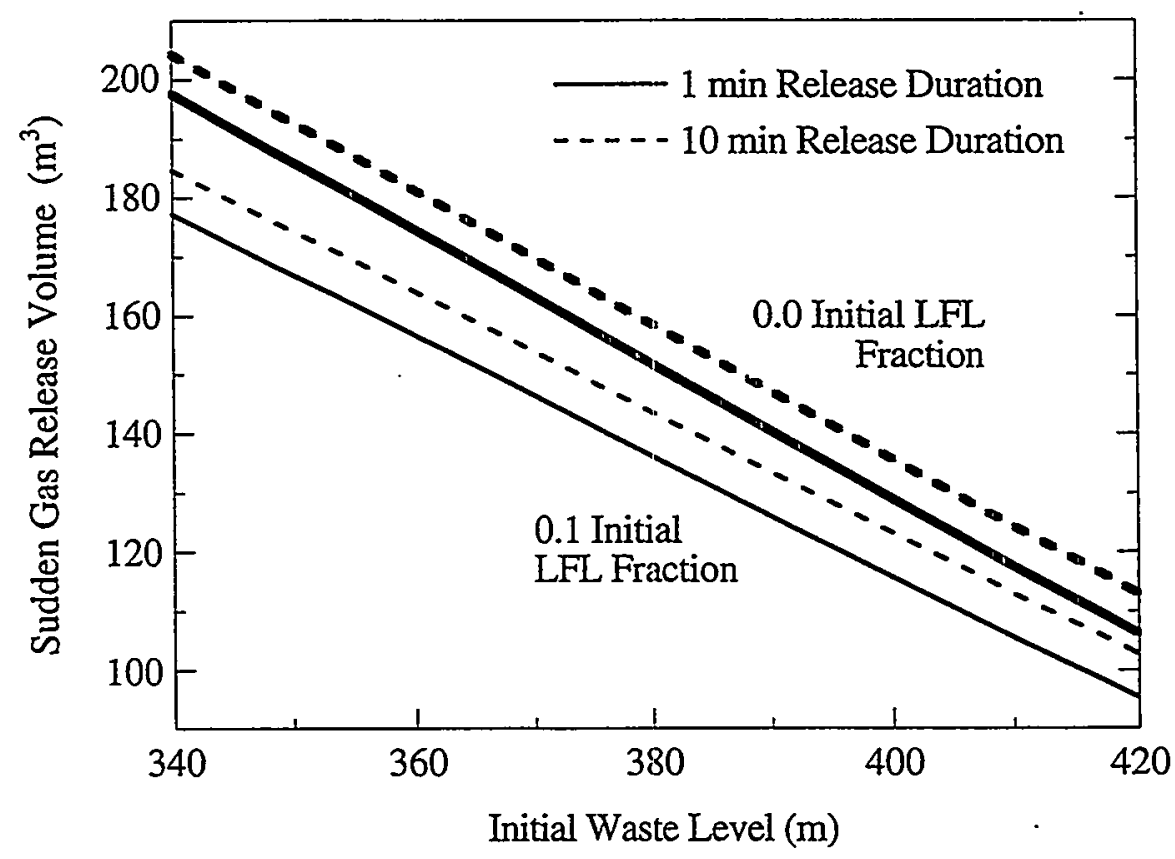

Figure 6.5.6. Total Gas Release Volume at Atmospheric Pressure Needed to Achieve the Hydrogen LFL as a Function of Initial Waste Level 
the total gas release volume needed to achieve the hydrogen LFL as a function of initial waste level. In each case it was assumed that the retained gas was at a pressure of 1.25 atm and was released to the domespace at $1 \mathrm{~atm}$. Two values of release duration ( 1 or 10 minutes) and two levels of initial domespace hydrogen concentration $(0$ or $0.1 \mathrm{LFL})$ are evaluated. Even under the worst-case conditions captured (420-inch waste level, 0.1 initial LFL fraction, and 1-minute release duration), nearly $100 \mathrm{~m}^{3}$ gas would need to be suddenly released to reach the LFL. Under more realistic post-second transfer conditions (380-inch waste level, near-0 initial hydrogen background concentration, and 1-minute release duration), the sudden gas release must be greater than $150 \mathrm{~m}^{3}$ to exceed the LFL. For comparison, the release volume of the largest retained bubble conceived in the analysis above was $\sim 95 \mathrm{~m}^{3}$.

The selection of a background dome concentration of hydrogen at $0.1 \mathrm{LFL}$ for the analyses depicted in Figure 6.5.6 is again intended to represent a conservative upper bound. For a 0.21 gas-fraction paste layer continuously releasing to the domespace, the crust degradation rate would need to exceed $8 \mathrm{~cm} / \mathrm{h}$ to reach $0.1 \mathrm{LFL}$. At the expected upper bound of the paste layer degradation rate $(\sim 1 \mathrm{~cm} / \mathrm{h})$, the background hydrogen concentration at steady state due to continuous release is only about 0.012 LFL.

In summary, the sudden release analyses of this section show the same result as the continuous release scenarios in the last section-with very conservative but realistic assumptions, it does not appear that the domespace hydrogen concentration will exceed the LFL by any conceived gas release mechanism. 


\subsection{References}

Abraham G. 1963. Jet Diffusion in Stagnant Ambient Fluid. Publication No. 29, Delft Hydraulic Laboratory.

Adamson AW. 1990. Physical Chemistry of Surfaces, Fifth Edition. John Wiley \& Sons, New York.

Allemann RT, ZI Antoniak, WD Chvala, LE Efferding, JR Friley, WB Gregory, JD Hudson, JJ Irwin, NW Kirch, TE Michener, FE Panisko, CW Stewart, and BM Wise. 1994. Mitigation of Tank 241-SY-101 by Pump Mixing: Results of Testing Phases $A$ and B. PNL-9423, Pacific Northwest National Laboratory, Richland, Washington.

Antoniak ZI and PA Meyer. 1999. Potential for Waste Stratification from Back-Dilution in Tank 241-SY-101. PNNL-13038, Pacific Northwest National Laboratory, Richland, Washington.

Antoniak ZI and KP Recknagle. 1997. Initial Parametric Study of the Flammability of Plume Releases in Hanford Waste Tanks. PNNL-11639, Pacific Northwest National Laboratory, Richland, Washington.

Barton WB. 1999. Maximum First Transfer and Dilution Volume for Tank 241-SY-101. RPP-5344, Lockheed Martin Hanford Company, Richland, Washington.

Beyler C. 1988. SFPE Handbook of Fire Protection Engineering, First Edition. National Fire Protection Association, Quincy, Massachusetts.

Bird RB, WE Stewart, and EN Lightfoot. 1960. Transport Phenomena. John Wiley \& Sons, New York.

Bredt PR and SM Tingey. 1996. The Effect of Dilution on the Gas Retention Behavior of Tank 241-SY-103 Waste. PNL-10893, Pacific Northwest National Laboratory, Richland, Washington.

Bredt PR, SM Tingey, and EH Shade. 1995. The Effect of Dilution on the Gas-Retention Behavior of Tank 241-SY-101 Waste. PNL-10781, Pacific Northwest Laboratory, Richland, Washington.

Brewster ME, NB Gallagher, JD Hudson, and CW Stewart. 1995. The Behavior, Quantity, and Location of Undissolved Gas in Tank 241-SY-101. PNL-10681, Pacific Northwest Laboratory, Richland, Washington.

Bryan SA, LR Pederson, JL Ryan, RD Scheele, and JM Tingey. 1992. Slurry Growth, Gas Retention, and Flammable Gas Generation by Hanford Radioactive Waste Tanks: Synthetic Waste Studies, FY 1991. PNL-8169, Pacific Northwest Laboratory, Richland, Washington. 
Bryan SA and LR Pederson. 1994. Composition, Preparation, and Gas Generation Results from Simulated Wastes of Tank 241-SY-101. PNL-10075, Pacific Northwest Laboratory, Richland, Washington.

Chassaing P, G Harran, and L Joly. 1994. Density fluctuation correlations in free turbulent binary mixing. JFM Vol. 279, pp. 239-278.

Conner JM and GM Koreski. 1999. Quarterly Review of 241-SY-101 Data: July - September, 1999. HNF-5265, Lockheed Martin Hanford Corp., Richland, Washington.

Cussler EL. 1984. Diffusion: Mass Transfer in Fluid Systems. Cambridge University Press.

Das BM. 1983. Advanced Soil Mechanics. Hemisphere Publishing, Washington, D.C.

Dean JA. 1992. Lange's Handbook of Chemistry, Fourteenth Edition. Mc-Graw-Hill, New York.

Denn MM. 1980. Process Fluid Mechanics. Prentice-Hall, Inc., Englewood Cliffs, New Jersey.

Epstein M and JP Burelbach. 199.8. Experimental and Theoretical Turbulent Diffusion Modeling of Light Gas Releases in a Tank Headspace: 2. Local Releases. FAI/98-50, Fauske \& Associates, Burr Ridge, Illinois.

Gauglitz PA, LA Mahoney, DP Mendoza, and MC Miller. 1994. Mechanisms of Gas Bubble Retention. PNL-10120, Pacific Northwest Laboratory, Richland, Washington.

Gauglitz PA, SD Rassat, MR Powell, RR Shah, and LA Mahoney. 1995. Gas Bubble Retention and Its Effect on Waste Properties: Retention Mechanisms, Viscosity, and Tensile and Shear Strength. PNL-10740, Pacific Northwest Laboratory, Richland, Washington.

Gauglitz PA, SD Rassat, PR Bredt, JH Konynenbelt, SM Tingey, and DP Mendoza. 1996. Mechanisms of Gas Bubble Retention and Release: Results for Hanford Waste Tanks 241-S-102 and 241-SY-103 and Single-Shell Tank Simulants. PNNL-11298, Pacific Northwest National Laboratory, Richland, Washington.

Herting DL, DB Bechtold, BE Hey, BD Keele, L Jensen, and TL Welsh. 1992. Laboratory Characterization of Samples Taken in December 1991 (Window E) from Hanford Waste Tank 241-SY-101. WHC-SD-WM-DTR-026, Westinghouse Hanford Company, Richland Washington.

Herting DL. 1997. Results of Dilution Studies with Waste from Tank 241-AN-105. HNF-SDWM-DTR-046 Rev. 0, Numatec Hanford Corporation, Richland, Washington.

Hines AL and RN Maddox. 1985. Mass Transfer, Fundamentals and Applications. PrenticeHall, Inc., Englewood Cliffs, New Jersey. 
Johnson GD, WB Barton, JW Brothers, SA Bryan, PA Gauglitz, RC Hill, LR Pederson, CW Stewart, and LM Stock. 1997. Flammable Gas Project Topical Report. PNNL-11500, Richland, Washington (also published as HNF-SP-1193 Rev. 2., Lockheed Martin Hanford Corp., Richland, Washington).

Koryta J, J Dvorák, and L Kavan. 1993. Principles of Electrochemistry, Second Edition. John Wiley and Sons, Chichester.

Kreith F and MS Bohn. 1986. Principles of Heat Transfer, Fourth Edition. Harper \& Row, New York, p. 258.

Kubic WL and AV Belooussov. 1999. Dilution to Eliminate and Prevent Crust Formation in Tank 241-SY-101. LA-UR-99-3770, Los Alamos National Laboratory, Los Alamos, New Mexico.

Lubliner J. 1990. Plasticity Theory. Macmillan Publishing, New York.

Mahoney LA, ZI Antoniak, JM Bates, and ME Dahl. 1999. Retained Gas Sampling Results for the Flammable Gas Program. PNNL-13000, Pacific Northwest National Laboratory, Richland, Washington.

Malvern LE. 1969. Introduction to the Mechanics of a Continuous Medium. Prentice-Hall, Englewood Cliffs, New Jersey.

Meyer PA, ME Brewster, SA Bryan, G Chen, LR Pederson, CW Stewart, and G Terrones. 1997. Gas Retention and Release Behavior in Hanford Double-Shell Waste Tanks. PNNL-11536 Rev. 1, Pacific Northwest National Laboratory, Richland, Washington.

Mullin JW. 1972. Crystallisation. Butterworth \& Co., London.

Mullin JW and C Gaska. 1969. "The Growth and Dissolution of Potassium Sulphate Crystals in a Fluidized Bed Crystallizer." The Canadian Journal of Chemical Engineering, Vol. 47, p. 483.

Person J C. Dilution Studies of Tank 241-SY-101 Waste. Preliminary Results. Memo 82100-99015 to Kirch N W, April 22, 1999, Numatec Hanford Corporation, Richland, WA.

Rajaratnam N. 1976. Turbulent Jets. Elsevier, Amsterdam.

Rassat SD and PA Gauglitz. 1995. Bubble Retention in Synthetic Sludge: Testing of Alternative Gas Retention Apparatus. PNL-10661, Pacific Northwest Laboratory, Richland, Washington.

Rassat SD, PA Gauglitz, PR Bredt, LA Mahoney, SV Forbes, and SM Tingey. 1997. Mechanisms of Gas Retention and Release: Experimental Results for Hanford Waste Tanks 241-AW-101 and 241-AN-103. PNNL-11642, Pacific Northwest National Laboratory, Richland, Washington. 
Rassat SD, SM Caley, PR Bredt, PA Gauglitz, DE Rinehart, and SV Forbes. 1998. Mechanisms of Gas Retention and Release: Experimental Results for Hanford Single-Shell Waste Tanks 241-A-101, 241-S-106, and 241-U-103. PNNL-11981, Pacific Northwest National Laboratory, Richland, Washington.

Rassat SD, PA Gauglitz, SM Caley, LA Mahoney, and DP Mendoza. 1999. A Discussion of SY-101 Crust Gas Retention and Release Mechanisms. PNNL-12092, Pacific Northwest National Laboratory, Richland, Washington.

Raymond RE. 1999. Tank 241-SY-101 Surface-Level-Rise Remediation Project Plan. HNF-3824 Rev. 0, Lockheed Martin Hanford Corporation, Richland, Washington.

Rousseau RW, ed. 1987. Handbook of Separation Process Technology. John Wiley \& Sons, New York, pp. 109-112.

Schlichting H. 1979. Boundary-Layer Theory (seventh edition). McGraw-Hill, New York.

Shekarriz, A, KJ Hammad, and MR Powell. 1997. Evaluation of Scaling Correlations for Mobilization of Double-Shell Tank Waste. PNNL-11737, Pacific Northwest National Laboratory, Richland, Washington.

Sherwood TK, RL Pigford, and CR Wilke. 1975. Mass Transfer, McGraw-Hill, New York.

Steen FH. 1999. Tank 24I-SY-101, Cores 255, 256 and 257, Analytical Results for the Final Report. HNF-1666, Waste Management of Hanford, Inc., Richland, Washington.

Stewart CW, SD Rassat, JH Sukamto and JM Cuta. 1999. Buoyancy and Dissolution of the Floating Crust Layer in Tank 241-SY-101 During Transfer and Back Dilution. PNNL-13040, Pacific Northwest National Laboratory, Richland, Washington..

Stewart CW, JM Alzheimer, G Chen, and PA Meyer. 1998. In Situ Void Fraction and Gas Volume in Hanford Tank 241-SY-101 as Measured with the Void Fraction Instrument. PNNL12033, Pacific Northwest National Laboratory, Richland, Washington.

Stewart CW, ME Brewster, PA Gauglitz, LA Mahoney, PA Meyer, KP Recknagle, and HC Reid. 1996. Gas Retention and Release Behavior in Hanjord Single-Shell Waste Tanks. PNNL-11391, Pacific Northwest National Laboratory, Richland, Washington.

Stewart CW, CL Shepard, JM Alzheimer, TI Stokes, and G Terrones. 1995. In Situ Determination of Rheological Properties and Void Fraction in Hanford Waste Tank 241-SY-101. PNL-10682, Pacific Northwest National Laboratory, Richland, Washington.

Stewart CW, JD Hudson, JR Friley, FE Panisko, ZI Antoniak, JJ Irwin, JG Fadeff, E Efferding, TE Michener, NW Kirch, and DA Reynolds. 1994. Mitigation of Tank 241-SY-101 by Pump Mixing: Results of Full-Scale Testing. PNL-9959, Pacific Northwest National Laboratory, Richland, Washington. 
Sullivan HL. 1995. A Safety Assessment for Proposed Pump Mixing Operations to Mitigate Episodic Gas Releases in Tank 241-SY-101: Hanford Site, Richland, Washington. LA-UR-923196 Rev. 14, Los Alamos National Laboratory, Los Alamos, New Mexico.

Tennekes H and JL Lumley. 1990. A First Course in Turbulence. The MIT Press, Cambridge.

Trent DS and LL Eyler. 1993. TEMPEST: A Computer Program for Three-Dimensional Time-Dependent Computational Fluid Dynamics. PNL-8857 Vol. 1, Version T, Mod 2, Pacific Northwest National Laboratory, Richland, Washington.

Wankat PC. 1990. Rate-Controlled Processes. Elsevier, London.

Weast RC ed. 1985. CRC Handbook of Chemistry and Physics, $66^{\text {th }}$ Edition. CRC Press, Inc., Boca Raton, Florida.

Yih C-S. 1977. Fluid Mechanics. West River Press, Ann Arbor, Michigan. 


\section{Appendix \\ 222-S Experimental Data and Conceptual Model}




\section{Appendix 222-S Experimental Data and Conceptual Model}

The conceptual model used for estimating the effect of dilution in a tank must apply to describing the effects of dilution on SY-101 waste determined in the 222-S laboratory experiments. The measurements made during the dilution tests can be described in terms of the initial mass of a slurry sample, the mass of water added, the parameters described in Section 2.1.1, and additional parameters specific to the laboratory experiments. The measurements considered in this analysis are presented in Table A.1.

The measured values used to fit the parameters are

- Volume of the undiluted bulk (B denotes bulk) slurry $\left(\mathrm{V}_{\mathrm{B}, 0}\right)$

- Volume of the diluted bulk slurry $\left(\mathrm{V}_{\mathrm{B}}\right)$

- Mass fraction of water $\left(\mathrm{H}\right.$ denotes water, i.e., $\left.\mathrm{H}_{2} \mathrm{O}\right)$ in the liquid phase $\left(\mathrm{w}_{\mathrm{H}}^{\mathrm{L}}\right)$

- Density of the diluted liquid phase $\left(\rho_{\mathrm{L}}\right)$

- Mass fraction of centrifuged solids after dilution $\left(\dot{w}_{S C}\right)$

- Volume fraction of centrifuged solids after dilution $\left(\phi_{\mathrm{SC}}\right)$

- Mass fraction of interstitial liquid in the centrifuged solids ( $\left.\mathrm{W}_{\mathrm{ISL}}\right)$.

The measured values are predicted from the parameters to be used to predict behavior in a tank and the following:

- the initial mass of the undiluted slurry sample $\left(\mathrm{m}_{\mathrm{B}, 0}\right)$

- the initial mass of water added relative to the mass of the sample $(x)$

- the computed fraction of solids dissolved upon dilution $(y)$

- the initial mass fraction of undissolved (free) solids in the undiluted slurry $\left(\mathrm{w}_{\mathrm{SF}, 0}\right)$

- the initial mass fraction of dissolved solids in the undiluted slurry $\left(\mathrm{w}_{\mathrm{SD}, 0}\right)$

- the volume fraction of solids in the centrifuged solids sample $\left(\phi_{s}\right)$

where

$$
\begin{aligned}
& y=\frac{w_{D, 0}}{w_{H, 0}} \frac{x}{w_{S, 0}} \text { if } y<y_{\max } \\
& y=y_{\max } \text { otherwise } \\
& \text { where } x=\frac{\Delta m_{H}}{m_{B, 0}}
\end{aligned}
$$

By "initial" is meant the value before dilution of the waste. This expression for y pertaining to laboratory experiments corresponds to Equation (2.6) in Section 2.1.1, which pertains to a tank. The parameters were determined by non-linear regression. They were fit using a nonlinear least squares approach to best fit the predicted values of the measured values to the measurements. The predictive expressions derived from the simple conceptual model are as follows: 
Volume of the slurry sample:

$$
\mathrm{v}_{\mathrm{Bi}_{\mathrm{i}}}=\mathrm{m}_{\mathrm{B}, 0 \mathrm{i}}\left\{\left(\frac{\mathrm{w}_{\mathrm{H}, 0}+\mathrm{x}}{\rho_{\mathrm{H}}}\right)+\left(\frac{\mathrm{w}_{\mathrm{SD}, 0}+\mathrm{w}_{\mathrm{SF}, 0} \mathrm{y}}{\rho_{\mathrm{SD}}}\right)+\left(\frac{\mathrm{w}_{\mathrm{SF}, 0}(1-\mathrm{y})}{\rho_{\mathrm{SF}}}\right)\right\}
$$

Mass fraction of water in the liquid:

$$
\mathrm{w}_{\mathrm{LH}}=\frac{\mathrm{w}_{\mathrm{H}, 0}+\mathrm{x}}{\mathrm{w}_{\mathrm{H}, 0}+\mathrm{x}+\mathrm{w}_{\mathrm{SD}, 0}+\mathrm{w}_{\mathrm{SF}, 0} \mathrm{y}}
$$

Density of the liquid:

$$
\rho_{\mathrm{L}}=\left\{\frac{\left(\mathrm{w}_{\mathrm{H}, 0}+\mathrm{x}\right)+\left(\mathrm{w}_{\mathrm{SD}, 0}+\mathrm{w}_{\mathrm{SF}, 0} \mathrm{y}\right)}{\left(\frac{\overline{\mathrm{w}}_{\mathrm{H}, 0}+\mathrm{x}}{\rho_{\mathrm{H}}}\right)+\left(\frac{\mathrm{w}_{\mathrm{SD}, 0}+\mathrm{w}_{\mathrm{SF}, 0} \mathrm{y}}{\rho_{\mathrm{SD}}}\right)}\right\}
$$

Mass fraction of centrifuged solids relative to the undiluted slurry:

$$
\mathrm{w}_{\mathrm{SC}}=\left[\left(\frac{\rho_{\mathrm{L}}}{\rho_{\mathrm{SF}}}\right)\left(\frac{1-\phi_{\mathrm{S}}}{\phi_{\mathrm{S}}}\right)+1\right] \mathrm{w}_{\mathrm{SF}, 0}(1-\mathrm{y})
$$

Volume fraction of centrifuged solids relative to the undiluted slurry:

$$
\hat{\phi}_{\mathrm{SC}}=\frac{\left(\frac{\mathrm{w}_{\mathrm{SF}, 0}(1-\mathrm{y})}{\phi_{\mathrm{S}} \rho_{\mathrm{SF}}}\right)}{\left(\frac{\mathrm{w}_{\mathrm{H}, 0}}{\rho_{\mathrm{H}}}\right)+\left(\frac{\mathrm{w}_{\mathrm{SD}, 0}}{\rho_{\mathrm{SD}}}\right)+\left(\frac{\mathrm{w}_{\mathrm{SF}, 0}}{\rho_{\mathrm{SF}}}\right)}
$$

Mass fraction of interstitial liquid in the centrifuged solids:

$$
\mathrm{w}_{\mathrm{ISL}}=\frac{1}{1+\left(\frac{\rho_{\mathrm{SF}}}{\rho_{\mathrm{L}}}\right)\left(\frac{\phi_{\mathrm{S}}}{1-\phi_{\mathrm{S}}}\right)}
$$

The predicted and measured results for the laboratory tests are shown in Figures A.1 through A.6. 
Table A.1. 222-S Experimental Data

$\begin{array}{ccccccccc}\begin{array}{c}\text { Initial } \\ \text { mass of } \\ \text { slurry } \\ (\mathrm{g})\end{array} & \begin{array}{c}\text { Mass of } \\ \text { water } \\ \text { added } \\ \text { relative to } \\ \text { initial mass } \\ \text { of slurry }\end{array} & \begin{array}{c}\text { Mass } \\ \text { fraction, } \\ \text { water in }\end{array} & \begin{array}{c}\text { Initial } \\ \text { volume of } \\ \text { slurry } \\ (\mathrm{ml})\end{array} & \begin{array}{c}\text { Diluted } \\ \text { volume of } \\ \text { slurry } \\ (\mathrm{ml})\end{array} & \begin{array}{c}\text { Liquid } \\ \text { density } \\ (\mathrm{g} / \mathrm{ml})\end{array} & \begin{array}{c}\text { Mass } \\ \text { fraction } \\ \text { centrif. } \\ \text { solids }\end{array} & \begin{array}{c}\text { Volume } \\ \text { fraction } \\ \text { centrif. } \\ \text { solids }\end{array} & \begin{array}{c}\text { Mass } \\ \text { fraction of } \\ \text { interstitial } \\ \text { liquid }\end{array} \\ \boldsymbol{m}_{B, 0} & \boldsymbol{x}_{\boldsymbol{i}} & \boldsymbol{w}_{H}{ }_{H} & \boldsymbol{V}_{B, 0} & V_{B} & \rho_{L} & \boldsymbol{w}_{S C} & \phi_{S C} & W_{\text {ISL }} \\ 76.61 & 0.000 & 0.4451 & 47.50 & 47.50 & 1.480 & 0.517 & 0.474 & 0.71 \\ 76.26 & 0.000 & 0.4451 & 47.50 & 47.50 & 1.486 & 0.513 & 0.47 .4 & 0.71 \\ 76.31 & 0.000 & & 47.50 & 47.50 & 1.488 & 0.512 & 0.474 & 0.71 \\ 67.27 & 0.064 & 0.4165 & 42.50 & 47.50 & 1.337 & 0.478 & 0.424 & 0.81 \\ 69.56 & 0.073 & 0.4165 & 42.50 & 47.50 & 1.493 & 0.407 & 0.388 & 0.81 \\ 67.53 & 0.077 & & 42.80 & 48.00 & 1.450 & 0.412 & 0.374 & 0.81 \\ 57.41 & 0.172 & 0.4779 & 35.50 & 45.50 & 1.416 & 0.309 & 0.282 & 0.77 \\ 54.15 & 0.210 & & 35.00 & 45.50 & 1.449 & 0.274 & 0.286 & 0.77 \\ 56.86 & 0.224 & & 37.00 & 47.50 & 1.379 & 0.264 & 0.216 & 0.77 \\ 36.63 & 0.601 & 0.6172 & 22.50 & 45.00 & 1.333 & 0.173 & 0.211 & \\ 34.54 & 0.613 & & 21.33 & 42.50 & 1.306 & 0.172 & 0.209 & 0.77 \\ 36.44 & 0.622 & & 22.50 & 45.00 & 1.298 & 0.162 & 0.178 & 0.80 \\ 35.87 & 0.626 & & 22.50 & 45.00 & 1.323 & 0.159 & 0.188 & 0.80 \\ 35.81 & 0.636 & & 22.50 & 45.00 & 1.330 & 0.16 & 0.188 & \\ 36.24 & 0.637 & & 22.50 & 45.00 & 1.302 & 0.165 & 0.178 & 0.77\end{array}$

Note: we did not attempt to fit the following data

$\begin{array}{lllllllll}77.81 & 0.000 & 0.6280 . & 47.50 & 47.50 & 1.547 & 0.429 & 0.400 & 0.74 \\ 75.40 & 0.000 & 0.6280 & 47.50 & 47.50 & 1.508 & 0.436 & 0.400 & 0.74 \\ 75.66 & 0.000 & & 47.50 & 47.50 & 1.467 & 0.425 & 0.368 & 0.74 \\ 66.74 & 0.053 & & 42.50 & 47.00 & 1.360 & 0.400 & 0.353 & 0.75 \\ 66.13 & 0.061 & & 42.50 & 47.00 & 1.433 & 0.399 & 0.376 & 0.75 \\ 67.14 & 0.050 & & 42.50 & 47.00 & 1.460 & 0.394 & 0.376 & 0.75 \\ 56.16 & 0.163 & & 35.00 & 45.00 & 1.487 & 0.327 & 0.314 & 0.81 \\ 57.24 & 0.160 & & 35.00 & 45.00 & 1.463 & 0.338 & 0.286 & 0.81 \\ 55.72 & 0.161 & & 35.00 & 45.00 & 1.436 & 0.298 & 0.257 & 0.81\end{array}$


Comparison of Data and Model Predictions

(closed symbols are data, open symbols are predictions)

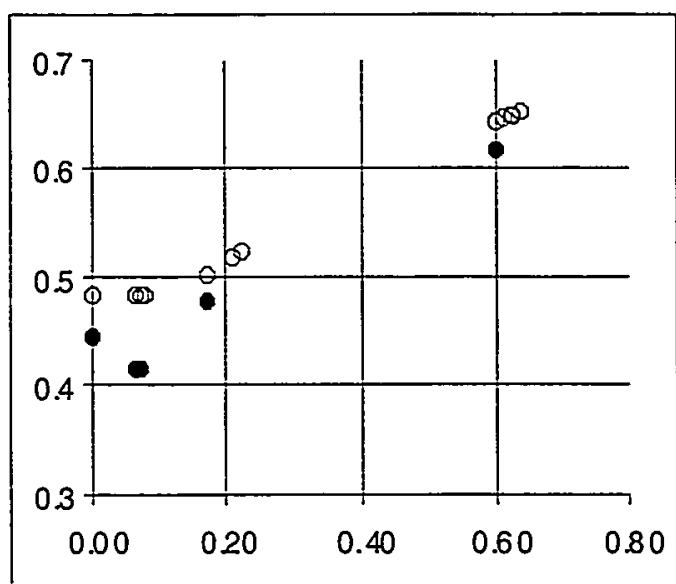

Figure A.1. Mass fraction of water vs X

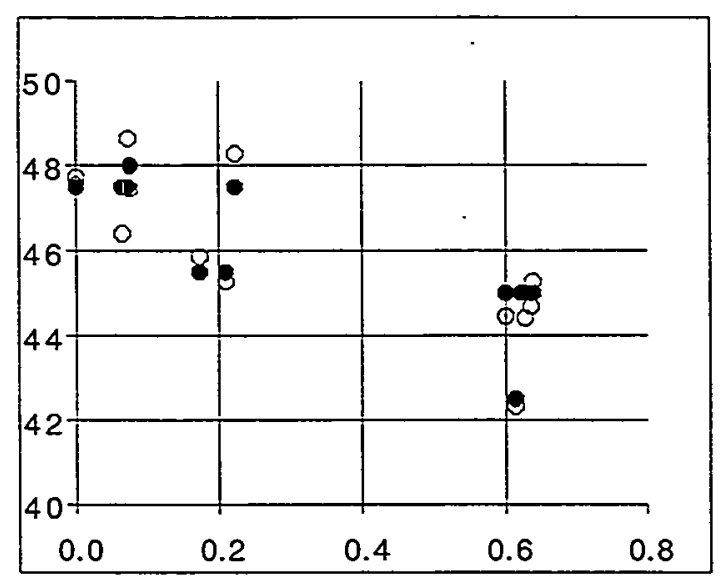

Figure A.3. Volume of diluted slurry sample vs $\mathrm{x}$

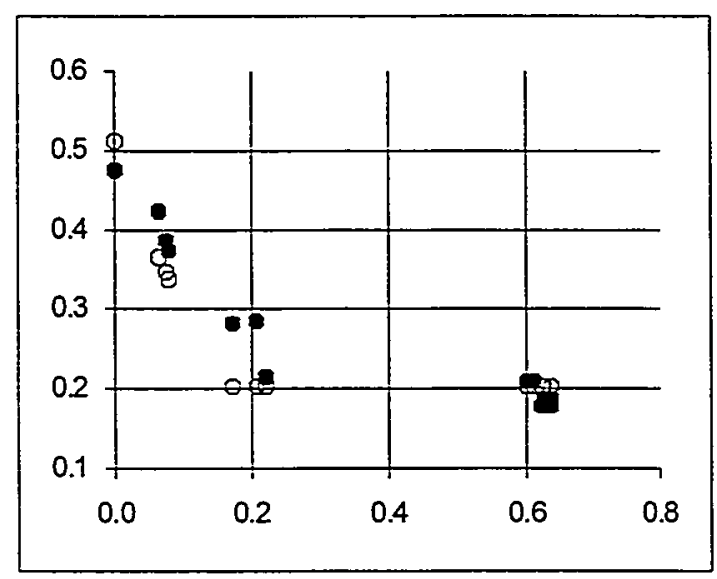

Figure A.5. Mass fraction of centrifuged solids vs $\mathrm{X}$

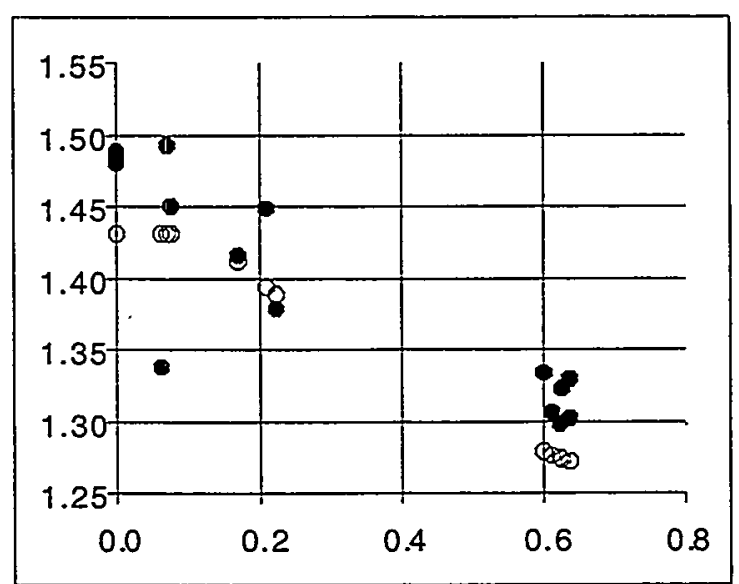

Figure A.2. Density of liquid vs $x$

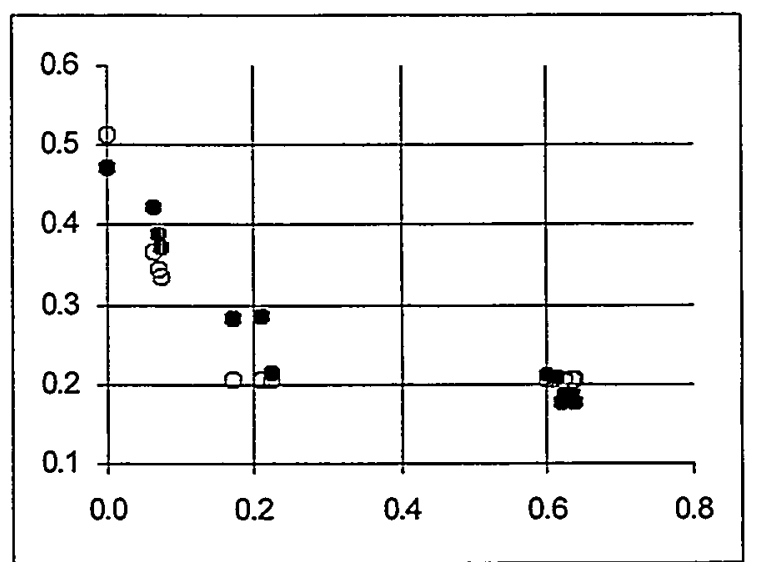

Figure A.4. Volume fraction of centrifuged solids

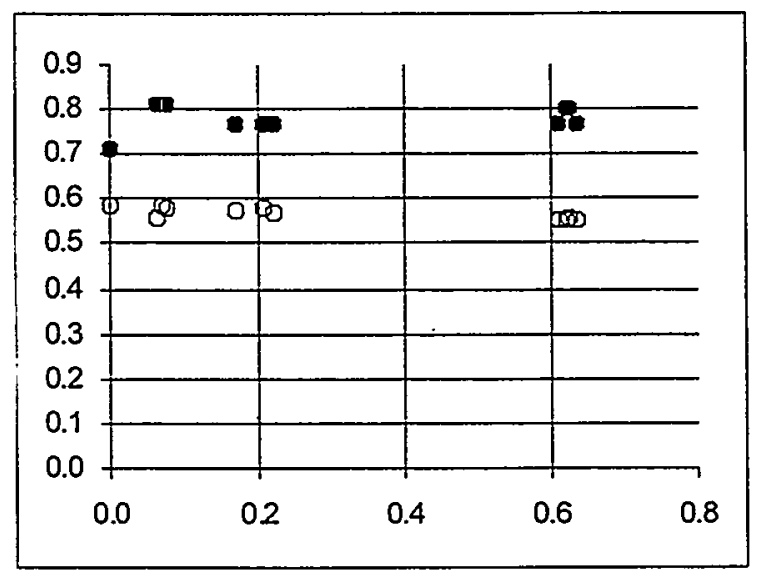

Figure A.6. Mass fraction of interstitial liquid 


\section{Distribution}

No. of

Offsite

2 Office of Scientific and Technical Information

WL Kubic

Los Alamos National Laboratory

PO Box 1663 K575

Los Alamos, NM 87545
Copies

No. of

Copies

SD Estey

R2-11

JM Grigsby

R1-44

CE Hanson

S7-70

GD Johnson (3)

S7-73

NW Kirch

R2-11

LJ Kripps

S7-73

CE Leach

R1-44

RE Raymond

S7-70

DA Reynolds

R2-11

30 Pacific Northwest National Laboratory

Onsite

8 DOE Richland Operations Office

CA Groendyke (6)

H6-60

DH Irby

JS Shuen

H6-60

H6-60

17 PHMC Team

WB Barton

R2-11

RE Bauer

S7-73

JR Biggs

S7-07

RJ Cash

S7-73

A-MF Choho

R3-73

JM Conner

R2-11
ZI Antoniak

K7-15

JM Bates

K7-15

SQ Bennett

JW Brothers (3)

K7-90

JM Cuta

K9-20

PA Gauglitz

K7-15

JL Huckaby

K6-28

WL Kuhn

K7-15

LA Mahoney

K7-15

DP Mendoza

K7-15

PA Meyer

S3-32

K7-15

SD Rassat (5)

K6-28

CW Stewart (3)

K7-15

JH Sukamto

K8-93

$\mathrm{G}$ Terrones

K7-15

BE Wells

K7-15

VV Viswanathan

K6-28

Information Release (5)

Distr. 1 